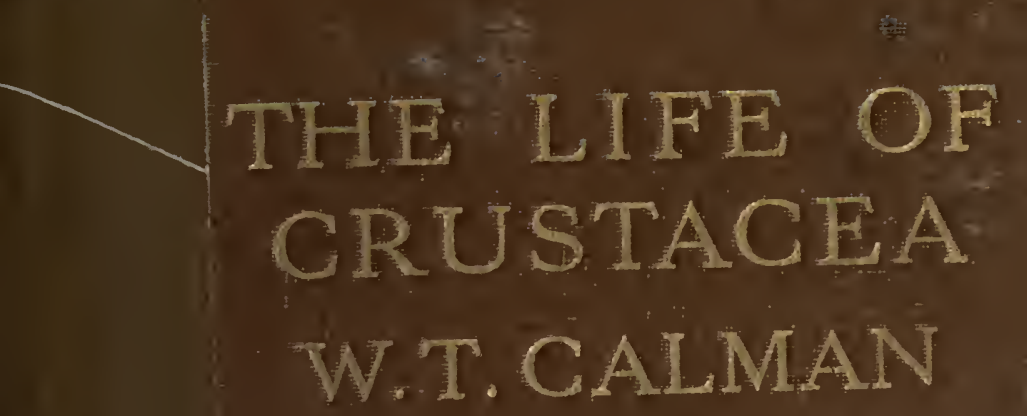




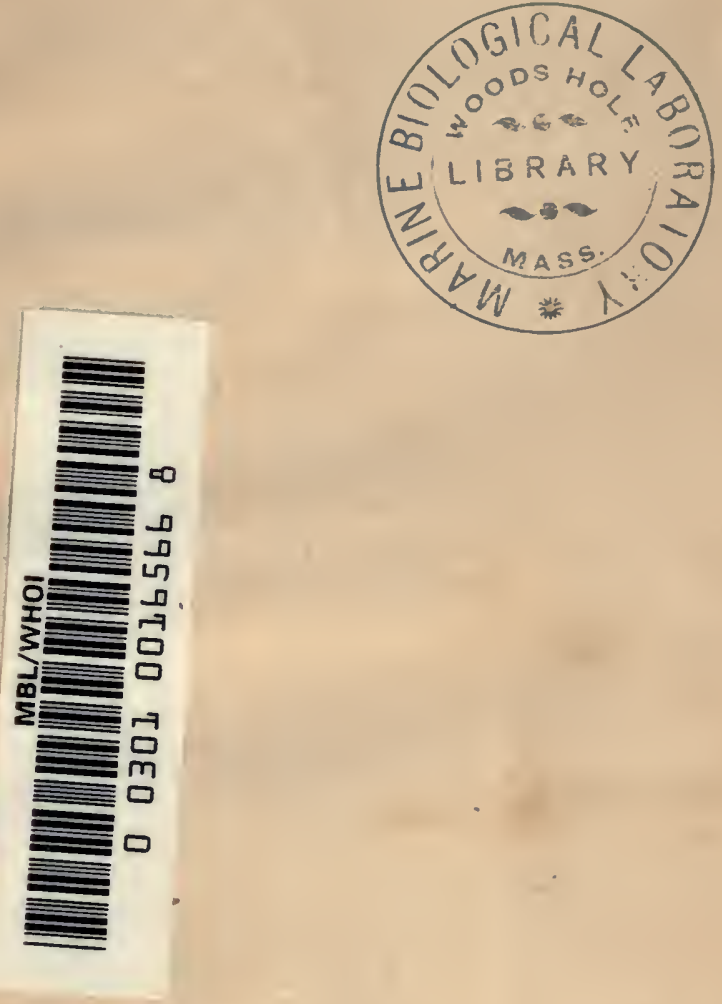



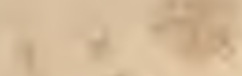

$4+5$

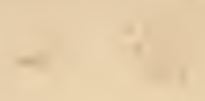

t.

$+$

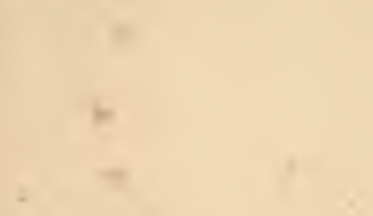

t

$+7$

$+4$

$$
\text { + }
$$$$
-
$$

$=$

7

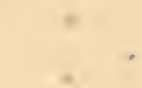

,

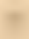

1 



\section{THE LIFE OF CRUSTACEA}


$+1+$

$$
\text { - } 4 \text { + } 1
$$

14. 


\title{
THE
}

\section{LIFE OF CRUSTACEA}

\author{
BY \\ W. T. CALMAN, D.Sc.
}

WITH THIRTY-TWO PLATES AND EIGHTY-FIVE FIGURES

METHUEN \& GO. LTD.

36 ESSEX STREET W.C.

L ONDON 
First Published in 1911 


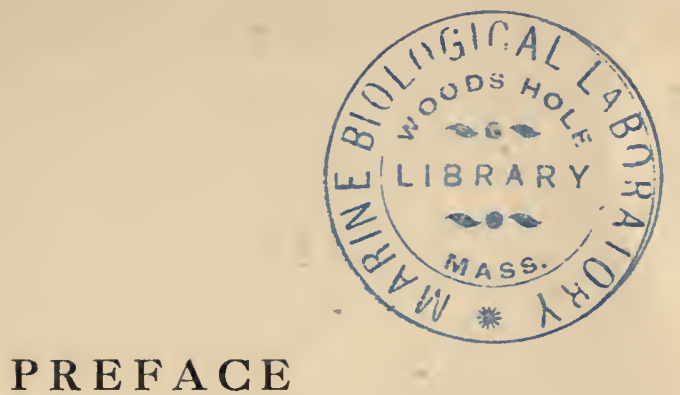

THIS sketch of the Natural History of the Crustacea deals chiefly with their habits and modes of life, and attempts to provide, for readers unfamiliar with the technicalities of Zoology, an account of some of the more important scientific problems suggested by a study of the living animals in relation to their environment.

I am indebted to the Trustees of the British Museum for leave to reproduce certain figures prepared for the "Guide to the Crustacea, Arachnida, Onychophora, and Myriopoda exhibited in the Department of Zoology"; also to Sir Ray Lankester, K.C.B., F.R.S., and to Messrs. A. and C. Black for the use of a number of figures from my volume on Crustacea in the "Treatise on Zoology," edited by Sir Ray Lankester. 
The source of these figures is indicated in the explanation attached to each. Of the remaining illustrations, some are reproduced from photographs of specimens in the collection of the British Museum; the others have been drawn from Nature, or copied from the original figures of various authors, by Miss Gertrude M. Woodward, to whom I am much indebted for the care and skill which she has given to their preparation.

W. T. C. 


\section{GONTENTS}

chapter
I. Introductory - - -
II. The lobster as a Type of Crustacea
III. The Classification of Crostacea -

APPENDIX :

I. Methods of Collecting and Preserving CrusTACEA -

II. Notes on Books

INDEX

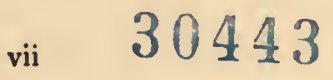





\section{LIST OF ILLUSTRATIONS IN THE TEXT}

FIG.

I. The Common Lobster (Homarus gammarus), Female, FROM THE SIDE -

2. One of the Abdominal Somites of the Lobster, with ITS APPENDAGES, SEPARATED AND VIEWED FROM IN

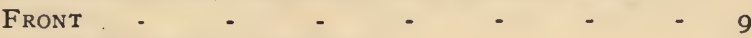

3. Third Maxilliped of Lobster - - - - $\quad$ - II

4. Y. JALKING Legs OF LOBSTER - - - - $\quad$ - 12

5. Appendages of Lobster in Front of Third MaxilLIPED

6. Dissection of Male Lobster, from the Side 13

7. Gills of THE LoBSTER, EXPOSED BY CUTtiNg AWAY THE Side-flap of the Carapace (Branchiostegite) * $\mathbf{I} 8$

8. First Larval Stage of the Common Lobster. $\times 4^{-} 28$

9. Side - view of Rostrum of (A) Common Lobster (Homarus gammarus) AND (B) AMERICAN LoBSTER

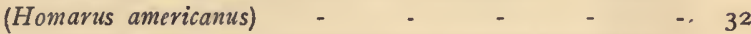

Io. The "FaIRY Shrimp" (Chirocephalus diaphanus), Male.

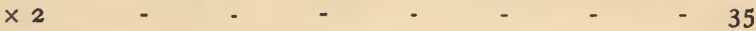

II. Estheria obliqua, ONE OF THE Conchostraca - $\quad 36$

12. Daphnia pulex, a Common Species of "Water-flea." MUCH ENLARGED - $\quad$ - $\quad$ - $\quad$ - $\quad$ - $\quad$ - 37

13. Shells of Ostracoda, Much enlarged - $\quad 38$

14. Cyclops albidus, A Species of Copepod Found in Fresh

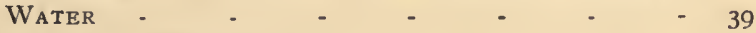

15. Nebalia bipes. ENLARged - - - - $\quad$ - 44

16. Mysis relicta, One of the MYsidacea. Enlarged - 47

17. Gnathophausia willemoesii, ONE OF the DeEp-sea Mysidacea. Half Natural Size - - - - 48

8. Diastylis goodsiri, ONe of the Cumacea. ENLarged - 49 ix 
FIG.

I9. Apseudes spinosus, One of the Tanaidacea. Enlarged

PAGE

20. A Woodlouse (Porcellio scaber), ONE OF THE IsOPODA. ENLARGED

21. AN AMPhipod (Gammarus locusta). ENLARGED - - 53

22. Two Species of Caprellide - $\quad$ - $\quad$ - 54

23. Paracyamus boopis, THE Whale-Lodse of THF HuMpBACK WHALE

24. Meganyctiphanes norvegica, ONE OF THE EUPhaUsiacea. Twice Natural Size

25. Larval Stages of the Common Shore Crab (Carcinus manas-SRE PLATE IX.) - - . . . . 50 5 I 53

56

68

26. Last Larval Stage of the Common Porcelain Crab (Porcellana longicornis-SEE FIG. 4I, P. II3). $\times 9$. 70

27. First Larval Stage of Munida mgosa (see Plate VI.) $\times$ Io

28. The Phyllosoma Larva of the Common Spiny Lobster (Palinurus vulgaris-SEE Plate V.). Much ENLARged 71 72

29. Larval Stages of the Prawn Pencus (see Plate IV.). $\times 45$

30. Newly - hatched Young of a Crayfish (Astacus fluviatilis). ENLARGED - $\quad$ - $\quad$ -

31. Young Specimen of an African River Crab (Potamon johnstoni), TAKEN FROM THE ABDOMEN OF THE MOTHER. MUCH ENLARGED -

32. Early Larval Stage of a Species of Souilla, probABLy S. dubia. $\times$ IO - - - - -

33. Larval Stages of the Brine Shrimp (Artemia salina)34. Early Nauplius Larva of a Copepod (Cyclops). Much ENLARGED -

35. Larval Stages of the Common Rock Barnacle (Balanus balanoides-SEE PLAte III.)

36. A Common Hermit CRAB (Eupagurus bernhardus) REMOVED FROM THE SHELL -

37. Pylocheles miersii, a Symmetrical Hermit CRAB - 94

38. Callianassa stebbingi (FEMALE), A SAND-BURROWING Thalassinid from the South Coast of England. Natural Size - $\quad$ - $\quad$ - $\quad$ - $\quad$ - $\quad$ -

39. The Common Sand-hopper (Talitrus saltator), Male, FROM THE SIDE. $\times 3$ - $\quad$ - $\quad$ - $\quad$ - $\quad$ - 108 
FIG.

40. A, a Piece of a Tropical Sea-weed (Halimeda); B, A CRAB (Huenia proteus) Which LIVES AMONG THE Fronds of Halimeda, AND CLOSELy RESEMBLES THEM IN FORM ANd Colour. Reduced -

4I. The Common Porcelain CRaB (Porcellana longicornis), Slightly enlarged, and ONe of the Third MaxilLIPEDS DETACHED AND FURTHER ENLARGED TO SHOW THE Fringe OF LoNg HaIRS

42. A DEEP-SEA LOBSTER (Nephropsis stewartii), FROM THE BAY OF BENGal, REdUCED - - -

43. Munidopsis regia, a DeEp-sea Galatheid from the Bay of Bengal. Reduced -

44. Thaumastocheles zaleucus. REDUCED

45. A DeEp-sea CRAB (Platymaia wyville-thomsoni). REduced 131 46. Polycheles phosphorus, One of the Eryonidea, Female, FROM THE INDIAN SEAS.

47. Eryon propinquus, ONE of THE Fossil ERyonidea, From THE JURASSIC Rocks OF SOLENHOFEN - - - $\mathbf{3} 35$

48. Conchacia curta, an Ostracod of the Plankton. $\times 40-$ I 44 49. Mimonectes loveni. A Female Specimen seen from the Side AND FROM Below, Showing the DistendedBALLOON-LIKE Form OF the ANTERIOR PART OF THE BODY. $\times 3$

50. THE ZoËa LARva OF a Species of Sergestes, taken by the "Challenger" Expedition, $\times 25$ - - I46

51. The Nauplius Larva of a Species of Barnacle of THE FAMILY LEPADID E, SHOWING GREATLY-DEVELOPED Spines. From a Specimen taken in the Atlantic Ocean, near Madeira. X II .

52. Calocalanus pavo, One of the Free-swimming Copepoda of the Plankton. Enlarged - 53. Copilia quadrata (Female), a Copepod of the Family CORYCAIDA, SHOWING THE PAIR OF LARGE "TELESCOPIC" Eyes, $\times 20 \quad$ - $\quad$ -

54. Phronima colletti, Male. From a SPEcimen taken in

Deep Water Near the Canary Islands. $\times$ I2 - I54

55. The Brine Shrimp (Artemia salina) - - - I64

56. Chydorus spharicus, a Common Species of Water-Flea. $\times 50$ 
FIG.

57. A Water-flea (Daphnia pulex), Female, with Ephippium containing Two "Resting Eggs." $\times 20$

58. Bythotrephes longimanus, FEMale, with EMBryos in the BROOD-SAC. $\times 12$

59. Diaptomus coeruleus, Female. $\times 25$

6o. Asellus aquaticus, Frmale. $\times 4$ - - - $\quad$ - $\quad$ - 173

61. Map showing the Distribution of Crayfishes - 175

62. A Well Shrimp (Niphargus aquilex). $\times 7$ - $\quad 185$

63. The Sea-slater (Ligia oceanica). About Twice Natural Size

64. Structure of the Breathing Organs of Porcellio scaber

65. Armadillidium vulgare. $\times 2 \frac{1}{2}$

66. Two Branches of a Coral (Seriatopora) showing "Galls" inhabited by the CRAB Hapalocarcinus marsupialis. ON THE Right THE Female Crab, EXTRACTED FROM THE GALL AND FURTHER ENLARGED 67. Hyperia galba, Female. EnLARged

68. A, The Crab Melia tessellata clinging to a Branch of

Córal, and carrying in Each Claw a Living Sea. anemone; B, ONe of the Claws further enlarged TO SHOW THE WAY in WHich THE ANEMONe IS HELD

69. The Common Pea Crab (Pinnotheres pisum), Female. Natural Size - . - - - -

70. Cirolana borealis. About Twice Natural Size -

7I. A, Front PART OF BODY OF A PRAWN (Spirontocaris polaris), FROM Above, showing on the Right Side a Swelling of the Carapace caused by the Presence of the Parasite Bopyroides hippolytes in the Gill Chamber; $B$, the Female Parasite EXTracted and Further enlarged; C, the Male Parasite on Same Scale as the Female - - 222

72. A Fish-Louse (Caligus rapax), Female. $\times 5$ - 525

73. Stages of Development of Lernaa branchialis. $F$ is SLightLy, the Other FigURES GREATLy, ENLARgED 226

74. Stages of the Life-history of Hamocera dane, One of The MONSTRILlide -

75. Free-swimming Stages of Sacculina carcini. Much ENLARGED - 
FIG.

PAGE

76. Early Stage of Sacculina within the Body of a CRAB

77. Rostrom and Fore Part of Carapace, SeEn from Above, of (A) RED-CLAWEd CRAYFish (Astacus fiviatilis) AND (B) WHITE-CLAWED OR ENGLISH CRAYFIsH (Astacus pallipes) - $\quad$ - $\quad$ - $\quad$ - $\quad$ - $\quad 242$

78. The Common Shrimp (Crangon vulgaris). Natural Size 244

79. The Norwegian Deep-water Prawn (Pandalus borealis),

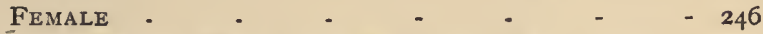

8o. The Gribble (Limnovia lignorum). Much enlarged - 254 8I. Restoration OF a TRILOBIte (Triarthrus becki), showing THE APPENDAges. UPPER Side ON Right, UNDER Side on Left. Slightly ENLARged - - - 258

82. Cevatiocaris papilio, ONe of the Fossil Phyllocarida - 262 83. Pygocephalus cooperi, From the CoAL-Measures: Under Side of a Female Specimen, showing the OverLAPPing Plates of the BROOD-POUCH -

84. The Tasmanian "Mountain Shrimp" (Anaspides tasmania), a Living Representative of the Syncarida. SLIGHTLY ENLARGED - $\quad$ - $\quad$ - $\quad$ -

85. Praanaspides pracursor, One of the Fossil Syncarida, From the Coal-Measures of Derbyshire. Slightly ENLARGED -

\section{FULL-PAGE PLATES}

PLATE

I. Male and Female Lobsters, showing the DifferENCE IN THE Relative BREadth OF the ABDomeN in the Two Sexes. This Figure also illustrates the Dissimilarity of the LaRge Claws, and the FaCt THAT THE "CRUShING Claw" MAY BE ON either the Right OR Left Side of the Body. (From Brit. Mus. Guide) - $\quad$ - $\quad$ - $\quad$ - $\quad ~ 26$

II. Apus cancriformis From KirkCUdbrightshire. Slightly ENLARGED - 
PLATE

FACING RAGE

(Group of Specimens of the Goose Barnacle (Lepas anatifera), ONE SHOWING THE CIRRI EXtended as in Life. Natural Size. (From Brit.

III. $\{$ Mus. Guide)

Grodp of a Common Species of ACorn-shell or Rock Barnacle (Balanus balanoides). Natural SIZE

IV. Pencus caramote, from the Mediterranean. Aboot Half Natural Size. (From Brit. Mus, Guide) -

V. The Common Spiny Lobster (Palinurus vulgaris).

MUCH REDUCED. (From Brit. Mus. Guide) -

VI. Munida rugosa. BRITISH. REDUCED - - 60

VII. The Common Hermit CRAB, Eupagurus bernhardus, IN the Shell of a Wilelk. Reduced. (From Brit. Mus. Guide)

VIII. The "Northern StOne CraB," Lithodes maia. Moch Reduced. The Last Pair of Legs are Folded out of Sight in the Gill Chambers. (From Brit. Mus. Guide)

IX. $\left\{\begin{array}{l}\text { The Common Shore Crab (Curcinus manas). Re- } \\ \text { doced } \\ \text { Dromia vulgaris, Carrying on ITs BaCk A Mass of } \\ \text { the Sponge, Clione celata. British. Reduced }\end{array}\right\} 68$

X. Calappa flammea. BRazil. Reduced -

XI. The Giant Japanese CRAB, Macrocheira kompferi. Male. The Scale of the Figure is given by a Two-foot Role placed below the SpeciMEN. (From Brit. Mus. Guide)

XII. Squilla mantis, From the Mediterranean. About One-half Natural Size. (From Brit. Mus. Guide) 80

XIII. $\left\{\begin{array}{c}\text { A Swimming Crab, Portunus depurator. British. } \\ \text { Reduced } \\ \text { A Spider Crab, Maia squinado, Dressed IN Frag- } \\ \text { ments of WeEds. British. ReddCed }\end{array}\right\} 96$ 
PLATE

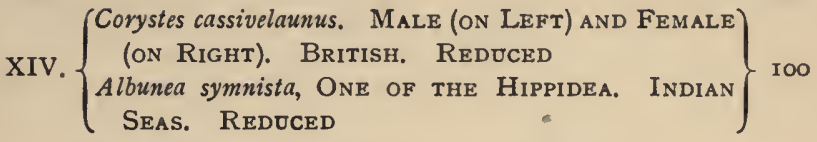

XV. $\left\{\begin{array}{c}\text { Ocypode cursor. Welasimus tangeri. Male above, Female below. } \\ \text { West Africa. Reduced }\end{array}\right\}$ ro4

XVI. A Deep-sea Hermit CRAB, Parapagurus pilosimanus, Sheltered By A Colony of Epizoanthus. From DeEP Water off the West of Ireland. SLIGHTLY REDUCED -

XVII. A DEEP-SEA PRAWN, Nematocarcinus undulatipes. Slightly ReDdCed. (From Brit. Mus. Guide) - 128

XVIII. Bathynomus giganteus. ABodt ONE-HaLF Natoral Size. (From Lankester's "Treatise on Zoology," after Milne-Edwards and Bouvier)

XiX. $\left\{\begin{array}{l}\text { Latreillia elegans, One of the Dromiacea which } \\ \text { Resembles a Spider Crab. From the } \\ \text { Mediterranean. Natural Size } \\ \text { The Golf-weed Crab, Planes mimutus. Slightly } \\ \text { enlarged }\end{array}\right\}$

XX. $\left\{\begin{array}{c}\text { The Morray River " Lobster," Astacopsis } \\ \text { spinifer. New Sodth Wales. Much redoced } \\ \text { The Land Crayfish, Engous cunicularis. Tas- } \\ \text { mania. Natural Size }\end{array}\right\}$

XXI. Palamon jamaicensis. A LARGE Freshwater Prawn of the Family Palamonide. West INDIES. MUCH REDUCED - $\quad$ - $\quad$ - $\quad$ - 179

XXII. Atya scabra. A Freshwater Prawn OF the Family Atyide. West Indies. Reduced - I80 XXIII. $\left\{\begin{array}{l}\text { The River Crab of' Sodthern Edrope, Potamon } \\ \text { edule (OR Telphusa fuviatilis). Redoced } \\ \text { Sesarma chiragra. A Freshwater CRab of the } \\ \text { FAmily Grapside. From Brazil. Slightly } \\ \text { REdoced }\end{array}\right\}$ I82 


\section{xvi THE LIFE OF CRUSTACEA}

PLATE

FACING PAGE

XXIV. Agglea lavis. South America. Natural Size - $\quad$ i84

XXV. The Blind Crayfish of the Mammoth Cave of Kentocky, Cambarus pellucidus. Natural SizE

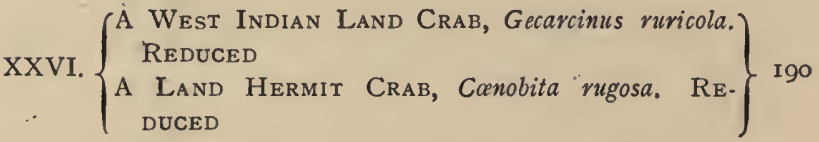

XXVII. The Coco Nut CRaB, Birgus latro. MUch RE-

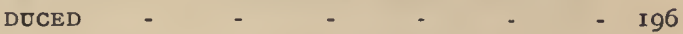

XXVIII. Group of Barnacles, Coronula diadema, on the Skin of a Whale. Japan. Reduced - - 209 XXIX. $\left\{\begin{array}{c}\text { Cymothoa astrum. An Isopod Parasite of Fish. } \\ \text { Slightly Enlarged } \\ \text { Sacculina carcini atTached Under The Abdomen } \\ \text { OF a Common Shore Crab. Reduced }\end{array}\right\} 220$

XXX. THE "NoRway Lobster," Nephrops norvegicus. About One-third Natural Size. (From Brit, . Mus. Guide)

XXXI. The Common Edible CRAB, Cancer pagurus. BRITISH. MUCH REDUCED - - 248

XXX1I. Piece of Timber from Ryde Pier, showing DAMAGE CAUSED BY Limnoria AND Chelura. (From Brit. Mus. Guide) 


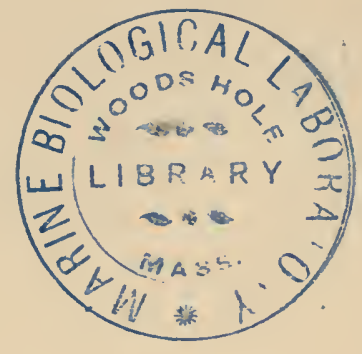

THE LIFE OF GRUSTACEA 



\title{
THE LIFE OF CRUSTACEA
}

\author{
CHAPTER I \\ INTRODUCTORY
}

F VERYONE has some acquaintance with the 1 animals that are grouped by naturalists under the name Crustacea. The edible Crabs, Lobsters, Prawns, and Shrimps, are at least superficially familiar, either as brought to the table or as displayed in the fishmonger's, and the most unobservant of seaside visitors must have had his attention attracted by living specimens of some of the more obtrusive species, such as the common Shore Crab. Many, however, will be surprised to learn that the Barnacles coating the rocks on the seashore, the Sand-hoppers of the beach, and the Woodlice of our gardens, are members of the same class. Still less is it suspected, by those who have not given special attention to the subject, that the living species of the group number many thousands, presenting strange diversities of structure and habits, and playing important parts in the general economy of Nature. 
In addition to those just mentioned, a few Crustacea are sufficiently well known to be distinguished by popular names, such, for example, as Crayfish and Hermit Crabs, but for the vast majority no names are available except those of technical zoology. In the following pages, therefore, while technical terms have been introduced as sparingly as possible, the unfamiliarity of the animals themselves makes it needful to use many unfamiliar names.

In the classification of the Animal Kingdom, the Crustacea form one of the divisions of a comprehensive group, or Phylum, known as Arthropoda. The typical members of this group have a more or less firm external skeleton, the body is divided into segments, there are jointed limbs, and some of these are modified to serve as jaws. The chief divisions or classes of the Arthropoda are-(i.) Insecta, including Butterflies, Moths, Bees, Wasps, Flies, Beetles, and the like ; (ii.) Chilopoda, or Centipedes ; (iii.) Diplopoda, or Millipedes ${ }^{1}$; (iv.) Onychophora, including the curious worm-like Peripatus; (v.) Arachnida, or Scorpions, Spiders, Mites, and their allies; and (vi.) Crustacea.

It is not easy to summarize in a few words the characters common to all Crustacea, and distinguishing them from the other groups of Arthropoda. As

1 The Chilopoda and Diplopoda are sometimes regarded as forming a single class-Myriopoda. 
a rough guide to classification, it is useful to remember that an Insect ${ }^{-c a n}$ generally be recognized by having three pairs of walking legs, an Arachnid by having four pairs, and a Centipede or Millipede by having a great many pairs, all nearly alike. The Crustacea, on the other hand, show great diversity in the number and arrangement of their walking or swimming legs, but they rarely show any special resemblance to those of the other large groups of Arthropoda. Thus, for example, a common species of Woodlouse, Armadillidium vulgare, is very similar at first sight to the Millipede Glomeris marginata, but it has only seven pairs of walking legs, while the Millipede has seventeen or nineteen pairs.

More precisely, it may be said of the great majority of Crustacea that they are aquatic animals, breathing by gills or by the general surface of the body, having two pairs of "feelers," or antennæ, on the front part of the head, and at least three pairs of jaws. Exceptions to each of these statements will be mentioned in later chapters in dealing with parasites and other highly modified types. In such cases, however, the larval or young stages afford indications of affinity, and comparison with less modified forms enables us to trace a connection with the typical Crustacea.

The best way to form a conception of a group of animals, however, is not to attempt in the first place to define its limits, but to begin by studying the structure of some typical and central species, and 
afterwards to note the divergences from this type presented by other members of the group. Speaking very generally, it may be said that these divergences are of two kinds. On the one hand there are characters that have no apparent relation to the animal's habits and mode of life, and on the other hand there are modifications of structure which are more or less plainly of use to the animal. It is to characters of the former class that we look for evidence of an animal's affinities, and it is upon them that our systems of classification are chiefly based. The characters of the second class- "adaptive" characters, as they are called-become of importance when we study the animal "as a going concern," so to speak, and endeavour to understand how its life is carried on in relation to its surroundings.

In pursuance of this plan of study, the next chapter will be devoted to a description of the Common Lobster as a type of the Crustacea. In the third chapter a survey of the classification of the group will be given; since, however, the characters on which the classification is based cannot be explained fully without entering into technical details which are beyond the scope of this work, this survey will be restricted to what is necessary for comprehension of the succeeding chapters. In the fourth chapter some account is given of the young or larval stages of Crustacea, and of the changes they undergo in the course of development. 
In the next five chapters the Crustacea are classified according to their habitats, and those living in the shallow waters, the depths, and the surface of the ocean, in the fresh waters, and on land, are discussed in turn; while a separate chapter is devoted to the curious forms that live as parasites on, or as associates with, other animals. The last two chapters deal respectively with the Crustacea as they affect man, and with the past history of the group as revealed by fossil remains. 


\section{CHAPTER II}

THE LOBSTER AS A TYPE OF CRUSTACEA

THE most noticeable feature distinguishing the 1 Lobster $^{1}$ (Fig. I) at first sight from other familiar animals is the jointed shelly armour that encases its body and limbs. Over the fore part of the body this armour is continuous, forming a shield, or carapace, which projects in front, between the eyes, as a toothed beak, or rostrum; on the hinder part-the tail, or abdomen-it is divided into six segments, or somites, connected with each other by movable joints. Each of these somites carries on the under-side a pair of fin-like limbs, or swimmerets, the last pair of which (uropods) are much larger than the others, and are spread out at the sides of a middle tail-plate, or telson, forming what is known as the tail-fan. Since the fore part of the body also has a series of paired limbs, constructed, as will be shown

1 The account given here of the structure of the Lobster applies almost equally well to the River Crayfish or the Norway Lobster. The student is recommended to follow the description with a specimen of one of these animals before him. 
later, on the same plan as the swimmerets, it is concluded that this part also is built up of somites, which have become soldered together. That this conclusion is correct is shown by comparison with some of the lower Crustacea in which this part of the body is divided up into eight separate somites, like those of the abdomen, each carrying, in place of

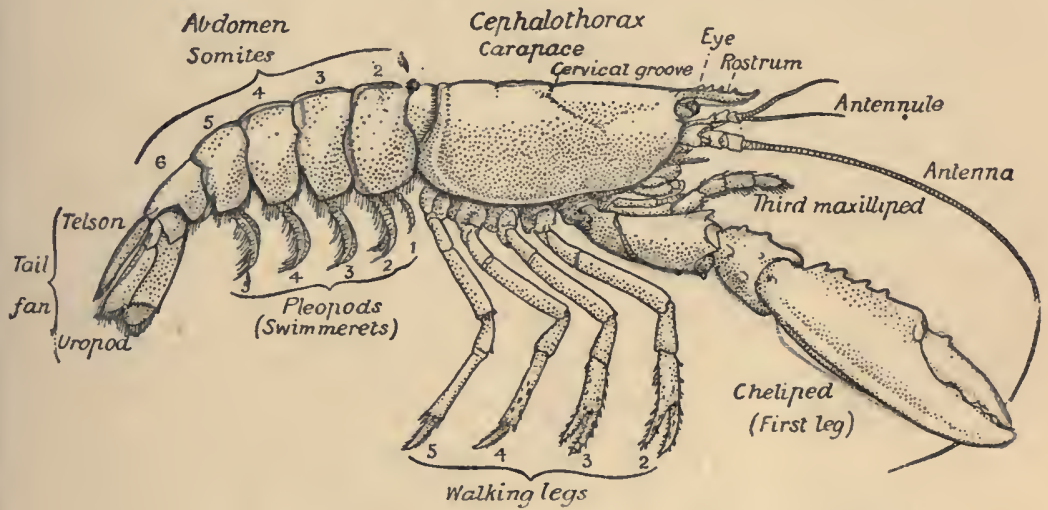

Fig. I-The Common Lobster (Homarus gammarus), Female, FROM THE Side. (From British Museum Guide.)

the swimmerets, a pair of walking legs. In front of these eight somites, forming what is called the thorax, is the head-a part of the body which is never, in any Crustacean, broken up into distinct somites, but which, since it carries five pairs of appendages, must consist of at least five somites. The part of the body covered by the Lobster's carapace includes both the head and the thorax, and is known, there- 
fore, as the cephalothorax. It is necessary to bear in mind that the parts of the body to which the names head, thorax, and abdomen, are applied in Crustacea are by no means exactly equivalent to those which bear the same names in Insects, for example, and that, beyond a rough similarity in position, they have no sort of relation to the parts so named in the body of a vertebrate animal.

There are altogether twenty pairs of appendages attached to the body of the Lobster. In front of the head are the stalked eyes (of which the nature will be discussed later) and two pairs of feelers-the antenmules and antenna (sometimes called the first and second antennæ). Near the mouth on the underside of the head are three pairs of jaw-appendages -the strong mandibles and the flattened, leaf-like maxillula and maxilla. Following these are the appendages of the thorax, of which the first three are intermediate in form between the true jaws and the legs, and are therefore termed foot-jaws, or maxillipeds. The remaining five pairs of thoracic limbs are the legs, the first pair forming the large and powerful pincer-claws, or chelipeds, while the others are the walking legs. The six pairs of swimmerets on the abdomen have already been mentioned.

If one of the somites of the abdomen be separated from the others, it will be seen (Fig. 2) to consist of a shelly ring, to which the two swimmerets are 


\section{THE LOBS'I'ER AS A TYPE OF CRUSTACEA 9}

attached, wide apart, on the under-side. The arched upper part of the ring is known as the tergum, and the more flattened under-part as the stermum. On each side the tergum overlaps the sternum, and hangs down as a side-flap, or pleuron. On the upper side of the abdomen the terga of the somites overlap, the front part of each being pushed under the tergum in front when the abdomen is straightened, and only exposed to view when the abdomen is bent. Below, the sternum of each somite is seen to be only a narrow bar, connected with those in front and behind by soft membrane, and there is no over-

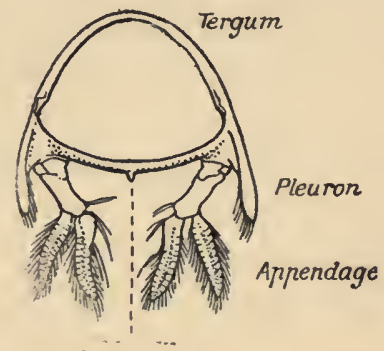

Fig. 2-ONE OF THE ABDOMINAL SOMITES OF THE LOBSTER, WITH ITS APPEN DAGES, SEPARATED AND VIEWED FROM IN FRONT. (From British Museum Guide.) lapping. At the sides the somites are connected together by hinge-joints, which allow them to move only in a vertical plane. Thus the abdomen can be straightened out or bent downwards and forwards, but cannot be moved from side to side. In life the Lobster can swim backwards through the water by vigorously flapping the abdomen.

The carapace which covers the upper side of the head and thorax is not formed, as might be thought, simply by the terga of the somites becoming soldered 
together. This is shown by a comparison with certain shrimp-like Crustacea (Mysidacea) in which the carapace arises, like a fold of the skin, from the hinder edge of the head, and envelops, like a loose jacket, the distinctly segmented thorax. In the Lobster this fold has become adherent to the thoracic somites down the middle of the back, but at the sides it hangs free, enclosing on each side a cavity within which lie the gills.

It seems at first sight strange to include in the same category as "limbs" or " appendages" organs which differ so much in form and function as do the swimmerets, the walking legs, the jaws, and the antennæ. Nevertheless it can easily be demonstrated that all of them are constructed on the same general plan, and arise in the embryo from rudiments which are, for the most part, exactly alike. This is expressed in technical language by saying that the appendages of the whole series are homologous with one another. A full discussion of this interesting fact would require more space than can be devoted to it here, but a few examples may be given to illustrate what is meant by the "serial homology" of the appendages in Crustacea.

If one of the swimmerets be detached from the third abdominal somite, it will be seen (Fig. 2) to consist of a stalk, known as the protopodite, bearing two branches, of which that on the outer side is called the exopodite, and that on the inner side the 
endopodite. The protopodite consists of two segments, the first very short, and the second much longer. It can easily be seen that the side-plates of the tail-fan (the middle plate, as already mentioned, is the telson) are simply the swimmerets of the sixth abdominal somite. They are much larger than the other swimmerets, and have the endopodite and exopodite broadened out into large plates; while the protopodite is very short, and not divided into segments.

If now the third maxilliped (Fig. 3) be examined, it will be found that, like the swimmeret, it consists essen-

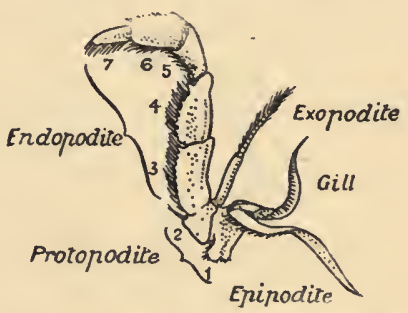

Fig. 3-Third MAXILLIPED OF LoBster. (From British Museum Guide.)

tially of two branches springing from a stalk of two segments. The exopodite, however, is much smaller than the endopodite, and it ends in a flexible lash made up of many small segments. The endopodite forms the main part of the limb, and has five segments, so that, with the two segments of the protopodite, there are seven segments in the main axis of the limb; the second and third segments are partly soldered together, but the line of union can be plainly seen. Attached to the outer side of the first segment is a membranous plate, known as the epipodite, on which is inserted, near its base, a 
brush-like structure, which is one of the gills. In the natural position the epipodite and its gill lie in the gill chamber, hidden from view by the side-flap of the carapace.

The legs (Fig. 4) can, without difficulty, be seen to consist each of seven segments like those of the

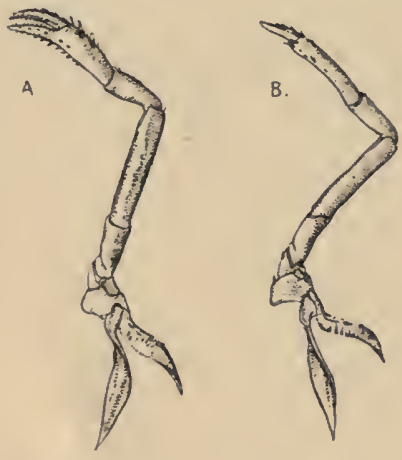

Fig. 4-Walking Legs of LOBSTER maxillipeds, but there is no exopodite. In the young Lobster, when just hatched from the egg, however, each of the legs has a large exopodite like that of the third maxilliped. These exopodites, which are used in swimming, are afterwards lost as the animal grows; but their presence in the young is interesting as confirming the conclusion that the legs, like the maxillipeds, are built on the same plan as the swimmerets. The large claws, and also the first and second pairs of walking legs, end in pincers, or chela, the penultimate segment projecting in a thumb-like process against which the last segment works. Each leg, except those of the last pair, has on its first segment an exopodite with a gill like those of the maxilliped. 


\section{THE LOBSTER AS A TYPE OF CRUSTACEA I3}

Following the series of appendages forwards from the third maxilliped (Fig. 5), it is easy to trace the gradual reduction of the endopodite and exopodite;

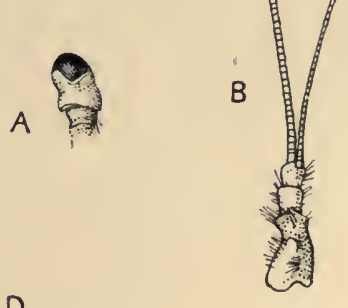

D.

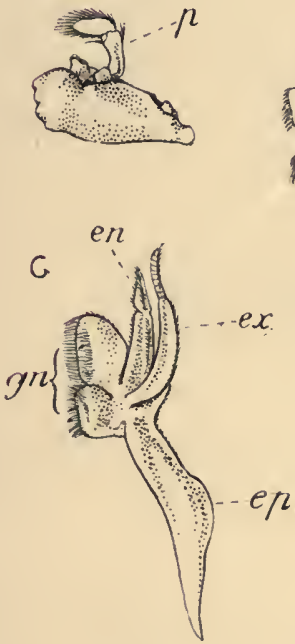

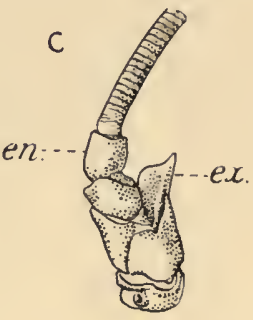
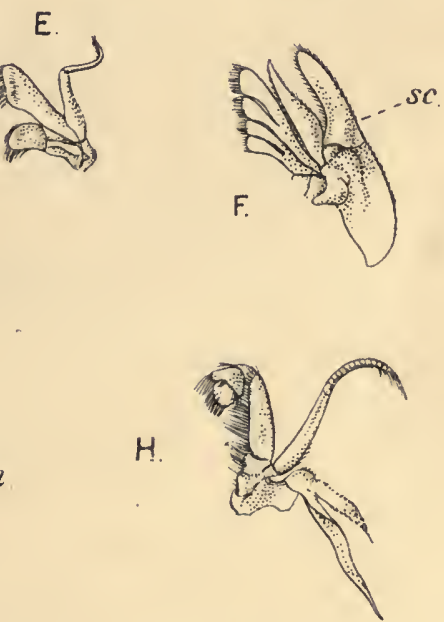

Fig. 5-Appendages of Lobster in Front of Third Maxilliped A, Eye-stalk ; B, antennule ; C, antenna (the flagellum is cut short); $D$, mandible; E, maxillula; F, maxilla ; G, first maxilliped ; $H$, second maxilliped. en, Endopodite ; ep, epipodite ; $e x$, exopodite ; $g n$, gnathobases, or jaw-plates; $p$, palp of mandible; $s c$, scaphognathite 
while the two segments of the protopodite become flattened and broadened inwards to form the jawplates. The mandibles (Fig. 5, D), which are the chief organs of mastication, consist mainly of the much enlarged basal segment of the protopodite, with a strongly toothed inner edge, where it works against its fellow of the opposite side; and the rest of the limb is reduced to a small sensory "palp," which represents the second segment of the protopodite and the endopodite.

The antennæ (Fig 5, C) can be shown, without difficulty, to conform to the same plan of structure as the other appendages. The two segments of the protopodite are short, but distinct; the endopodite forms the long lash, or flagellum, composed of very numerous small segments; the exopodite is reduced to a small movable scale or spine.

The antennules (Fig 5, B) seem at first sight to present the two-branched type of structure in its simplest form; but there is considerable doubt as to whether the two lashes which each bears on a threesegmented stalk are really equivalent to the endopodite and exopodite.

The movable stalks which carry the eyes (Fig. 5, A) have been considered by some to belong to the series of the appendages, and to be, in fact, modified limbs. If this be the case, we have here the greatest simplification which the limb undergoes in the Lobster, for each eye-stalk consists only of two segments: the 
first small and incompletely formed, the second in the form of a short cylinder, having the eye at its end. There are, however, reasons for doubting whether the eye-stalks are really appendages.

The hard outer covering of the Lobster not only protects and gives support to the internal organs, but also affords points of attachment for the muscles by means of which the animal moves. In other words, it plays the part of a skeleton; but since, unlike the skeleton of vertebrate animals, it is outside instead of inside the soft parts of the body, it is known as an exoskeleton. Closer examination shows that this outer covering is really continuous over the whole of the body and limbs, but is thin and soft at the joints, allowing the parts to move one upon another. It is composed of a horn-like substance known as chitin, which, except at the joints, is hardened by the deposition in it of carbonate and other salts of lime.

As this external covering does not increase in size after it has been formed, and as it cannot stretch to any great extent, the Lobster requires to cast its shell at intervals as it grows. In this process of moulting the integument of the back splits between the carapace and the first abdominal somite. The body and limbs are gradually worked loose and withdrawn through the opening, leaving the cast shell with all its appendages almost entire. The new covering, which had been formed underneath the 
old before moulting, is at first quite soft, and the animal rapidly increases in size owing to the absorption of water. The shell then gradually hardens by the deposition of lime salts.

The internal anatomy (Fig. 6) presents many points of interest which can only be briefly touched on here. The food-canal consists of a short gullet leading into a capacious stomach, from which the straight in-

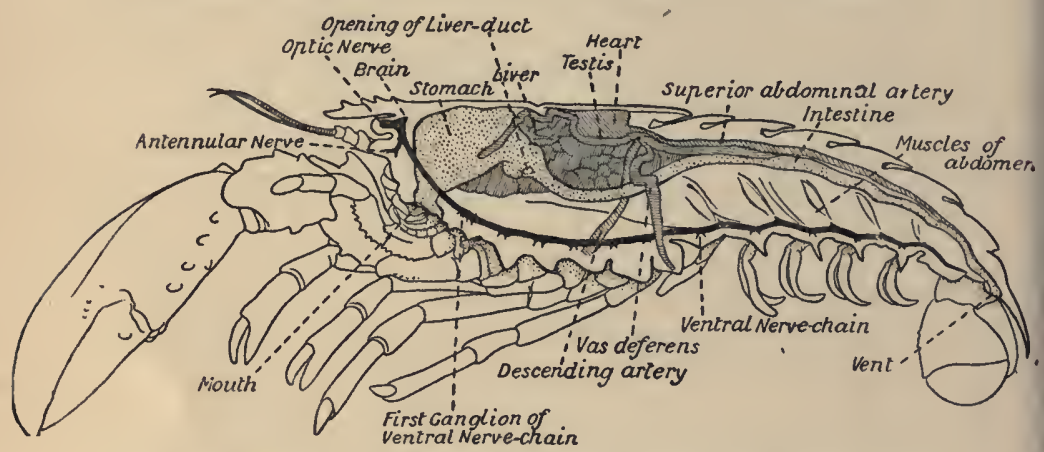

Fig. 6-Dissection of Male Lobster, from the Side. (From British Museum Guide.)

testine runs to the vent on the under-side of the telson. The stomach has a most remarkable and complicated structure. It consists of two chambers, a larger in front and a smaller behind, which are lined by a continuation of the chitinous outside covering of the body. This chitinous lining is thickened in places to form a system of plates and levers connected with three strong teeth set in the narrow opening between the two chambers. By the 
action of muscles attached to certain of these plates the teeth work together so as to divide up the food more finely than had been done by the mandibles and other jaws. The whole apparatus, in fact, serves as a kind of gizzard, and is known as the gastric mill.

A small part of the intestine at the hinder end is lined, like the stomach, by a continuation of the chitinous covering, which is turned in at the vent. This lining and that of the stomach, with the plates and teeth of the gastric mill, are cast and renewed when the shell is moulted.

On each side of the food-canal in the thorax lies a -large mass of soft tissue, yellowish-green in 'colour. This is the digestive gland, or "liver," which secretes the digestive juice, discharging it into the foodcanal by a short duct on each side just behind the stomach.

The heart lies in the middle of the back, just under the hinder part of the carapace, and gives off, in front and behind, a number of arteries which carry the blood to the various organs of the body. From the smaller branches of these arteries the blood passes, not, as in vertebrate animals, into capillaries, but into the spaces lying between the organs of the body, and it finds its way back to the heart, not in definite veins, but by ill-defined venous channels which open into the pericardium, or space surrounding the heart. From the pericardium the blodd 
enters the heart by six openings in its walls, each guarded by a pair of valves which close when the heart contracts, and prevent the blood from returning to the pericardium.

The venous channels which convey the blood back to the heart are so arranged that most of the

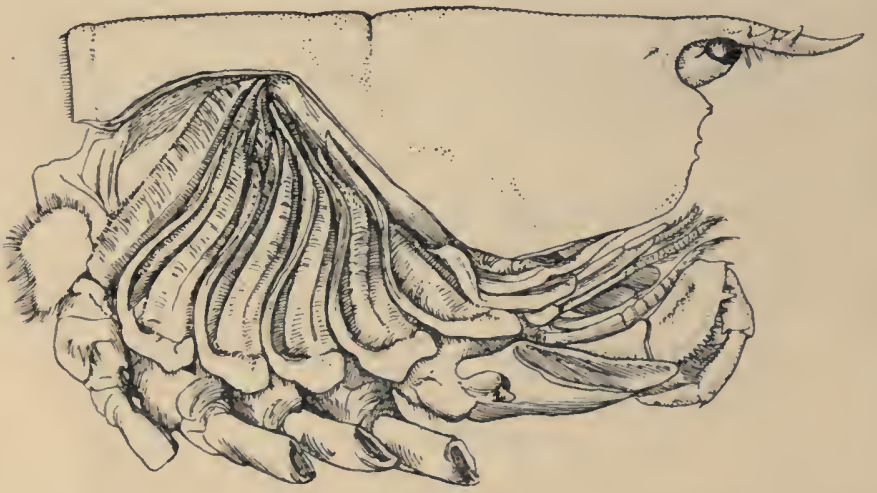

Fig. 7-Gills of the Lobster, Exposed by cutting away the Side-flap of the Carapace (Branchiostegite)

blood passes first through the gills, for the purpose of respiration, before it reaches the heart and is again distributed through the body. These gills, as already mentioned, lie in the two branchial chambers under the side-flaps of the carapace (Fig. 7), and are attached, some to the epipodites of the thoracic limbs (as described above), and some to the soft membrane of the joints between the limbs and the body; while others are attached 
to the side-wall of the thorax itself. Each gill is somewhat like a bottle-brush in shape, consisting of a central stalk set round with rows of soft hairlike processes. As the blood streams through the minute channels inside these filaments, it is separated only by a thin membrane from the surrounding water, and the absorption of oxygen and discharge of carbon dioxide can go on easily. For this purpose, however, it is necessary that the water within the gill chamber should be constantly renewed, and this is effected in the following way: the front part of the gill chamber forms a narrow channel running forward under the side-wall of the carapace. Within this channel lies a large plate known as the scaphognathite, attached to the outer side of the maxilla, which during life is constantly in movement, causing a current of water to flow forwards through the channel. The water enters the gill chamber by the narrow slit-like space between the lower edge of the carapace and the bases of the legs, and is discharged in front at the sides of the head, where its movement is helped by the vibrating exopodites of the maxillipeds.

At the sides of the stomach, in the front part of the head, lie a pair of glands which, from their colour, are known as the green glands. These are the excretory organs, corresponding in function to the kidneys of the higher animals. Each has connected with it a thin-walled bladder, which opens to 
the outside through a small perforation on the under-side of the first segment of the antenna.

The chief part of the nervous system is the ventral nerve-chain, which runs along the under-side of the body. This is a long cord having at intervals a series of knots or swellings, the ganglia or nervecentres, from which nerves are given off to the appendages and to the organs of the body. In the hinder part of the thorax and in the abdomen there is a ganglion in each somite, but in front these ganglia become crowded together and coalesced, so that we find only a single large ganglion, corresponding to the somites from that of the mandibles to that of the third maxillipeds. Between the ganglia the cord is really double, although for the greater part of its length the two parts are more or less completely fused into one. In front of the head and above the gullet is a ganglion which sends nerves to the eyes, antennules and antennæ, and is known as the brain, although it is, perhaps, hardly so important as that name would suggest. It is connected with the ventral chain by two cords that pass on either side of the gullet.

The eyes, as already mentioned, are set on movable stalks, so that they can be turned in any direction at the will of the animal, and are of the type known as "compound eyes." If the convex black area at the end of the eye-stalk be examined with a strong lens, it will be seen that the membrane which covers it is 
divided up into a beautifully regular series of square facets. This membrane is a thin and transparent continuation of the chitinous covering of the body, and if it be stripped off and examined under a microscope, it will be found that each facet is capable of acting as a lens and forming an image of external objects. It is not to be supposed, however, that the Lobster sees a separate image in each of the facets, some thirteen thousand in number, which go to make up each eye. In the interior of the eye, at some distance from the surface, are a large number of rod-like bodies, connected with the fibres of the optic nerve, and believed to be the actual organs for the perception of light. Each rod corresponds to one of the facets, and as it lies at the bottom of a long conical tube, of which the walls are covered with dark pigment, it can only receive light from a single point in line with the axis of the tube. In this way the image of any object will be built up, like a mosaic, out of the impressions of light and darkness received through the separate facets, and transmitted to the underlying rods. It has been shown in some Crustacea that, when the animal is in a very dim light, the curtain of pigment separating the tubes is partially withdrawn, so that the light from each facet can reach, not one, but several rods. In this way the images of objects received are much brighter, although they are less sharply defined.

It might be thought that in animals like the 
Lobster, enclosed in a hard shelly covering, the sense of touch must be very dull, if not altogether absent. This, however, is not the case. What is probably a very delicate tactile sense is provided for by the numerous hairs which are found, of many sorts and sizes, all over the body and limbs. Each of these hairs is really a hollow outgrowth of the chitinous covering, containing a delicate prolongation of the soft tissues underneath, and also supplied, in many if not in all cases, with a nerve-fibre, so that the slightest movement of the hair caused by contact with a solid body is perceived by the animal. Many of these hairs are themselves beset with delicate secondary hairs, arranged so that the whole looks like a feather or like a bottle-brush. These hairs are adapted for detecting slight movements or vibrations in the surrounding water.

Whether Crustacea living in water can hear, in the sense in which the word is used of animals living in air, is doubtful; but it is certain that they are extremely sensitive to vibrations only a little coarser, so to speak, than those we know as sound. The Lobster, and many other Crustacea, do indeed possess a structure which was long supposed to be an organ of hearing, and may possibly in part fulfil that function, although it is now known that that is not its only or even its chief use. It consists of a small cavity in the basal segment of the stalk of the antennule, opening to the outside by a narrow slit 
on the upper surface of the segment. The cavity is lined by a delicate continuation of the chitinous covering of the body, and has on its inner surface a series of feathered hairs of the kind described above, which are richly supplied with nerve-fibres from a large nerve entering the base of the antennule. Within the cavity, and for the most part entangled among these hairs, are a number of grains of sand. When the Lobster moults, the lining membrane of this cavity is thrown off like the rest of the exoskeleton, and with it the contained sand-grains. While the shell is still soft after moulting, and the lips of the slit are not rigid, as they afterwards become, fresh sand-grains find their way into the cavity to take the place of those which have been cast off. Perhaps, like some other Crustacea, the Lobster buries its head in the sand to insure that some grains may find their way in; for its pincers are too clumsy for it to pick up sand-grains and to place them in the cavity, as some Prawns have been seen to do. At all events, if a freshly moulted Prawn be placed in a vessel of sea-water, and supplied, instead of sand, with powdered glass or metal filings, particles of glass or metal will after a short time be found in its antennular cavities. This habit has been utilized in a very ingenious experiment by which the function of these organs was demonstrated. A Prawn had been induced in this way to place particles of iron filings in the cavities, 
and a strong electro-magnet was brought near the side of the vessel in which it was kept. It was observed that the Prawn, which had been swimming in the usual horizontal position, at once turned the under-side of its body towards the magnet, and swam about on its side as long as the magnet was in action. When the current exciting the magnet was cut off, the animal resumed its ordinary position. This experiment shows that these organs, to which we may now give their proper name of statocysts, are organs for perceiving the direction of the force of gravity. The magnetic force acted on the particles of iron in the same way that the force of gravity acts on the sand-grains in normal conditions, and the Prawn felt the weight of them, so to speak, pulling towards the side instead of the bottom ot the vessel, and turned its body accordingly, to swim, as it supposed, right side up. It is now known that those parts of the human ear called the "semicircular canals" have a somewhat similar function as "organs of orientation," although to animals walking on the solid ground this function is not so important as it doubtless is to animals swimming in water.

The sense of smell is believed to have its seat chiefly in the antennules. The outer branch of each antennule bears tufts of peculiar hairs, in which the chitinous covering is extremely delicate, so that substances dissolved in the water can easily pass through 


\section{THE LOBSTER AS A TYPE OF CRUSTACEA 25}

and affect the nerve-endings within. These hairs are known as "olfactory filaments."

The sense of taste in aquatic animals is, perhaps, not sharply defined from that of smell, but it is not very rash to assume that certain hairs on the mouth parts and on the fleshy upper and lower lips which bound the opening of the mouth have to do specially with this sense.

The relative importance of the various senses in the Lobster is well illustrated in the following account of its habits given by Dr. H. C. Williamson in the Report of the Scottish Fishery Board for I904. After noticing that, in daylight at least, the Lobster appears to be "purblind," only distinguishing light from shadow, Dr. Williamson goes on : "It tests a shadow with its antennæ, or sometimes, when a strong shadow is thrown on it, it jumps at it with its chelæ outstretched and snapping. It is dependent on its antennæ for guiding it in safe places. It is especially careful in testing any hole before it is satisfied with it. It discovers the cavity by means of its antenna, which is waved well out to the side and in front as it walks. It searches the innermost depths of the hole with the antenna, and then inserts its chela. If the examination with the chela is also satisfactory, it immediately turns and backs smartly into the hole. In feeding it is guided to the food by the antennules. A piece of food which is dropped near a Lobster may fall quite unnoticed unless it 
happens to touch the antenna or the [legs]. It is not seen at all. But sooner or later, according as the distance is short or great, the scent of the food, carried by the currents set up by the exopodites of the maxillipeds, reaches the Lobster. The Lobster is immediately excited, although previously it was lying quite inert in its hole. It whips the water with its antennules in a staccato fashion, and feels about with the antennæ and chelæ, at first without leaving its hole. At once both antennules are seen to be whipping in the direction in which the food is lying, and an active search is made with the antennæ. If they do not succeed in locating the bait, the lobster rather reluctantly leaves its hole, but cautiously, feeling all round about with its antennæ. It goes off straight in the direction in which the food is lying, and, if it misses it with its antennæ and chelæ, walks over it and gets it with its chelate [walking legs]; it usually picks up its food with the second [walking leg]. Meanwhile the expected feast has by association stimulated the maxillipeds, which are actively working as if they were already masticating the food. Once the food is seized it is conveyed to the maxillipeds, and the Lobster retreats to its hole, there to enjoy its meal."

Lobsters, like most other Crustacea, are of separate sexes. The females (see Plate I.) may be distinguished from the males by the fact that the abdomen is broader and has deeper side-plates, and by differ- 


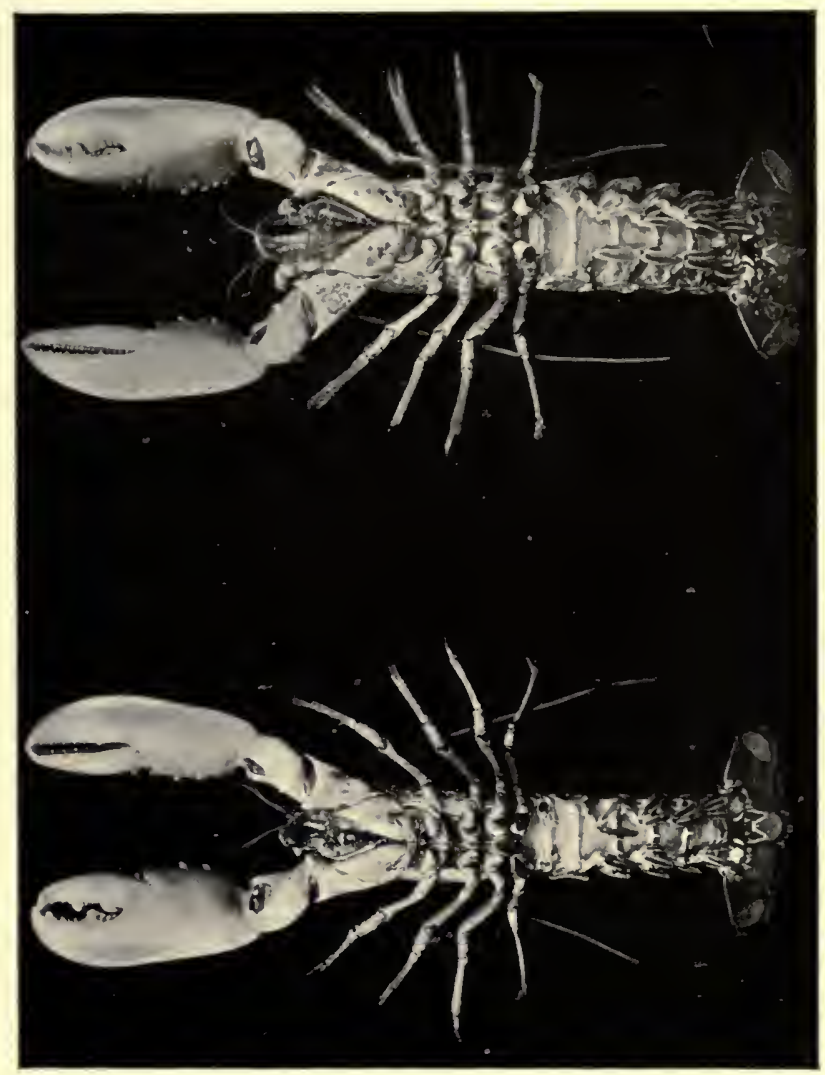

볼 논

s.

볼

$=5$

공

는

政

손

案步

的

됯본

i-

z势台

난

Ux

台存立

$x$

式:

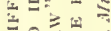

ํ.

밀

$=\frac{1}{2}$

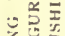

空

里

家



if

舟

彭

돈

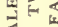

到照

도ㄷㅏㅠ

능

zzis

口.

罂 



\section{THE LOBSTER AS A TYPE OF CRUSTACEA 27}

ences in the form of the first two pairs of swimmerets. In the female the first pair, which have only one branch, are short and slender filaments, while in the male they are stout and peculiarly twisted rods. The second pair in the female are similar in form to the succeeding pairs, but in the male they have an additional lobe on the inner branch. The openings of the generative organs will be found in the male on the basal segments of the last pair of legs, while in the female they occupy the same position on the legs of the last pair but two. The testis of the male lies in the thorax, just below the heart. The ovary, which has the same position in the female, is usually much more conspicuous, and from its red colour in the cooked lobster it is known as the "coral." On the under-side of the thorax of the female, between the last two pairs of legs, is a three-lobed structure enclosing a cavity known as the "sperm-receptacle." Its function is to receive the fertilizing substance from the male, and to retain it until the eggs are ready to be deposited.

In the Lobster, as in many other Crustacea, the eggs are carried by the female until they hatch. After being extruded from the oviducts, they are attached by a kind of cementing substance to the swimmerets, where they hang in bunches. The swimmerets are kept constantly moving, so that the eggs may obtain the oxygen necessary for the developing embryos within. A female Lobster carrying 
eggs in this way is said by the fishermen to be "in berry," and may carry, according to its size, from about 3,000 to nearly 100,000 eggs. A period of about ten months elapses between the deposition of the eggs and hatching.

The young Lobster when first hatched (Fig. 8) differs considerably in general appearance from the adult animal. The

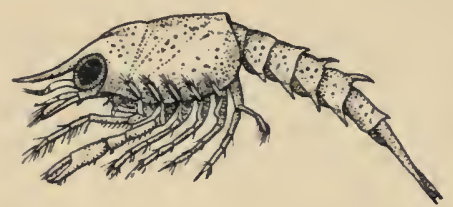

Fig. 8-First Larval Stage of the Common Lobster. $\times 4$. (After Sars.) abdominal somites have a row of spines down the middle of the back, and the telson has a forked shape. There are no swimmerets, but, as already mentioned, the legs bear large exopodites, which are used like oars, and by means of these the larval Lobster swims about at the surface of the sea. The claws or chelæ are at first hardly larger than the other legs, but later they increase in size, the swimmerets are developed, the exopodites of the legs are lost, and the young Lobster, sinking to the bottom of the sea, takes on the creeping habits and gradually assumes the shape of the adult.

In many Crustacea the changes of shape or metamorphoses undergone after hatching are much greater than in the Lobster. Some of these changes and their probable significance will be considered at greater length in a later chapter. 
The two large claws of the Lobster (see Plate I.) are not quite alike in size or in shape. The smaller of the two has the inner edges of the fingers sharp and set with saw-like teeth; the larger has the fingers armed with blunt rounded knobs. The larger claw is adapted for crushing the shells of the animals on which the Lobster feeds, while the smaller serves for holding and tearing the prey. In the Lobster, as in many of the higher Crustacea in which this asymmetry occurs, the larger claw may be indifferently on either side of the body. There are certain cases, however, among Crabs where the large claw is constantly on the same side of the body, or, in other words, all the individuals are either righthanded or, more rarely, left-handed.

If a Lobster be caught by one of its claws or by a leg, it very readily parts with the limb in its struggles to escape ; and if one of the limbs be crushed or otherwise injured, it is often cast off by the animal. The separation always takes place at the same point, near the base of the limb, and is not simply due to the limb breaking at its weakest part. It is a reflex act, brought about by a spasmodic contraction of some of the leg muscles. At the place of separation, corresponding to the junction of the second and third segments of the limb, which, as already mentioned, are soldered together, the internal cavity is crossed by a transverse partition, having only a small aperture in the centre through which the nerves and 
bloodvessels pass. When the limb is cast off, this small opening quickly becomes closed by a clot of blood, and further bleeding is stopped. If, as sometimes happens, a limb which has been seriously injured is not cast off, the animal not infrequently bleeds to death. This power of self-mutilation or autotomy, as it is called, is frequently used by Crustacea as a means of escaping from their enemies, and is closely connected with the power of regeneration of lost appendages. Beneath the scar which forms on the stump of a separated limb a sort of bud grows, and gradually assumes the form of the lost segments. At the next moult this straightens out, and, increasing in size at succeeding moults, it ultimately provides, in normal cases, a new member similar in every detail to that which had been lost. Occasionally it happens, under circumstances not yet altogether understood, that the process of regeneration may, so to speak, go wrong, and in this way various malformations and abnormalities result. For instance, it has been found that, if the larger, crushing claw of a very young Lobster be removed by operation or by accident, the limb which grows in its place may assume the form of the smaller, toothed claw. Further, in some other Crustacea (but not in the Lobster, except in the very youngest stages), it is found in such cases that, after removal of the large claw, the claw of the other side assumes at the next moult the form of a crushing claw, so that there is a "reversal of asymmetry." 
A still more remarkable change sometimes occurs when one of the eye-stalks is injured. If only the tip of the eye-stalk be cut off, so that the nerve-ganglion which lies in the basal part of the stalk remains uninjured, it will be found that a normal eye is in course of time regenerated. If, however, the whole eye-stalk be amputated, and with it the optic ganglion, there grows in its place, not a new eye-stalk, but a segmented appendage similar to one of the flagella of the antennules. This fact is considered by some zoologists to indicate that the eye-stalks are, like the antennules, true appendages, homologous with the mouth parts and limbs, but this is a much-disputed question into which we cannot enter further here.

Lobsters vary a good deal in colour, but as a rule a living Lobster is of a more or less mottled dark blue, becoming nearly black on the back, and shaded off into orange yellow or red on the under-side. This coloration resides in the shell, and does not change much after the shell has hardened. In this respect the Lobster is unlike many of the smaller Crustacea which have a thin and more or less transparent exoskeleton, and in which the colour resides in certain living cells (chromatophores) of the underlying skin. Many of these Crustacea possess the power of changing their colours to a remarkable degree, by the expansion and contraction of the branched chromatophores.

The question which is often asked, "Why does a 
Lobster turn red when it is boiled ?" is one to which it is not easy to give a simple answer. A chemical change takes place under the influence of heat in the pigment of the shell, which changes it from blue to red; how slight the change is, is perhaps shown by the fact that occasionally living Lobsters are found of

A.

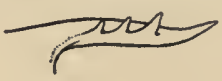

B.

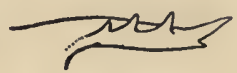

FIG. 9-SIDE-VIEW OF

ROSTRUM OF (A)

Common LOBSTER

(Homarus gammarus)

AND (B) AMERICAN

LOBSTER (Homarus americanus)

a red colour almost as brilliant as that which is assumed on boiling.

The Common Lobster is found on the coasts of Western Europe, from Norway to the Mediterranean, living in shallow water, generally a little way below low-tide mark, wherever a rough, rocky bottom affords suitable lurking-places. On the Atlantic coast of North America, Lobsters are also found abundantly in similar situations. These American Lobsters, if examined carefully, will be found to differ from the European kind in certain small details of structure, of which the most conspicuous is the presence, on the under-side of the rostrum, of two spines or teeth. In the European Lobsters the under-side of the rostrum is smooth (Fig. 9). In the nomenclature of technical zoology, these two kinds or species of Lobster are said to constitute (along with a third species found at the Cape of Good Hope) the genus Homarus, the European species being known as Homarus gam- 
marus, and the American as Homarus americanus. The so-called "Norway Lobster" or "Dublin Prawn," which differs from the Common Lobster in having large kidney-shaped eyes and long and slender claws, and in many other details of structure, is placed in a distinct genus, and is known as Nephrops norvegicus. The genera Homarus and Nephrops, together with some others, constitute the family Homaridæ, which again is grouped with other families in a tribe, Nephropsidea, forming a part of the order Decapoda. These groups are intended to express the varying degrees of resemblance and difference in structure between the species of animals which make up the class Crustacea. Since we have good grounds for believing that all these species have arisen by some mode of evolution, this classification also represents the varying degrees of actual relationship between the different forms, so far as this relationship can be discovered. In the next chapter a brief sketch of the chief subdivisions of the Crustacea is given, with such details as to the characteristics of each as are necessary to render intelligible the succeeding chapters on their habits and modes of life.

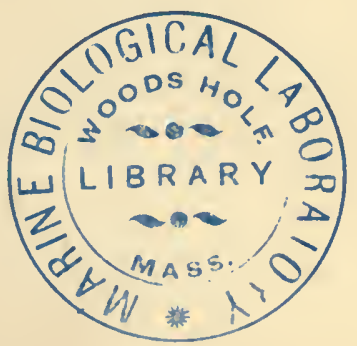




\section{CHAPTER III}

THE CLASSIFICATION OF CRUSTACEA

$$
\text { Table of Classification of Crustacea }
$$

\section{Class CRUSTACEA.}

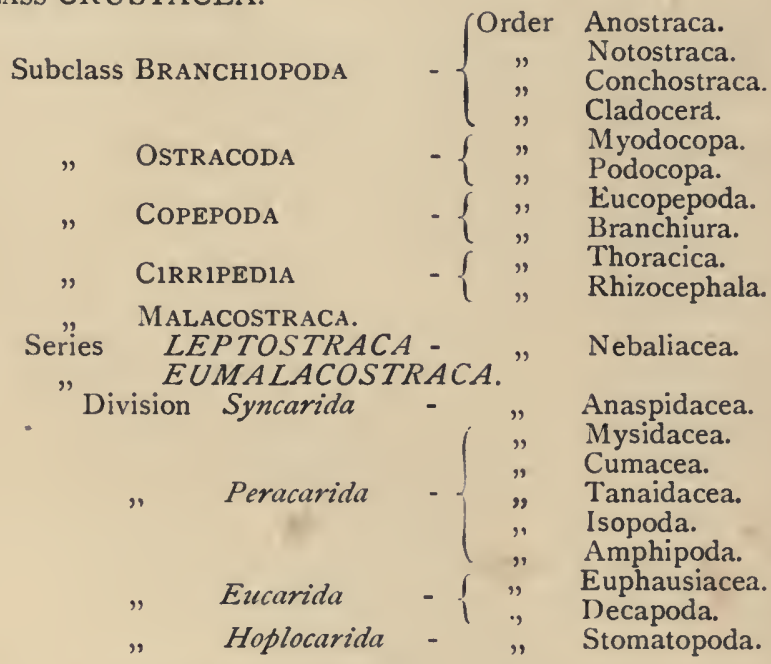

CCASIONALLY there may be found in rainwater puddles and the like, in the South of England, a beautiful, transparent, shrimp-like animal, an inch or more in length, to which the name of 
"Fairy Shrimp" has been given (Fig. ro). It is known in technical zoology as Chirocephalus diaphanus, and is a representative of the subclass BRANCHIOPODA. The members of this group are distinguished from other Crustacea by their flattened, leaf-like feet, each of which is divided into a number of lobes, and has a gill plate on the outer side. In Chirocephalus there is no carapace, and the head is followed by eleven distinct body segments, each bearing a pair of leaf-like, or rather fin-like, feet.

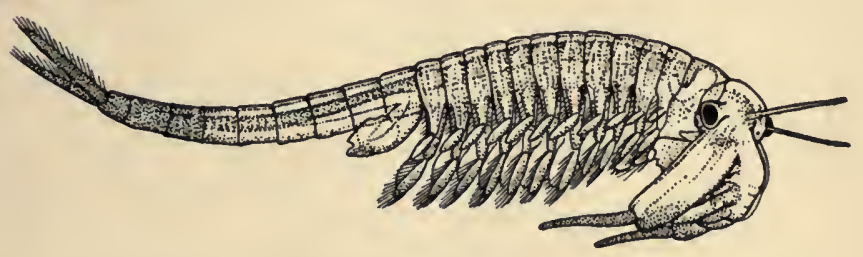

Fig. Io-The "FAIRY Shrimp" (Chirocephalus diaphamus), MALE. $\times$ 2. (After Baird.)

The hinder part of the body has no appendages, and ends in a forked tail. In the female a large pouch hangs from the under-side of the body, just behind the limb-bearing part, and is often found filled with eggs. In the male, a pair of remarkablelooking appendages, each shaped somewhat like a hand with webbed fingers, hang in front of the head. These are connected with the antennæ, and are known as the "claspers," from their function in seizing and holding the female. The eyes are set on movable stalks. Those Branchiopoda which, like 
Chirocephalus, have no carapace, form the order Anostraca.

A second order, the Notostraca, is represented by Apus cancriformis (Plate II.), which occurs in

A.
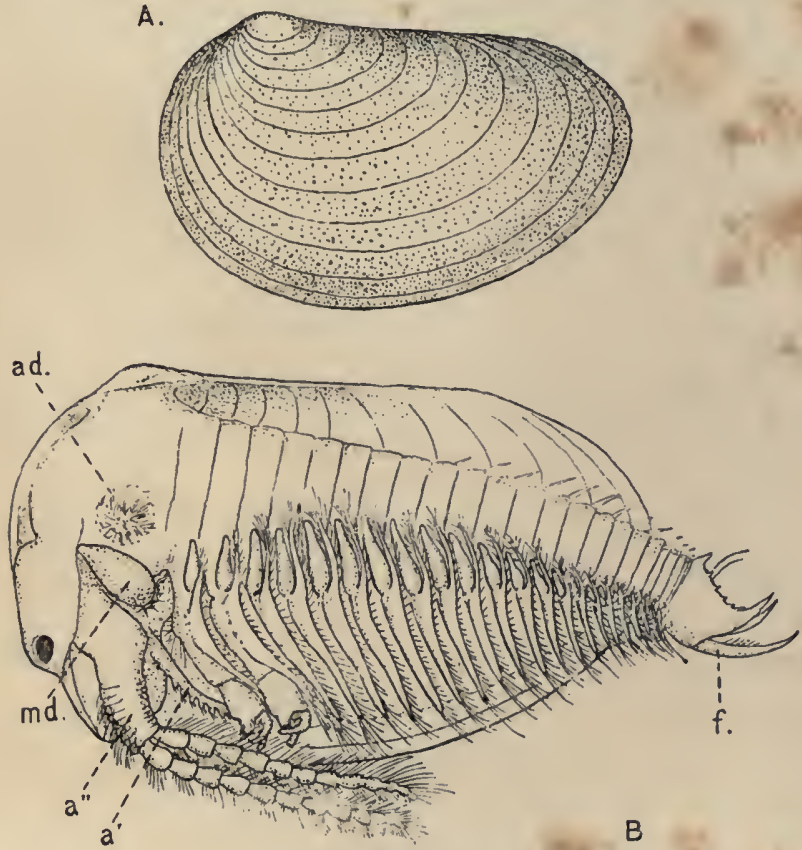

Fig. II-Estheria obliqua, ONE of the Conchostraca. (After Sars, from Lankester's "Treatise on Zoology.")

$A$, Shell of female, from the side; $B$, male, from the side, after removal of one valve of the shell. (Enlarged.) $a^{\prime}$, Antennule; $a^{\prime \prime}$, antenna; $a d$, muscle which draws together the valves of the shell ; $f$, tail fork; $m d$, mandible

many places in Europe in ponds and puddles, and very rarely indeed in Britain. In Apus there is a large 


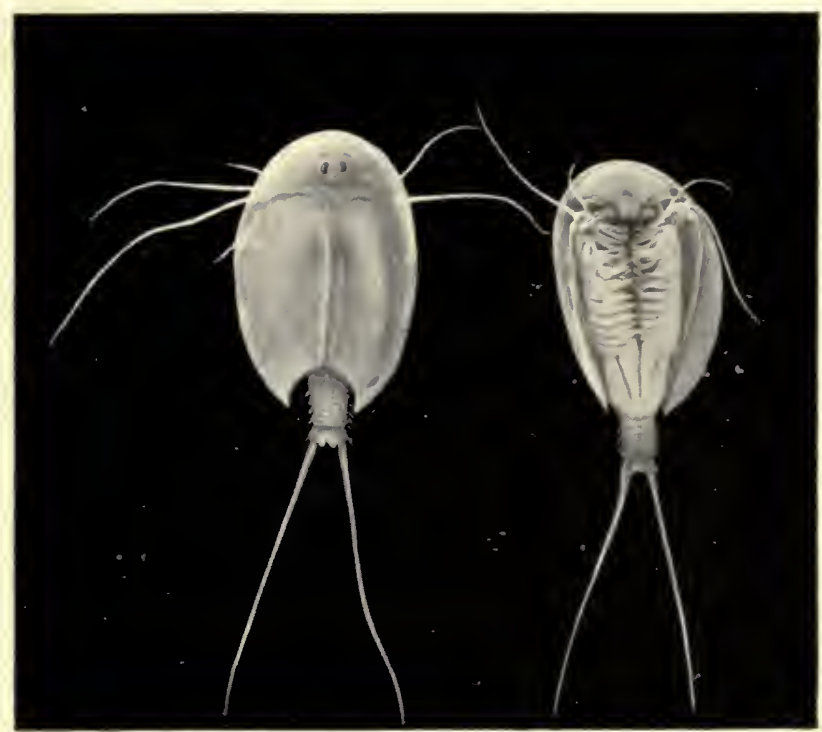

Apus cancriformis, FROM KIRKCUDRRIGH'SSHIRE. (SLIGHTLY ENLARGED) 



\section{THE CLASSIFICATION OF CRUSTACEA 37}

dorsal shield, or carapace, covering the greater part of the body, which consists of a large number of segments (about twentyeight), and ends behind in a pair of long antenna-like filaments. The fin-like feet are also very numerous (about sixtythree pairs). The eyes are not stalked, but are set close together on the upper surface of the carapace.

The third order of the Branchiopoda, the Conchostraca (Fig. II), are not represented in Britain, though several species occur on the Continent of Europe. In these the carapace forms a bivalved shell, completely enclosing the body and

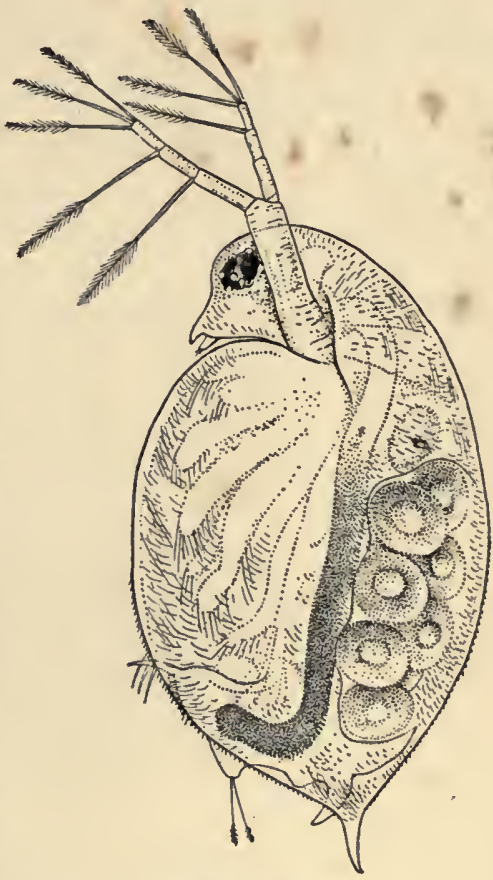

Fig. 12-Daphnia pulex, A СоммоN SPECIES OF "Water-FLea." Much ENLARGED. (From British Museum Guide.)

Female carrying eggs in the brood. chamber limbs, and closely resembling that of a small mollusc.

The fourth order, the ClADOCERA, comprises the so-called "Water-fleas," which are abundant every- 
where in ponds and lakes (Fig. I2). They are all of small size, almost or quite microscopic. The carapace, as in the Conchostraca, forms a bivalved shell, but does not enclose the head. There is a single large eye, which really corresponds to two eyes fused together. A pair of large antennæ, each with two branches, carrying long feathered hairs, project at the sides of the head, and are used in
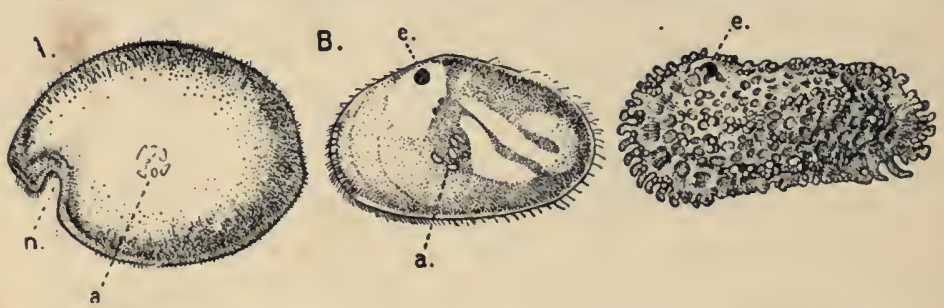

Fig. I3-Shells of Ostracoda, Much enlarged. (From Lankester's "Treatise on Zoology," after Brady and Norman, and Müller.)

A, Philomedes brenda (Myodocopa); B, Cypris fuscata (Podocopa); C, Cythereis ornata (Podocopa). n, Notch characteristic of the Myodocopa; $e$, the median eye; $a$, mark of attachment of the muscle connecting the two valves of the shell. $A$ and $C$ are marine species; $B$ is from fresh water

swimming with a peculiar jumping motion, from which the popular name of the animals is derived. There are not more than six pairs of feet. The "Water-fleas," of which Daphnia pulex is one of the commonest species, are very beautiful and interesting objects for microscopic examination, on account of their transparency, which allows many details of their internal structure to be studied in the living animal. The Ostracoda (Fig. 13), which form the second 


\section{THE CLASSIFICATION OF CRUSTACEA 39}

subclass in the system of classification here adopted, are nearly all microscopic animals, and are found abundantly in fresh water as well as in the sea. The carapace forms a bivalved shell, which completely encloses the body and limbs, and is often sculptured in an elegant fashion. The Ostracoda are remark-

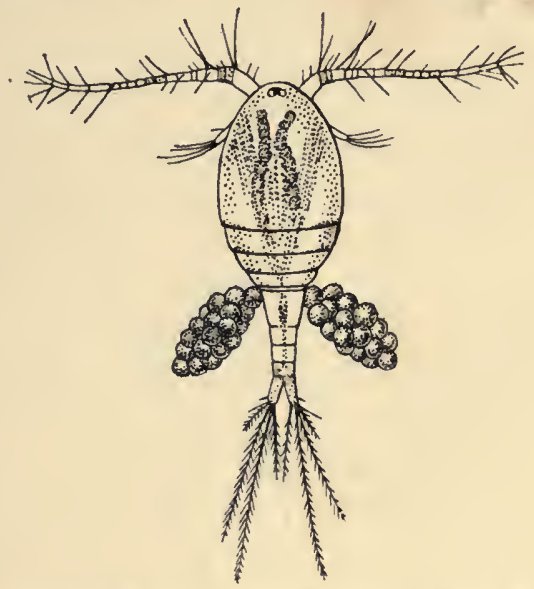

Fig. I4-Cyclops albidus, A Species of Copepod Found IN Fresh WATER. (After Schmeil.)

Female specimen carrying a pair of egg-packets. The actual length is about one tenth of an inch

able for the very small number of their appendages. There are not more than two pairs of limbs behind the maxilla. Most of the species are included in two orders, the Myodocopa and the Podocopa, of which the former may generally be distinguished by a notch in the anterior part of the margin of the shell (Fig. I3, A, n). In the Podocopa the margin is entire. 
The subclass COPEPODA comprises animals, for the most part of microscopic size, which are abundant in fresh water and in the, sea. The common freshwater genus Cyclops (Fig. I4) furnishes a good example of the type of structure characteristic of the class. The body is somewhat pear-shaped, with a narrow abdomen ending in a "caudal fork." The body is divided into somites, and there is no overlapping carapace, although the head and the first two thoracic somites are coalesced. There are four pairs of two-branched, oar-like, swimming feet, and a fifth pair, found in some other Copepoda, is represented in Cyclops by minute vestiges on the first segment of the narrow posterior part of the body. The antennules are very large, unbranched and composed of numerous segments; the antennæ are much smaller. In addition to the usual mandibles, maxillulæ, and maxillæ, there is a pair of maxillipeds which really represent the first pair of trunk limbs. There is a single red eye in the middle of the front of the head. This eye is not formed, like the single eye of the Cladocera, by fusion of a pair of eyes, but it corresponds to a median eye of simple structure which is found in the Branchiopoda, Ostracoda, and many other Crustacea, in addition to the paired compound eyes. From the fact that this median eye is the only one present in the earliest larval stage of Crustacea, the Nauplius (see Chapter IV.), it is sometimes known as the "nauplius eye." The 
female Cyclops carries her eggs until they hatch, in two oval packets attached to the sides of the body.

Forming a separate order (BRANCHIURA) apart from the more normal Copepoda (order EucopePODA) is the little group of the Carp-lice, one of which, Argulus foliaceus, is common in England, living as a parasite on different species of fresh-water fish, and often found swimming free in ponds and rivers It has a broad, flat, and very transparent body, about three-sixteenths of an inch in length. It differs from Cyclops in a great many points, of which, perhaps, the most conspicuous is the possession of a pair of true compound eyes in addition to the median eye. On the under-side of the head are a pair of large round suckers, by means of which the animal fixes itself on to its prey. A study of their development shows that these suckers are really the maxillæ, which in the young animal are jointed limbs ending in a strong claw, but later become changed into the suckers of the adult. A sharp spine, which can be protruded in front of the mouth, is connected with what is believed to be a poisongland. The eggs are not carried in packets by the female as in Cyclops, but are deposited on stones or water-weeds.

The fourth subclass, CirRIPEdiA, comprises the Barnacles and Acorn-shells. These are very unlike any of the other Crustacea, and, in fact, they were 
long classed by naturalists with the Mollusca. It was not until their larval development was made known that they were recognized as Crustacea. The common Goose Barnacle (Lepas anatiferaPlate III.) is found adhering to the bottoms of ships and to floating timber. It has a fleshy stalk or peduncle which is fixed at one end to the supporting object, and bears at the other end a shell, made up of five separate plates, enclosing the body of the animal. The stalk corresponds to the front part of the head, and careful examination may discover at its end, among the hardened cement which fixes it to the support, the remains of the antennules by which the attachment of the young animal was first effected. The body of the animal within the carapace or shell bears the usual mandibles, maxillulæ, and maxillæ, close to the mouth, and six pairs of long, tendril-like feet. These feet have each two branches, composed of numerous short segments and fringed with long hairs. They can be protruded from the slit-like opening of the shell, forming a sort of "casting-net" for the capture of minute floating prey.

The Acorn-shells, of which one species (Balanus balanoides-Plate III.) is abundant everywhere on our coasts, covering rocks and stones just below high-water mark, differ from Lepas and its allies in having no peduncle. The shell is cemented directly to the rock, and is conical in shape, like a small 

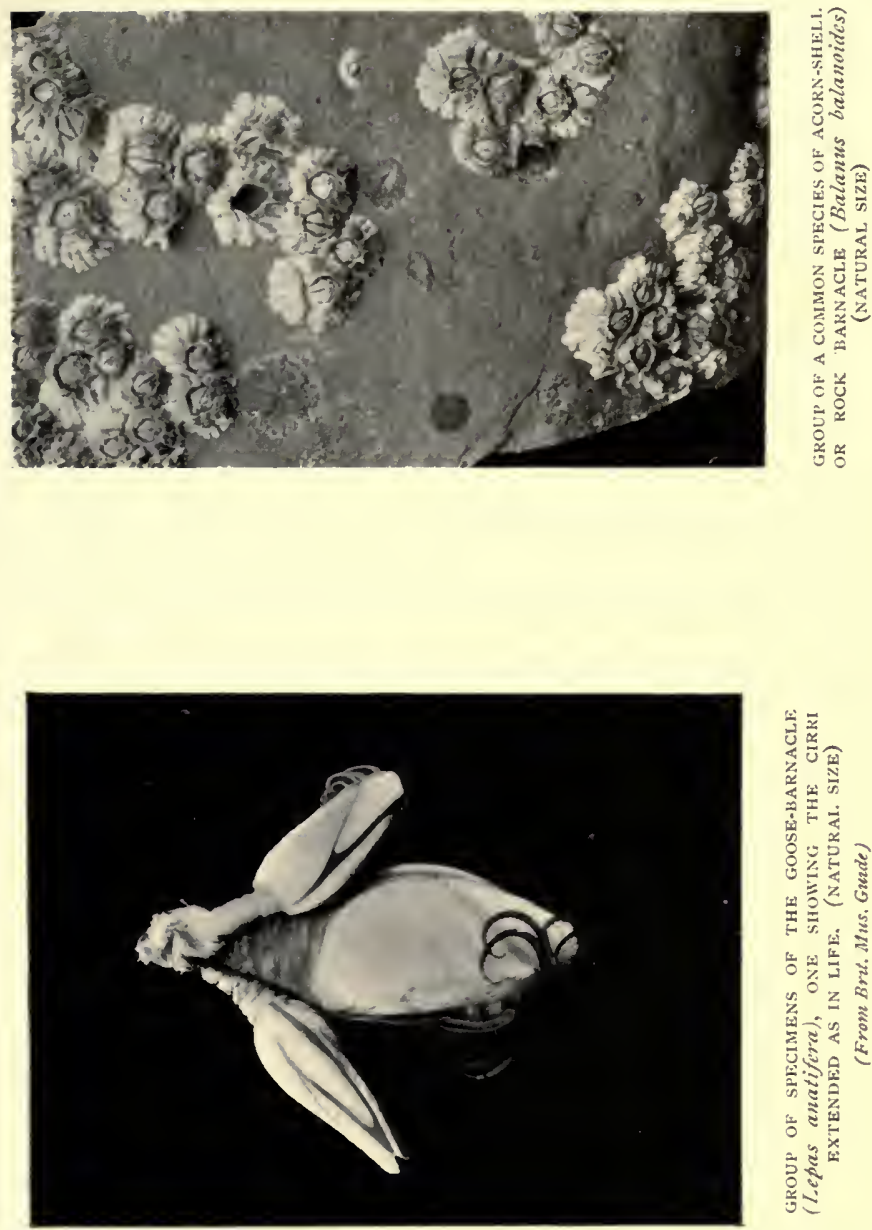

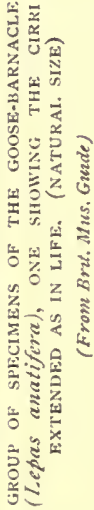


limpet, with a hole at the top which is closed by four movable valves.

The Stalked Barnacles, like Lepas (suborder Pedunculata), and the Sessile Barnacles, or Acornshells, like Balanus (suborder Operculata), together form the order THORACICA. Of the other orders which compose the subclass Cirripedia, the only one that need be mentioned here is the RHIzOcEPHALA, which comprises strangely degenerate parasites living on other Crustacea.

The Cirripedia are unlike nearly all other Crustacea in the fact that, with few exceptions, they are hermaphrodite, having both sexes united in each individual. In certain species of the Stalked Barnacles, however, there are minute male individuals that are attached, like parasites, to the large hermaphrodites. In a few species the large individuals only possess female organs, so that the separation of the sexes is complete.

The remarkable larval metamorphoses of Cirripedes and the modifications of structure presented by some parasitic forms will be described in later chapters.

The fifth and last subclass, that of the MaLAcosTRACA, is by far the largest and most important, and will require to be considered in more detail than any of the others. The animals composing the various orders into which the subclass is divided differ very greatly in structure, but they all agree in having typically the same number of appendages as the 
Lobster-namely, nineteen pairs (or twenty, if the eyestalks be included). They also agree in the very important character that the trunk limbs are divided into two sets, thoracic and abdominal, the former of eight, and the latter of six pairs.

The first order of the Malacostraca, the NEBALIACEA, comprises a few Crustacea of small size,

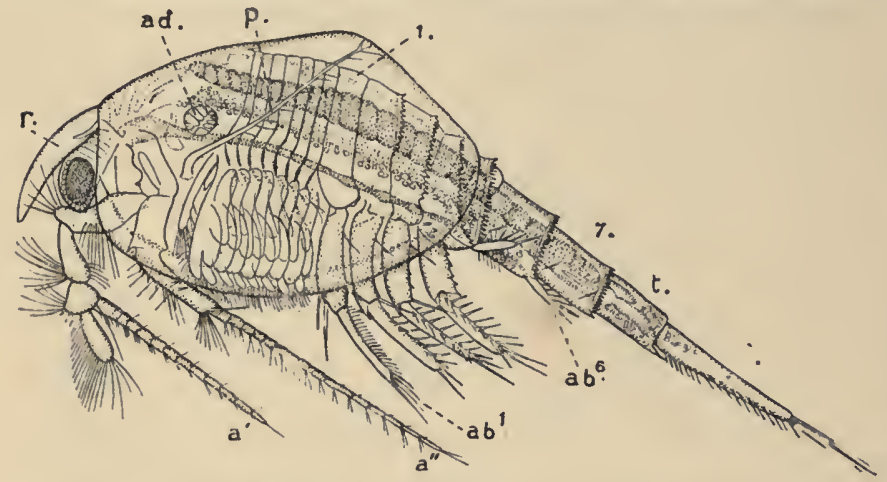

FIg. I5-Nebalia bipes. EnLARGed. (From Lankester's " Treatise on Zoology," after Claus.)

$a^{\prime}$, Antennule; $a^{\prime \prime}$, antenna; $a b^{1}-a b^{6}$, the abdominal limbs; $a d$, muscle joining the two valves of the shell; $f$, tail-fork; $p$, palp of maxillula ; $r$, rostral plate ; $t$, telson ; I- 7 , the seven somites of the abdomen

which differ in some very important characters from all the other orders. Nebalia bipes (Fig. I5), which occurs on the southern coasts of the British Isles, has a large bivalved carapace enclosing most of the limbs. In front, a small "rostral plate" is joined to the carapace by a movable hinge, and partly covers the stalked eyes. The eight pairs of thoracic 
feet are all alike, and are flattened and leaf-like in form, resembling those of the Branchiopoda. The first four pairs of abdominal limbs are large twobranched swimming feet, but the last two pairs are reduced to small vestiges. Two of the most important points in which the Nebaliacea differ from all the other Malacostraca are that there are seven instead of six somites in the abdomen (the last somite has no appendages), and that the telson has connected with it a pair of movable rods forming a "caudal fork" like that of the Branchiopoda. On account of the leaf-like thoracic feet and the possession of a caudal fork and other features, the Nebaliacea were formerly classified with the Branchiopoda, but a closer examination of their structure has shown that they are true Malacostraca. In having an additional somite in the abdomen and in other points, however, they may be regarded as forming a link between the Malacostraca and the lower forms of Crustacea, and for this reason they are set apart as a series Leptostraca, while the other orders form a series Eumalacostraca.

The orders of the Eumalacostraca, again, are grouped, as shown in the table of classification, into four divisions. The first of these, the SYNCARIDA, includes only one order, comprising a few small Crustacea (see Fig. 84, p. 264) which have recently been discovered in fresh water in Tasmania and Australia. They have no carapace, and all the 
thoracic somites, or all but the first, are distinct. The antennules are two-branched, the antennæ may have a scale-like exopodite, and the last pair of abdominal appendages form, with the telson, a tail-fan. The eyes are sometimes stalked, but in one species they are sessile. The thoracic limbs, which are not clearly divided into maxillipeds and legs, carry a double series of plate-like gills or epipodites. As will be shown later, the living Syncarida are especially interesting on account of their resemblance to certain very ancient fossil Crustacea.

The second division of the Eumalacostraca, the PERACARIDA, includes five orders, the members of which differ very greatly in appearance. They all agree, however, in certain important points of structure, of which the most conspicuous is the possession, in the female sex, of a brood-pouch for carrying the eggs and young. This brood-pouch is formed by a series of overlapping plates attached to the bases of the thoracic limbs.

The first order of the Peracarida, the Mysidacea, consists of small, free-swimming, shrimp-like animals (Fig. I6). Many species are common in the sea round the British coasts, and from their possession of a brood-pouch, in which the young are carried, they are sometimes known as "Opossum Shrimps." The eyes are stalked, and the carapace is well developed, although it does not unite with all the thoracic somites. The antennæ have a flattened, 


\section{THE CLASSIFICATION OF CRUS'TACEA 47}

scale-like exopodite, probably of use for keeping the animal balanced in swimming. Only one pair of the thoracic limbs are modified to form maxillipeds, and all the legs (as in the larval Lobster) have exopodites which form the chief swimming organs. The uropods and telson form a "tail-fan." One of the most curious points in the organization of some Mysidacea

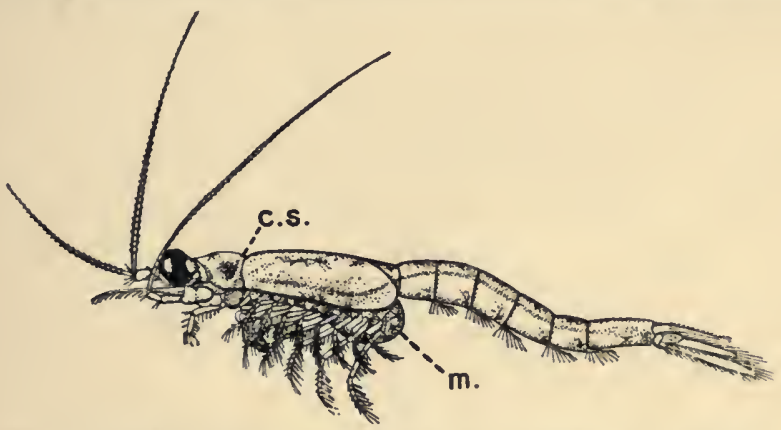

FIG. I6-Mysis relicta, ONE OF THE MysidaceA. ENLARGED.

(From Lankester's "Treatise on Zoology," after Sars.)

cs, Cervical groove of the carapace ; $m$, brood-pouch

is the possession of a pair of statocysts in the endopodites of the uropods. Each statocyst consists of a small cavity containing a cake-shaped concretion known as a "statolith," resting on a group of sensory hairs. There is reason to believe that these organs have the same function as the statocysts of the Lobster, although they are placed at the other end of the body. The statolith serves the same purpose as the sand-grains found in the Lobster's statocyst, although, unlike these, it is not introduced 
from outside, but is formed in position by secretion from the walls of the sac.

Most of the Mysidacea have no special organs of respiration, that function being discharged (as in many of the smaller Crustacea) by the general surface of the body, and especially by the thin carapace; but certain deep-sea Mysidacea (Fig. I7) have tufted gills attached at the base of the thoracic

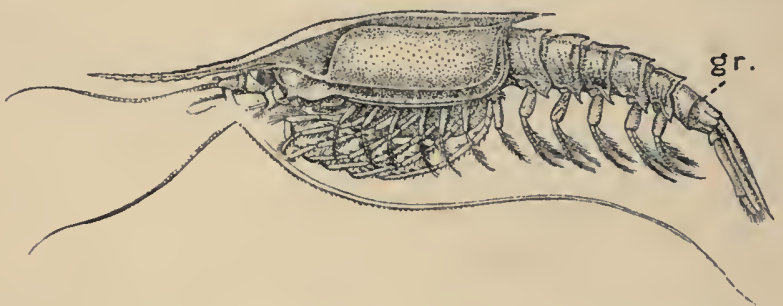

FIG. 17-Gnathophausia willemoesii, ONE OF THE DeEP-SEA MysIdacea. Half Natoral Size. (From Lankester's "Treatise on Zoology," after Sars.)

$g r$, A groove dividing the last abdominal somite

legs. In all cases the maxilliped has a plate-like epipodite, which lies under the side-fold of the carapace, and no doubt assists respiration, causing by its movements a current of water to flow under the carapace.

The members of the second order of the Peracarida, the Cumacea (Fig. I8), are small marine Crustacea in which the anterior part of the body is generally stout, while the abdomen is slender and very mobile. The short carapace does not cover 
more than the first three or four of the thoracic somites. The eyes are not stalked, and are usually fused together to form a single organ on the front part of the head. Swimming branches (exopodites) are usually present on some of the thoracic legs, at least in the males, which are more active swimmers than the females. In the males, also, the swimmerets of the abdomen are often more or less developed,

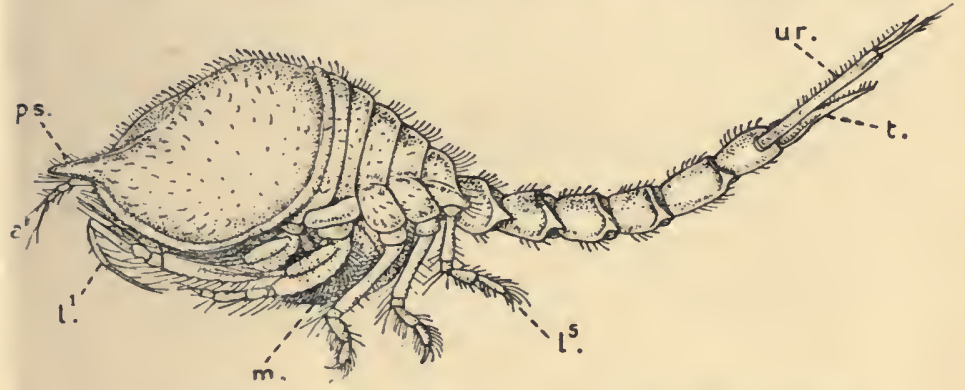

FIG. I8-Diastylis goodsiri, ONE of THE CUMACEA. ENLARGED. (From Lankester's " Treatise on Zoology," after Sars.)

$a^{\prime}$, Antennule ; $l^{n} l^{5}$, the five pairs of walking legs; $m$, brood-pouch ; $p s$, "pseudo-rostrum " formed by lateral plates of the carapace ; $t$, telson ; $u r$, uropods

but they are always absent in the females. The uropods do not form a tail-fan, but are slender forked rods carrying comb-like rows of spines, said to be used in cleaning the anterior appendages from the mud among which these animals generally live. The telson is often absent, or, rather, it is coalesced with the last somite of the abdomen. Under the side-fold of the carapace on each side lies, as in the 
Mysidacea, the epipodite of the maxilliped; but in this order it forms a gill, and usually carries a row of flattened gill lobes.

The third Order, that of the Tanaidacea (Fig. I9), is of special interest, since in many respects it forms a transition to the next. It comprises a number of minute Crustacea, generally found burrowing in mud in the sea. They have a small carapace, which only involves the first two thoracic somites, the rest of

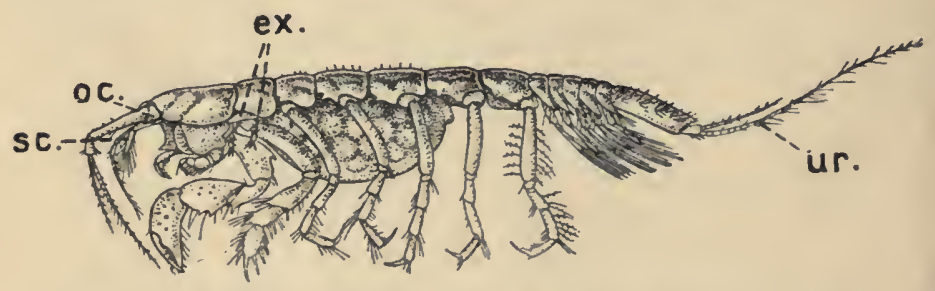

Fig. I9-Apseudes spinosus, One of the TAnaidacea. ENLARGED. (From Lankester's "Treatise on Zoology," after Sars.)

$e x$, Vestiges of exopodites on second and third thoracic limbs; $o c$, the small and immovable eye-stalks; $s c$, scale or exopodite of antenna; ur, uropod

the somites being distinct. The side-folds of the carapace enclose a pair of small cavities, within which lie, as in the case of the last two orders, the epipodites of the maxillipeds. The eyes are not movable, although they are set on little side-lobes of the head, representing the vestiges of eye-stalks. The first pair of thoracic limbs are maxillipeds, and the second pair are very large, and form pincer-claws (chelæ). Minute vestiges of exopodites are some- 


\section{THE CLASSIFICATION OF CRUSTACEA 5I}

times found on the second and third pairs, but they are not used for swimming, and only help to keep a current of water flowing through the gill cavities. The abdomen is very short, with small swimmerets, and the telson is not separated from the last somite. The uropods are generally very small, and do not form a tailfan.

Unlike the Tanaidacea, the IsOPODA, which form the fourth order of the Peracarida, are very numerous in species, and very varied in structure and habits. The most familiar are the Woodlice, or Slaters, which are commonly found in damp places, under stones and the like. Besides these, however, the order includes a vast number of forms living in the sea and a few that live in fresh

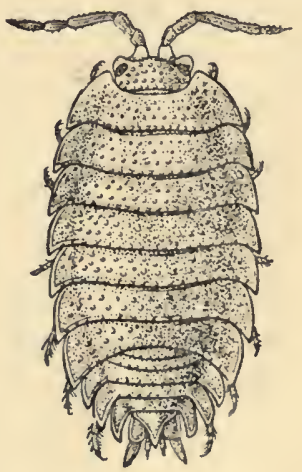

Fig. $20-\mathrm{A}$ WOODLouse (Porcellio scaber), ONE OF THE ISOPODA. ENLARGED. (From Lankester's "Treatise on Zoology," after Sars.) water. The examination of a common Woodlouse, such as Oniscus or Porcellio (Fig. 20), will give a general idea of the form and structure of a typical Isopod, although many curious modifications are found, some of which will be mentioned in later chapters.

There is no distinct carapace, but the last vestige of one may be indicated by the fact that the first 
thoracic somite is completely fused with the head. All the other somites of the body are distinct (in some Isopods, however, the abdominal somites are coalesced), but the telson is not separate from the last somite. The eyes are not stalked, but are sessile on the sides of the head. The antennules have only a single branch, and in the Woodlice are very small. The antennæ have no exopodite, although in a few other Isopods a minute vestige is present. The thoracic limbs never have any trace of exopodites. The first pair are maxillipeds, and if they carry an epipodite it is never enclosed in a gill cavity, as in Tanaidacea. The swimmerets form one of the most characteristic features of the Isopoda, for they are always flattened into thin plates, which act as gills. In the Woodlice, which breathe air, certain curious modifications of the swimmerets are found, which will be described in a later chapter. In some Isopods that live as parasites on fish or on other Crustacea, each individual is at first a male, and later becomes a female. They are almost the only Crustacea, except the Cirripedes already mentioned, which are normally hermaphrodite.

The fifth order of the Peracarida, the AMPHIPODA, is also a very large one. The "Sand-hoppers," which are very common on sandy coasts, belong to this order, as do also a very large number of other forms found in the sea and in fresh water, which have no popular names. A common species is 


\section{THE CLASSIFICATION OF CRUSTACEA 53}

Gammarus pulex, sometimes called the "Fresh-water Shrimp," which is found everywhere in streams and ditches. Several closely allied species, such as G. locusta (Fig. 2I), are found in the sea. The body is flattened from side to side, and the abdomen is generally bent upon itself. There is no carapace,

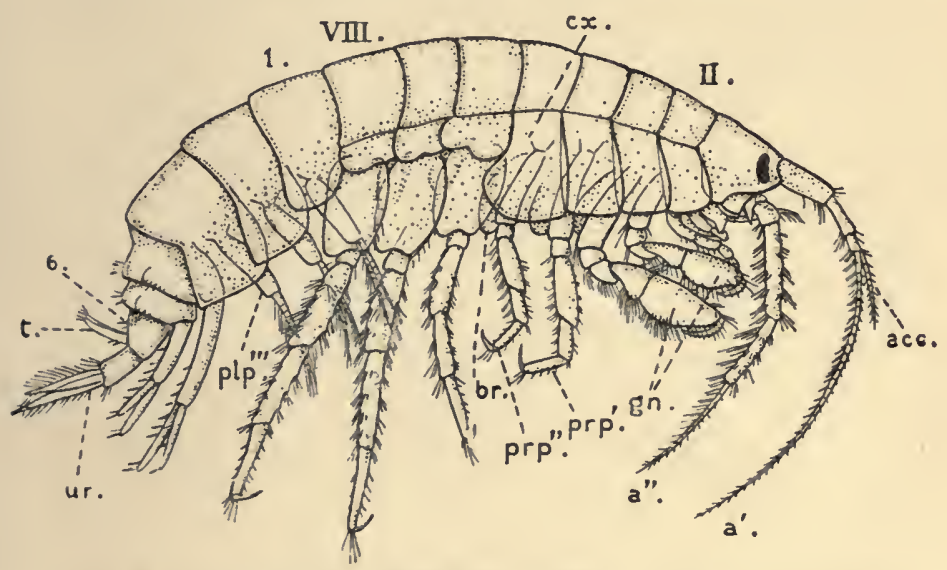

Fig. 2I-AN AMPHIPOD (Gammarus locusta). ENLARged. (From Lankester's "Treatise on Zoology," after Sars.)

$a^{\prime}$, Antennule; $a^{\prime \prime}$, antenna; $a c c$, accessory (inner) flagellum of anten. nule; $b r$, gill plate; $c x$, coxal plate (the expanded first segment of the leg); gn, the two pairs of gnathopods (prehensile legs); $p l p^{\prime \prime \prime}$, abdominal appendage of third pair; $p r p^{\prime}, p v p^{\prime \prime}$, first and second peræopods, or walking-legs ; $t$, telson; $u r$, uropod ; II, VIII, second and eighth thoracic somites; I, 6, first and sixth abdominal somites

but, as in the Isopods, the first thoracic somite is fused with the head. The eyes are sessile on the sides of the head. The antennules have a small inner branch, and the antennæ have no exopodites. 
The thoracic limbs, of which the first pair form maxillipeds, have no exopodites, and are partly hidden by a row of shield-like plates along the sides of the thorax. These plates are formed by the
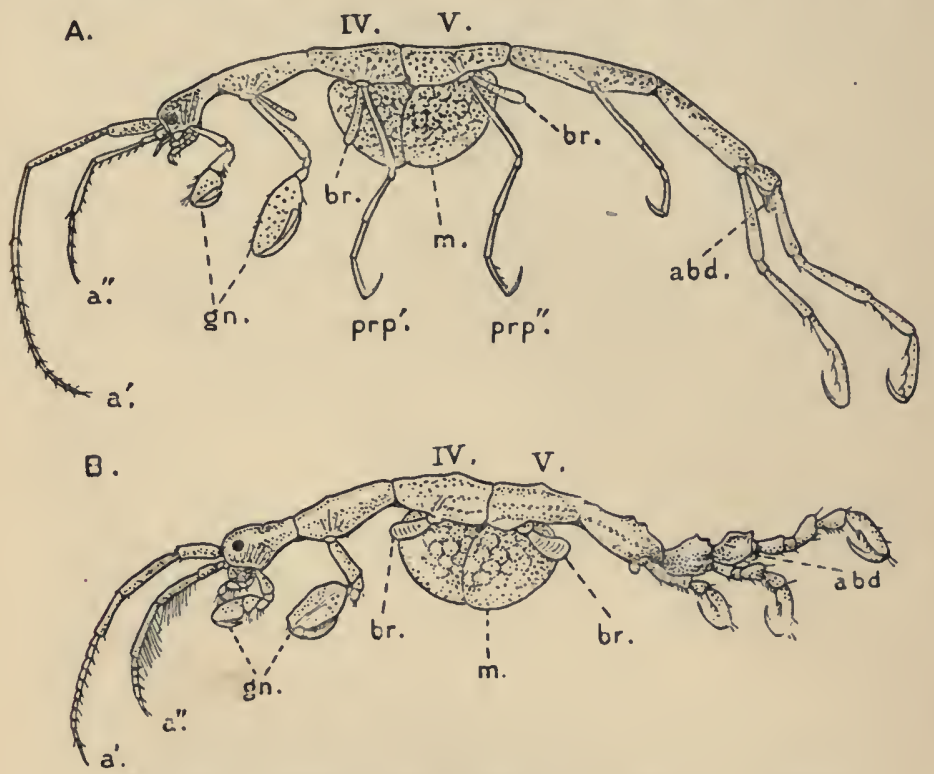

Fig. 22-Two Species of CAPrellide. (From Lankester's "Treatise on Zoology," after Sars.)

A, Phtisica marina a species which retains the fourth and fifth pairs of thoracic limbs $\left(p r p^{\prime}, p r p^{\prime \prime}\right) ; \mathrm{B}$, Caprella linearis, in which these limbs are represented only by the gills $(b r)$. (Enlarged.) $a^{\prime}$, Antennule ; $a^{\prime \prime}$, antenna ; $a b d$, vestigial abdomen; gn, gnathopods; $m$, brood-pouch ; IV, V, fourth and fifth thoracic somites

enlarged and flattened basal segments of the limbs themselves, and on the inner side they carry a series of oval plates, which are the gills. The abdominal 


\section{THE CLASSIFICATION OF CRUSTACEA 55}

appendages are divided into two sets : the first three pairs have each two slender, many-jointed branches, and are used in swimming; the last three pairs are short, stiff, and directed backwards, and are used in pushing the animal through mud or among water-weeds. In many Amphipods, such as the Sandhoppers, the last three pairs of abdominal limbs are used in jumping bysudden backward strokes of the abdomen.

Two families of the Amphipoda differ so much in general appearance from the others that they deserve mention. The Caprellidæ (Fig. 22) have the body drawn out to a thread-like

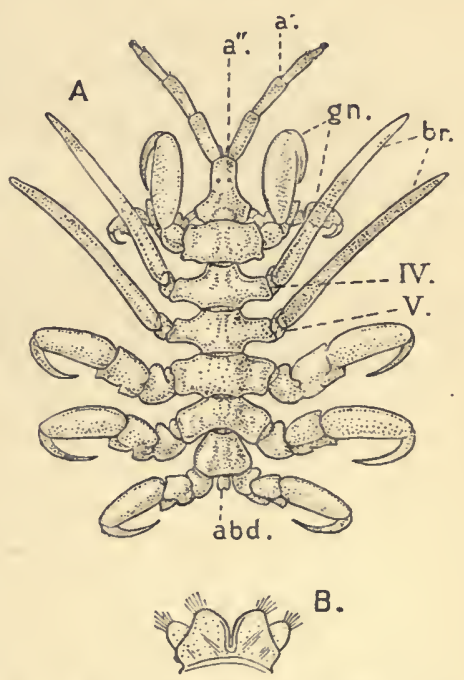

FIG. 23 - Paracyamus boopis, THE Whale-lodse OF THE HUMPBACK Whale. (From Lankester's "Treatise on Zoology," after Sars.)

A, Male, dorsal view, enlarged; $B$, the maxillipeds detached and fur. ther enlarged. $a^{\prime}$, Antennule; $a^{\prime \prime}$, antenna; $a b d$, vestigial abdomen; $b r$, gills ; gn, gnathopods ; IV, V, fourth and fifth thoracic somites

- slenderness, and the abdomen reduced to a mere vestige. The fourth and fifth pairs of thoracic limbs are generally absent, though the corresponding gills 
remain. The animals live in the sea, clambering among sea-weeds or zoophytes in a fashion which recalls the movements of "looper" caterpillars. The Cyamida, or "Whale-lice" (Fig. 23), are, as the name implies, parasites on the skin of whales, and are closely related to the Caprellidæ. They have, however, a broad, flattened body, more like that of an

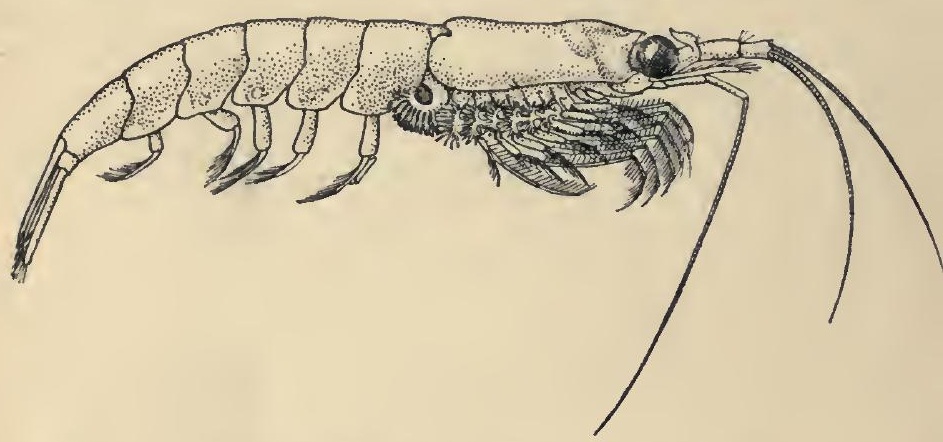

FIG. 24-Meganyctiphanes norvegica, ONE OF THE Euphausiacea. Twice Natural Size, (From Lankester's "Treatise on Zoology.")

Isopod than an ordinary Amphipod, and their legs have strong curved claws with which they cling to the skin of their host.

The third division of the Malacostraca, the EUCARIDA, consists of two orders of very unequal interest and importance. The first of these, the order Euphausiacea (Fig. 24), comprises only a single family of small, shrimp-like Crustacea found swimming freely at the surface or in the depths of 



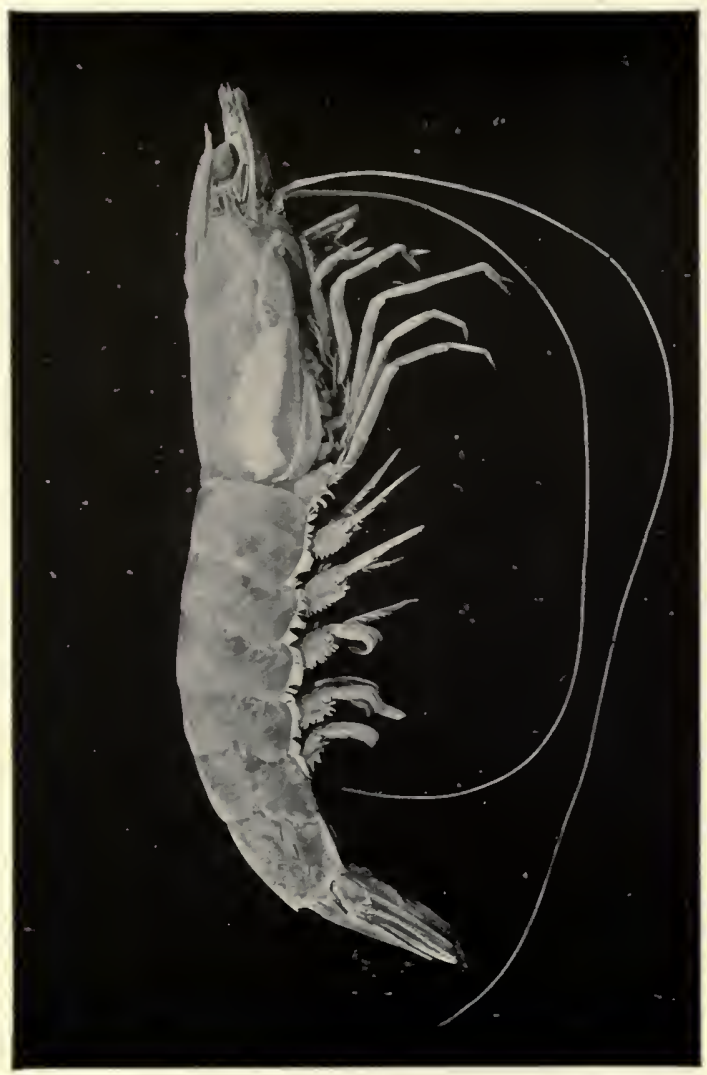

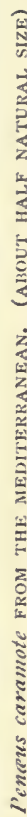




\section{THE CLASSIFICATION OF CRUSTACEA 57}

the sea. In these the carapace fuses with all the thoracic somites, the eyes are stalked, the antennules have two flagella, and the antennæ have a broad scale. None of the thoracic limbs are modified into maxillipeds, and all carry swimming exopodites. The uropods and telson form a tail-fan. A single series of feathery gills are attached to the bases of the thoracic limbs. Nearly all the Euphausiacea possess the power of emitting light, and are furnished for the purpose with a number of organs which were formerly supposed to be " accessory eyes."

The second order of the Eucarida, the DEcapoda, is by far the largest of the orders of Crustacea, and it includes all the larger and more familiar members of the class. It is necessary, therefore, to give a considerably fuller account of its subdivisions than has been given in the case of the other orders. The typical characters of the Decapoda are well illustrated by the Lobster, which has been already described. As in the Euphausiacea, the eyes are stalked, and the carapace fuses with all the thoracic somites. From the Euphausiacea the Decapoda differ in the fact that three pairs of the thoracic limbs are modified as maxillipeds, the remaining five pairs forming the "ten legs" to which the name of the order alludes. Further, the gills are arranged in more than one series, not all attached to the bases of the legs, as in the Euphausiacea, and covered over by the side-flaps of the carapace 
instead of being freely exposed. While agreeing in these essential characters, however, the members of the order Decapoda differ very widely among themselves in structure and in general form, and they are classified (in the arrangement adopted here) in two suborders, which are again subdivided into sections and tribes.

ORDER DECAPODA.

Suborder NATANTIA

- $\left\{\begin{array}{cc}\text { Tribe Penæidea. } \\ \Rightarrow, & \text { Stenopidea. } \\ , " & \text { Caridea. }\end{array}\right.$

, REPTANTIA.

Section Palinura

, Astacura

" Anomura

" Brachyura

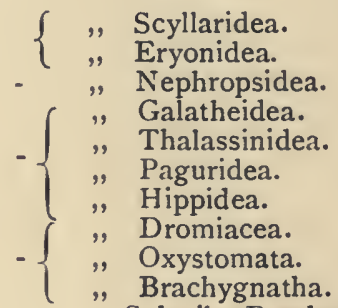

Subtribe Brachyrhyncha. , Oxyrhyncha.

The suborder Natantia includes the numerous species of what are commonly known as Prawns and Shrimps. These are characteristically powerful swimmers, with lightly armoured bodies, more or less flattened from side to side, with a thin, sawedged rostrum, and with large swimmerets which are the chief organs of swimming; in addition, some of the more primitive Natantia have swimming branches, or exopodites, like those of the Euphausiacea, on the thoracic legs. This suborder is divided into three 



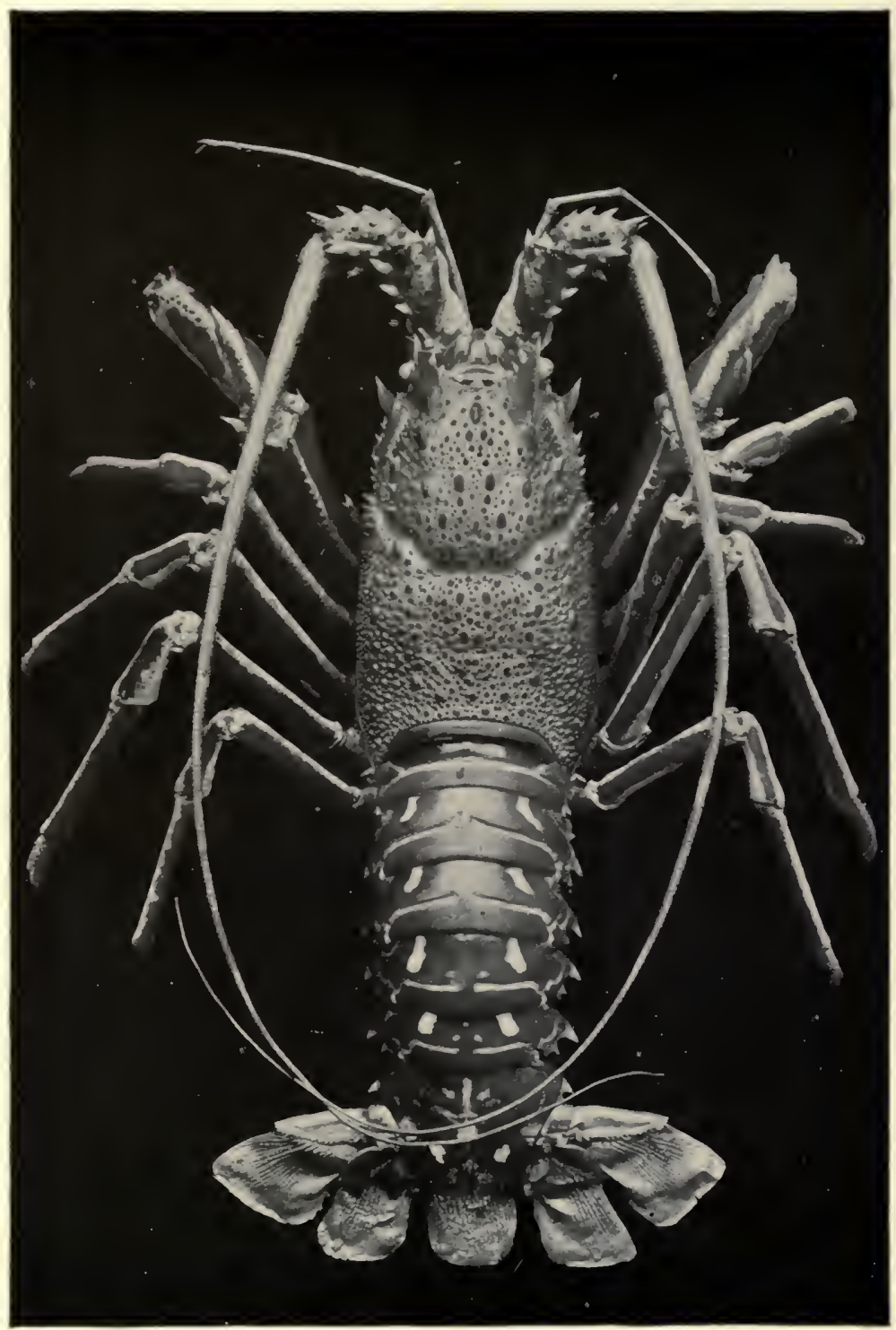

THE COMMON SPINY LOBSTER (Palinurus vulgaris). (MUCH REDUCED) 
tribes. The Pencidea include the large Prawns of tropical seas (Penaus-Plate IV.), which have the first three pairs of legs provided with chelæ, and not differing greatly in size. The Stenopidea are a small group of forms resembling the Pencidea in having chelæ on the first three pairs of legs, but the third pair are much larger than the others. The Caridea comprise our common Prawns (Leander, Pandalus) and Shrimps (Crangon), besides a host of less generally known forms; in these the third legs are never chelate, although the first and second often are.

The second suborder, that of the REPTANTIA, is much more diversified, but the animals composing it are united by certain characteristics, of which the most obvious are their creeping habits (although some species can swim well), their heavily armoured bodies, often more or less flattened from above downwards, with the rostrum never thin and sawedged, and the swimmerets not used to any great extent for swimming.

The first section of the Reptantia, the Palinura, includes the Spiny Lobsters, Rock Lobsters, or SeaCrawfish, and their allies, forming the tribe Scyllaridea. They are distinguished by having no large pincer-claws, though the last pair of legs may have small pincers in the female sex. One species, the Common Spiny Lobster (Plate V.), is found on the southern and western coasts of the British Islands. 
The other tribe belonging to this section is the Eryonidea, comprising a number of small lobster-like forms living in the deep sea. They have pincerclaws on the first four, or on all five, pairs of legs, and they are of special interest on account of their geological antiquity.

The section Astacura contains only a single tribe, Nephropsidea, formed by the true Lobsters and the fresh-water Crayfishes. They have pincer-claws on the first three pairs of legs, and the first pair are much larger than the others.

The third section of the Reptantia, the Anomura, comprises forms in which the abdomen is variously modified, being either bent upon itself or, if extended, more or less soft and feebly armoured. The last pair of legs are commonly reduced in size, and not used in walking. The members of the four tribes composing the section differ widely in their general appearance.

The Galatheidea.(Plate VI.) are small, flattened, lobster-like animals which have the abdomen bent under the body. In one family (Porcellanida) the animals have quite the appearance of little Crabs (see Fig. 4I, p. II3), but they may be distinguished from the true Crabs (Brachyura) by the fact that there are only three pairs of walking legs behind the great chelæ, the last pair of legs being very small and carried folded up at the sides of the body, or even within the gill chambers. 


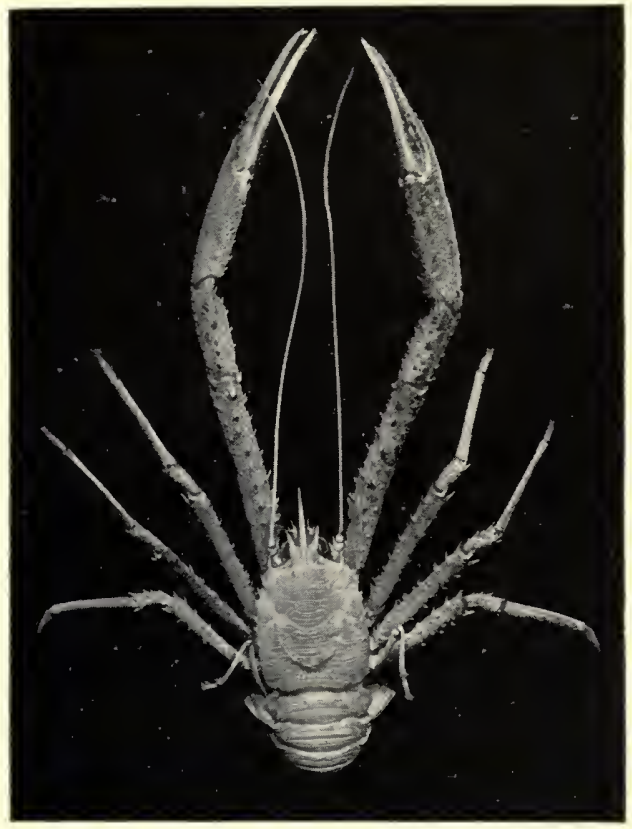

Munida rugosa. BRITISH. (REDUCED) 



\section{THE CLASSIFICATION OF CRUSTACEA 6I}

The Thalassinidea are small lobster-like animals which burrow in sand and mud, and have generally a more or less soft abdomen (see Fig. 38, p. 103).

The tribe Paguridea includes the Hermit Crabs (Pagurida) and their allies. The typical Hermit Crabs (Plate VII.), which are familiar objects in seaside rock-pools, live in the empty shells of Whelks and other Gasteropod Molluscs, which they carry about with them as portable shelters. The structure of the animals is modified in adaptation to this curious habit. The abdomen, which is protected during life by the borrowed shell, is soft and unarmoured, and is spirally twisted. The swimmerets, which have only the function of carrying the eggs in the female, are much reduced, and are usually present only on one side of the body. The uropods no longer form a tail-fan, but are adapted for firmly wedging the hind part of the body into the coils of the shell. One of the chelipeds is much larger than the other, and serves to block up the opening when the animal withdraws into its shelter. In tropical countries certain Hermit Crabs (Canobitidce) have become adapted to a life on land, and one of these, the well-known Coconut Crab, or Robber Crab (Birgus latro), which is the largest species of the tribe, has given up the habit of protecting itself with a shell, and its abdomen has again acquired a strong armour on the upper side. The marine Lithodida - to which the British Stone 
Crab, Lithodes maia (Plate VIII.) belongs-seem at first sight to have little resemblance to the Hermit Crabs, for they have the abdomen very small, and tucked up under the body as in the true Crabs. Like the Porcellanidæ, mentioned above, however, the Lithodidæ have only three pairs of walking legs behind the chelipeds, the last pair being feeble and usually folded out of sight within the gill chambers. The relationship of the Lithodidæ to the Hermit Crabs is shown by the abdomen, which is more or less twisted to one side, and has swimmerets only on one side in the female, and quite wanting in the male.

The Hippidea are curious little Crabs found burrowing in sandy beaches in the warmer seas. They have the abdomen tucked under the body, and the legs flattened for shovelling the sand.

The BRACHYURA, or true Crabs, form the fourth section of the Reptantia, and are distinguished by having the abdomen reduced to a tail-flap, which is doubled up under the cephalothorax, and is usually without any trace of the uropods which are present in all the groups already mentioned, with the single exception of the Lithodidæ. At the sides of the head the side-plates of the carapace become firmly soldered to the "epistome," a plate which lies in front of the mouth, and in this way there is formed the "mouth-frame," within which lie the jaws, covered in by a pair of "folding-doors" formed by the flattened third maxillipeds. 

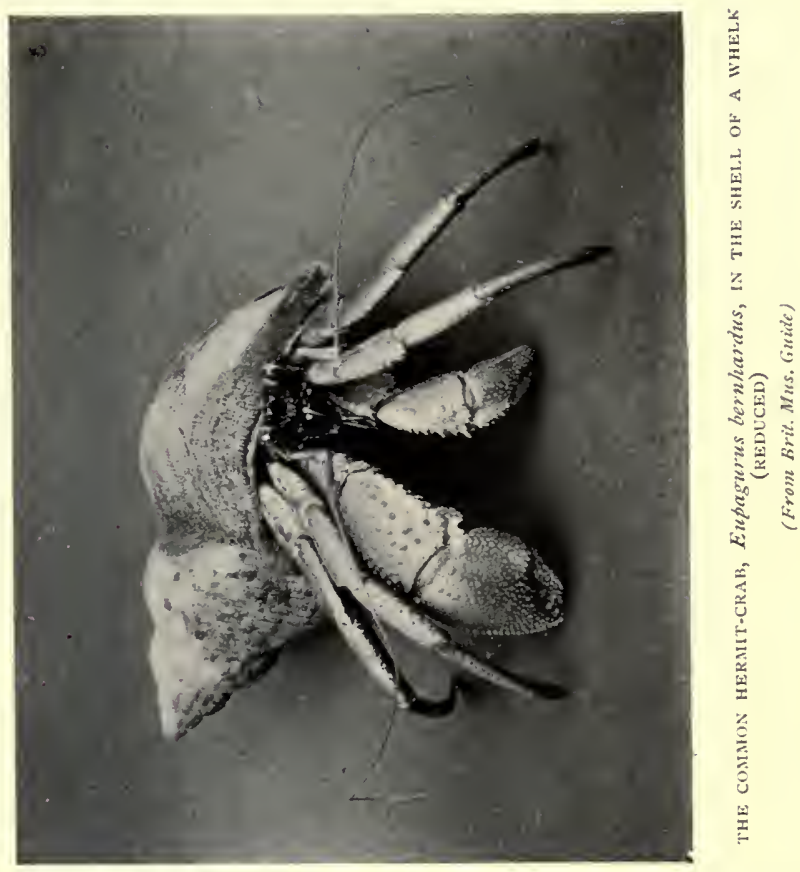




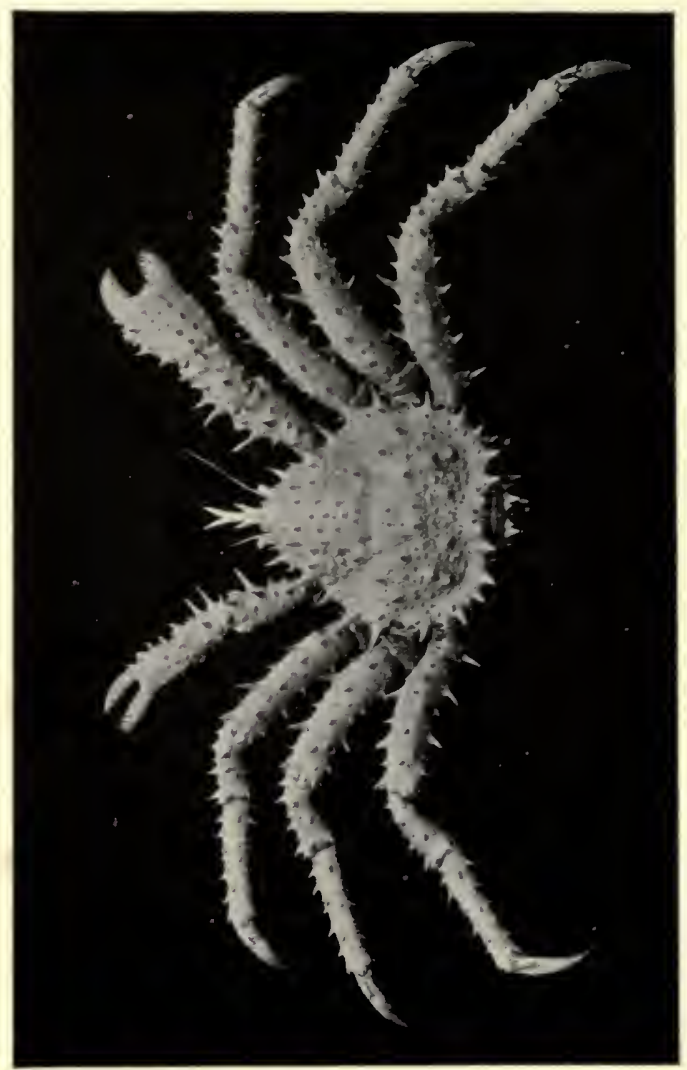

空

(3)




\section{THE CLASSIFICA'TION OF CRUSTACEA 63}

The first tribe of the Brachyura, the Dromiacea, comprises a number of Crabs that in many points of structure resemble the Lobsters, and are regarded as the most primitive members of the section. Dromia vulgaris (Plate IX.), a furry, clumsy-looking Crab, occasionally found on our southern coasts, has the last two pairs of legs short and carried up over the back, where they are used for holding a mass of living sponge which the Crab uses as a cloak to protect and conceal itself. At the sides of the abdomen, wedged in between the telson and the last somite, a pair of small plates may be seen, which are the last vestiges of the uropods. These are wanting in the other tribes of the Brachyura.

The Oxystomata (Plate X.), which form the second tribe of the Brachyura, are distinguished by the form of the mouth-frame, which is narrowed in front so as to be triangular instead of square in outline. The passages through which the water passes out from the gills, which in other Crabs open at the front corners of the mouth-frame, are carried forwards to the front of the head. The Oxystomata are most abundant in tropical seas, but are represerited on the British coasts by species of Ebalia, small and compact Crabs which are not unlike pebbles of the gravel among which they live.

The remaining Crabs form the tribe Brachygnatha, in which the mouth-frame and the maxillipeds that close it are more or less quadrilateral in shape. 
The tribe is divided into two subtribes, which may be recognized by the general shape of the carapace. In the Brachyrhyncha this is generally rounded or square-cut in front, without a projecting rostrum. In this subtribe are included the great majority of Crabs. The Edible Crab and the Shore Crab (Plate IX.) are familiar examples. In the Oxyrhyncha, on the other hand, the carapace is generally narrowed in front, with a projecting rostrum, either simple or forked, and is often armed with spines. In this subtribe are included the long-legged Spider Crabs, several species of which are common on our coasts. The Giant Spider Crab of Japan (Plate XI.) is the largest of living Crustacea.

The last division of the Eumalacostraca; the Hoplocarida (Plate XII.), is one of very small extent, comprising only a single order (Stomatopoda) of very remarkable Crustacea which are common in tropical seas, and of which at least one species, Squilla desmarestii, is occasionally captured on the south coast of England. The Stomatopoda are prawn-like Crustaceans, usually with a flattened body, and are easily recognized by the form of the large claws (the second pair of thoracic limbs), in which the last segment shuts down, like the blade of a pocket-knife, on the preceding segment, and forms a very efficient weapon, so that the larger species are not to be handled without caution. The resemblance of these claws to those of the mantis- 


\section{THE CLASSIFICATION OF CRUS'TACEA 65}

insect of Southern Europe led to a common Mediterranean species receiving long ago the name Squilla mantis (Plate XII.).

The Stomatopoda have a small carapace, which does not cover the last four thoracic somites, and has in front a small flattened rostrum, attached by a movable hinge, like that of the Leptostraca. The eyes are stalked, and, like the antennules, are attached to a separate movable segment of the front part of the head-a peculiarity not found in any other Crustacea. There are small plate-like gills at tached to the bases of some of the thoracic limbs, but the chief organs of respiration are large feathery gills attached to the pleopods or swimmerets.

The Stomatopoda are all found in the sea, generally in shallow water, burrowing in sand or hiding in crevices of rocks or corals. Some species are more than a foot in length:

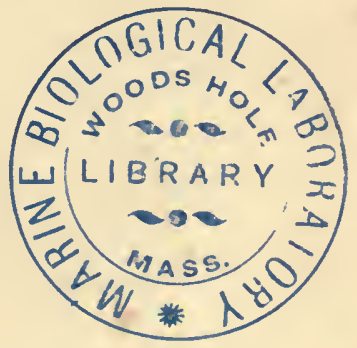




\section{CHAPTER IV}

THE METAMORPHOSES OF CRUSTACEA

$\mathrm{HE}$ great majority of Crustacea are hatched
from the egg in a form very different from that which they finally assume, and reach the adult state only after passing through a series of transformations quite as remarkable as those which a caterpillar undergoes in becoming a butterfly, or a tadpole in becoming a frog. Many of these young stages were known for a long time before their larval nature was suspected, and it is one of the curiosities of the history of zoology that, even after the actual changes from one form to another had been observed and described in several Crustacea, many eminent naturalists refused to believe in the possibility of their occurrence. This scepticism was largely due to the fact that the common fresh-water Crayfish, when hatched from the egg, has practically the same structure as the adult, and it was assumed that other Crustacea were developed in a similar fashion. Although certain cases of metamorphosis had been actually seen and described by naturalists in the eighteenth century, these observations were for- 


\section{THE METAMORPHOSES OF CRUS'TACEA 67}

gotten or misunderstood till they were confirmed by Mr. J. Vaughan Thompson, a naval surgeon stationed at Cork, the first part of whose "Zoological Researches" was published in I828. Thompson's statements were much disputed at the time, but they have been confirmed by subsequent research, and it is now known that the majority of Crustacea undergo a more or less extensive metamorphosis after leaving the egg, although, as will be seen later, there are many important exceptions to this rule.

If a fine muslin net be towed at the surface of the sea on a calm day, and the contents turned out into a jar of sea-water, it will usually be found to have captured, among other things, clouds of animated specks, which dance in the water or dart hither and thither with great rapidity. Many of these specks, when examined with the microscope, will be found to be Crustacea. Besides adult animals belonging to various groups, such as the Copepoda, which pass the whole of their life swimming near the surface of the sea, there will be numerous larval stages of species which in their adult form live on the sea-bottom. The identification of the species to which the various larvæ belong is a matter of considerable difficulty, and, although the general course of development is now well known for all the chief groups of Crustacea, there are very many even of the common British species in which the larval transformations have not yet been worked out in detail. 
As an example of the larval history of the higher Crustacea, we may take the case of the Common Shore Crab, Carcinus manas (Fig. 25). The young stages are common in tow-net gatherings round the
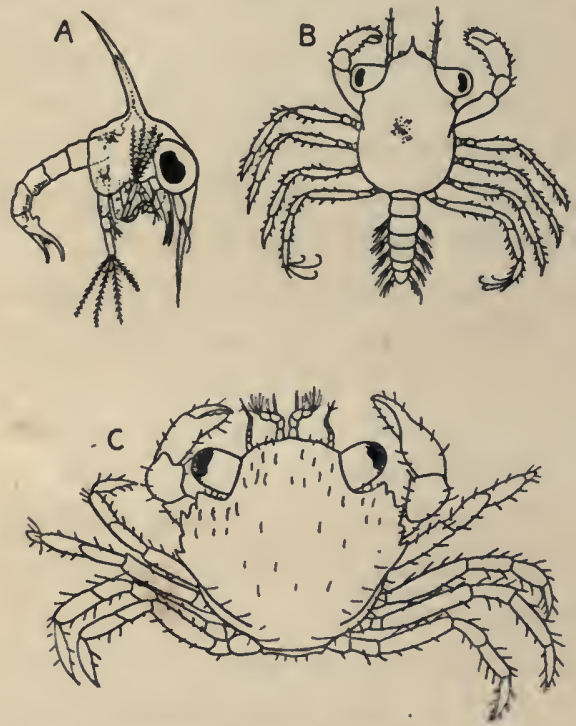

Fig. 25-Larval Stages of the Common Shore Crab (Carcinus manas-see Plate IX.). (Partly after WVilliamson.)

A, Young zoëa, shortly after hatching; $B$, megalopa stage;

C, young Crab. $A \times 20, B$ and $C \times 10$

British coasts in the summer-time. The youngest larvæ (Fig. 25, A) are translucent little creatures about one-twentieth of an inch long. They have the head and front part of the body covered by a helmet-shaped carapace, with a long spine standing 


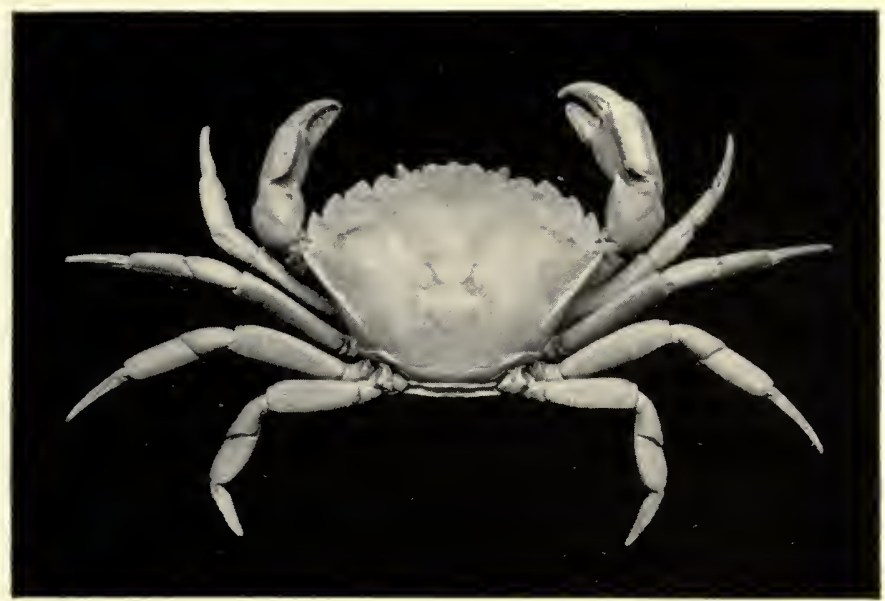

THE COMMON SHORE-CRAB (Carcinus mienas). (REDUCED)

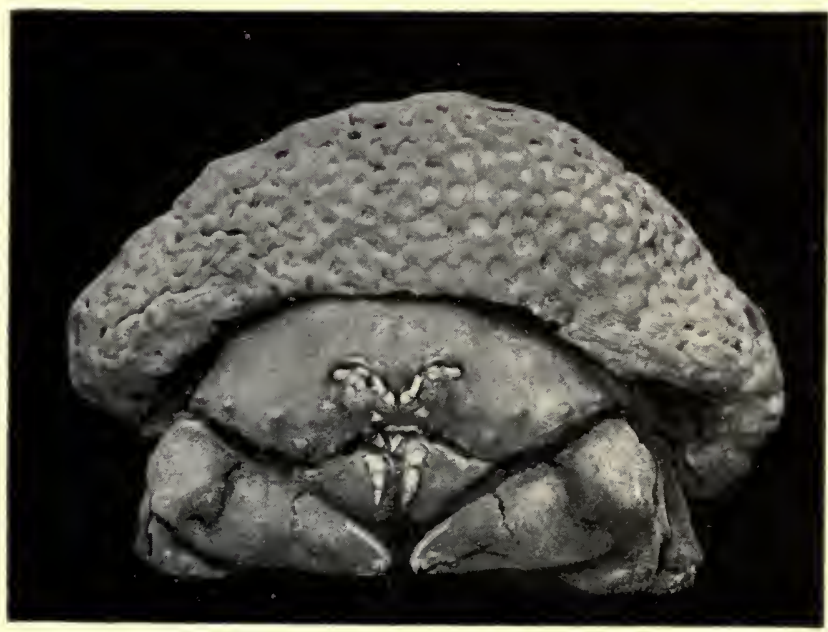

Dromia wulgaris, CARRYING ON ITS BACK A MASS OF THE SPONGF Clione celata. BRITISH. (REDUCED) 



\section{THE METAMORPHOSES OF CRUSTACEA 69}

out from the middle of the back, and another projecting, like a beak, in front.

The narrow abdomen or tail is very flexible, and can be doubled up under the body or stretched out behind; it ends in a forked telson. There are two pairs of swimming limbs, each with endopodite and exopodite, and the short antennules and antennæ are seen on either side of the rostrum. There are a pair of very large compound eyes, which are not set on movable stalks, but are under the front part of the carapace. The two-branched swimming feet are really the first and second maxillipeds (the mandibles, maxillulæ, and maxillæ, can be found in front of them), but none of the other thoracic limbs are yet developed, and, although the somites of the abdomen are distinct, there are no swimmerets. This type of larva is known as a zoëa, a name which was given to it when it was supposed to be an independent species of Crustacean. As a matter of fact, the zoëa just described is not quite the earliest stage of the Shore Crab, for when hatched from the egg it is without the spines on the carapace, and is slightly different in other respects. A few hours after hatching, however, it casts its skin for the first time, and becomes a fully-formed zoëa. It swims rapidly about at the surface of the sea, feeding on the minute floating animals and plants which are found there, and growing in size with repeated castings of its skin. In the later stages of the zoëa the rudiments 
of the hinder thoracic limbs and of the swimmerets appear as little buds. In the next stage (Fig. 25, B) all the appendages are present, the dorsal spine of the carapace has disappeared, the eyes are stalked and movable, and the animal has all the appearance of a little Crab, except that the abdomen is stretched out instead of being tucked up under the body, and the swimmerets are used as paddles in swimming. In this stage the larva, which is known as a megalopa,

Fig. 26-Last Larval Stage of the Common Porcelain CRAB (Porcellana longicornis-SEE FIG. 4I, p. II3). $\times 9$. (After Sars.)

swims at the surface of the sea, but later it sinks to the bottom, and, moulting again, appears as a little Crab (Fig. 25, C), with tucked-up abdomen and swimmerets no longer adapted for locomotion.

Most of the true Crabs (Brachyura) have a larval history similar to that just described, and pass through zoëa and megalopa stages which differ only in details from those of Carcinus. The Anomura are also hatched as zoëæ, and one of the most remarkable forms common in tow-nettings in British waters is the zoëa of the little Porcelain Crabs (PorcellanaFig. 26). In this larva the carapace has two long spines 


\section{THE METAMORPHOSES OF CRUSTACEA 7 I}

behind, and a rostral spine which is several times as long as the body of the animal. A great development of spines also characterizes the larva of Munida (Fig. 27).

The larval form of the Common Lobster has already been described, and it will be noticed that the differences from the adult are much less than in the case of the Crab. From the fact that this larva has swimming exopodites on its legs, like the adult Mysidacea and Euphausiacea

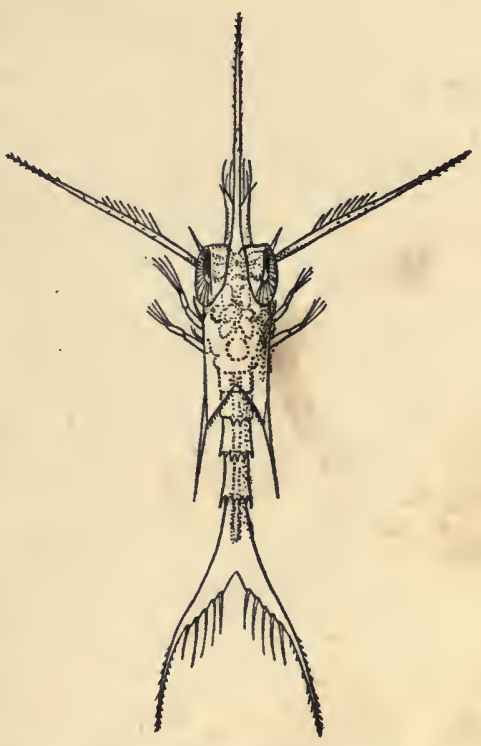
(formerly grouped to- Fig. 27-First Larval Stage of gether as "Schizo- Munida rugosa (SEE PLATE VI.). poda"), it is said to be in the "schizopod stage." The larva of the Norway Lobster (Nephrops norvegicus) is essentially of the same type, but the great development of the spines on the abdomen and of the forked telson gives it a-striking appearance.

A very remarkable type of larva is found among the Spiny Lobsters and their allies (Scyllaridea). 
This larva, known by the name of phyllosoma (Fig. 28), is very broad, thin, and leaf-like, and quite transparent, so that some of the larger kinds were formerly known as "Glass Crabs." The thin oval carapace does not cover the whole of the thoracic region, which is disc-shaped, with four pairs

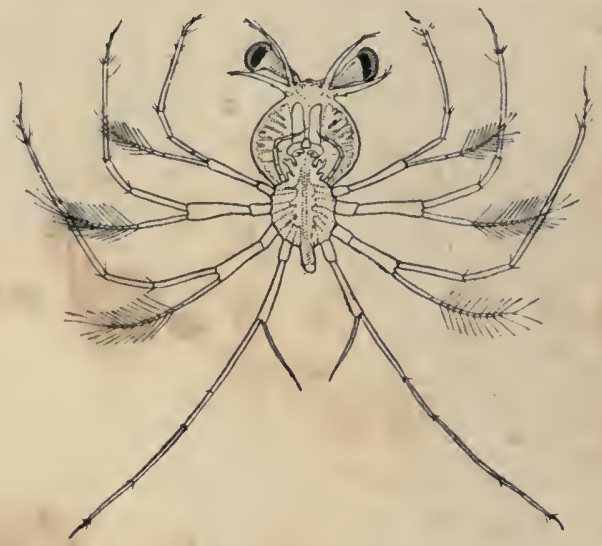

Fig. 28-The Phyllosoma larva of the Common Spiny LOBSTER (Palinurus vulgaris-SEE Plate V.). MUCh ENLARGED. (After J. T. Cunningham.)

of long slender legs, each with an exopodite. The abdomen is relatively small. The intermediate stages between the phyllosoma and the adult are still very imperfectly known. In tropical seas phyllosoma larvæ of large size are found, sometimes reaching two or three inches in length. The larva of the Common Spiny Lobster (Palinurus vulgaris), however, does not exceed half an inch in length. 
PLATE $X$

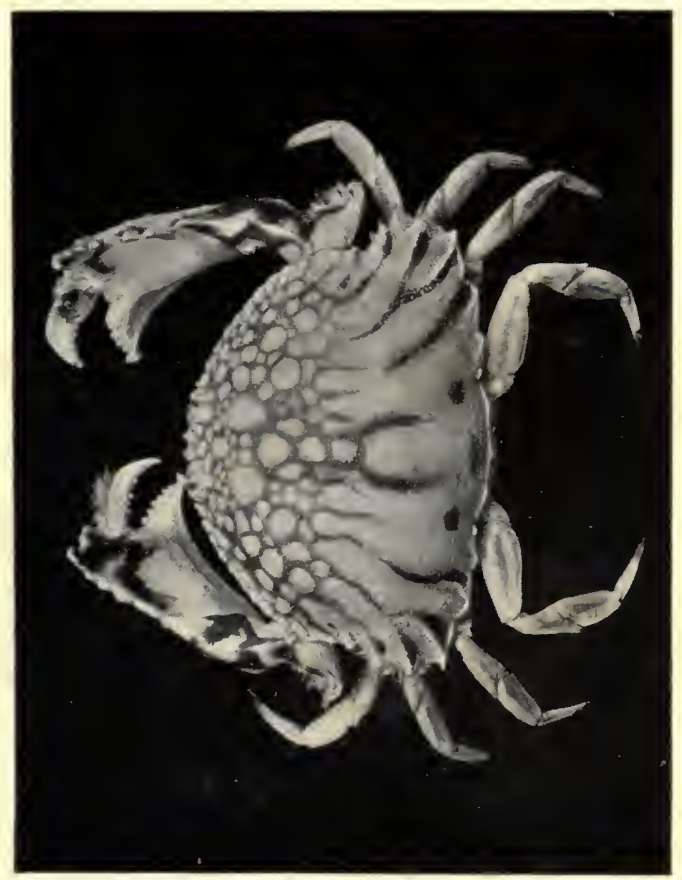

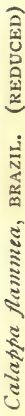





\section{THE METAMORPHOSES OF CRUSTACEA 73}

The Shrimps and Prawns of the tribe Caridea are mostly hatched as zoëæ, and pass through a "schizopod" stage comparable to that of the Lobster, in which they swim by means of exopodites on the legs. Some of the Prawns belonging to the tribe Penæidea, however, have a still more remarkable metamorphosis, which is very important on account of the resemblance of the earlier stages to those of the lower Crustacea. Fritz Müller discovered in 1863 that Penceus is hatched from the egg as a Nauplius (Fig. 29, A), a form of larva which was previously known among the Copepoda, Branchiopoda, and Cirripedes. The nauplius, unlike the larvæ which we have been considering, has an unsegmented body, and has only three pairs of limbs. The body is pear-shaped in outline, and near the front end is seen the median eye, sometimes called, from its presence in this type of larva, the "nauplius-eye"; the paired eyes are not yet developed. The three pairs of limbs are shown by their later development to be the antennules, antennæ, and mandibles; the first pair are unbranched, the second and third divided into exopodite and endopodite. It is interesting to notice that the antennæ and mandibles, which in the adult animal are so widely different that it is difficult to trace any resemblance between them, are in the nauplius almost identical in form. Further, the antennæ, instead of being placed in front of the mouth as in the adult, lie on either side 
of it, and each has at its base a hooked spine which projects inwards and serves for seizing particles of food and passing them into the mouth; the antennæ of the nauplius, in fact, serve as jaws, while it is only later that the mandibles take on this function.

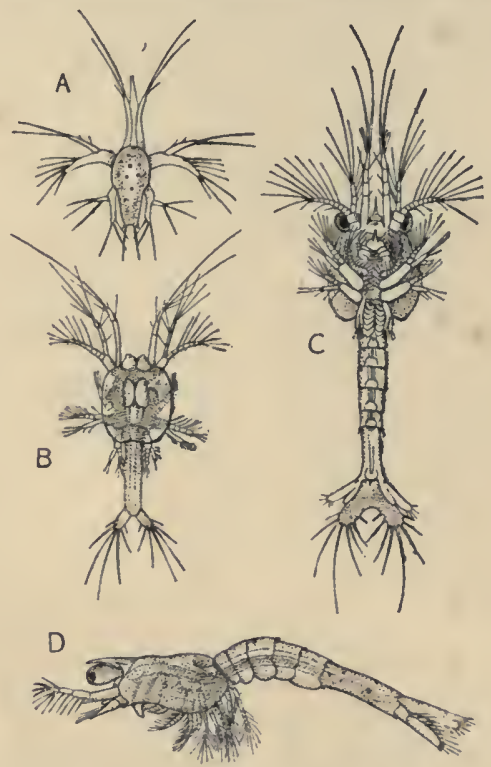

Fig. 29- Larval Stages of the Prawn-Pencus (see Plate IV.). $\times$ 45. (After F. Müller.)

A, Nauplius ; B, young zoëa ; C, older zoëa ; D, early "schizopod " stage

In the further development of the larva, the body increases in length and becomes divided into somites which increase in number by new somites appearing behind those already marked off ; the rudiments 


\section{THE METAMORPHOSES OF CRUSTACEA 75}

of the limbs also appear in regular order from before backwards; the dorsal shield of the nauplius grows out into a carapace, beneath which the paired eyes begin to develop in front. Thus after passing through metanauplius and protozoëa stages (Fig. 29, B) the larva becomes a zoëa (Fig. 29, C), resembling that of the Crab already described in that the swimming organs are the maxillipeds, but differing in having the uropods well developed and forming a tail-fan at the end of the abdomen, the hinder thoracic somites marked off and their appendages present as rudiments, and the stalked eyes free from the carapace. This is followed by a schizopod stage (Fig. 29, D), in which the prawn-like shape is assumed and the thoracic legs have large exopodites used for swimming. Later these exopodites diminish in size, though they do not quite disappear in the adult Penceus, and the function of swimming organs is taken over by the abdominal swimmerets.

In Penaus the larvæ are of comparatively simple form, but in the allied genus Sergestes the zoëa has a very remarkable appearance. The carapace is armed with long spines, each bearing two comb-like rows of secondary spines. The development of spines and other outgrowths of the surface of the body is a very common characteristic of organisms that, like these larvæ, float or swim in the open sea ; its probable significance will be discussed in a later chapter. 
The shrimp-like Euphausiacea have a larval development very like that of Pencus. Most, if not all, of the species are hatched from the egg in the nauplius stage, and pass through stages very similar to those described above. The adult animals, however, may be said to remain in the "schizopod"

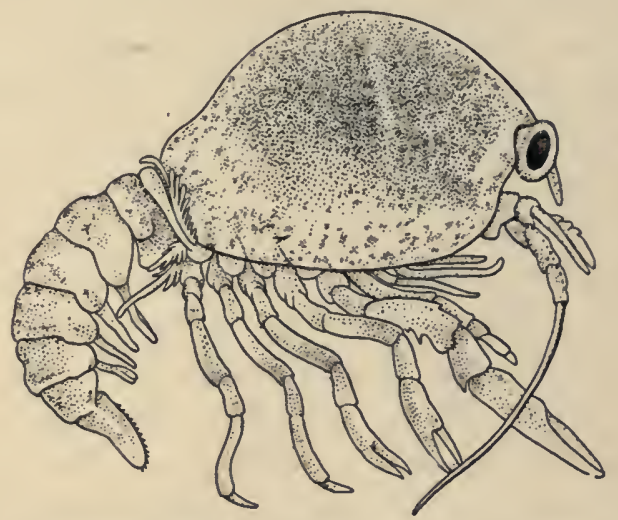

Fig. 30-Newly-hatched Young of a Crayfish (Astacus fuviatilis). ENLARGED

stage, since the exopodites of the thoracic legs remain large and are used in swimming.

Even among the Decapoda, however, there are many species that are hatched from the egg in a form that does not differ essentially from the adult, and are therefore said to have a direct development. This is often the case with species which live in fresh water or in the depths of the sea. For example, the young of the fresh-water Crayfish 


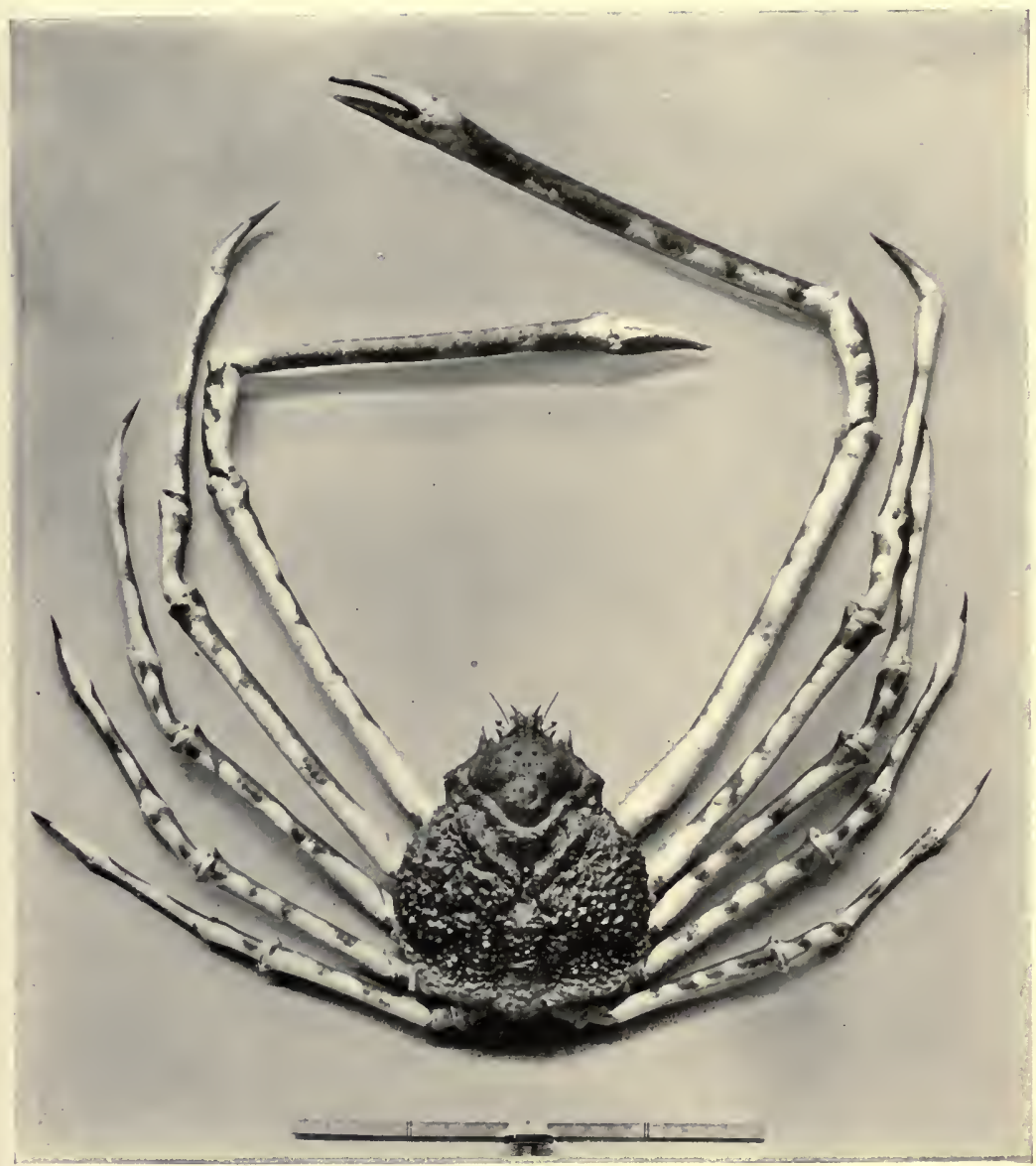

THE GIANT JAPANESE CRAB, MaCrocheira kampferi, MALE. THE SCALE OF THE FIGURE IS GIVEN BY A TWO-FOOT RULE PLACED BELOW THE SPECIMEN

(From Brit. Mus Guide) 

(Fig. 30), when hatched, possess all the appendages of the adult except the first pair of swimmerets and the uropods, or outer plates of the tail-fan. The carapace is almost globular, owing to the presence inside the body of a large amount of food-yolk, which supplies the nourishment necessary for the young animal in the early stages of its development. The chelæ have hooked tips, by means of which the young animal clings securely to the swimmerets of the mother. After a time it moults, and the uropods are set free, the chelæ lose their hooked tips, the carapace assumes nearly its final shape (the foodyolk having been largely absorbed), and the young Crayfish leaves the protection of its parent, to shift for itself. The essential point of difference between the development of the Crayfish and that of the closely related Lobster (see Fig. 8, p. 28) is not so much that the changes in structure which occur after hatching are less profound in the former case, but that there is no free larval stage. In the Lobster the earlier stages are capable of independent existence, and they differ from the full-grown animal not only in structure, but also in habits, swimming at the surface instead of creeping at the bottom of the sea.

A similar case to that of the Crayfishes is found in the River Crabs of tropical countries, belonging to the family Potamonidæ These Crabs are as closely related to some marine Crabs as are the Crayfishes 
to the Lobsters, yet the difference in their mode of development is even more pronounced. Instead of beginning life as minute pelagic zoëæ, they leave the shelter of the mother's abdomen as perfectly-formed little Crabs (Fig. 3I).

Amongst the Decapoda, instances of direct development like those just described are exceptional, but in some of the other orders of the Malacostraca direct development is the rule. In the great division Peracarida, as we have already seen, the females are

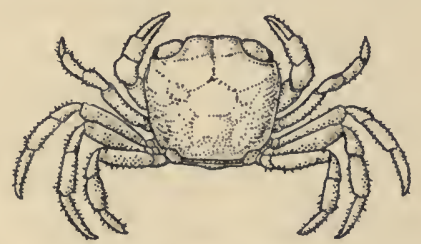

Fig. 3i-Young Specimen of an African River Crab (Potamon johnstoni), taken From the ABDomen of the Mother. MUCH ENLARGED

The adult of an allied species is figured on Plate XXV

provided with a pouch, or marsupium (from which the name of the division is derived), in which the eggs are carried. Within this pouch the young undergo the whole of their development, and they only leave it, as a rule, when they have attained the structure of the adults. Among the more familiar representatives of this division, the Sand-hoppers (Amphipoda), the Woodlice (Isopoda), and the Opossum Shrimps (Mysidacea), may be mentioned 


\section{THE METAMORPHOSES OF CRUSTACEA 79}

as examples of this mode of development. The Woodlice and their immediate allies differ a little from the other members of the division in the fact that the young leave the brood-pouch with the last pair of legs still undeveloped, though in other respects they are like miniature adults.

In those Crustacea which have a direct development without free-swimming larval stages, it is sometimes possible to find traces of such stages in the early development of the embryo. This is shown most clearly, perhaps, in the Opossum Shrimps (Mysidacea). In these the embryo becomes free from the egg-membrane (or may, in a sense, be said to "hatch ") at a very early stage, and lies free within the brood-pouch as a maggot-shaped body, on which three pairs of rudimentary limbs can be made out. The later development shows that these three rudiments correspond to the antennules, antennæ, and mandibles, so that the maggot-shaped embryo is, in fact, a disguised nauplius without the power of swimming or of leading an independent existence. In other cases-as, for instance, in the Crayfish, where the earlier stages are confined within the egg-membrane (or "egg-shell")-the nauplius stage, although more difficult to examine, is quite as well marked.

Of the other groups of the Malacostraca, the Syncarida and Leptostraca are hatched in nearly the adult form, but the Stomatopoda have a long series 
of larval stages. These larvæ (Fig. 32) are all distinguished by the large size of the carapace, which in some cases envelops the greater part of the body. Some stomatopod larvæ, in the warmer seas, attain

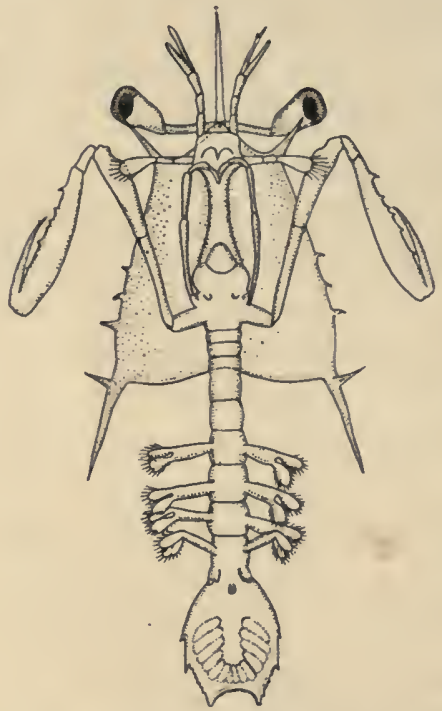

Fig. 32-Early Larval Stage of a Species of Squilla, PRob ABLY S. dubia. $\times$ Io. (After Brooks.) to a relatively great size, sometimes exceeding 2 inches in length, and their glass-like transparency gives them a very striking appearance.

As we have seen, it is exceptional to find a free-swimming naúplius larva among the Malacostraca, but it is the commonest larval stage in the other subclasses of Crustacea. Most of the Branchiopoda are hatched in this form (Fig. 33), and reach the adult state by a very gradual series of changes in which new somites and appendages are added in regular order from before backwards till the full number is reached. The Water-fleas (Cladocera), however, differ from most of the uther Branchiopoda in having a direct development. The eggs are 


\section{THE METAMORPHOSES OF CRUSTACEA 8I}

carried in a brood-pouch under the back of the carapace, and in this the embryos undergo their development. In the common Daphnia, for instance, numerous eggs or young can generally be seen through the transparent carapace (see Fig. I2, p. 37).

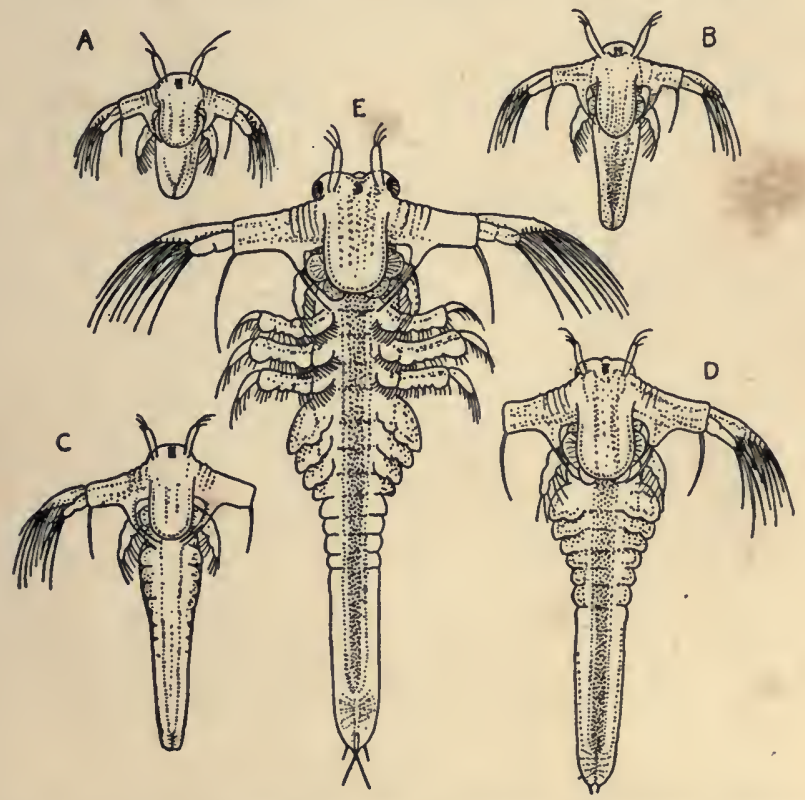

Fig. 33-Larval Stages of the Brine Shrimp (Artemia salina). (After Sars.)

A, Nauplius, just hatched; $B-E$, later stages, showing progressive increase in number of somites and appendages. The adult form of this species is shown in Fig. 55, p. I64

Many of the Ostracoda have a direct development, but in some cases the young animal, on hatching, 
has only the first three pairs of appendages, and is therefore regarded as a nauplius, although it possesses a bivalved shell like that of the adult, and is very unlike the nauplius larvæ of other Crustacea.

Most of the Copepoda also leave the egg in the nauplius stage; and, indeed, it was to the young of the common fresh-water Cyclops (Fig. 34) that the name of Nauplius was first given by the Danish

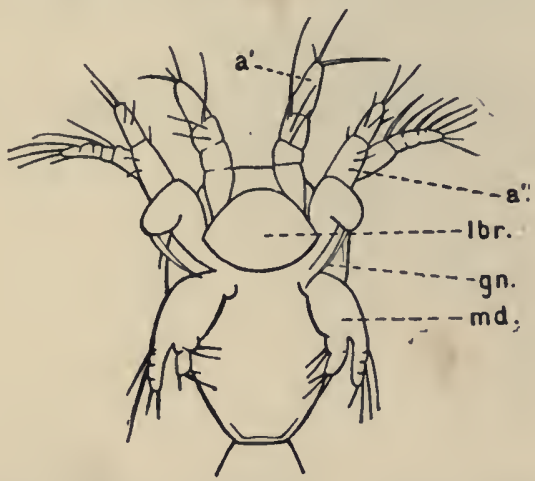

Fig. 34-Early Nauplius Larva of a Copepod (Cyclops). Much ENLARGED. (From Lankester's "Treatise on Zoology.")

$a^{\prime}$, Antennule ; $a^{\prime \prime}$, antenna; $g n$, jaw-spine of antenna; $l b r$, upper lip ; $m d$, mandible

naturalist, O. F. Müller, in the eighteenth century, in the belief that it was an adult and independent species of Crustacea. In the Copepoda, the changes which transform the nauplius into the adult are gradual, and consist chiefly in the successive addition of new somites and appendages.

The development of the Cirripedia is of special 


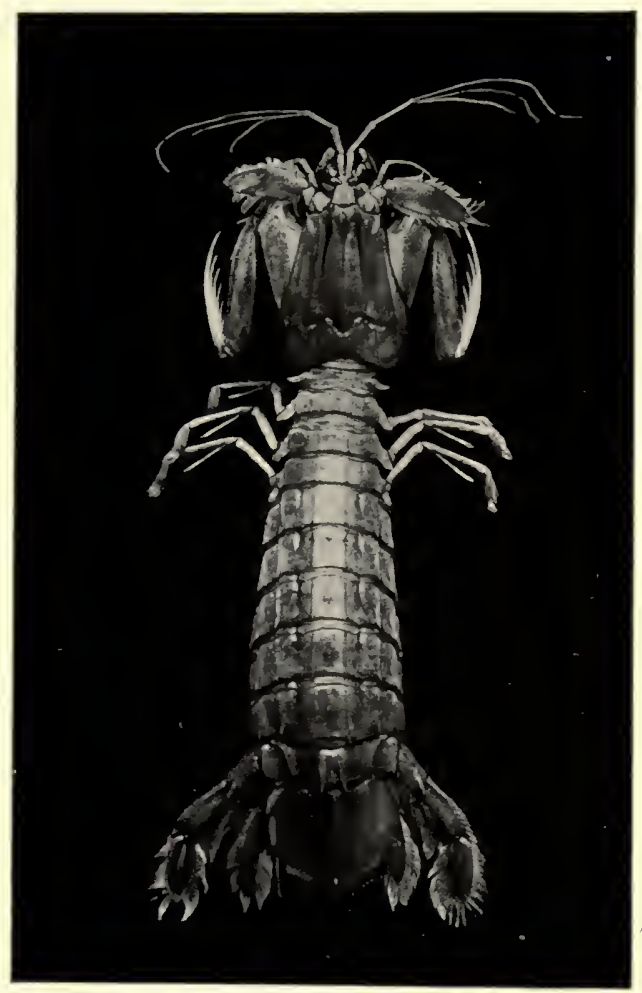

Squilla mantis, FROM THE MEDITERRANEAN. ABOUT ONE-HALF NATURAL SIZE

(From Brit, Mhus. (intite) 



\section{THE METAMORPHOSES OF CRUSTACEA 83}

interest, since it was the discovery of the larval stages by J. Vaughan Thompson that first demonstrated to naturalists that the Barnacles were Crustacea and not, as had been supposed, Molluscs.
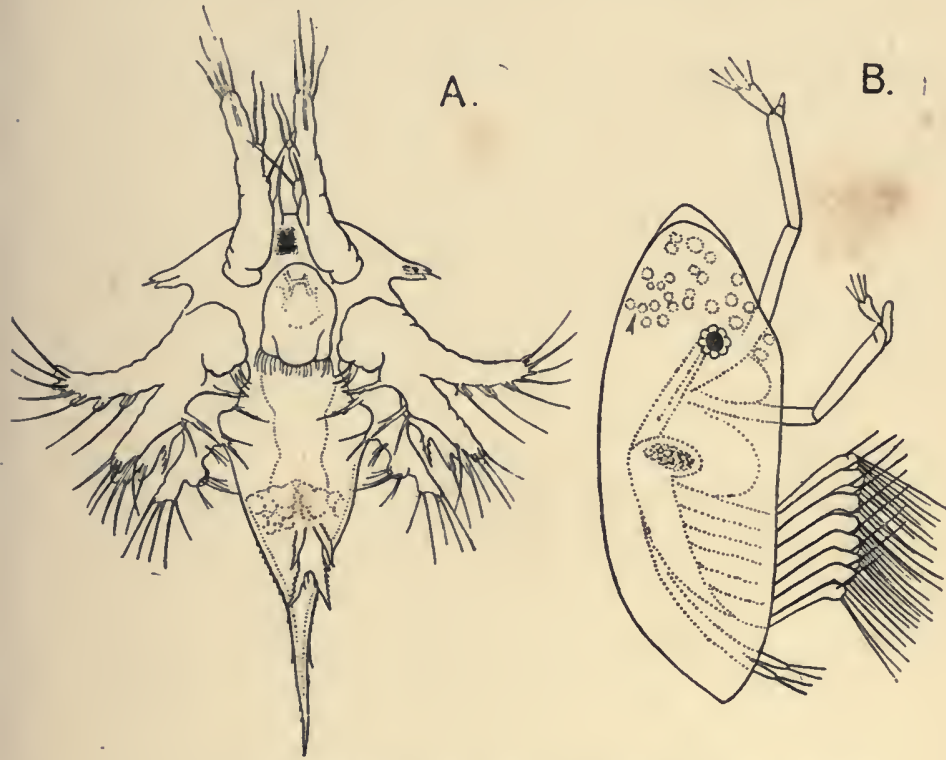

Fig. 35-Larval Stages of the Common Rock Barnacle (Balanus balanoides-SeE Plate III.)

A, Nauplius stage (after Hoek) ; B, cypris stage (after Spence Bate)

The earliest stage is generally a nauplius (Fig. 35, A) of very peculiar and characteristic form, with a pair of horns projecting sideways from the front corners of the dorsal shield, and a forked spine on the under- 
side behind. The later development is very unlike those which have been described above, for after a series of nauplius stages the larva passes suddenly, at a single moult, into a stage in which the body and limbs are enclosed in a bivalved shell (Fig. 35, B). From the superficial resemblance of the shell to that of an Ostracod, this is known as the cypris stage. Through the valves of the shell a pair of large compound eyes can be seen, as well as six pairs of two-branched swimming feet, while in front a pair of antennules project between the valves. On each antennule is a sucker-like disc by means of which the larva, after swimming freely for some time, attaches itself to a stone or some other object, where it remains fixed for the rest of its life. A cementing substance produced by a gland at the base of the antennules attaches the front part of the head firmly to the support; the valves of the shell are cast off, and replaced by the rudimentary valves of the adult shell; the six pairs of swimming feet grow out into tendril-like cirri ; the compound eyes disappear, and the animal assumes the structure of the adult.

The parasitic Rhizocephala have a very remarkable life-history, which will be described in a later chapter; but it may be mentioned here that their free-swimming larval stages resemble very closely those of the ordinary Barnacles. It was the discovery of this fact which led to its being recognized that the Rhizocephala are highly modified and 


\section{THE METAMORPHOSES OF CRUSTACEA 85}

degenerate Cirripedes, although their structure in the adult state gives little evidence of their affinities.

A number of interesting problems in speculative biology are suggested by the larval stages of Crustacea. A full discussion of these problems would involve matters too technical for these pages, but some indication of the broader issues may be attempted.

The obvious question, Why do some Crustacea pass through a complicated metamorphosis while others do not? is, like many obvious and simple questions, one of the most difficult to answer. It will be pointed out later, in dealing with the freshwater Crustacea, that one of the most general characters of fresh-water animals as compared with their marine allies is the absence of free-swimming larval stages. This applies, for instance, to the case of the Crayfishes and the marine Lobsters, and to that of the River Crabs, as compared with those which live in the sea. But it does not apply to all fresh-water Crustacea, and, on the other hand, there are many cases of direct development in marine species.

Some of the advantages gained by the possession of free-swimming larval stages are obvious enough. Many Crustacea which live on the sea-bottom, and are not very powerful swimmers, have their progeny scattered far and wide by winds and currents while in the surface-living larval stages. In the extreme 
case of the Barnacles, which are fixed to one spot when adult, a locomotive larval stage is clearly a necessity. But, here as elsewhere, to demonstrate the usefulness of any character is to go only a very little way towards explaining its origin. Moreover, the mere necessity for a locomotive larva throws no light on the remarkable resemblances between the larval stages of widely different species. In the adult state, a Branchiopod, a Copepod, an Ostracod, a Barnacle, and a Penæid Prawn, are separated by enormous differences of form and structure; yet, as we have seen, all these are hatched from the egg as six-limbed nauplius larvæ differing from each other only in trivial details. It seems hardly possible to imagine any other interpretation of this very striking fact than is afforded by the theory of Evolution. We are forced to assume that all these diverse forms of Crustacea are descended from very similar or identical ancestral types, and that the modifications arising in the course of their evolution have affected the adult but not the larval stages. Some naturalists would go farther than this, and would apply the so-called "theory of recapitulation" to the larval stages of the Crustacea. According to this theory, the stages in the development of any animal tend to recapitulate, more or less closely, the history of the race. Thus it is assumed, for instance, that the nauplius reproduces the structure of a sixlimbed ancestral form, from which, in the distant 


\section{THE METAMORPHOSES OF CRUSTACEA 87}

past, all the diverse branches of the Crustacean class took their origin. There are, however, considerable difficulties in the way of this view. That some such ancestral type did exist may be regarded as tolerably certain; that it resembled in its adult state the nauplius larvæ of present-day Crustacea is, on the whole, unlikely; but it is not at all improbable, whatever its adult structure may have been, that it hatched from the egg as a nauplius larva.

With regard to some of the other larval forms, it is possible to speak with a little more confidence. There are good grounds for believing, apart from the evidence of development, that the Lobster and its allies have descended from Crustacea which, like the existing Euphausiacea, possessed swimming branches (exopodites) on the thoracic legs; and there seems no reason to doubt that the "schizopod" larva of the Lobster does recapitulate this stage in the evolution of the race. On the other hand, it is impossible to believe that any of the ancestors of the Shore Crab resembled, even remotely, the zoëa stage with which the life-history of the individual now begins. 


\section{CHAPTER V}

\section{CRUSTACEA OF THE SEASHORE}

THE tract of seashore which is laid bare by the 1 retreat of the tide offers on most coasts a rich collecting-ground to the student of Crustacea. In places where shelving, weed-covered rocks run out to sea, innumerable Crustacea have their home in the rock-pools, or lurk in crannies awaiting the return of the tide. On sandy beaches, at first sight apparently barren of life, a closer search will reveal a whole fauna, amongst which burrowing Crustacea of various orders are prominent. Further, the shore collector will find. from time to time stray specimens of forms that have their proper habitat beyond low-tide mark, and occasionally their remains are thrown in quantities on the beach by storms. It is convenient, therefore, to treat the Crustacea of the shore as a sample of those inhabiting the shallower waters of the ocean. In these shallower waters-down to the limit where light no longer penetrates from above, where vegetable life ceases, and where the strangely modified inhabitants of the deep sea begin to appear 
- the sea-bottom is perhaps the most densely populated of all parts of the earth's surface. Nowhere, at all events, do we find so wide a range of animal forms, from the simplest organisms (Protozoa) up to highly-organized Vertebrates. Nowhere, perhaps, is the struggle for existence more keen, and it is not without justice that some naturalists have regarded the shallow waters of the sea as " one of the great battle-fields of life," where, in the long course of evolution, the main branches of the animal kingdom have had their origin.

Conspicuous among the animals of this region are Crustacea of all sorts and sizes. To identify all the species that may be obtained in a single haul of the dredge in British seas would sometimes be a hard task even for the most expert student of the group. Our present purpose, however, is not to compile a faunistic catalogue, but merely to give some idea of the endless diversity of form, and to note a few of the "shifts for a living"- of the ways in which structure and habit are adapted to the conditions of life in the Crustacea of the shore and of shallow water.

Though it might seem that the heavily armoured Lobsters and the larger Crabs would be sufficiently protected against most enemies when once they have attained their full size, yet they are preyed upon by the Octopus, which seizes them with its suckers and pierces their armour with its powerful beak, injecting 
a poison that paralyzes its victims. Some years ago a "plague" of Octopus very seriously affected the Lobster fishery in the English Channel. To escape from enemies such as these, the Lobsters and many Crabs have the habit of lurking in crevices of the rocks, while in case of sudden alarm the Lobster may escape from danger by swimming, or rather darting, with great swiftness, tail foremost, through the water by powerful strokes of the abdomen and tail-fan. In the more lightly armed Prawns and other Crustacea of the tribe Natantia, which are characteristically swimmers, the power of rapid motion is probably the chief means of protection against enemies. There is reason to believe that the Lobsters have been derived from prawn-like swimming forms which have sacrificed some of their agility in developing their heavy armour-plating, retaining, however, the power of sudden and rapid motion in emergency. This power, again, has been lost by the typical Crabs (Brachyura), in which the abdomen is reduced in size and without a tail-fan, so as to be useless for swimming. While most of the Crabs, however, are somewhat slow of movement, trusting to their armour and their powerful pincers for defence, the Swimming Crabs (Portunidæ -Plate XIII.) have reacquired the power of swimming by means of the paddle-shaped legs of the last pair. Some of the tropical species of Portunidæ are probably the most expert swimmers among the Crustacea, 
and are described as shooting through the water like fish.

The Lobster's habit of seeking shelter in rockcrevices or under stones is one which is shared by a

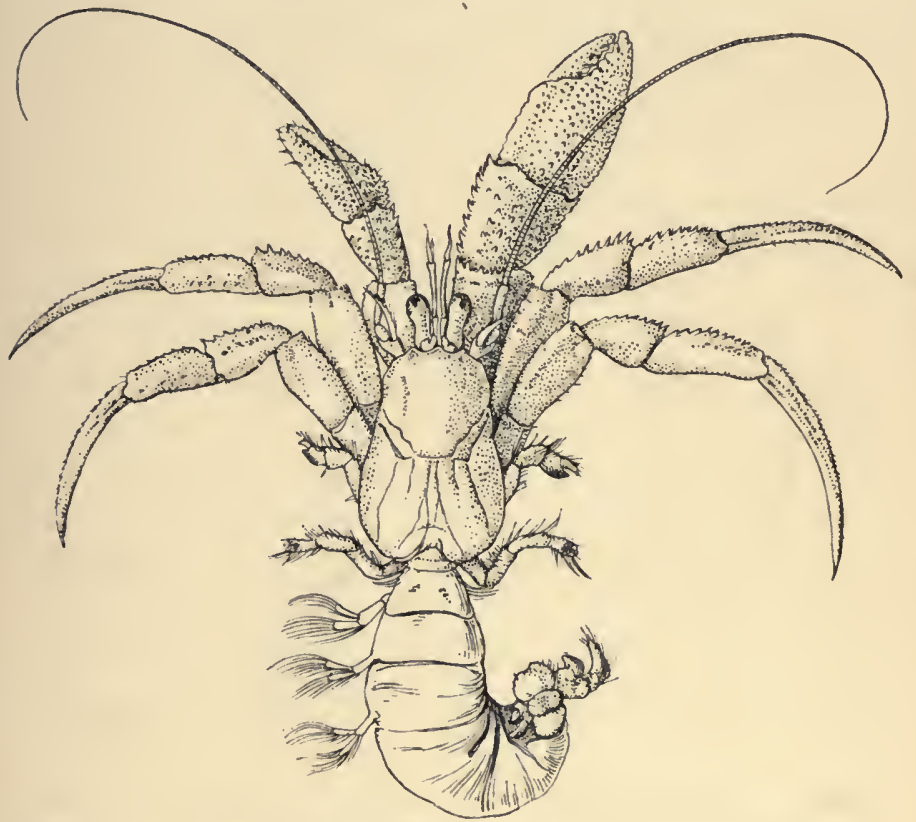

Fig. 36-A Common Hermit Crab (Eupagurus bernhardus) Removed FROM THE SHELL

very large number of shore Crustacea. From some primitive kind of Lobster which discovered the advantages of a portable shelter have been derived the Hermit Crabs. In rock-pools one may often see whelk or periwinkle shells tumbling about with an 
activity quite foreign to the nature of their original molluscan inhabitants, and closer examination will show that each contains a Hermit Crab, which retreats into the shell when disturbed. If extracted from the shell, the Crab (Fig. 36) can be seen to be most beautifully adapted to its peculiar mode of life. The abdomen is soft and spirally twisted to fit into the interior of the spiral shell, and the uropods, instead of forming a tail-fan, are modified into holding organs, with roughened, file-like surfaces which can be pressed outwards against the walls of the shell, and wedge the body so firmly that an attempt to drag the animal forcibly from its retreat often results in tearing it in half. The front part of the body, which is exposed when the animal is walking, retains its shelly armour. One of the pincer-claws, most commonly the right, is much larger than the other, and serves to block the opening of the shell when the body is withdrawn into it. The next two pairs of legs are long and slender, and are used for walking; but the last two pairs are short, with a roughened surface at the end, and serve to steady the body in the mouth of the shell. The swimmerets on the right side of the body, which is pressed against the central pillar of the shell, have disappeared, but those of the left side remain.

As the Hermit grows, it is necessary for him to remove from time to time into a larger dwelling. 
It has been stated that he will sometimes dispossess the rightful owner of a whelk-shell for this purpose, dragging him out piecemeal and eating him; but other observers deny that this ever happens, and in most cases, at all events, the Hermit is content to wait until he finds an empty shell of suitable size. After turning this over and exploring the interior with his claws, to satisfy himself that it is unoccupied, he deftly whips the unprotected hinder part of his body into the new habitation, keeping hold of the old one meanwhile, so that he can return to it if the other proves unsuitable. The Hermits are very pugnacious, and fight with one another for the possession of desirable shells, the victor dragging his opponent out and establishing himself in his place. Besides appropriating the shell of a dead Mollusc, many Hermits seem to go into partnership with living animals of various kinds, and some of these associations will be noticed in a later chapter. A number of species adopt other dwellings than molluscan shells, and some tropical Hermits, for instance, are found living in the cavities of waterlogged stems of bamboo (Fig. 37); while others, relinquishing the advantages of a portable shelter, live in holes in corals or in the canals of living sponges. Although in some of these cases the body is straight, it usually shows traces of its original adaptation to a spiral shell in having no swimmerets on the left side. 
The only Hermits which have a full series of swimmerets are the primitive Pylochelidæ (Fig. 37),
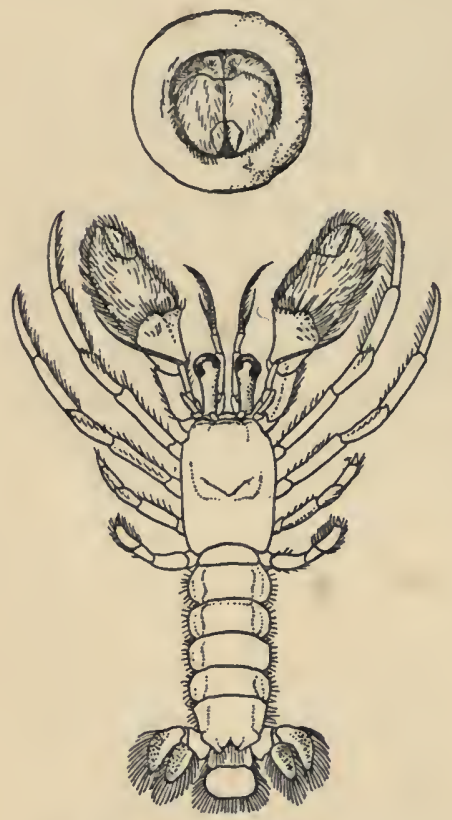

FIG. 37 -Pylocheles miersii, A SymMETRICAL HERMIT CRAB. (After Alcock.)

The upper figure gives an end view of the animal lodged in a tube of waterlogged mangrove or bamboo, its large claws closing the opening. The lower figure shows the animal removed from its shelter. which come very near to what we imagine the ancestral form of the group to have been like, and can hardly be separated from the mud-burrowing, lobster-like Thalassinidea. A few Hermits have given up altogether the use of any protective covering. One of these is the $\mathrm{Coconut} \mathrm{Crab}$ (Birgus), to be mentioned when we come to deal with the Crustacea of the land. Another is the Stone Crab (LithodesPlate VIII.) of our own seas, and its kindred, which have redeveloped shelly plates on the back of the abdomen, but carry it doubled up under the body like the true Crabs. 


\section{CRUSTACEA OF THE SEASHORE}

These also preserve some traces of the original twisting of the abdomen, and have swimmerets only on one side.

Some Crustacea construct habitations for themselves. On turning over a flat stone between tidemarks, one often finds a little mass of bits of weed and rubbish attached to it, and if this be torn open a greenish-brown, shrimp-like animal, about threequarters of an inch long, is seen slithering away on its side. This is an Amphipod (A mphithoë rubricata) which builds the shelter for itself, sticking the fragments together with threads of a cementing material produced by glands on the surface of its body and legs. Other Amphipods construct more neatly finished tubular dwellings of mud, or even of small stones, which are attached to sea-weeds and the like; and some make portable shelters of the same kind, which they carry about with them like the caddisworms of fresh-water streams.

Some of the true Crabs also employ portable shields for purposes of defence or of concealment. The species of Dorippe which are found in tropical seas have the last two pairs of legs short, elevated on the back so that they cannot be used for walking, and ending in a kind of grasping claw. By means of these claws the Crab holds over its back some object, generally one valve of a molluscan shell, sometimes even a mangrove-leaf, to supplement the protection afforded by its carapace. The "Sponge 
Crabs" (Dromiide), of which one species, Dromia vulgaris (Plate IX.), occurs on the southern coasts of Britain, have also the last two pairs of legs elevated on the back and used in a similar way; but in this case the covering is usually a mass of living sponge, one of the Sea-squirts (Tunicata), or some similar organism.

Even more remarkable are the "masking" habits of the Spider Crabs (Oxyrhyncha). In these the carapace is almost always covered with sea-weeds, zoophytes, and other organisms which afford a very effective disguise. For example, specimens of the British species of Hyas ( $H$.araneus and $H$.coarctatus) and Maia (M. squinado-Plate XIII.), which are very common on our coasts, readily escape the notice of the collector, as they lurk in the rock-pools. They are slow-moving animals, and the carapace and limbs are usually quite hidden by dense tufts of growing sea-weed, sponges, and other organisms. By observing the Crabs in an aquarium, it has been found that they actually dress themselves, plucking pieces of weed and the like and placing them on the carapace, where they are held in position by numerous hooked hairs. The transplanted fragments continue to live and grow until the Crab appears like a miniature moving forest. Still more strange is the fact that the Crabs appear to be able in some degree to adapt the nature of their covering to their surroundings. It has been found that specimens dressed in 


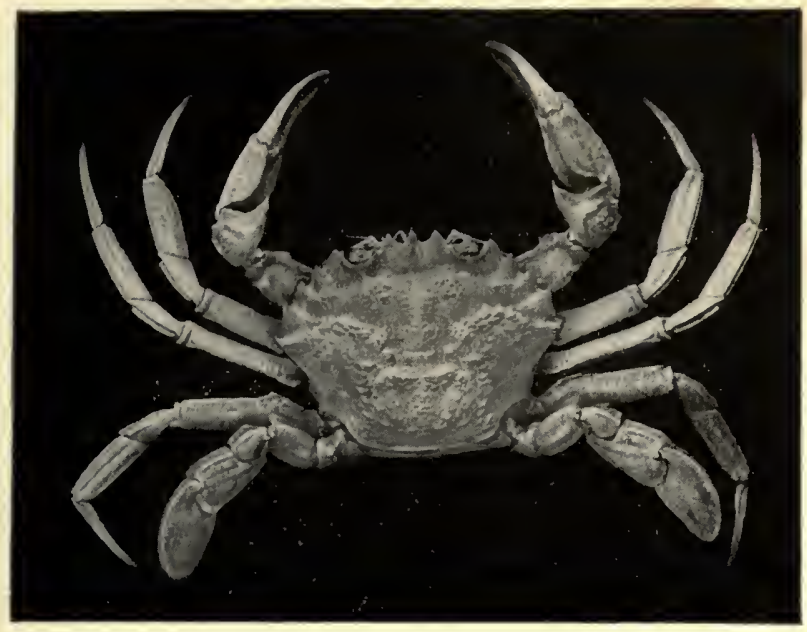

A swimmixg crab, Portunus depurator. British. (Reduced)

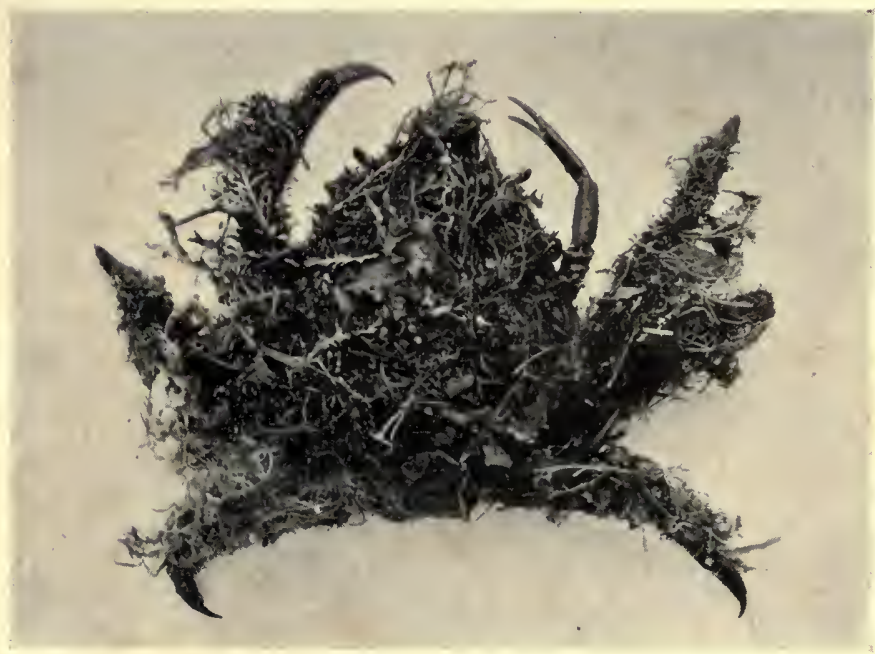

A SPIDER-CRAB, Main squinado, DRESSEI) IN FRAGMIENTS OF WEED. BRITISH (REDUCED) 

sea-weeds, when placed in an aquarium among sponges, picked off the weeds from their bodies and limbs, and planted fragments of sponge in their place. Not only does this habit afford the Crabs protective concealment, but it may also in some cases serve as a source of food-supply. The late Dr. David Robertson, of Cumbrae, one of the most observant of marine naturalists, saw the Crab Stenorhynchus (or Macropodia) longirostris picking foodparticles from among the vegetation on its body, and conveying them to its mouth.

Many Crustacea of different orders seek concealment and protection by burying themselves in sand. A pool left by the tide on a sandy beach may at first sight appear empty of all life, but if it be watched for a little while a greyish, shadowy form may often be seen to dart across it, to settle on the bottom with a little puff of sand, and to disappear. Even a close scrutiny of the spot will hardly discover anything, but with a hand-net one may succeed in scooping up, before it can dart away again, a specimen of the Common Shrimp (Crangon vulgaris - see Fig. 78, p. 244), whose translucent body is finely mottled with greyish-brown so as to match exactly the sand among which it rests.

If a spadeful of sand from between tide-marks be stirred up in a bucket of sea-water and allowed to settle for a few seconds, and the water then poured off through a fine muslin net, a wonderful assemblage 
of minute Crustacea may often be obtained. Numerous species of Ostracods, Copepods, and Amphipods, and some Isopods, can be collected in this way, and some of these, at least, show peculiarities of structure which appear to be adapted to a sand-burrowing habit. Perhaps the most remarkable Crustacea living in such situations, however, are the Cumacea. In these, as already mentioned, the gills, which are attached to the first pair of thoracic limbs, lie one on each side of the thorax in a cavity enclosed by the carapace. These cavities are continued forwards to the front of the head, where they unite in a single opening from which a transparent tube (or a pair of tubes) can be protruded. It appears probable that this very peculiar arrangement of the respiratory system is adapted to enable the animals to breathe while buried in sand or mud. The water is probably drawn in behind through the narrow slit between the side-plates of the carapace and the bases of the legs, and is expelled through the tube which is protruded from the front of the head. In this way the delicate gills are protected from injury and kept from becoming clogged with sand, while the effete water, loaded with the products of respiration, is carried off to a safe distance, so that it does not re-enter the gill chamber.

In the case of such minute forms, however, it is very difficult to determine the precise details of their mode of life by observation of the living animals. In 
the larger Decapods, which can be watched in their natural haunts, or more closely in aquaria, many interesting adaptations to burrowing in sand have been discovered. Many Crabs belonging to the tribe Brachyrhyncha often take refuge in sand or gravel, burying themselves till only the eyes remain exposed. TheSwimming Crabs (Portunidæ-Plate XIII.) of our own coasts have been found to use the paddle-shaped last pair of legs for digging as well as for swimming. In the sand, the Crab keeps its large claws, or chelipeds, folded close up to the front edge of the carapace, which is cut into sharp, saw-like teeth. Between these teeth the water passes, to reach the entrance to the gill chamber which lies at the base of each cheliped, and in this way an efficient strainer is provided, which in coarse sand at least prevents the clogging of the respiratory passages. The out-going current of water from the gills passes through channels that open on either side of the mouth-frame.

A more complex adaptation of structure to the habit of sand-burrowing is found in the Masked Crab (Corystes cassivelaunus-Plate XIV.). This Crab is common on the British coast, living in moderately deep water wherever the bottom is sandy, and it has received its English name from the fact that the furrows on the back of the carapace give it a grotesque resemblance to a human face. It is noteworthy, among other things, for the marked difference between the sexes, the male having very long, slender chelipeds, 
while those of the female are quite short. The most remarkable features of its organization, however, have to do with its habit of burrowing in sand. The antennæ, which in most Crabs are extremely short, are in this species as long as the body, and each bears a double fringe of stiff hairs disposed along the upper and under sides of the antenna, but curved inwards, so that when the two antennæ are brought together parallel with each other, the hairs interlock and form a long tube. At its base this tube communicates with a space in front of the mouth, into which open the channels from the gill chamber at the front corners of the mouth-frame. The Crab burrows in fine sand, and the process is thus described by Professor Garstang: "The Crab sits upright on the surface of the sand; the elongated, talon-like claws of the four hindmost pairs of legs dig deeply into the sand; the body of the Crab is thus forcibly pulled downwards by the grip of the legs, and the displaced sand is forced upwards on the ventral side of the body by the syccessive diggings and scoopings of the legs; the slender chelate arms of the first thoracic pair assist in the process of excavation by thrusting outwards the sand which accumulates round the buccal region of the descending Crab." In this way the Crab descends deeper and deeper, until nothing is visible above the surface of the sand but the tips of the antennæ. The antennal tube keeps open a channel leading from the buried $\mathrm{Crab}$ to the water 

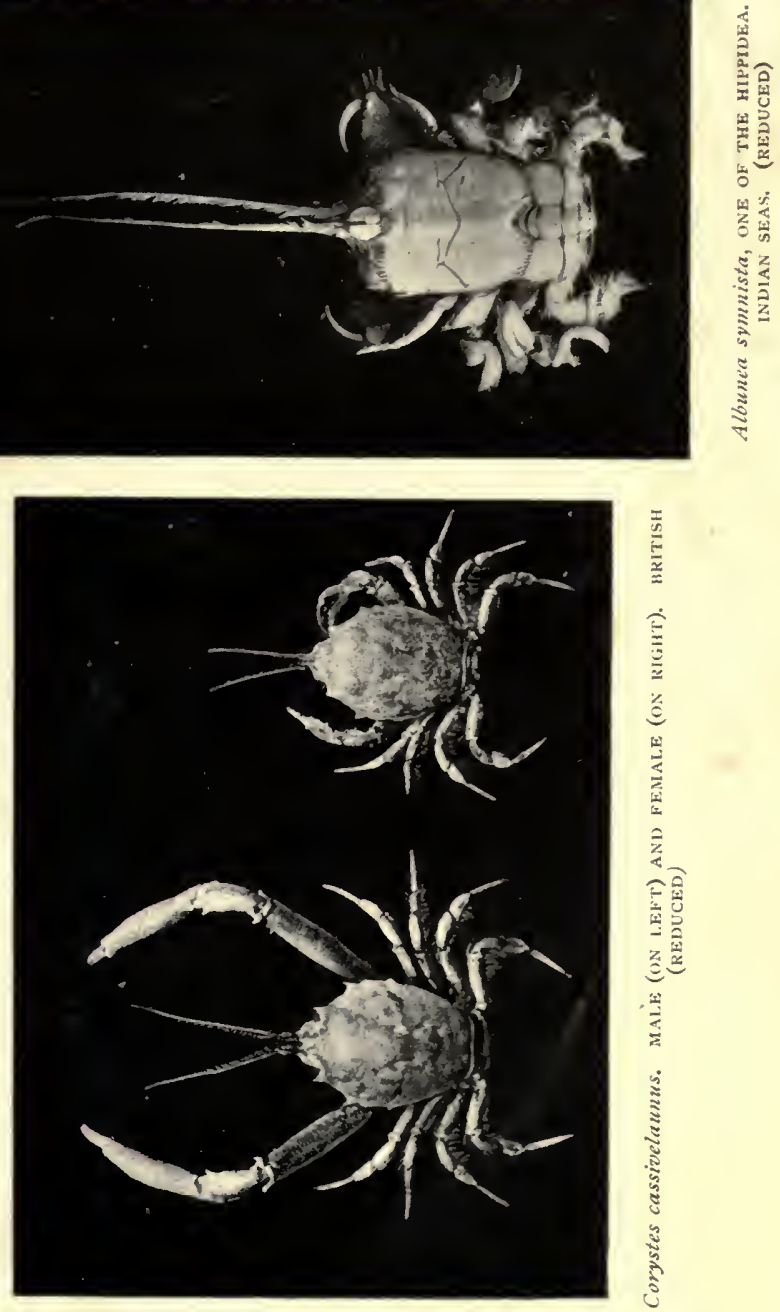

above. Since this tube communicates at its base with the passages through which the water passes out from the gill chamber in most Crabs, it was assumed by the older observers that the antennal tube served to carry the outflowing water to the surface of the sand. It has recently been shown, however, by Professor Garstang that when the Masked Crab is buried in sand the normal respiratory current is reversed, water being drawn down the antennal tube, into the gill chambers, and passing out through the openings at the base of the chelipeds which, when the Crab is not buried, serve for its entrance.

Most, if not all, of the Crabs belonging to the tribe Oxystomata are sand-burrowers, and the structure of the mouth parts characteristic of the tribe appears to have been acquired as an adaptation to this habit. As already mentioned, the mouth-frame in these Crabs is triangular instead of square, being produced forwards between the eyes, and the third maxillipeds, which cover it, are also elongated. In this way the exhalent channels carrying the water from the gill chambers open on the front margin of the head, and are exposed even when the $\mathrm{Crab}$ is buried. In the different families of this tribe the inhalent openings by which the water enters the gill cavities are protected in various ways, and so arranged that respiration can go on without danger of the gills becoming clogged by sediment. 
The members of the tribe Hippidea (sometimes called "Mole Crabs"), among the Anomura, have habits somewhat similar to those of the Crabs just described. They are common on sandy beaches in the warmer parts of the globe, and they burrow with great rapidity by means of the curved, flattened end-segments of the legs. The carapace is generally smooth and oval, and the body is compact, the short abdomen being folded up as in the Crabs.

In Albunea (Plate XIV.), which belongs to this tribe, a long " antennal tube," which looks very like that of Corystes, is believed to have a similar function in connection with respiration when the animal is buried. In this case, however, the tube is formed, not by the antennæ, as in Corystes, but by the antennules, so that it affords a striking example of the independent evolution of similar structures from quite different origins.

Hippa emerita, which is found on the coasts of North and South America, has the mouth parts imperfectly formed, and not adapted for biting; and it is stated by Professor S. I. Smith that the animal feeds in the way that an earthworm does, swallowing the sand through which it burrows, and extracting the nutriment which it may contain. This habit, however, is not followed by other members of the tribe, for Mr. Borradaile found that a species of Remipes in the Maldive Islands could "easily be caught by a bait of Crab at the end of a line, 
pouncing on it with its sharp maxillipeds, and allowing itself to be flicked out of the sand if the rod be sharply lifted."

In the cases mentioned above, the Crustacea do not bury themselves much below the surface of the sand, and do not form definite burrows; but there are many Crustacea which live in open tunnels dug deep into the sand. Some of these belong to the

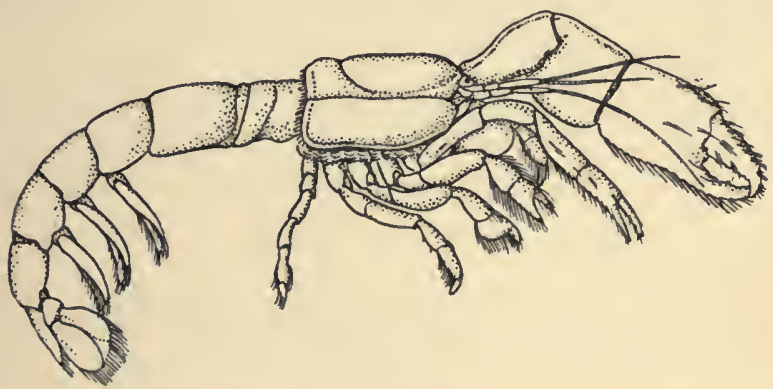

Fig. 38-Callianassa stebbingi (Frmale), a SAND-BURrowing Thalassinid from the South Coast of England. Natural SizE

category of amphibious forms, to be mentioned presently; but there are others which live in deeper water, and of which the habits are less open to observation.

Nearly all the Thalassinidea (Fig. 38) live in burrows, often of considerable depth, in sand or mud. Although now classed with the Anomura, these animals are lobster-like in form, loosely built, generally with short carapace and long, soft abdomen. 
They have usually very small eyes, which appear as if they were not of much use for vision; and some of the hinder pairs of legs are short, and carried folded against the sides of the body, probably for use when the animal is moving up or down in its burrow.

Most of the Stomatopoda resemble the Thalassinidea in their mode of life, and show some curious similarities to them in structure, although by no means closely related. They are described as lying in wait for prey at the mouth of their burrows, darting out on passing fish or other animals, which they seize with their great saw-toothed claws, and retreating with great rapidity to the bottom of the burrow.

Most of the Crustacea mentioned live below tidemarks, and at all events are rarely seen when the sand in which they burrow is left bare by the tide; but there are others, especially on tropical shores, which seem to have their chief period of activity when the sand or mud banks on which they live are exposed to the air. Chief among these amphibious forms in the warmer seas are the Crabs of the genera Ocypode and Gelasimus and some of their allies.

Some of the species of Ocypode (Plate XV.) dig their burrows between tide-marks, where they are swamped by the advancing tide, and must be excavated afresh when the water retreats. Other species, however, live above high-water mark, and 


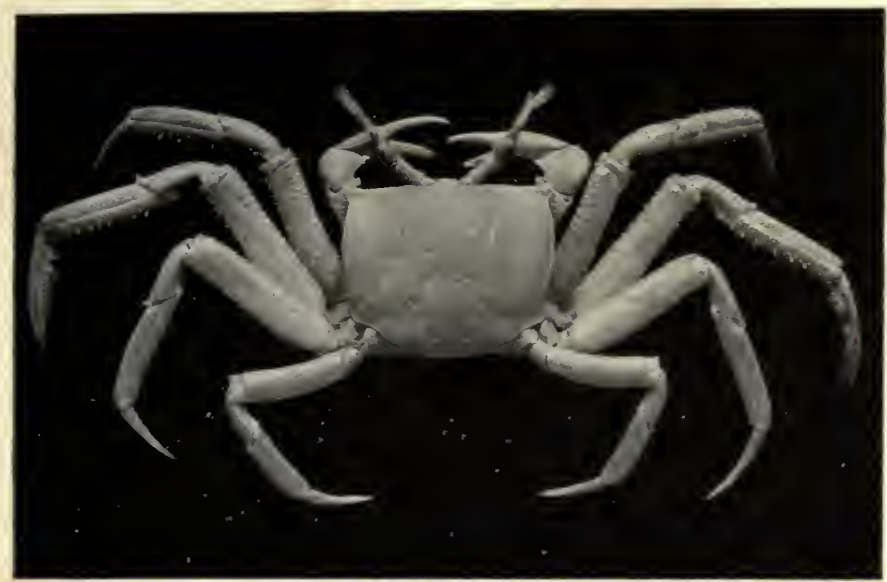

Ocypode cursor: WEST AFRICA. (REDLCED)

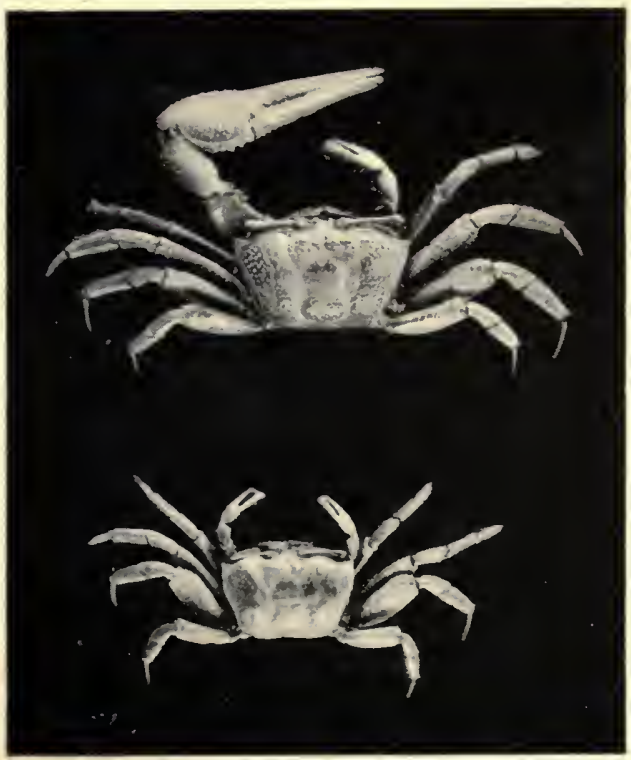

Gelasimus tangeri. MALE ABOVE, FEMAI.E BELOW. WEST AFRICA. (REDUCED) 

are practically terrestrial animals, only entering the water occasionally, and, indeed, unable to survive prolonged immersion. The work of excavating the burrows has been watched in several species. The Crab comes out of the burrow sideways, carrying a load of sand between two of the walking legs on the rear side. By a sudden movement the sand is jerked away to some distance, where it accumulates in a little heap, and the Crab dives into the burrow for another load. Most of the Crabs belonging to this genus possess a curious "stridulating organ" on one of the large claws, by means of which they can produce a buzzing or hissing sound. On the inner surface of the "hand" there is a raised patch, which, when examined with a lens, is seen to be made up of a series of fine ridges, like the teeth of a file. When the limb is bent in towards the body, this patch can be rubbed up and down against a sharp-edged ridge or scraper on the third segment of the limb, and in this way the sound is produced. What the use of the sound may be is not quite clear, but there is probability in Dr. Alcock's suggestion that it serves to warn intruders that the burrow is already occupied. These Crabs run very swiftly, and one species was seen by Professor S. I. Smith to catch Sand-hoppers (Amphipods of the family Talitridæ) by springing on them suddenly, "very much as a cat catches mice," but it also fed on dead fish and the like. 
Of somewhat similar habits are the numerous species of the genus Gelasimus ("Fiddler Crabs"Plate XV.), which abound on sand and mud flats of tropical shores. These little Crabs are remarkable for the great dissimilarity between the sexes in the form of the chelipeds. In the female both chelipeds are small and feeble, but in the males one of them, either the right or the left, is enormously enlarged, sometimes exceeding in length and breadth the body of the Crab which carries it. What the precise use of this enormous claw may be does not seem to be quite certainly known. It is said to be used as a weapon by the males in fighting with one another, but it seems too clumsy to be very efficient for this purpose. It is often brilliantly coloured, and has been supposed to be a sexual adornment.

In Ocypode and Gelasimus the respiratory apparatus is modified for the purpose of breathing air. The gills are similar to those of purely aquatic Crabs, and no doubt serve for respiration when the animal is in the water; but the gill chambers are much more spacious than usual, and the lining membrane is richly supplied with bloodvessels. Air is admitted to the gill chambers by an opening, protected by a brush of hairs, between the second and third pairs of walking legs on each side. It is believed that in this way the gill chamber is fitted to be used as a lung when the animals are out of the water. Similar arrangements in some of the more exclusively 
terrestrial Crustacea will be mentioned in a later chapter.

There are many Shore Crabs, however, which lead a more or less amphibious existence without showing any marked modifications of structure as compared with their more purely aquatic relatives. On our own coasts, the Common Shore Crab (Carcinus manas-Plate IX.) commonly spends several hours each day exposed to the air, and in an aquarium it will voluntarily leave the water if the opportunity be afforded it. On tropical coasts the species of Grapsus and allied genera are often seen clambering with great agility about exposed rocks.

Analogous habits to those of the sand-burrowing, amphibious Crabs described above are shown on a small scale by the Amphipods of the family Talitridæ, known as "Sand-hoppers " or "Beach-fleas." Everyone who has walked over the firm sand near high-water mark on our own shores must have noticed the myriads of actively hopping little creatures disturbed at every step. The commonest species of Sand-hopper on the British coasts is Talitrus saltator (Fig. 39), but Orchestia gammarellus is also common. Both species occur together on sandy beaches or among decaying sea-weeds, and are among the most important scavengers of the seashore, picking clean the bones of fish or other animals cast up by the tide. In this country the Sand-hoppers do not, as a rule, venture far above 
high-water mark; but in warmer climates species of Talitridæ live in the damp forests at great distances from the sea, and deserve to be ranked among the terrestrial Crustacea.

It has been mentioned above that the Common Shrimp is protected, not only by its habit of lying half buried in sand, but also by its close resemblance in colour to the sand among which it lives. There

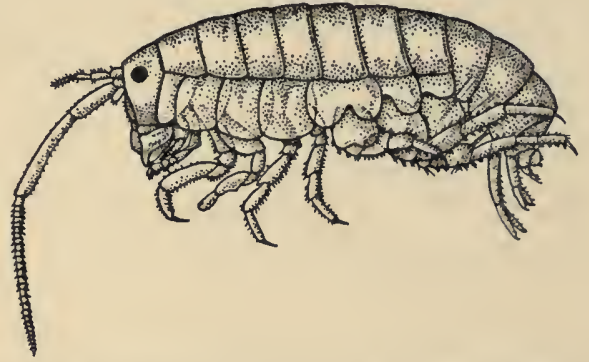

Fig. 39 - The Common SAnd-hopper (Talitrus saltator), Male, FROM THE SIDE. $\times 3$. (After Sars.)

are many others among the shore Crustacea which show what seems to be a "protective resemblance" in colour and form to their surroundings. It is necessary to be cautious in interpreting these resemblances as necessarily protective, since the fish and other enemies which prey on these Crustacea see them with eyes very different from ours, and probably, in many cases, are guided to their prey by the sense of smell rather than by sight. The "masking" habit of the Spider Crabs, already 
described, strongly suggests, however, that concealment from sight is an important protection to some shore Crustacea, and helps to make it probable that the same end is reached in other cases by modifications of form and colour.

There can be no doubt, at all events, that many Crustacea are very inconspicuous to human eyes when they remain motionless in their natural surroundings. Thus, for example, the Caprellidæ, or "Skeleton Shrimps" (see Fig. 22, p. 54), are hard to detect without very close search, as they cling to the feathery branches of the hydroid zoophytes among which they are usually found. They are strangely modified Amphipods, in which the body is slender and thread-like, and generally of a semi-transparent, whitish or yellowish colour, like the zoophytes on which they live. They clamber about among the branches with a movement like that of a "looper" caterpillar, and often remain clinging by means of the hooked claws of the hinder pairs of legs, with the fore part of the body gently waving about.

The little Crabs of the family Leucosiidæ (Oxystomata), of which the British representatives are several species of the genus Ebalia, are often extremely like pebbles of the gravel among which they live. In many tropical species the carapace is pitted and eroded, so as to resemble a worn fragment of coral shingle. One of the most striking cases among the Crabs, however, is that of Huenia proteus 
(Fig. 40), one of the Spider Crabs (Oxyrhyncha), which is found in the Indian and Pacific Oceans. In this little Crab the carapace is flat, and is extraordinarily variable in form. In most of the males it

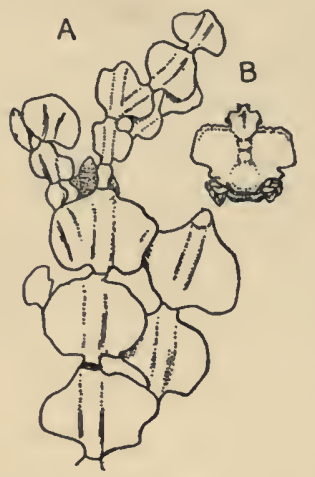

Fig. 40-A, A PIEce of A TROPICAL SEA-WEED (Halimeda); B, A CRAB (Huenia proteus) wHICH LIVES AMONG THE FroNDS of Halimeda, AND CLOSELY RESEMBLES THEM IN FORM AND COLOUR. REDuCED. (After Borra. daile.)

is triangular in outline, but in most of the females and in some males it is broadened by leaf-like expansions of the side edges. Borradaile has pointed out that these broad individuals are usually found among the sea-weed Hali$m e d a$, and that they closely resemble the fronds of this weed in form and in their greenish colour.

A number of Crustacea are known to possess a chameleon-like power of changing their colour. The mechanism by which this change is effected is similar to that found in other animals, such as fish and frogs, which have the same power. The pigment which gives its colour to the animal is lodged in microscopic star-shaped bodies known as chromatophores, lying for the most part just below the skin. Each chromatophore consists of a central body from which a number of branching filaments radiate. The pigment may con- 
tract into the centre of the chromatophore, forming a minute and hardly visible speck, or it may spread out into the branching filaments, forming a distinct spot of colour. Each chromatophore may in some cases contain several colours of pigment, and these may expand or contract independently of each other, so that a whole series of changes may be produced by a single chromatophore. In the larger Crabs and Lobsters the visible colour of the animals depends on pigment in the shelly exoskeleton, which is thick enough to hide the chromatophores in the living tissues underneath, and no very rapid or considerable changes are apparent; but in the smaller forms, in which the exoskeleton is thin and translucent enough to allow the underlying colours to appear through it, the changes in the chromatophores may produce striking effects. Thus, Fritz Müller describes a species of Fiddler Crab of the genus Gelasimus, in which the hinder part of the carapace was brilliantly white, but five minutes after the Crab was captured it had changed to a dull grey. Many other cases of colour change have been described, but most remarkable and the most fully studied is that of the Prawn, Hippolyte varians, which is very common on our own coasts, and has recently been the subject of a very elaborate series of researches by Professors Keeble and Gamble. The specimens of this Prawn show " a bewildering variety of colour and of colour-pattern"; they may be uniformly 
coloured in various shades of brown, green, or red, or they may be "blotched," "barred," or "lined," with colour. These different varieties are generally found among sea-weeds, which they resemble in colour and pattern, the "lined " forms, for instance, frequenting finely branched and feathery weed. Like many other protectively coloured animals, they are of sedentary habits, clinging to the weed, and seldom moving by day. If a specimen be removed from its habitat and placed in an aquarium with different kinds of sea-weed, it will take refuge among that which it most closely resembles. It appears that this resemblance in colour-pattern is acquired during the growth of the Prawn, and that a young specimen kept among finely branched sea-weed will acquire the "lined" pattern, while others, living among coarser weed, become "barred," "blotched," or "monochrome." Even in the adult Prawns the colour (though not the pattern) becomes changed in a day or two if they are placed among weed of a different colour-from green to brown, or the like. Within certain limits still more rapid changes of colour take place. If kept in the dark, or if placed on a white background (for example, in a porcelain dish) in the light, the Prawn quickly becomes nearly colourless, by contraction of the chromatophores, a transparent bluish tint alone remaining, due to a substance which diffuses from the chromatophores into the fluids of the body. In natural conditions this phase is assumed 
at night; and the interesting observation has been made that Prawns kept in the dark continue for three or four days to show a periodic expansion and contraction of the chromatophores, corresponding to the alternation of day and night. It seems that the rhythm of light and darkness has become impressed on the chromatophore system of theanimal,

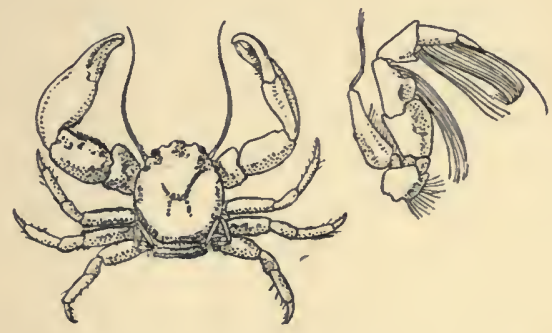

Fig. 4I-The Common Porcelain Crab (Porcellana longiconis), SLightly ENLARged, aND ONe OF the Third MAXillipeds DETACHED AND FORTHER ENLARGED TO SHOW THE FRINGE OF LONG HAIRS

and the movement of the pigments is regulated by something analogous to memory.

It has already been mentioned, in dealing with the Lobster, that certain Crustacea have the power of voluntarily throwing off some of their limbs (autotomy). In many cases, as in the Lobster, this power is mainly of use in enabling the animal to discard an injured limb; but there are some Crustacea which seem to adopt it as a means of escaping from the attack of an enemy. On our own coasts the shore 8 
collector will, often find, on turning over a large stone, one or more specimens of the little Porcelain Crabs (Porcellana platycheles, or P. longicornis-Fig.4I) clinging to its under-side. If these Crabs be seized by one of the large claws, they frequently leave the claw in the captor's hand and scuttle off without it ; and it cannot be doubted that, as in the case of lizards and other animals which have a similar power of self-mutilation, this habit often enables them to escape from their natural enemies.

Although the Crustacea as a whole are predominantly active animals, many examples have already been mentioned of species which are more or less sluggish and sedentary in their habits. The extreme degree of passivity is reached by the Barnacles (Cirripedia), which differ from all other Crustacea (except some parasites) in being fixed to one spot, and quite without the power of locomotion in the adult state. Most of the Barnacles met with on the shore or in shallow water belong to the division of the Sessile Barnacles or Acorn-shells (Operculata). Every visitor to the seashore has noticed the little conical shells which cover exposed rocks as if with a coat of rough-cast. On the British coasts the commonest species is Balanus balanoides (Plate III.), though other species closely resembling it are also common. They are to be found almost up to high-water mark in situations where they are left uncovered for many hours every 
day; but the valves which close the opening of the shell fit so tightly that a little sea-water is enclosed, and the animal is protected from drying up even when exposed to the heat of the sun. If a stone or a chip of rock, with a few of these animals on it, be placed in a jar of sea-water, their peculiar mode of obtaining food can easily be watched. The valves will presently be seen to open a little, and the curled cirri will be protruded, opened out like the fingers of a hand, and withdrawn again with a sort of grasping motion. These movements are continued without stopping while the animal is under water. If the cirri be examined with a pocket-lens or under a microscope, it will be seen that they are fringed with stiff bristles, so that, when they are opened out, the whole forms a kind of "casting-net." As it is swept through the water, this net entangles minute floating particles of animal or vegetable matter, and carries them into the shell, so that they can be seized by the jaws and swallowed. The cirri, as we have already seen, are really the modified thoracic limbs, so that, in Huxley's words, "A Barnacle may be said to be a Crustacean fixed by its head, and kicking the food into its mouth with its legs."

A mode of obtaining food by " net-fishing," not unlike that employed by the Barnacles, is found in certain Crustacea belonging to a widely different group - the little "Porcelain Crabs" (Fig. 4I) mentioned above. Mr. Gosse observed that the 
Broad-clawed Porcelain Crab (Porcellana platycheles) employed its third pair of maxillipeds, which are thickly fringed with long feathered hairs, in making alternate casting movements " exactly in the manner of the fringed hand of a Barnacle, of which both the organ and the action strongly reminded me." 


\section{CHAPTER VI}

\section{CRUSTACEA OF THE DEEP SEA}

I $\mathrm{T}$ has already been mentioned that the animals 1 living on the sea-bottom in shallow water do not differ greatly in character from those that may be found between tide-marks. As we go farther out from land, however, into the deeper water, the character of the fauna gradually changes. One by one the species found near the shore become rare and disappear, and their places are taken by others characteristic of the intermediate depths. These in their turn give way to others, till in the abysses of the great oceans we find an assemblage of strange animals adapted to the conditions of life in the great depths, and differing widely in many respects from the more familiar inhabitants of the coastal waters. In this "fauna of the deep sea," which extends to the greatest depths reached by the dredge or trawl, the Crustacea occupy a prominent place. Before proceeding to discuss some of these peculiar forms, however, it is necessary to attempt to form some idea of the conditions under which they live. 
In the first place, the character of the sea-bottom changes very greatly as we pass away from the coast. Near the shore it is extremely diversified, consisting in one place of rocks swept bare by the tides or overgrown with jungles of sea-weed, in another of banks of gravel or shingle, of sand or of mud, but in all cases derived from the "waste" of the land, as it is eaten away by the waves or washed down by the rivers. As the distance from land increases, the deposits become finer and finer, till they shade off into a soft oozy mud, composed of the finest particles brought down by the rivers. In the neighbourhood of large rivers this mud may sometimes extend for hundreds of miles from the land, but there is a limit to the distance to which even the finest particles can drift before they settle to the bottom, and beyond this limit the floor of the ocean is covered by sediments which owe their origin, not to the land, but to the ocean itself. The surface waters of the ocean everywhere teem with a vast variety of floating animals and plants, and, as these die, their remains sink to the bottom "like a perpetual shower of rain."

Among the most abundant floating organismsin the warmer seas, at any rate-are certain minute animals known as Foraminifera, which belong to the lowest class of the animal kingdom, and have shells composed, in most cases, of carbonate of lime. Over vast areas the bottom of the ocean 
is covered with a soft grey ooze, made up almost entirely of the dead shells of Foraminifera rained down from above. Since the commonest species of Foraminifera found under these circumstances belong to the genus Globigerina, the deposit is known as "Globigerina ooze."

In certain regions of the ocean the shells of other floating organisms largely replace those of the Foraminifera in covering the ocean floor, and in the deepest abysses-so deep that the shells of surface animals are dissolved before they can sink to the bottom-there is found a deposit known as the "red clay," which appears to be derived largely from the impalpable volcanic and cosmic dust that floats in the atmosphere. It is not necessary for our present purpose to enter more fully into the interesting questions connected with these deep-sea deposits, but it is important to remember that, generally speaking, the floor of the deep sea is everywhere soft ooze, without rocks or stones, except for an occasional water-logged lump of pumice or a stone dropped by a melting iceberg. This fact is probably of great importance in the life of deepsea animals.

One of the most peculiar and characteristic of the physical conditions in the deep sea is the enormous pressure under which life has to be carried on. At the surface of the sea the pressure of the atmosphere is, roughly speaking, I $4 \frac{1}{2}$ pounds per square inch. 
At a depth of only 33 feet of water this pressure is doubled, and at greater depths the pressure increases in proportion, till at 2,000 fathoms it is more than $2 \frac{1}{2}$ tons on the square inch. As a matter of fact, however, the animals at the bottom of the sea are probably but little affected by this enormous pressure. Only, when they are brought up by the dredge the sudden release of pressure causes the fluids of the body to expand and destroys the tissues, so that the animals are generally dead or dying when they reach the surface.

More important than the pressure in its influence on life is the darkness of the depths. The light of the sun only penetrates the water of the sea to a comparatively small depth. At 200 fathoms there is not enough light to produce any effect on a photographic plate. Even at a considerably less depth the absence of light puts an end to all plant-life, except for the ubiquitous bacteria, and it follows that all the animals of the deep sea ultimately depend for their food-supply on the rain of dead bodies of surface animals which, as already mentioned, is constantly falling on the sea-bottom.

The temperature at the bottom of the deep sea is always very low. Dr. Alcock states that " in the open part of the Bay of Bengal, where the mean surface temperature is about $80^{\circ} \mathrm{F}$., the temperature at a depth of 100 fathoms is only about $60^{\circ} \mathrm{F}$., at a depth of 300 fathoms not quite $50^{\circ} \mathrm{F}$; while at a 
depth of 2,000 fathoms the temperature all the year round is only $3^{\circ}$ above freezing-point."

Finally, it is important to notice the uniformity of the conditions at the bottom of the sea; not only are the alternation of night and day and the progress of the seasons unfelt in the abysses, but the conditions are practically the same over vast areas in all the oceans.

In the case of deep-sea Crustacea, we are frequently confronted with a difficulty which does not occur in the case of some other groups of animalsCorals or Echinoderms, for example-the difficulty, namely, of deciding whether the animals really lived on or near the bottom, or were captured by the open mouth of the trawl on its way to the surface. When the animals are plainly not well adapted for swimming-as, for instance, most of the Crabs-it may be assumed that they did actually live on the bottom; but, with the prawn-like forms, the possibility that they may really be inhabitants of the intermediate depths must always be taken into consideration.

In animals that live in perpetual darkness we should expect to find, in accordance with the principle of adaptation which runs through the whole of organic nature, that the eyes are wanting or imperfectly developed. In a great many deep-sea animals this is indeed the case. The deep-sea Lobsters of the genus Nephropsis (Fig. 42), which 
are very closely allied to the Norway Lobster (Nephrops) of shallow water, have very short and slender eye-stalks hidden under the rostrum, and showing at the tip only the merest traces of what

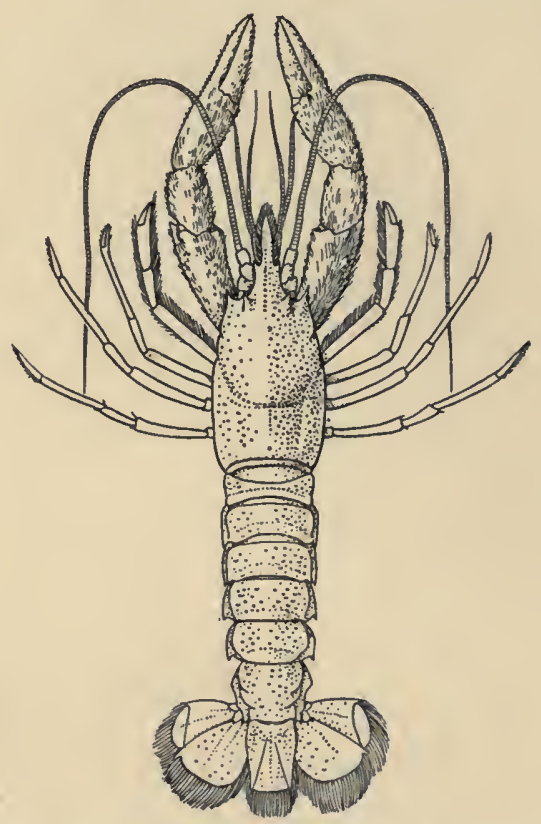

FIg. 42-A DEEP-SEA LOBSTER (Nephropsis stewartii), FROM THE Bay of Bengal. Reduced. (After Alcock and Anderson.)

was once an eye. In the lobster-like Eryonidea (see Fig. 46, p. 133), the reduced eye-stalks are firmly fixed in notches in the front edge of the carapace. Some of the deep-sea Crabs and Prawns seem also to be totally blind. In a great many cases degenera- 
tion has not quite gone so far, and the eyes are present, although much reduced and modified. Thus,

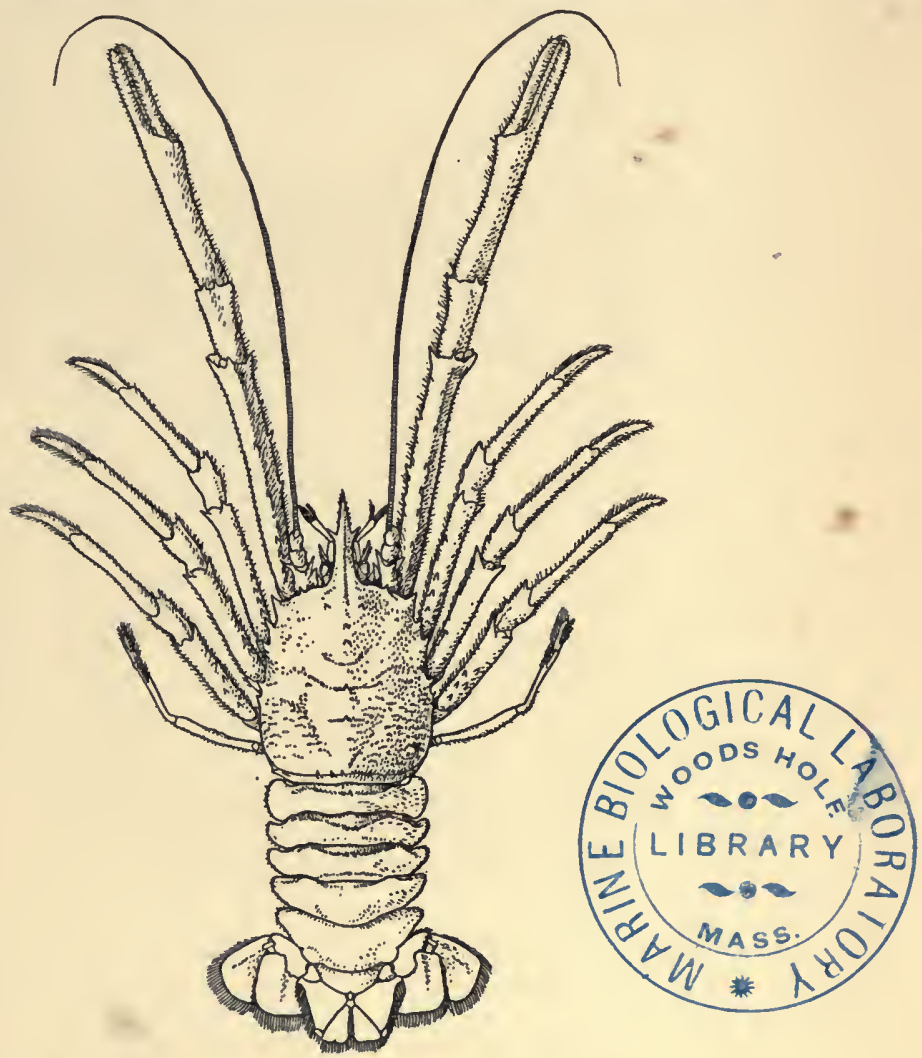

Fig. 43-Munidopsis regia, A DeEp-Sea Galatheid from the Bay OF BENGal. REDUCED. (After Alcock and Anderson.)

the very numerous deep-sea species of Galatheidæ, belonging to the genus Munidopsis (Fig. 43) and its 
allies have, as Alcock says, "pallid, milky-yellow, lack-lustre eyes which, though they may perhaps serve to distinguish between light and darkness, can never form a definite visual image." It is probable, indeed, that these pale-coloured eyes are specially adapted for vision in a dim light, for it has been shown that in certain deep-sea Euphausiacea the pigment-sheaths between the separate elements of the compound eyes are greatly reduced, and are fixed in the position temporarily assumed by those in the eyes of normal Crustacea when kept in the dark. Be this as it may, there are many deep-sea Crustacea which have well-developed and darklypigmented eyes. Some of these are swimming forms, which may at times migrate into the upper strata of water to which some rays of light penetrate; but there are some cases of Crabs and other bottomliving species that have well-developed eyes, although they live at great depths. This would seem to suggest that, although shut off from the light of day, they are not condemned to grope in perpetual darkness. Many deep-sea animals are known to be phosphorescent, and it seems probable that the large-eyed species may profit by the light emitted by the glow-worms and fireflies of the abyss. Thus, Alcock points out that the deep-sea Hermit Crab Parapagurus pilosimanus (Plate XVI.), which lives in partnership with a colony of sea-anemones which it carries about with it, has large eyes, although it 


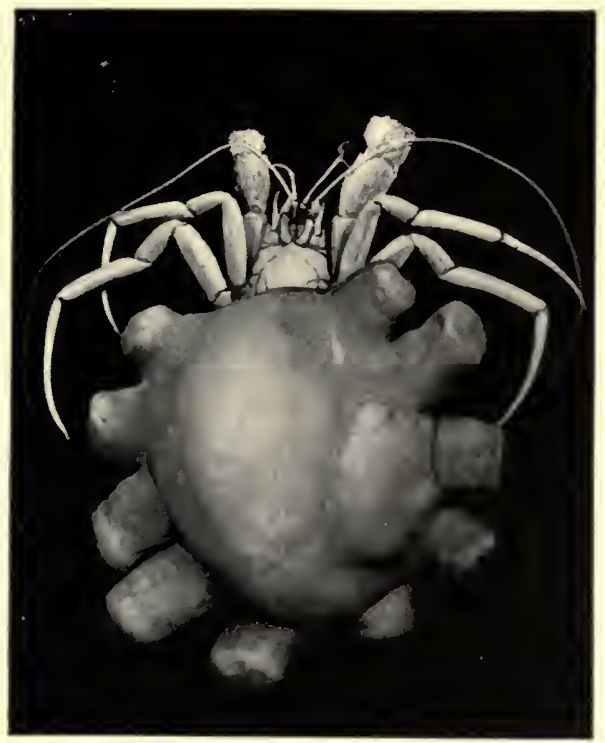

A DEEI-SEA HERM1T-CRAB, P'arapagurus pilosimanus, SHELTERED BY A COLONY OF EPIZOanthus. FROM DEEY WATER OFF THE WEST OF IRELAND (SLIGHTLY REDUCED) 

descends to depths of at least 2,000 fathoms; and he suggests that the Crab may be able to see its way by the light emitted by the zoophytes.

Some of the Crustacea, however, are themselves luminous. Thus, Alcock records how specimens of a deep-sea Prawn, Heterocarpus alphonsi, "poured out, apparently from the orifices of the 'green glands' at the base of the antennæ, copious clouds of a ghostly blue light of sufficient intensity to illuminate a bucket of sea-water so that all its contents were visible in the clearest detail." Certain other Prawns are known to possess special light-producing organs on various parts of the body and limbs. It is in the Euphausiacea, however, that these organs have been most fully examined, and although the members of this group (see Fig. 24, p. 56) are by no means all deep-sea animals, some of them occurring at the surface of the sea, the structure of their luminous organs, or "photophores," may appropriately be described here. They are situated on the undersurface of the abdomen, in the basal segments of some of the thoracic legs, and on the upper surface of the eye-stalks. Each consists of a globular capsule covered by a layer of pigment, except on the outer side, where there is a transparent biconvex lens. In the centre of the capsule is a peculiar "striated body" which seems to be the actual seat of luminescence, and behind it is a concave reflector composed of concentric lamellæ, and having a silvery 
lustre. Before their luminosity was observed, these organs were described as " accessory eyes," but there can be little doubt that they serve rather as searchlights, although, from the positions that some of them occupy on the body, it is not easy to see how they can illuminate objects within range of the eyes. That the function of phosphorescent organs is not always that of giving light for their possessor to see by is shown by the fact that many luminous animals are blind. It is important to notice, however, that these blind animals never have complex "photophores" like those just described, but only exhibit a diffuse luminosity or give off luminous secretions; as an example among Crustacea, the blind Eryonidea (see Fig. 46, p. 133) may be mentioned, one species of which was observed by Alcock to be "luminous at two points between the last pair of thoracic legs, where there is a triangular glandular patch." In a recent discussion of the whole question of phosphorescence in marine organisms, Dr. Doflein concludes that the part it plays in the life of the animal probably differs in the different cases. In some it may serve to attract prey, as moths are attracted to a candle; in others it may help individuals of the same species to keep together in a swarm or to find their mates, the varying arrangement of the photophores producing characteristic light-patterns that serve as "recognition marks" like the colour-patterns of animals that live in the 
light of day. The clouds of luminous secretion thrown out by Heterocarpus and other Prawns, and by certain Mysidacea and Ostracods, may serve to baffle pursuers, like the cloud of ink thrown out by a Cuttlefish, and in some cases the more complex organs may illuminate objects within the range of vision. That this does not exhaust the possibilities of speculation on the subject, however, is shown by the case of certain deep-sea Prawns which have been recently discovered to possess photophores placed so as to illuminate the interior of the gill cavities. What function they can discharge in this position seems beyond conjecture.

The colours of deep-sea Crustacea are very curious. Few of them have the blanched appearance common, for instance, in animals that live in the darkness of caves; on the contrary, their colours are often very vivid, but they are neariy always uniform, without spots or markings, and in a large proportion of cases are in some shade of red or orange. This red colour seems to be associated, in some way that we do not understand, with the darkness of their habitat. The general absence of markings is very striking. Dr. Alcock remarks that in deep-sea Crustacea we never see "those freaks of colour, or those labyrinthine mottlings and dapplings, that excite our curiosity when handling the Crabs and Shrimps of the reefs." Possibly the explanation of this may be that in these dwellers in darkness colour is merely, as it were, an 
accident, a by-product of physiological processes directed to other ends, not a character of protective or warning value, as in animals that hunt and are hunted in the light of day. It is a curious fact, which may have some bearing on this problem, that in many cases, while the adults are coloured in some shade of red, the eggs carried by the female are bright blue or green.

Some of the peculiarities of structure observed in deep-sea Crustacea seem to be correlated with the difficulties of resting or moving about with security on the soft ooze of the sea-floor. Among the Crabs we find a preponderance of long-legged species, not only among the true Spider Crabs (Oxyrhyncha), but also in other groups (Dromiacea like Latreillia, figured on Plate XIX., and Oxystomata), the members of which assume the same spider-like form. In some cases the legs are fringed with long stiff hairs, which may help to prevent the animal from sinking in the ooze, and the spines on the body and legs of many species may have the same effect. Among the deep-sea Prawns, the species of the family Nematocarcinidæ (Plate XVII.) have extremely long and slender legs, which we may assume to be used like stilts for walking over the soft ooze.

Not much is known regarding the food of deepsea animals. In the absence of plant-life they must of necessity be all carnivorous, and all ultimately dependent on the food-supply falling from above. 


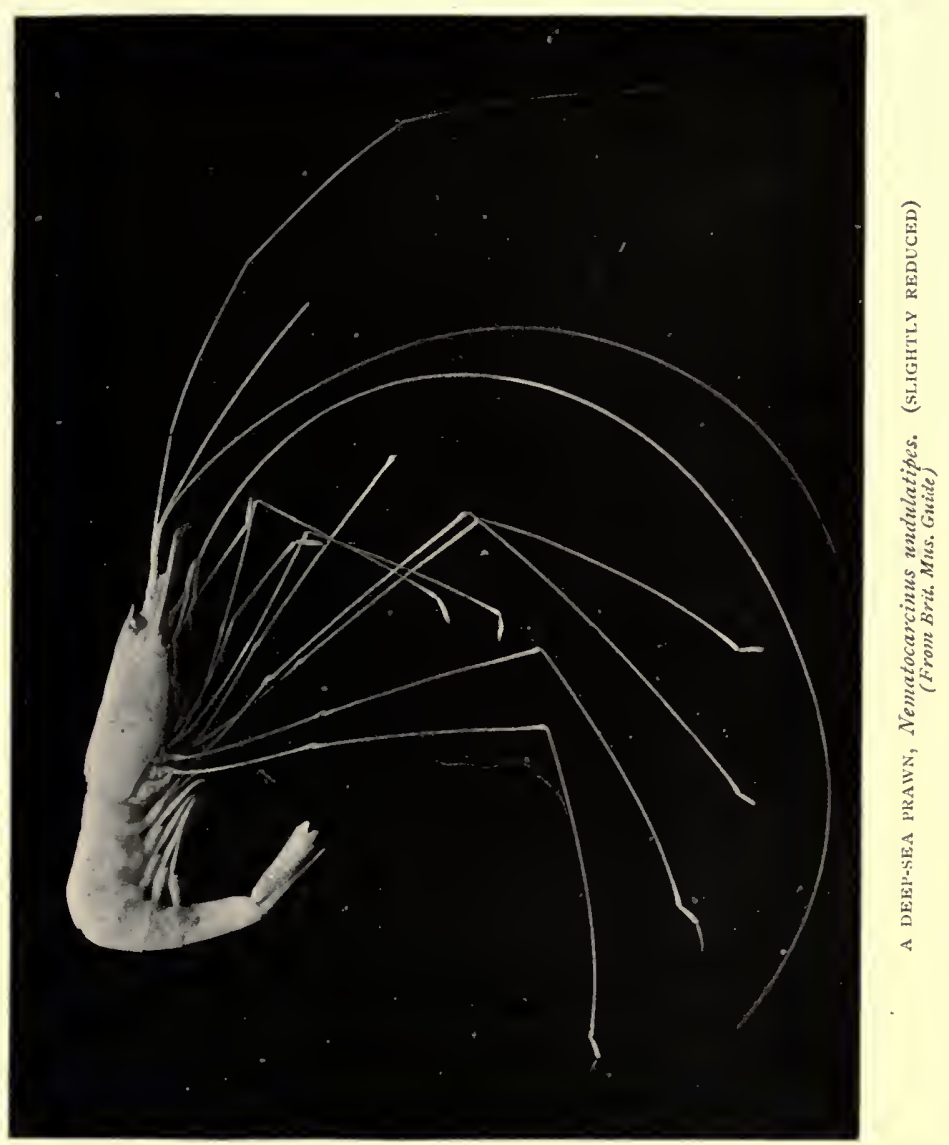



Some species have been found to have the foodcanal filled with Globigerina ooze, which they no doubt swallow, as earth-worms do the soil in which they burrow, for the purpose of extracting the nutriment that it contains. In one species of deep-sea

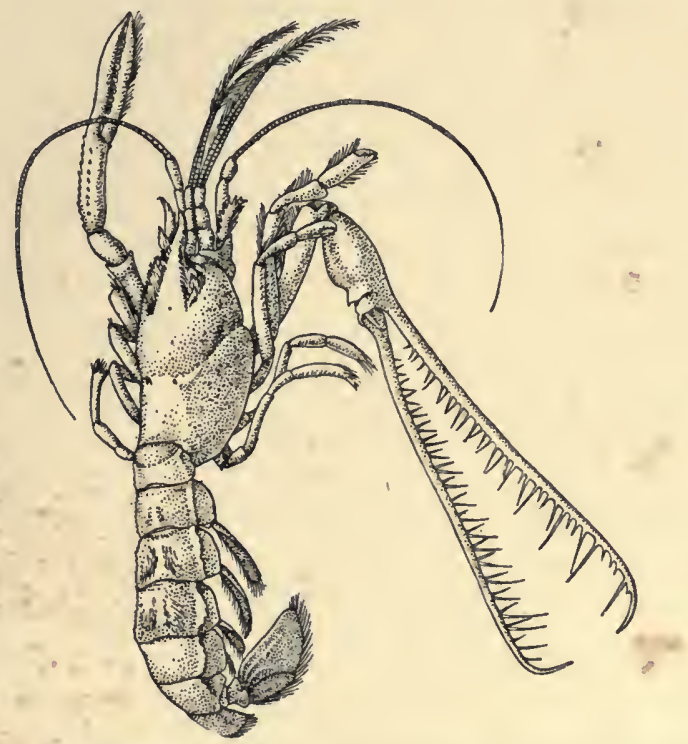

FIG. 44-Thaumastocheles zaleucus. REDUCEd. (After Spence Bate.) Cumacea (Platycuma holti), which appears to feed in this manner, the food-canal is coiled, a condition very rare in Crustacea; in all probability this is due to the necessity for an increase of the absorptive surface, since it is common to find such an increase, either by lengthening and consequent coiling of the 


\section{THE LIFE OF CRUSTACEA}

gut, or by infolding of its walls, in animals that have to swallow large quantities of relatively innutritious food material. Many species, however, no doubt have more selective habits of feeding. The lobsterlike Thaumastocheles (Fig. 44), which was dredged by the Challenger expedition in the West Indies at a depth of $45^{\circ}$ fathoms, and has since been got from deep water off the Japanese coast, has one of the chelæ enormously enlarged, with long and slender fingers set with spines like the teeth of a rake. It has been suggested that this remarkable claw may be used for raking or sifting the ooze for small animals on which the Thaumastocheles feeds. A similar function may be suggested for the long and spiny first pair of walking legs in the Spider Crab Platymaia (Fig. 45).

In many deep-sea Crustacea the eggs are of very large size, indicating that the young are hatched in an advanced stage of development. For example, in the numerous species of the genus Munidopsis the eggs are always large and correspondingly few in number, in striking contrast to the closely allied genus Galathea, from shallow water, in which the eggs are small and very numerous. Alcock mentions that a deep-sea Prawn of the genus Psathyrocaris, although only about $3 \frac{1}{2}$ inches long, has eggs nearly a quarter of an inch in length. It would seem that, in some way or other, the conditions are unfavourable for a free-swimming larval life; but they cannot 



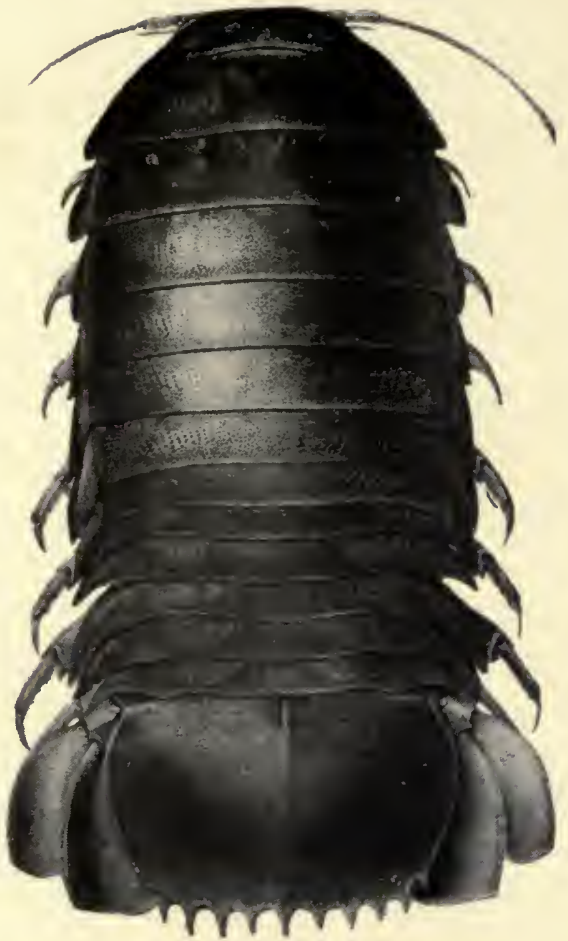

Bathynomus giganteus, ABOUT ONE-HALF NATURAL SIZE (From Lankester's. "Treatise on Zoology," after Milne-Edzuards
and Bouver) 
be altogether prohibitive, for there are a good many characteristically deep-sea Crustacea, such as the Eryonidea, that have small eggs and presumably a larval metamorphosis.

The uniformity of the physical conditions over vast àreas in the deep sea is no doubt the cause of the enormously wide geographical range of many

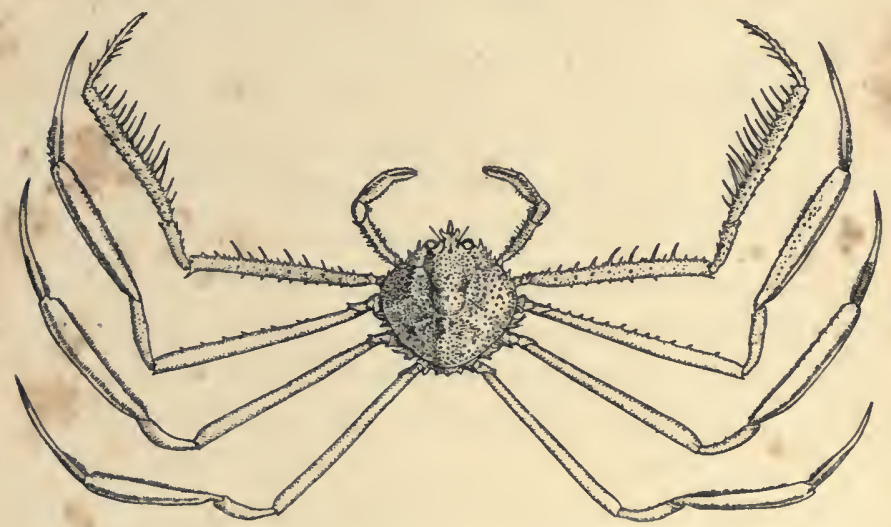

Fig. 45-A DeEp-Sea Crab (Platymaia wyville-thomsoni). Reduced. (After Miers.)

species of deep-sea animals. There are many examples of this among Crustacea, and they are added to by every deep-sea dredging expedition. For example, the giant Isopod Bathynomus (Plate XVIII.) was first discovered in West Indian seas, and the same species has since been dredged near Ceylon, while a second species has been found off the Japanese coast. Of the strange lobster-like 
Thaumastocheles (Fig. 44), mentioned above, only four specimens are known-one dredged by the Challenger in the West Indies, and three others more recently brought from Japan.

The low temperatures prevailing in deep water, even in tropical seas, render it possible for many Crustacea to live there which are closely allied to, or identical with, species occurring in shallow water in the colder seas of the North and South. Many examples of this are mentioned by Dr. Alcock in his discussion of the deep-sea fauna of Indian seas; for example, the Lobster Nephrops andamanicus, found at depths of 150 to 400 fathoms in the Indian seas, is very closely allied to the Norway Lobster (Nephrops norvegicus) of our own coasts. To some extent this fact affords an explanation of the phenomenon that has been called "bipolarity" in the distribution of marine animals. It has been observed that certain families, genera, and even species, are found in the Arctic and Antarctic seas, although they seem to be entirely absent from the intervening tropical zones. In some cases, however, it has been found that these forms occur in the deep sea in the warmer regions where the cold water offers them a connection between North and South without any great difference of temperature.

In the early days of deep-sea exploration, when naturalists were becoming aware of the rich fauna inhabiting the abysses of the ocean, which till then 
had been supposed to be barren of all life, it was confidently expected that representatives would be discovered of some of the animals known as fossils from the earlier geological periods. It was believed that the great ocean basins had remained unchanged for vast periods of geological time, and that numerous "living fossils" would be found surviving in the depths. These hopes have not been fully realized, for the deep-sea fauna as a whole has proved to be of a comparatively modern type ; nevertheless, it does include a considerable number of primitive and old-fashioned forms of life, some of which belong to groups elsewhere extinct. This is conspicuously the case among the Crustacea. The lobster-like Eryonidea, which at the present day

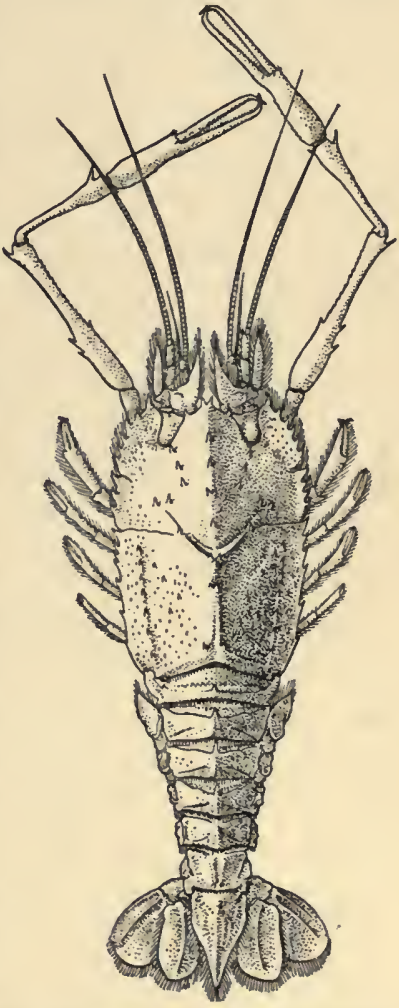

FIG. 46-Polycheles phosphorus, ONE OF THE ERYONIDEA, FEMALE, FROM THE INDIAN SEAs. (From British Museum Guide, after Alcock.) are only found in the deep sea, were long known as fossils before they were discovered to survive as living 


\section{I34}

\section{THE LIFE OF CRUS'TACEA}

animals. The existing species (Fig. 46) are all blind, with only vestiges of eye-stalks, and they may be readily distinguished by the fact that the first four, and sometimes all five, pairs of legs end in chelæ, no other Decapods having more than three pairs of chelate legs. The fossils occur in rocks of the Secondary Period, from the Trias to the early Cretaceous. Some of them, at least, had well-developed eyes, and probably lived in shallow water. This was almost certainly the habitat of those (Fig. 47) that are found preserved in a marvellously perfect state in the lithographic limestone of Solenhofen (famous for the discovery of Archeopteryx and many other remarkable fossils), which is believed to have been deposited in a lagoon. After the early part of the Cretaceous epoch, the Eryonidea are no longer found as fossils, and it is, at all events, a probable conjecture that about that period they forsook the shallow waters for the deeper recesses of the ocean, where their descendants have held their own till the present day. Another group of deep-sea Crustacea which has affinities with certain fossil forms is the little family Homolodromiidæ among the Crabs. It has already been mentioned that the Dromiacea are the most primitive tribe of the Brachyura, and Professor Bouvier has shown that among these the Homolodromiidæ approach most nearly to the lobster-like forms from which the Crabs have been derived. He has further shown that the members of this family 
closely resemble in the arrangement of the grooves upon the carapace the extinct Prosoponidæ, which

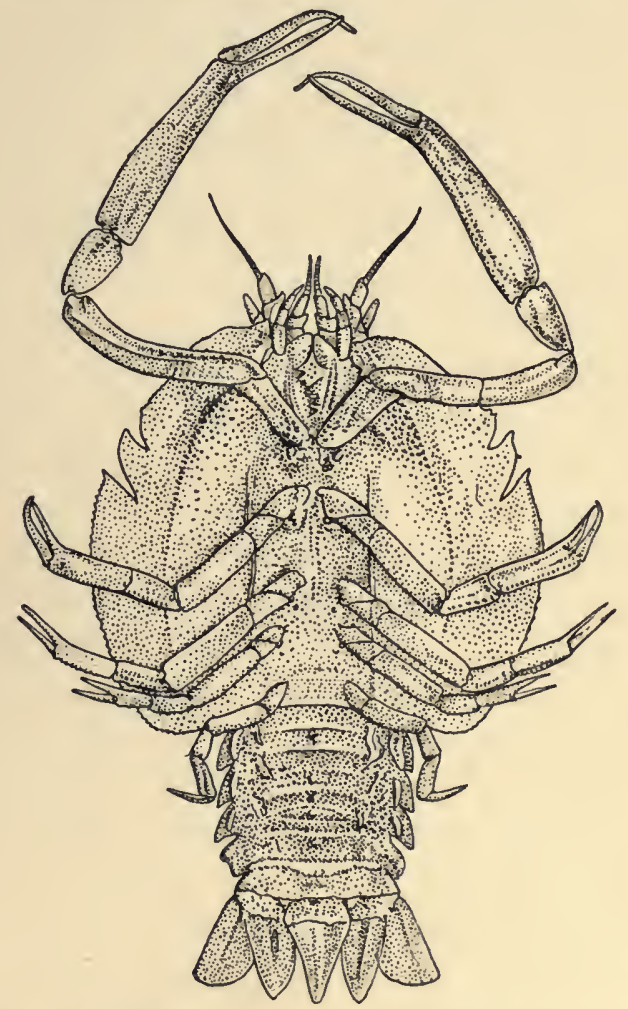

Fig. 47-Eryon propinquus, ONE OF THE Fossil ERYONIDEA, FROM THE JURASSIC ROCKS OF SOLENHOFEN. (From Lankester's "Treatise on Zoology," after Oppel.)

are known as fossils from Jurassic and Cretaceous rocks. 
It is in the deep sea also that we find the curious Hermit Crabs of the family Pylochelidae (Fig. 37, p. 94), which are perfectly symmetrical and show no trace of having ever adopted the habit of living in Gastropod shells; so primitive, indeed, are these forms that it is not easy to find characters by which to define them from the lobster-like Thalassinidea or from the true Lobsters themselves, and, although no fossil representatives are yet known, there seems no reason to doubt that the Pylochelidæ are nearly related to the primitive stock from which the other Hermit Crabs have been evolved. Among the deep-sea Prawns there are many forms, both of Penæidea and of Caridea, which are more primitive than most of their relatives from shallow water; and although in these cases also the geological records are faulty, we may assume, if we cannot prove in detail, a general similarity to the fossil Prawns of Mesozoic rocks.

When all has been said, however, perhaps the most surprising thing about the deep-sea fauna is, not that the animals are unlike those living in shallow water, but that they differ from them so little. When we consider the physical conditions of the oceanic abysses-the absolute darkness, the freezing cold, the pressure measured in tons on the square inchit would seem inevitable that the physiological processes of deep-sea animals must differ greatly from those of animals living in shallow water; yet in very many cases these differences of function are 


\section{CRUSTACEA OF THE DEEP SEA I37}

accompanied only by the most trivial differences in structure. To take one example, the "Pink Shrimp" (Pandalus montagui), which we may find commonly between tide-marks on our own coasts, differs only in inconspicuous details from species of the same genus living at a depth of 600 fathoms; while other genera of the family Pandalidæ range downwards to 2,000 fathoms or more, without any important divergences in structure. 


\section{CHAPTER VII}

FLOATING CRUSTACEA OF THE OPEN SEA

$\mathrm{T}^{\mathrm{T}}$ is only rarely that the floating organisms of the I. surface of the sea are so large or so abundant as to catch the attention of the casual observer. Except for an occasional shoal of porpoises or of flying-fish, the waste of waters seen from the deck of a ship in mid-ocean usually seems to be barren of life. Nevertheless, there is probably no region of the ocean where the tow-net will not reveal the existence of a more or less varied fauna and flora: Sometimes, indeed, these organisms, though minute, are so numerous as to discolour the water over large areas; whalers in the Arctic seas know by the appearance of "whale-food" where whales are likely to be found, and herring or mackerel fishermen recognize the changes in colour of the water among the "signs" which guide them when and where to shoot their nets.

The organisms which make up this "pelagic" fauna and flora may be grouped into two classes, which may be termed the "swimmers," or Necton, 
and the "drifters," or Plankton. The former include the larger and more active animals, such as fish, whales, and the like, whose movements are more or less independent of the movements of the water; the latter comprise the plant-life and the floating or feebly swimming animals that drift at the mercy of waves and currents. A great deal of attention has been given in recent years to the study of the plankton, and it has come to be recognized as filling a very important place in the balance of life in the sea. In the sea, as on land, all the animals are ultimately dependent on plants for their food. The larger and more conspicuous sea-weeds which grow on the sea-bottom, however, can only flourish in comparatively shallow water, and the region which they occupy forms only a narrow fringe round the land-masses of the globe. It is only necessary to look at a map of the world, showing the depth of the sea, to realize what an insignificant part of the area of the oceans contributes in this way to the food-supply of marine animals. The microscopic plant-life of the plankton, however, makes up for the individual minuteness of its constituents by their incalculable numbers. The lowly organisms known as "diatoms," familiar to the microscopist from the beauty of their flinty skeletons, are among the most numerous and important of these, and they are associated with a great variety of other single-celled algæ and allied organisms, some of them so minute 
that they pass through the finest silk plankton-nets, and have to be sought for by special methods of collection recently devised for the purpose. All these organisms possess the green colouring matter (chlorophyll) that enables them to live, as the higher plants do, on the carbon dioxide and other substances dissolved in the water. The smaller animals of the plankton feed on these vegetable organisms, and in their turn serve as food for larger animals. The Herring, the Mackerel, the gigantic Basking Shark, and the still more gigantic Greenland Whale, all feed directly on the animal plankton, and we have already seen that the animals of the deep sea depend entirely on the same source of food-supply. Further, very many of the bottom-living animals of shallow water swim at the surface in the early stages of their life, and feed on the other plankton animals and plants. Indeed, it is no exaggeration to say that "all fish is diatom" in the same physiological sense as "all flesh is grass," and the study of the plankton is thus of practical importance as well as of scientific interest.

Of all the minute animals that form the intermediate links in the chain between diatom and fish or whale, the Crustacea are the most important and the most numerous both in species and in individuals. The Copepoda are more richly represented than any of the other groups, and it would be difficult to find a sample of marine plankton from which they were 
altogether absent. Associated with them we find one or two species of Cladocera, a larger number of Ostracoda (chiefly of the family Halocypridæ), a few Mysidacea, the Amphipoda of the suborder Hyperiidea, the Euphausiacea, and some of the shrimplike Decapods; while the larval stages of these and other groups also form an important part of the plankton.

It is necessary to make a distinction between the "neritic" plankton of shallow water near the coast and the "oceanic" plankton of the open sea. In the inshore waters the plankton consists not only of organisms that pass the whole of their life at or near the surface, but also, and very largely, of the freeswimming larvæ of bottom-living species, and of others that make occasional and temporary excursions to the surface. For example, if the tow-net be used a short distance from land-say in some sheltered bay on our own coasts-the catch will often be found to consist largely of larval Crustacea. The zoëa and megalopa stages of Crabs, the zoëa and schizopod stages of Prawns and Shrimps, are often conspicuous by their numbers, or we may find swarms of the nauplius and cypris larvæ of Barnacles. Sometimes, and especially at night, numbers of Cumacea may be found in the tow-net; and it is noteworthy that these are usually males, which leave the females burrowing in the mud at the bottom, and swarm to the surface for a brief period of 
activity. Besides all these more or less temporary visitors, however, there are numerous species, even in the inshore waters, which are adapted to a floating life, and pass their whole existence as members of the plankton. Copepoda of many kinds, some Mysidæ, Amphipods like Hyperia-which is commonly found sheltering under large jellyfishsome species of actively swimming Isopods, and many other forms, are only to be captured by the tow-net; and now and then, in certain localities, winds and currents may drive into coastal waters shoals of species whose proper home is the open ocean.

In a similar way the strictly neritic forms may sometimes be carried far out to sea, so that it is nowhere possible to draw a hard-and-fast line between the regions occupied by the neritic and the oceanic plankton. With increasing distance from land, however, the larval stages of bottom-living species become fewer, and finally disappear altogether, and there is left an assemblage of animals whose whole existence is passed floating at the surface or at the intermediate depths. How far down from the surface this floating fauna actually descends is a question which has been much debated. It appears now to be certain that there is no stratum of water between the surface and the bottom of the ocean which is devoid of life, although the upper layers (not at, but some distance below, the surface) 
are probably much more densely populated than those of the abyss. Many of the species appear to undertake more or less extensive migrations in a vertical direction, coming nearer the surface at certain stages of their life-history, and sinking into deeper water at others. Further, some species at least seem to rise to the surface at night, and to sink again during the day. Apart from these vertical movements, which are as yet only imperfectly understood, it is desirable to distinguish between the "epiplankton," comprising the organisms which inhabit the superficial strata of the ocean down to about roo fathoms, and the "mesoplankton," found at greater depths. The plant-life which is dependent on sunlight belongs to the epiplankton, while the animals of the mesoplankton are dependent, like the bottom animals of the deep sea, on the supply of dead food material falling from above. A third division, the "hypoplankton," has been established for those animals which live immediately above the bottom, but its distinctness from the mesoplankton has not yet been satisfactorily established. Indeed, many of the swimming forms which have already been mentioned in dealing with the Crustacea of the deep sea are probably rather to be considered as belonging to the deep mesoplankton-at least, where their size and swimming powers do not entitle them to be ranked with the "necton."

Many of the modifications in structure character- 
istic of pelagic animals may be traced to the necessity for keeping continuously afloat with a minimum of exertion. The Crustacea of the plankton never carry the heavy armour found in bottom-living species. Thus, the thick-slielled Ostracoda of the bottom are represented in the plankton chiefly by the family Halocypridæ (Fig. 48), in which the shell - is thin, uncalcified, and almost membranous. Many species, particularly of the Copepoda, are seen,

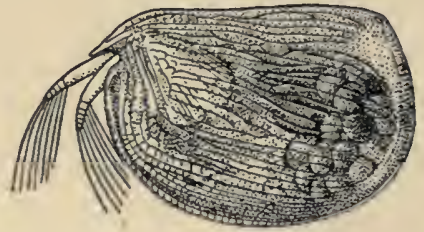

Fig. 48-Conchacia curta, an Ostracod of the Plankton. $\times 40$. (Partly after G. W. Müller.)

under the microscope, to have large globules of oil distributed through the tissues of the body, and these no doubt serve as floats, increasing the buoyancy of the animal. The same purpose is probably served, in many cases, by having large spaces, filled with fluid, within the body. This is characteristic of pelagic animals, and is well seen in many of the Crustacea in which the viscera and muscles occupy a relatively small part of the interior of the animals, the intervening spaces being filled with colourless transparent fluid. Many of the 


\section{PELAGIC FLOATING CRUSTACEA}

Hyperid Amphipoda show this peculiarity-for example, the relatively gigantic Cystisoma, which is mesoplanktonic in deep water; and it reaches its extreme in Mimonectes (Fig. 49), in which the anterior part of the body is, as it were, blown out into a
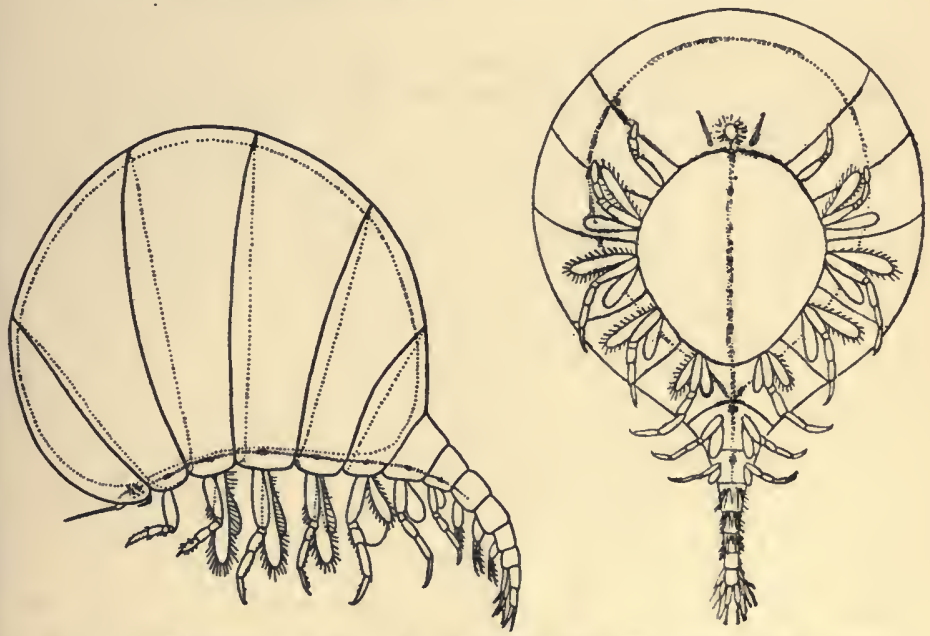

Fig. 49-Mimonectes loveni. A Female Specimen seen from the Side aNd FROM Below, showing the Distended-BalloonLIKE Form of the ANterior Part of the Body. $\times 3$. (After Bovallius.)

balloon, giving the animal the aspect of a small jellyfish rather than an Amphipod.

If, as seems probable, the body-fluid of these animals is of a lower specific gravity than the seawater, it will act like the oil-globules of the Copepoda in keeping the animals afloat. Even if the specific gravity be the same, however, the distension 
of the body with fluid acts in another way, by increasing the surface exposed to friction with the surrounding water, and so retarding sinking. The

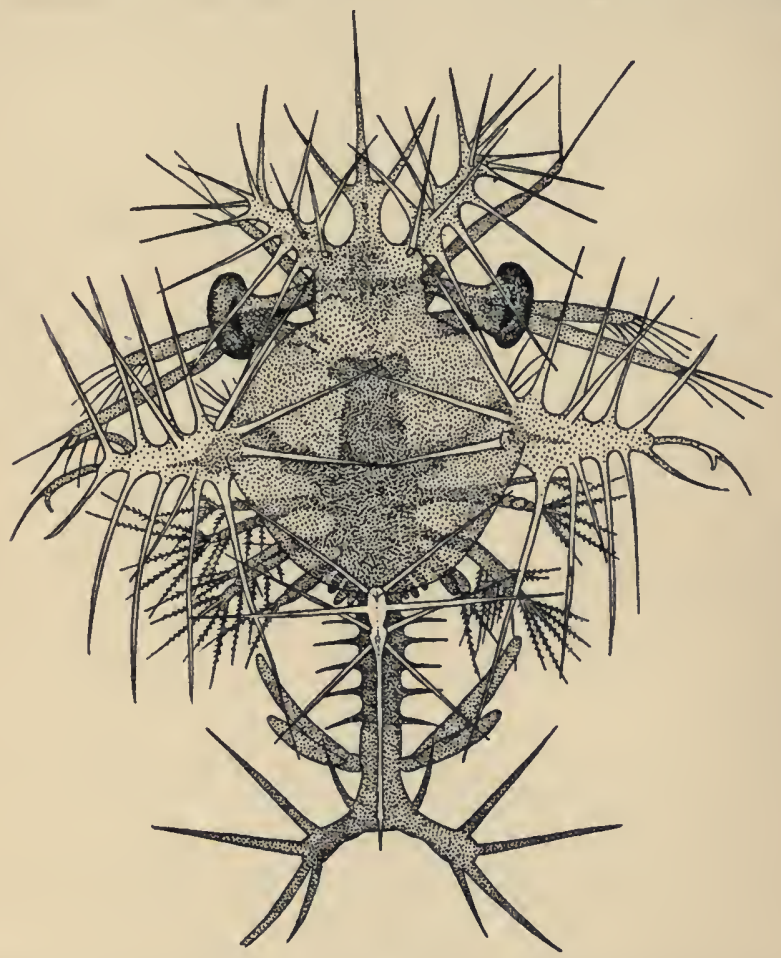

Fig. 50-The ZoËa Larva of a Species of Sergestes, taken by the "Challenger" Expedition. $\times 25$. (After Spence Bate.)

principle involved is illustrated by the fact that a soap-bubble sinks much more slowly through the air than the drop of water into which it collapses. 
The same result is produced if the surface is increased by outstanding spines or hairs, just as, for instance, a downy feather sinks slowly through the air, but

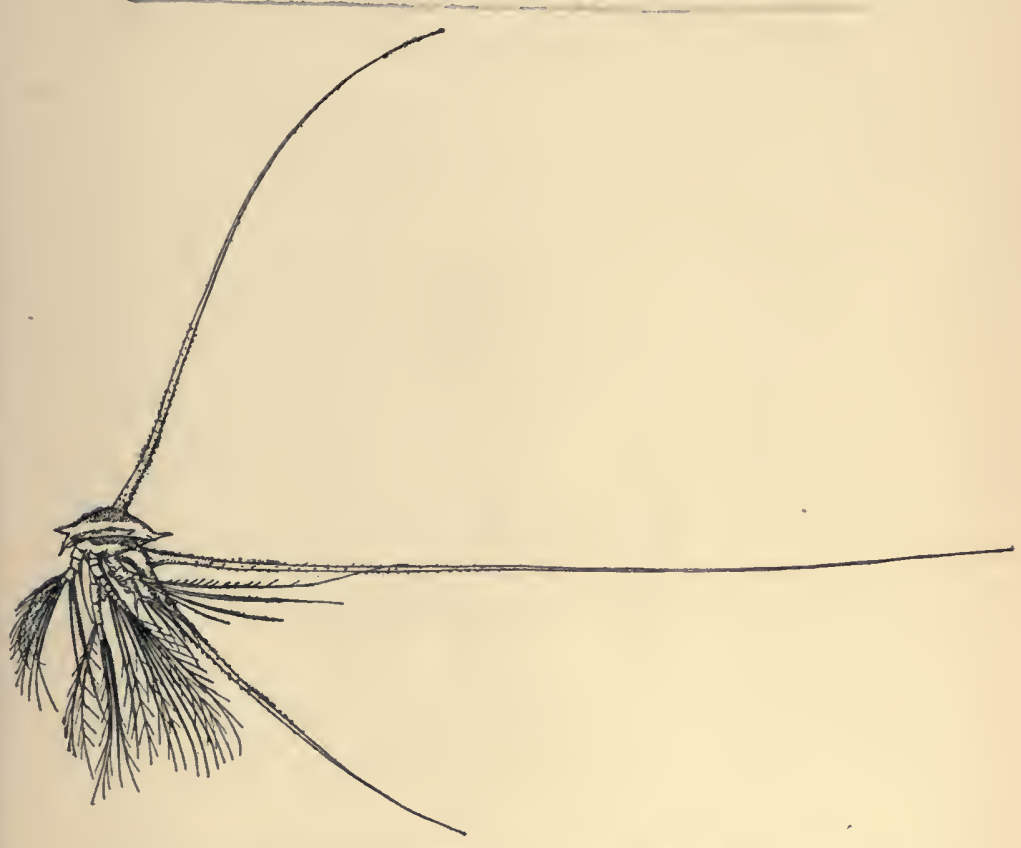

Fig. 5i-The Nadplius Larva of a Species of Barnacle of the Family LePadide, SHOWiNg GREatLy-deVEloped SPINES. From a Specimen taken in the Atlantic Ocean, near Madeira. $\times$ I I. (After Chun.)

drops rapidly if it is rolled into a ball between the fingers. This is, no doubt, one function of the spines with which plankton Crustacea, and particularly larvæ, are frequently provided, though they 
may also serve in some cases as a protection against enemies. The spines have been already alluded to in describing the various larvæ, but it may be noted here that they are most strongly developed in larvæ which live in the open ocean; for example, the most elaborately armed of all Decapod larvæ are the zoëa stages of Sergestes (Fig. 50), which, like the

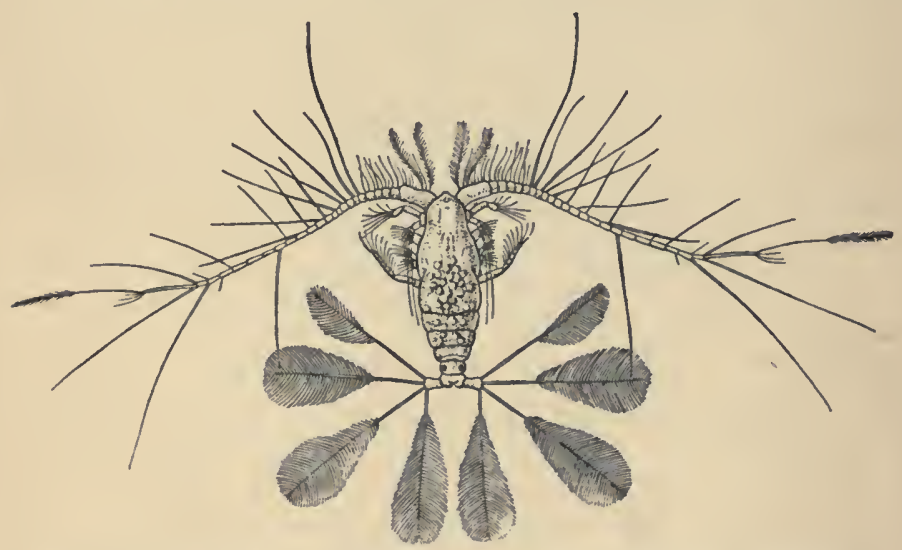

Fig. 52-Calocalanus pavo, One of The Free-swimming Copepoda. of the Plankton. Enlarged. (From Lankester's "Treatise on Zoology," after Giesbrecht.)

adults, belong to the oceanic plankton. The nauplius larvæ of Cirripedes are all more or less spiny, and the spines reach an exaggerated development in the larvæ of the genus Lepas (Fig. 5I), of which the adults are attached to floating drift-wood or the like, and belong to the oceanic fauna, although hardly to be classed with the plankton. 
The large feathered bristles that decorate the limbs or tail of many plankton Copepoda have no doubt the same function in assisting flotation. In the genus Calocalanus (Fig. 52), for example, the tail setæ are large and brilliantly coloured feathery plumes, and in one species, C. plumulosus, one of these setæ is of relatively enormous size, five or six times as long as the body of the animal itself.

Among the most singular of plankton Crustacea are the Phyllosoma larvæ (see Fig. 28, p. 72) of the Spiny Lobsters and their allies (Scyllaridea), which have been already described. These larvæ are sometimes found far out at sea, and it seems likely that their larval life is unusually prolonged, and that they may be drifted to great distances by ocean currents. At all events, they are well adapted for pelagic life, since the broad flat body, hardly thicker than a sheet of paper, can be sustained in the water like a "hydroplane" by comparatively slight efforts of the swimming legs.

The watery character of the body, together with the thinness of the exoskeleton, helps to explain the glassy transparency which is a feature of most plankton Crustacea. This transparency has been regarded as a protective adaptation rendering the animals inconspicuous in the water, and it has indeed that effect to human eyes, but it is very doubtful whether the animals derive much benefit from this. Many of the animals-such as Herring 
and other pelagic fishes-that prey upon plankton Crustacea appear to swallow them in bulk, without much selection; and the Greenland Whale, as it swims open-mouthed through the sea, is not likely to be guided by the greater or less visibility of the Copepods that it sifts out on its baleen plates. Further, this glass-like transparency is by no means universal, for many plankton Copepoda are brightly coloured. In some, as in the beautiful blue Anomalocera, common in British waters, the colour is due to pigment in the fluids and tissues of the body; in others the feathery hairs on the body and limbs show brilliant metallic colours, produced, like the colours of a peacock's feather, not by pigments, but by the diffraction of light in the texture of the organ. The most beautiful of all Copepoda is Sapphirina, in which the surface of the body absolutely sparkles with iridescent colours.

The striking phenomenon known as the "phosphorescence of the sea " is familiar to every ocean voyager, and is seen from time to time on our own coast. On a dark night the crest of every wave often seems to break in a pale glow, the wake of the vessel is a trail of light, and an oar dipped in the water seems on fire. This luminosity is due to the animals of the plankton, largely to the lowly Protozoa and the jellyfishes, but in part also to certain Crustacea. A number of pelagic Copepoda have been shown by Giesbrecht to secrete, from 
special glands on the surface of the body, a substance which becomes luminous on coming in contact with the water. Even specimens which had been dried were found to give out light on being wetted. Some pelagic Ostracods of the family Halocypridæ have been observed to emit clouds of a luminous secretion from a gland in the neighbourhood of the mouth. A similar habit has been seen, as already mentioned, in certain deep-sea Prawns and Mysidacea, which may perhaps belong to the deeper part of the mesoplankton rather than to the bottom fauna. The complex light-producing organs of the Euphausiacea have already been described in dealing with deep-sea Crustacea. A great many species of this group, however, are members of the epiplankton, and in these the phosphorescent apparatus is quite as fully developed as in species coming from greater depths. Meganyctiphanes norvegica (Fig. 24, p. 56), which is one of the largest of the Euphausiacea, is common at no great depths in many places in British seas. If a jar of sea-water in which specimens of this species are swimming be brought into a dark room, a tap on the glass will cause the photophores to flash. out like a row of tiny lamps along the side of the body. After shining for a few seconds the light dies out, to appear again if the tapping be repeated.

There are certain peculiarities in the structure of the eyes in some plankton Crustacea which suggest that the sense of sight is of special importance to 
their possessors, although we can hardly do more than guess at their special significance. Most Copepoda have only a single eye in the middle of the head, corresponding to the single eye of the nauplius larva, and of far simpler structure than the paired compound eyes of most other Crustacea. In many plankton species, however, this simple eye becomes much enlarged and complicated in various ways. The three parts of which it is normally made up may become separated from each other, and are sometimes increased in number to five, while lenses serving to concentrate the light are often developed by thickening of the overlying cuticle. The most elaborately constructed eyes are found in the family Corycæidæ. In Copilia (Fig. 53) a pair of eyes of relatively enormous size are present. Each has in front a large biconvex lens set at the end of a conical tube which extends backwards to a smaller lens (like a telescope with object-glass and eyepiece), behind which, again, are the sensory cells, corresponding to the retina, enclosed in a tube of dark pigment, the whole apparatus being more than half the length of the body. These eyes, although paired, do not correspond to the paired compound eyes of other Crustacea, but have arisen by the separation and enlargement of two of the three divisions of the typical median Copepod eye.

A peculiarity of the paired compound eyes found in plankton Crustacea of several different orders 
consists in the division of each eye into two parts, which differ in structure. In many Euphausiacea and Mysidacea, especially in those haunting the

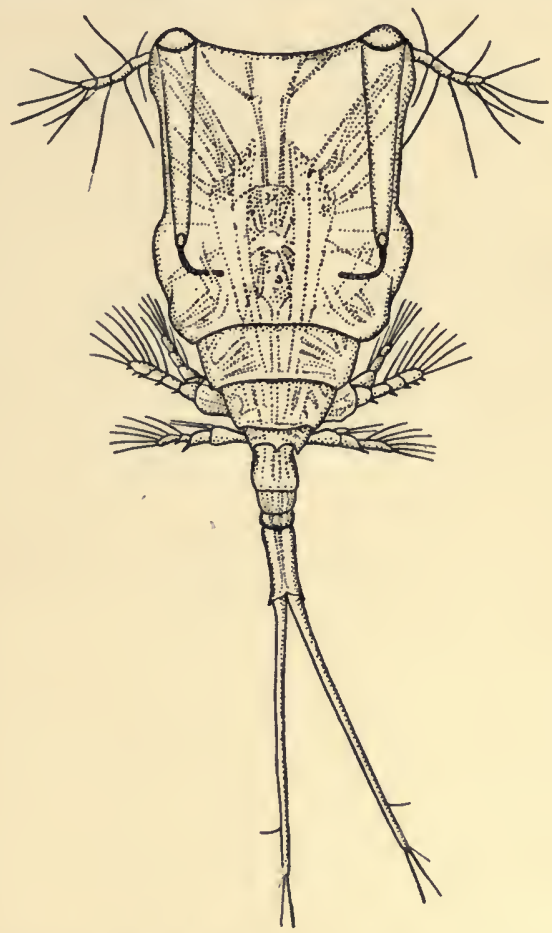

Fig. 53-Copilia quadrata (Female), A Copepod of the Family Coryceide, Showing the Pair of LARGe "Telescopic" Eyes. $\times$ 20. (After Giesbrecht.)

deeper strata (mesoplankton), this division of the eyes is well marked, a frontal or dorsal part having the separate elements of the eye (ommatidia) greatly 
lengthened and with reduced pigment, while the lateral part is of more normal structure. It seems probable, from the researches of Professor Chun, that the fronto-dorsal division is adapted for the perception of very faint light, while the lateral division will give a more accurate image of brightly illuminated objects.

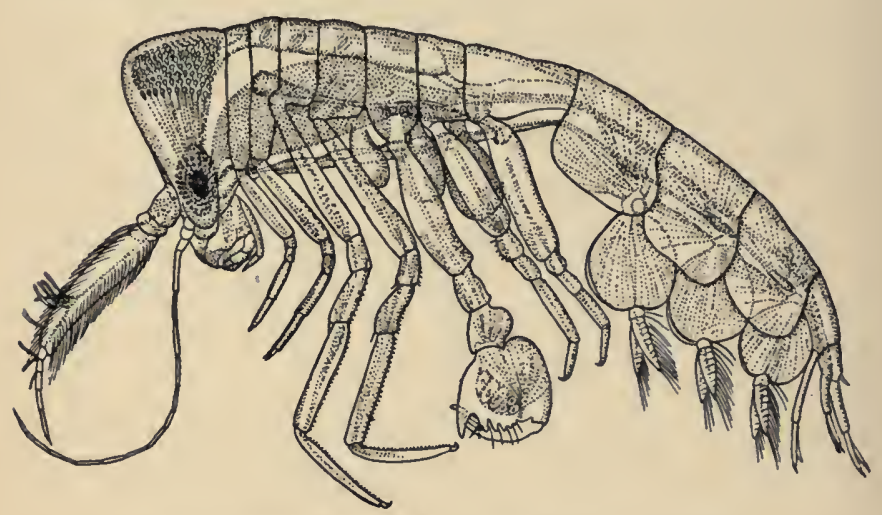

Fig. 54-Phronima colletti, Male. From a Specimen taken in Deep Water near the Canary Islands. $x$ 12. (After Chun.)

In the pelagic Amphipoda, forming the suborder Hyperiidea, the eyes are of very large size, generally occupying almost the whole surface of the head, and giving the animals a very characteristic appearance, in contrast to the small-eyed, bottom-living Gammaridea. In the family Phronimidæ (Fig. 54) the eyes are each divided into two parts, differing in structure in the way just described. 



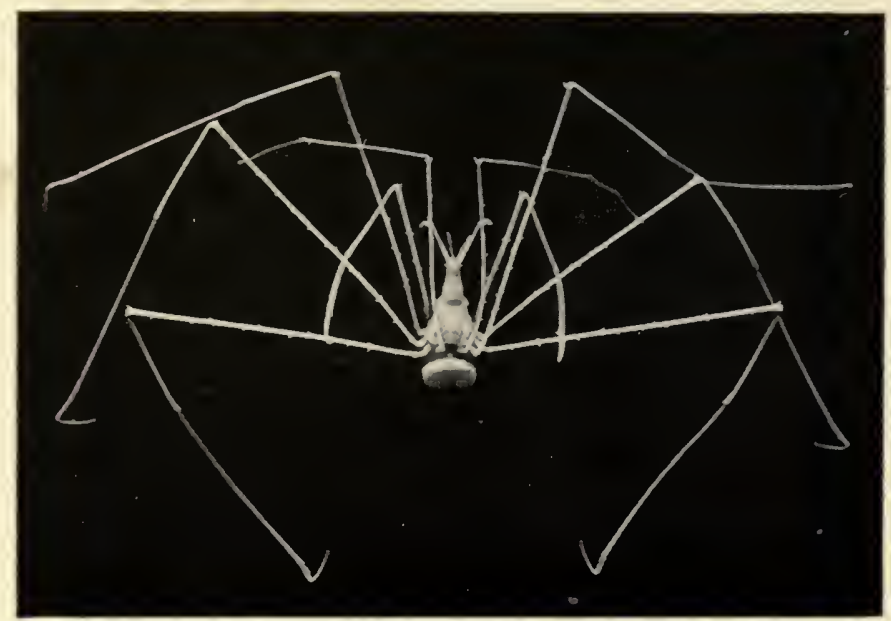

Latreillia elegans, ONE OF THE DROMIACEA WHICH RESEMBLES A SPIDER-CRAB. FROM THE MEDTTERRANEAN. (NATURAL SIZE)

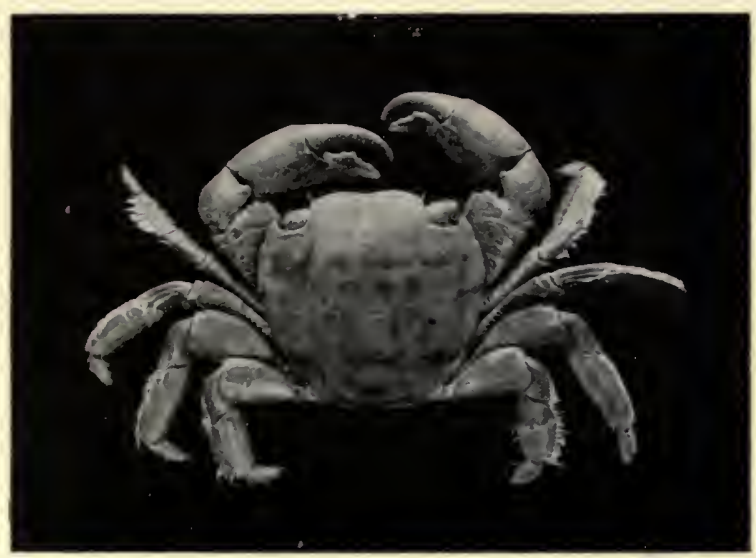

THE GULF-WEed CRAB, Planes minutus. (St.IGHTLy ENI.ARGed) 
There are a few Crustacea living habitually on the high seas which cannot be reckoned as belonging either to the true plankton or to the necton, since they depend on outside help for keeping themselves afloat. Among these are the Barnacles which cluster on logs of drift-wood, and are among the most important causes of the "fouling" of ships' hulls on long voyages. The stalked Barnacles of the genus Lepas are especially common in such situations, and the characters of their larvæ have been already alluded to. Certain species of sessile Barnacles are constantly found attached to large marine animals. For example, Chelonobia adheres to the shell of Turtles, while Coromula and some allied genera are found on Whales.

The little "Gulf-weed Crab" (Planes minutusPlate XIX.) is found clinging to floating drift-weed nearly everywhere throughout the temperate and tropical seas of the globe, and is especially common in the area known as the Sargasso Sea, in midAtlantic. It is occasionally drifted to the south coasts of the British Islands. In Sloane's "Natural History of Jamaica," published in I707-I725, it is stated of the Gulf-weed Crab that "Columbus, finding this alive on the Sargasso floating in the sea, conceived himself not far from some land, on the first voyage he made on the discovery of the West Indies."

A few other Crustacea also form part of the 
peculiar fauna which is associated with the Sargasso weed, notably a swimming Crab, Neptumus sayi, and two or three species of Prawns. All of these are coloured olive-green, like the weed among which they live. 


\section{CHAPTER VIII}

CRUSTACEA OF FRESH WATERS

THE Crustacean fauna of fresh water is much I less rich and varied than that of the sea. Although the number of individuals in a pond or lake may be enormous, they will be found to belong to a comparatively small number of species. All the subclasses of Crustacea with the exception of the Cirripedia have representatives in fresh water, but in most of them only a very few of the families and genera comprise truly fresh-water species. In spite of the comparative poverty of the fauna, however, it is of very great interest, more especially with regard to the problems of geographical distribution; and the ease with which specimens may be collected everywhere, and kept in small aquaria, renders it a particularly attractive subject of study for the amateur naturalist.

The general uniformity of the fresh-water fauna throughout the world has often been remarked. Darwin says: "When first collecting in the fresh waters of Brazil, I well remember feeling much 
surprise at the similarity of the fresh-water insects, shells, etc., and at the dissimilarity of the surrounding terrestrial beings, compared with those of Britain." This uniformity is well illustrated by many of the smaller Crustacea. In a gathering of Cladocera, Copepoda, and Ostracoda, from Central Africa or from Australia, we find that most of the genera, and even some of the species, are identical with those found in similar situations in this country. It is by no means the case that all the species and genera are thus universally distributed, for there are many, especially among the larger forms, which have a very restricted range; but this does not render less striking the general uniformity of the fauna over very wide areas.

When we consider the physical environment of fresh-water animals, it seems at first sight as if this wide distribution were the reverse of what might have been expected, for the area occupied by them is far more discontinuous than in the case of terrestrial or marine animals. The inhabitants of a pond or lake are to a great extent isolated; and although they may spread to other ponds and lakes by way of communicating streams or rivers, where these are not too swiftly flowing and are not interrupted by falls, yet direct passage from one river system to another is rarely possible. Further, since practically the whole of the fresh water on the surface of the globe is constantly flowing, more or less rapidly, 
towards the sea, the smaller feebly swimming forms tend to be swept down with the current, and ultimately carried to perish in the sea. It follows that only those forms which possess special adaptations for dispersal are able to flourish in fresh water. In many cases, as will be described below, the eggs of the smaller Crustacea can survive being dried up, and in this state they may be blown about by wind or carried to great distances in mud, adhering to the feet of migratory wading birds. Darwin says: "The wide-ranging power of fresh-water productions can, I think, in most cases be explained by their having become fitted, in a manner highly useful to them, for short and frequent migrations from pond to pond, or from stream to stream, within their own countries; and liability to wide dispersal would follow from this capacity as an almost necessary consequence" ("Origin of Species," sixth edition, chapter xiii.). In accordance with this, we find that it is just those groups of Crustacea which show these adaptations for dispersal that are most universally distributed in fresh water. On the other hand, the larger Crustacea, like the Crayfishes and River Crabs, which cannot so easily be transported from one locality to another, have as a rule a more restricted range. These larger forms, from their size and powers of swimming or creeping, can make their way upstream and spread throughout a river system, and in some cases they can leave the water 
and journey for short distances overland. On the other hand, since free-swimming larvæ would be liable to be swept out to sea, most of them have a direct development, the young only leaving the protection of the mother when they have attained the form and habits of the adult. When all these factors have been taken into account, however, there still remain many cases where the distribution of individual species or of groups is hard to explain, and shows indications of dating from a time when the outlines of continents and the connections of river systems were different from what they are now.

Before proceeding to mention some of the more characteristic forms of fresh-water Crustacea, it should be mentioned that in large lakes, as in the sea, we can distinguish a littoral fauna in the shallow waters close to the shore, a plankton fauna of the surface waters, and a deep-water fauna. The littoral fauna does not differ in general characters from that found in smaller ponds and gently-flowing rivers; the plankton comprises many peculiar species showing adaptations for flotation, as in the case of the marine plankton; and the deep-water fauna is very poor in species and in individuals, and shows some relations with the subterranean fauna to be mentioned later.

Of all the subclasses of Crustacea, the Branchiopoda are the most characteristically fresh-water animals, only a few Cladocera being found in the 
sea, and some Anostraca in salt lakes and brine pools.

The larger Branchiopoda (Anostraca, Notostraca, and Conchostraca) are generally found in small, shallow ponds which are liable to be dried up in summer. The "Fairy Shrimp" (Chirocephalus diaphanus; see Fig. Io, p. 35) has been found in swarms in the water standing in deep cart-ruts in a country lane in England, and Apus sometimes appears suddenly in rain-water puddles of a few square yards in area, which dry up after a few weeks of hot weather. The eggs of these animals, when dried in the mud, may remain dormant for long periods, and many species have been hatched out from samples of dried mud brought by travellers from distant countries. In such a sample from the Pool of Gihon at Jerusalem, it is recorded that the eggs of Estheria (see Fig. II, p. 36) were found to be capable of hatching after being kept dry for nine years. In some species it is said that the eggs will not develop unless they have been first dried, but this is not the case with Chirocephalus. In favourable conditions development takes place very rapidly. Messrs. Spencer and Hall, in describing the Branchiopoda of Central Australia, say: " Certainly not more than two weeks after a fall of rain, and probably only a few days, numberless specimens of Apus, measuring in all about $2 \frac{1}{2}$ to 3 inches in length, were swimming about; and, as not a single one was to be 
found in the water-pools prior to the rain, these must have been developed from the egg."

From what has been said, it is apparent that the larger Branchiopoda are particularly well fitted to be distributed by the agency of birds, and this is no doubt the explanation of the way in which many of the species suddenly appear in localities where they were previously unknown, and, after swarming for a longer or shorter time, sometimes for several successive seasons, as suddenly vanish. A striking example of this is afforded by Apus cancriformis (see Plate II.), which formerly occurred in several localities in the South of England, and appears more or less irregularly in many parts of the Continent of Europe. No British specimens had been recorded for over forty years, and the species was believed to be extinct in this country, when it was found in 1907 by Mr. F. Balfour Browne in a brackish marsh near Southwick, in Kirkcudbrightshire. It can hardly be supposed that so large an animal as Apus, and one so easily recognized, would have escaped notice altogether had it occurred regularly in any part of the British Islands. It is much more probable that the Scottish specimens found in 1907 had developed from eggs accidentally transported by some bird from the Continent. In I9o8 a careful search in the same locality failed to reveal a solitary specimen.

The Anostraca and Notostraca usually swim with 
the back downwards. Particles of mud and of animal and vegetable matter are drawn by the currents produced in swimming, into the ventral groove between the pairs of feet, and are passed forwards to the mouth to serve as food. Some species of Conchostraca are said to swim in the same inverted position; but Messrs. Spencer and Hall, in the memoir already quoted, state that the Australian Conchostraca swim back uppermost. They attribute the difference in habit between the Conchostraca and Notostraca to the fact that in the former group the valves of the shell can be rapidly closed to protect the soft and vulnerable appendages, while no such protection is possible in the Notostraca. They found on one occasion a specimen of Apus (Notostraca) attacked by three Water-beetles, which were tearing its soft appendages, and they suppose that $A$ pus generally escapes such attacks by swimming upside down.

The breeding habits of the Branchiopoda are also of interest, from the prevalence in many species of reproduction by unfertilized eggs, or "parthenogenesis." This may go on for many generations, and in Apus, for instance, it is possible to examine thousands of specimens before finding a single male, although, for some unexplained reason, males are sometimes comparatively common. It is probable that males must appear sooner or later, otherwise the series of parthenogenetic generations will come to an end; but it is not certain that this is the 
case, and there are some species of Conchostraca of which the males have never been seen.

The genus Artemia (Fig. 55), among the Anostraca, is peculiar in its habitat; for, while most of the

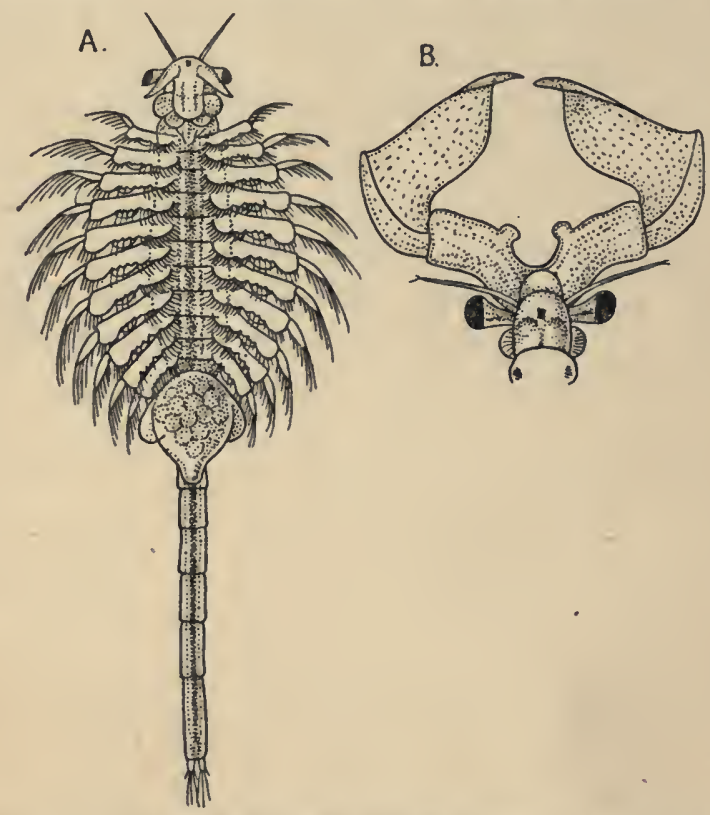

Fig. 55-The Brine Shrimp (Avtemia salina). (After Sars.)

$A$, Female, under-side, $\times 6 ; \mathrm{B}$, head of male, upper side, further enlarged, showing the large clasping antennæ. The larval stages of this species are shown in Fig. 33, p. 8I

Branchiopoda inhabit fresh or brackish water, it flourishes in concentrated brine. In the South of Europe it is found, as it was formerly in England, in the shallow ponds in which sea-water is exposed 
to evaporation for the manufacture of salt, and in these it occurs in such numbers as to give the water a reddish colour. It is also found in salt lakes, like the Great Salt Lake of Utah, in the United States, and in many other parts of the world. The specimens from different localities often differ considerably, especially in the form of the tail-lobes; but it has been shown that these differences are more or less directly correlated with the degree of salinity of the water in which the animals live, and it is probable that the forms which have been described are all variations of a single cosmopolitan species ranging from Greenland to Australia, and from the West Indies to Central Asia. Artemia is the only one of - the Anostraca that is known to be parthenogenetic, some colonies consisting entirely of females, while in others males are abundant. The reddish colour above alluded to is found also in Branchipus, Apus, and other Branchiopoda, and is due, as Sir Ray Lankester first showed, to the presence in the bodyfluids ot hæmoglobin, the red colouring matter of the blood of Vertebrates, which is important in the process of respiration.

The smaller Branchiopoda known as "Water-fleas," forming the order Cladocera, are abundant everywhere in fresh water. Daphnia pulex and other speces of the genus, and the little Lynceidæ, of which Chydorus spharicus (Fig. 56) is the commonest species, are to be found in ponds and ditches, and 
often swarm in farmyard ponds where the water is foul with decaying matter. In most gatherings from such localities only female specimens will be found, and nearly all of these will be seen to carry a cluster of eggs or of developing embryos in the "broodchamber" between the back part of the body and the shell. In Daphnia pulex (see Fig. 12, p. 37) a single brood may consist of

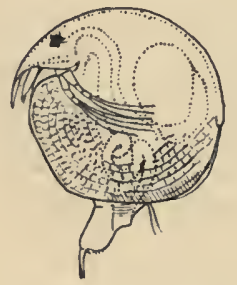

Fig. 56-Chydorus spharicus, A COMMON SPECIES OF WATERFLEA. $\times$ 50. (After Lilljeborg.) thirty young, and occasionally of more than twice that number. As the broods may succeed each other at intervals of two or three days, it will be seen that the multiplication of the species in favourable circumstances may be exceedingly rapid. It has been calculated that in sixty days the progeny of a single female might amount to about $13,000,000,000$. In addition to these parthenogenetic eggs, which hatch at once while still within the brood-chamber, the Cladocera produce, at certain seasons, another kind of egg which requires to be fertilized by the male before it will develop. These eggs are dark in colour and are enclosed in a thick shell, and they do not hatch at once, but are cast off when the shell of the female is moulted. Very commonly these " resting eggs," as they are called, are produced in the autumn and lie dormant until the following spring, and they can 
survive drying or freezing without injury, while the thin-shelled parthenogenetic eggs within the broodchamber of the mother are easily killed. In addition to having thick shells, the resting eggs are further protected in most, but not in all, cases by the moulted carapace of the parent, which is specially thickened for the purpose. This modification of the carapace is most highly developed in the family Daphniidæ (Fig. 57), where a saddleshaped area on the dorsal side, known as the "ephippium," becomes thickened, and on moulting separates from the rest of the carapace to form a compact case enclosing the two resting eggs. The outer wall of the ephip. pium is divided up into small

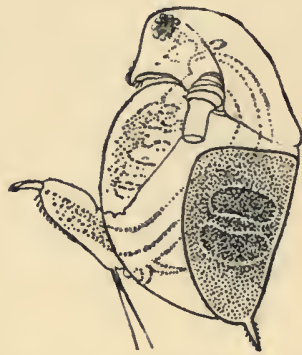

Fig. 57-A Water-Flea, (Daphnia pulex), FEMALE, WITH EPHIPPIOM CONTAINING Two "RESTING EgGs." × 20. (Partly after Lilljeborg.)

The Antenna is cut short. Compare Fig. 12, p. 37. hexagonal cells, which become filled with air, causing the ephippium to float at the surface of the water. In this position the ephippia readily become entangled in the feathers of birds, and in some cases the shell is provided with spines or hooks, which facilitate transport to other localities by such means. The appearance of males and the production of ephippial eggs-in other words, the "sexual period" -is generally more or less restricted to one season 
of the year. In most species, particularly in those which live in lakes, the sexual period occurs in the late autumn, and the ephippial eggs lie dormant during the winter, and hatch in the spring. In species living in small ponds exposed to the risk of overheating or of drying up during summer, there is often a distinct sexual period in the spring, when ephippial eggs are produced to tide over the unfavourable conditions of the warmer months of the year. Although no species is known to be exclusively parthenogenetic, yet it appears that purely parthenogenetic colonies of certain species may be found in favourable localities, where they may reproduce from year to year without males ever being found.

Certain species of Cladocera belong to the plankton of lakes and large ponds, and show modifications which adapt them for a floating life. Some of these belong to the genus Daphnia, and differ from the species found in other situations by their glassy transparency. As in the case of many marine plankton Crustacea, this transparency is probably due to the thinness of the shell and to the general watery condition of the body, giving the necessary buoyancy to enable the animal to remain constantly afloat. The same effect is no doubt produced by the long terminal spine of the carapace and by the great helmet-shaped crest into which the upper part of the head is often produced: A form very characteristic of the plankton of large lakes is Bythotrephes 
(Fig. 58), which is found in the lakes of Scotland, Ireland, Wales, and the Lake District of England. In Bythotrephes the carapace does not enclose the body, but is reduced to a small brood-sac; the addomen, however, is drawn out into a long spine, which may be two or three times as long as the body. A further point of interest is the division of the eye into a dorsal and a ventral portion, differing

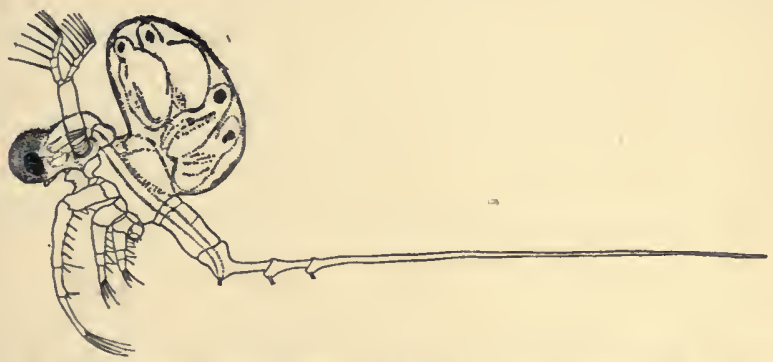

FIG. 58-Bythotrephes longimanus, FEMALE, WITH EMBRYos IN THE BROOD-SAC. $\times$ I2. (After Lilljeborg.)

in structure in much the same way as do the two divisions of the eyes in certain marine plankton Crustacea (see p. 152). Another very remarkable lacustrine form is Leptodora, the largest of all the Cladocera, being sometimes more than half an inch in length. In this case also the carapace is very small, and does not enclose the body. The swimming antennæ are very large, and the abdomen is long and divided into several segments.

Leptodora is further remarkable on account of its mode of development. The parthenogenetic eggs, 
as in other Cladocera, develop directly, but the resting eggs give rise to larvæ of the nauplius type.

Holopedium, which is found in similar situations, surrounds itself with a mass of a jelly-like substance which it secretes. A similar envelope of jelly is found in some marine plankton animals, though not, so far as is known, in any Crustacea, and it no doubt serves to give buoyancy to the animal.

The Copepoda of fresh water are as abundant and universally distributed as the Cladocera. Species of the genus Cyclops (see Fig. I4, p. 39), easily recognized by the pear-shaped body and the two egg-packets carried by the female, are to be found in almost every pond and ditch. The genus Canthocamptus comprises species of smaller size, with slender, flexible body, and carrying only a single egg-packet. The plankton of lakes and ponds includes species of Diaptomus (Fig. 59), which have a narrow body and very long antennules. The latter are held out stiffly while the animal swims by rapid movements of the antennæ and mouth parts, making occasional sudden leaps by means of its oar-like feet. In this genus also the egg-packet is single. The development can easily be studied by keeping eggcarrying females of Cyclops in a jar of water, when the nauplius larvæ will soon hatch out.

Although the Copepoda, unlike the Cladocera, are not parthenogenetic, it has been found that certain species of Diaptomus produce resting eggs capable of 


\section{CRUSTACEA OF FRESH WATERS}

surviving freezing or drying. In the early part of the breeding season the eggs have thin shells, and they hatch after a short time. In the autumn, however, thick-shelled eggs are produced, which lie dormant in the mud until the following spring. It has recently been discovered that species of Cyclops and Canthocamptus pass through a resting stage, in

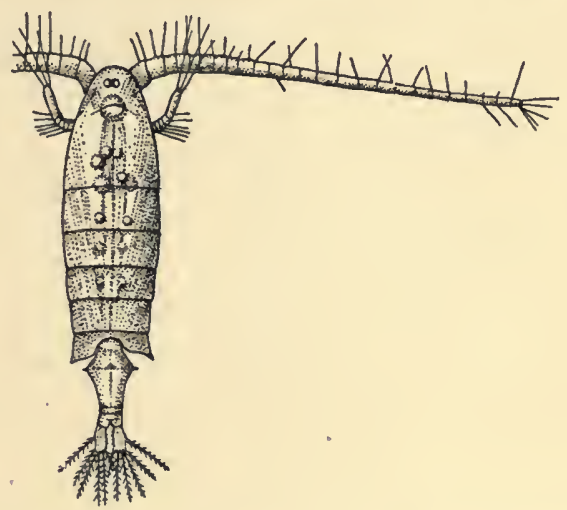

Fig. 59-Diaptomus cceruleus, Female. $\times$ 25. (After Schmeil.)

which the animal surrounds itself with a cocoon-like capsule of mud held together by a glutinous secretion produced by glands on the surface of the body and limbs. The encapsuled animals, in the cases observed, lie dormant in the mud during the summer, to resume active life in the colder months of the year. It is very probable that they can also be dried without injury, and that the "cocoons" 
serve the same purpose as the resting eggs of other species.

Numerous species of Ostracods, belonging to the genus Cypris (see Fig. I3, B, p. 38), and other closely related genera, occur in fresh water. Like the Cladocera, they reproduce largely by parthenogenesis, and the males of many species are rarely found, while in some species they have not yet been discovered. In Professor Weismann's laboratory at Freiburg a colony of Cypris was kept in an aquarium for eight years, and during the whole of that time no males made their appearance, the colony reproducing exclusively by parthenogenesis. Probably in all species the eggs survive drying.

The common "Freshwater Shrimp" (Gammarus pulex), which has already been described, may be taken as a type of a large number of Amphipoda, for the most part closely allied, which are widely distributed in most regions of the world, with the exception of the tropics. G. pulex itself ranges from the British Islands to Mongolia. As the eggs are carried, till they hatch, in the brood-pouch of the parent, and are not known to survive drying, it - is difficult to understand in what way Gammarus and its allies contrive to spread from one locality to another.

The little fresh-water Isopod Asellus aquaticus (Fig. 6o) is common in ponds and canals in this country. It may be recognized by its general resem- 
blance to a Woodlouse, with very long antennæ, and with a pair of long, slender, forked uropods projecting behind. The species is widely distributed in Europe, and other species of the same and closely related genera are found in North America.

In Australia and New Zealand the Isopoda are represented in fresh waters by a very peculiar group

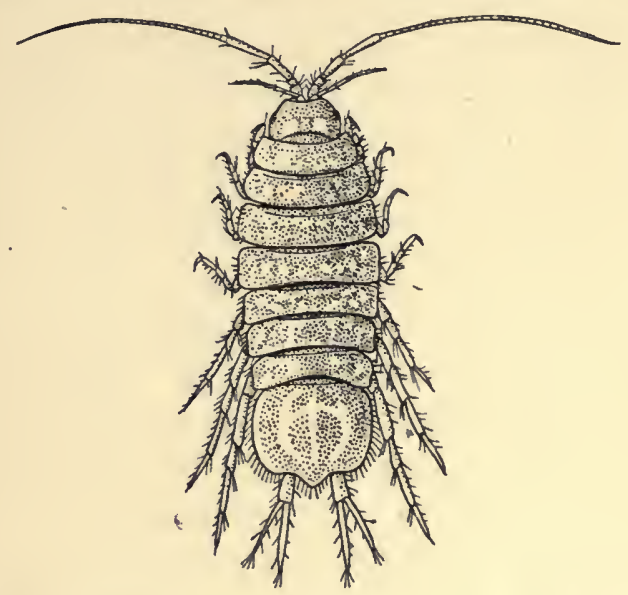

Fig. 60-A sellus aquaticus, Female. $\times$ 4. (After Sars.)

of species, forming the suborder Phreatoicidea, which have more the aspect of Amphipods than of Isopods, since the body is more or less flattened from side to side, instead of from above downwards.

With regard to the mode of distribution of the fresh-water Isopoda, there is the same difficulty as in the case of the Amphipoda, for the eggs are 
carried in a brood-pouch, and do not seem to be in any way protected against drought. It is no doubt in consequence of this that the fresh-water species and genera of both Amphipoda and Isopoda, though widely distributed, do not have the world-wide range of many of the more minute Crustacea described above.

The common Crayfish, Astacus (or Potamobius) pallipes, is the only truly fresh-water Decapod found in England, although a small Prawn, Palamonetes varians, which usually inhabits brackish water, may occasionally be found in places where the water is practically fresh. The structure of the Crayfish is very similar to that of the Lobster, but, as already mentioned, it differs in its mode of development, having no free-swimming larval stage. From its size, and from the fact that the eggs are carried by the female, the Crayfish cannot be transported from one locality to another by the agencies which distribute the smaller fresh-water Crustacea. On the other hand, the adult animals can live out of the water for days, or even weeks, if they are kept moist, and the English species is stated to leave the water occasionally, and to make short excursions on land. Many species found in foreign countries are still more truly amphibious in their habits. It is clear, however, that the means of dispersal of the Crayfishes are very limited, and on this account the problems connected with their geographical distribu- 


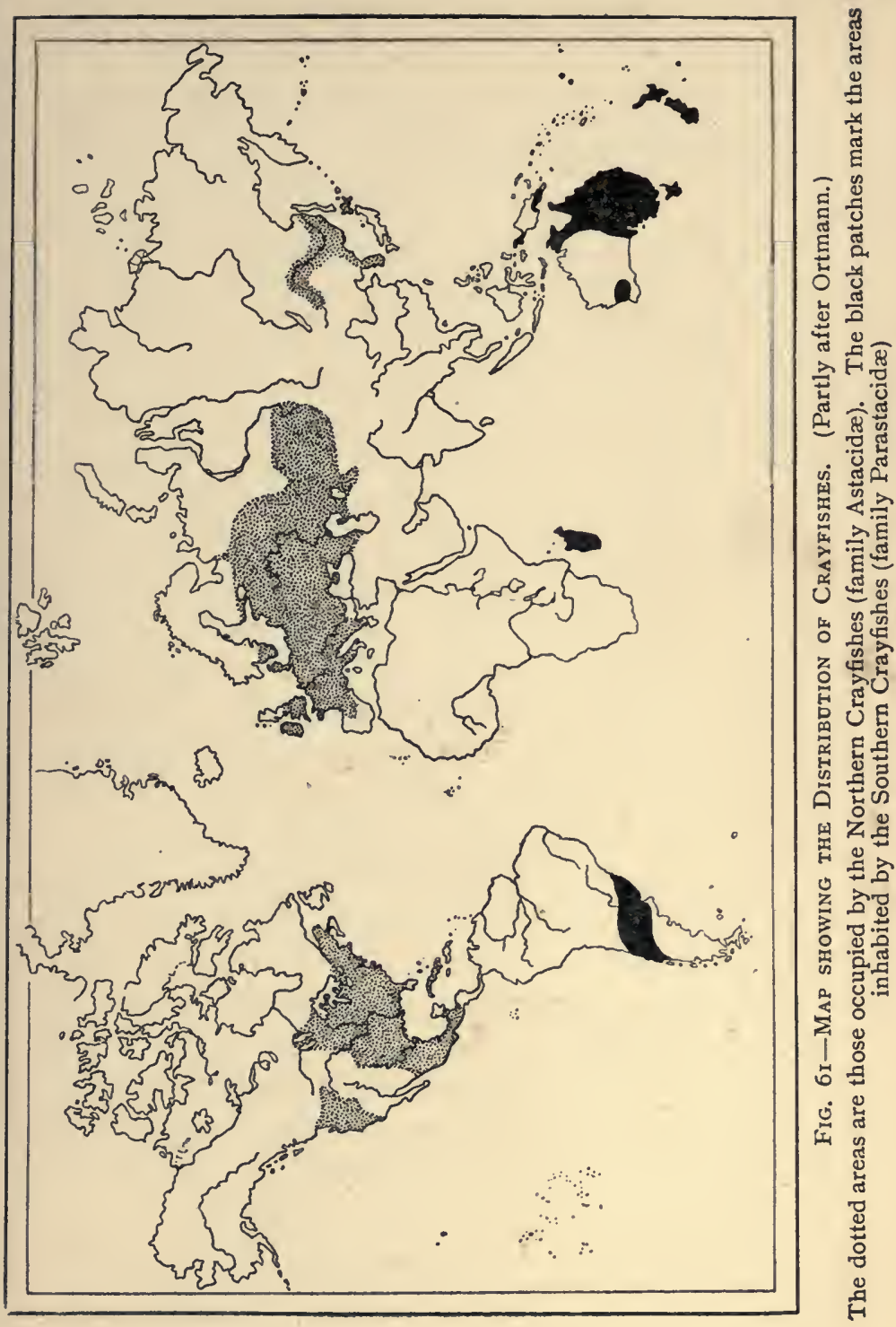


tion are of great interest. An admirable discussion of the subject will be found in Professor Huxley's book on the Crayfish, and the conclusions reached by him have hardly been modified by thirty years of subsequent research. Only a very brief outline can be attempted here.

Crayfishes are found in the fresh waters of the Northern and Southern Hemispheres (Fig. 6I), but in each case they are practically confined to the temperate regions, and are absent from a broad intervening tropical zone. The Northern Crayfishes, forming the family Astacidæ (or Potamobiidæ) are distinguished, among other characters, by having a pair of appendages on the first abdominal somite, at least in the male sex; the Southern Crayfishes have no appendages on that somite, and for this and other reasons are regarded as constituting a distinct family-Parastacidæ. There is thus a general correspondence between the geographical distribution of the Crayfishes and the more important structural differences expressed in their classification. There can be no doubt that the two families have been derived from a common stock of marine lobster-like animals, and it is reasonable to suppose that two branches of this stock became independently adapted to a fresh-water habitat in the North and in the South, giving rise to the Astacidæ and the Parastacidæ respectively.

The distribution of the individual genera is, how- 


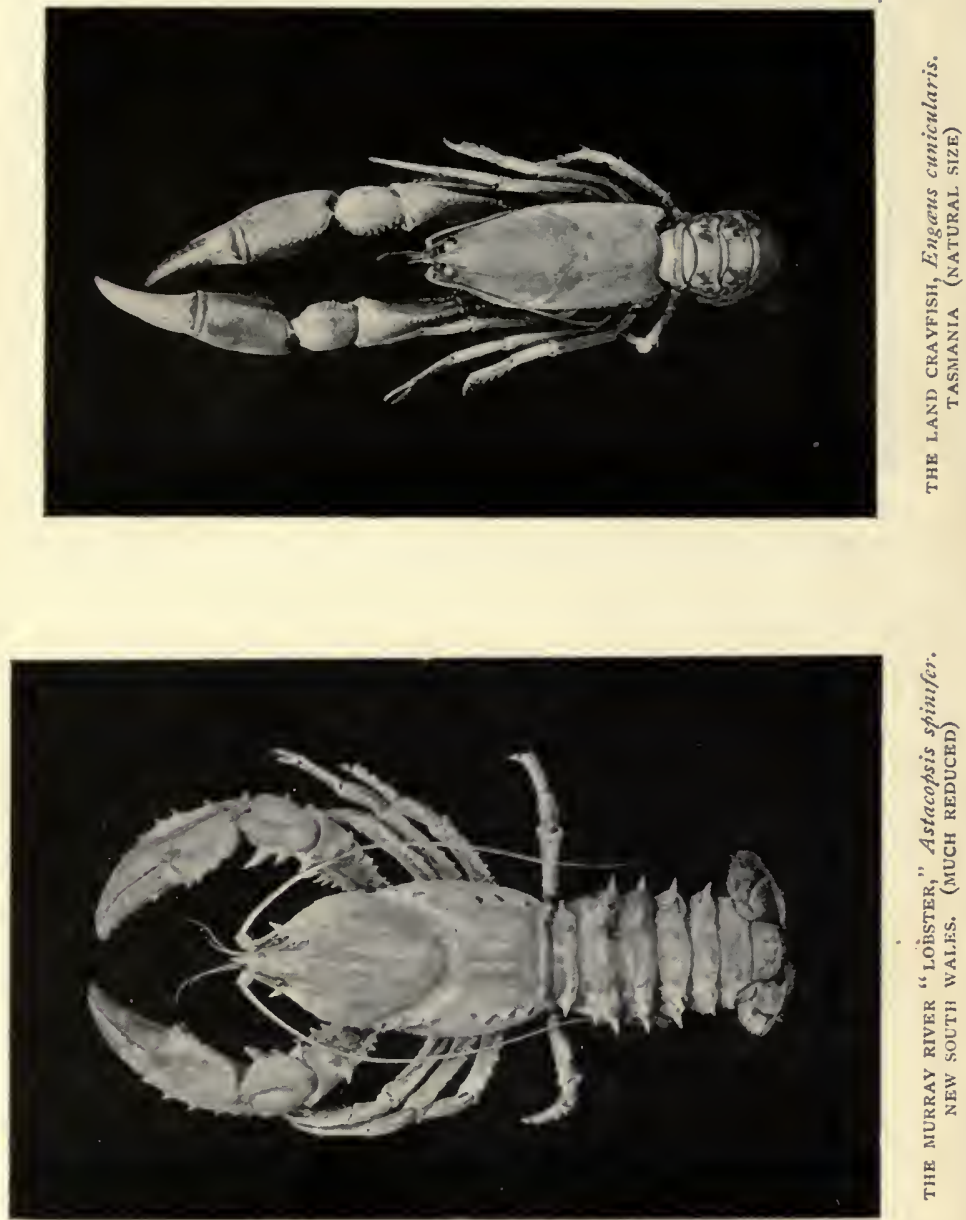
ever, not so easy to understand. The species found in Europe all belong to the genus Astacus, which also penetrates into Asia as far as Turkestan and the basin of the River Obi.

Throughout the greater part of Asia no Crayfishes are found until we come to the Far East, where we find an isolated colony in the river-system of the Amur, in Korea, and in the north of Japan. These far eastern Crayfishes, however, differ so much from the typical species of Astacus that they are now placed in a subgenus (sometimes regarded as a distinct genus), Cambaroides. Curiously enough, the typical genus Astacus reappears again on the other side of the Pacific, where several species occur in that part of North America which lies west of the Rocky Mountains. East of the Rockies, again, numerous species are found belonging to a distinct genus, Cambarus, which ranges from Canada to Central America and Cuba, and this genus is allied in certain respects to the Cambaroides of Eastern Asia. If the systematic relations of these genera have been properly interpreted, it is by no means easy to understand in what way their present distribution' has been brought about.

The Southern Crayfishes have an even more scattered and discontinuous range. In New Zealand the genus Paranephrops occurs, in Australia and Tasmania the genera Astacopsis (Plate XX.), Cheraps and Engaus (Plate XX.). A single species of Cheraps has been re- 
corded from New Guinea, but no Crayfishes are found in any part of the Malay Archipelago, in Southern Asia, or on the continent of Africa, although, curiously enough, a single species of a peculiar genus (Astacoides) is found in Madagascar. In South America species of Parastacus are found in Southern Brazil, Argentina, and Chili. It is evident that these various genera of Parastacidæ, which are now so widely isolated from each other, must have reached their present habitats when the relative distribution of land and sea in the Southern Hemisphere was very different from what it is now. What exactly the nature of the land connection between the various islands and continents was, whether by way of an Antarctic continent or otherwise, is a question that can only be suggested here. To attempt to answer it would involve the consideration of the distribution of many other groups of animals besides Crayfishes.

Before leaving the Crayfishes, it may be mentioned that certain species have become adapted to almost terrestrial habits. A number of species of Cambarus in North America are often found at considerable distances from open water, burrowing in damp earth, their burrows reaching down to the ground-water. In many cases they throw up chimney-like piles of mud at the mouths of their burrows, and in places their chimneys are so numerous as to "hamper farming operations by interfering with the harvesting machines, clogging and ruining them." The species 



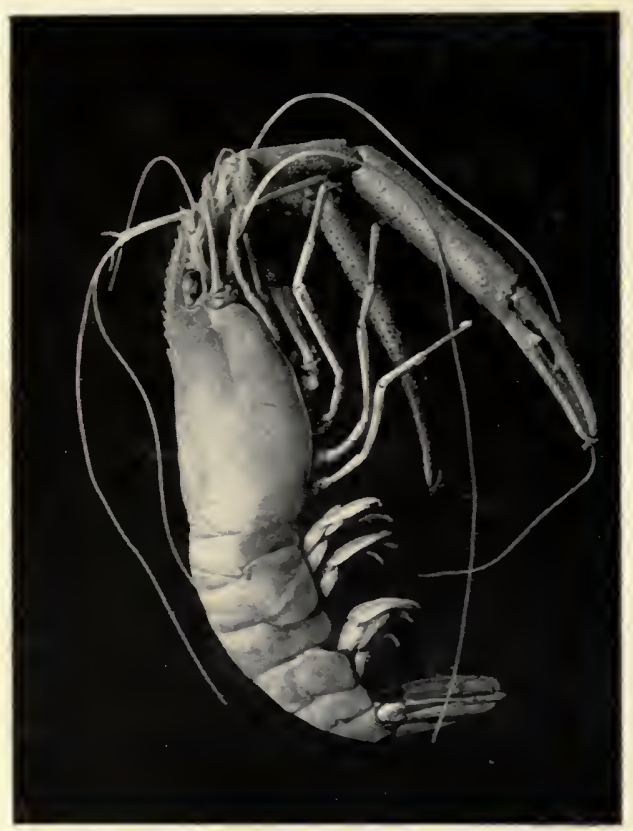

 
of Engaus (Plate XX.), found in Tasmania, are there known as "Land Crabs," and burrow in marshy places and in the forests up to an elevation of 4,000 feet.

The broad equatorial belt which separates the regions inhabited by the Northern and the Southern Crayfishes is characterized by the presence of several other groups of fresh-water Decapoda. The large River Prawns, which are found nearly everywhere within the tropics, belong to the genus Palamon (Plate XXI.), which is very closely related to the common marine Prawns (Leander) of our own coasts. Some of these Prawns grow to a foot or more in length of body, and the large claws may measure as much again. From the Crayfishes, for which they are sometimes mistaken, they may be easily distinguished by the fact that the large pincerclaws are not the first, but the second pair of legs. Another widely-spread group of River Prawns, for the most part of small size, is the family Atyidæe (Plate XXII.), in which the two pairs of pincerclaws are feeble, and have the fingers tipped with brushes of long hairs, used in sweeping up minute particles of food from the mud. The distribution of these Prawns presents many difficult problems, as an example of which we may mention the presence of identical or closely related species in the fresh waters of West Africa and of the West Indies.

The Brachyura (or Crabs) include many species 
that live in fresh water. Some of these, like the species of Sesarma (see Plate XXIII.) and some other genera of the family Grapsidæ, are common throughout the tropics, passing up the rivers from the brackish water of estuaries, and being often found long distances inland in quite fresh water. The true River Crabs, however, belong to the family Potamonidæ, and are very common throughout the warmer regions of the globe. One species, Potamon edule (Plate XXIII.), formerly called Telphusa fluviatilis, is found in the South of Europe (Italy, Greece, etc.). Very numerous species, as yet only imperfectly known, occur throughout the whole of Africa, in Southern Asia, and in the Malay Islands, extending to Australia in the south and Japan on the north. In the New World the River Crabs are found in South America, and extend north to Mexico and the West Indian Islands. Many of the River Crabs are amphibious in habits, and may be found burrowing in marshy ground or in damp forests. The young are hatched from the egg with all the appendages developed, and they remain clinging to the abdomen of the mother until after the first moult, when they are perfectly-formed little crabs (see Fig. 3I, p. 78).

The groups which have been mentioned are all characteristic inhabitants of the fresh waters over considerable areas of the surface of the globe. There are, however, in addition to these, certain Crustacea which occur in isolated localities, and have no close 


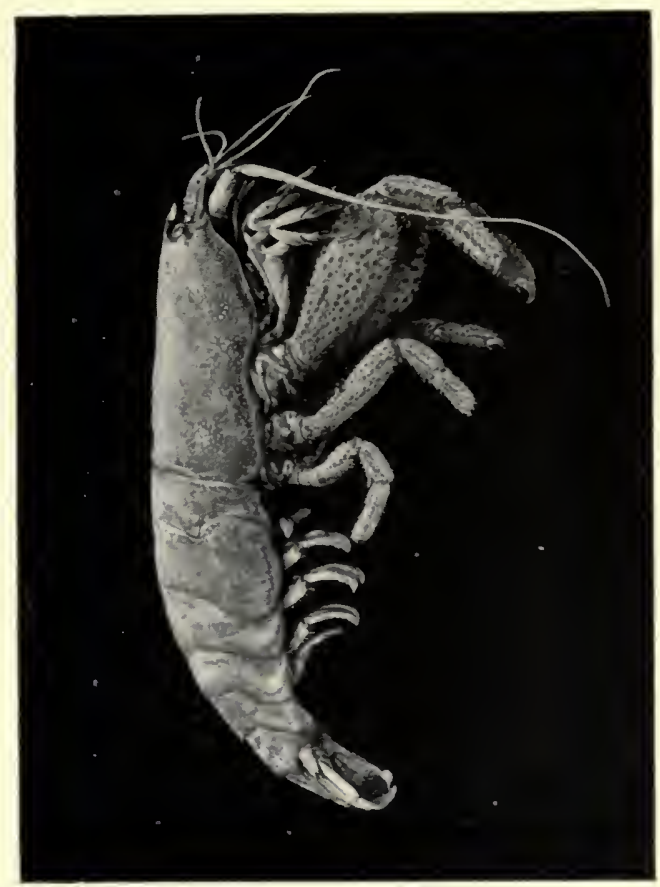

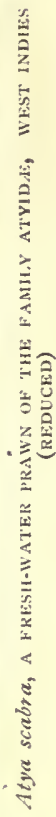





\section{CRUSTACEA OF FRESH WATERS I8I}

allies in fresh waters elsewhere. In the streams of Southern Brazil and Chili there is found a small Crustacean (Eglea levis-Plate XXIV.), not unlike the Galatheas of our own coasts, which is interesting as being the only species of the Anomura found in fresh water. Still more remarkable are the Syncarida, which are represented by two species of "Mountain Shrimps" (see Fig. 84, p. 264) in Tasmania, and by a third species found near Melbourne. These forms have no near allies among living Crustacea, but appear to be related, as will be shown in a later chapter, to certain fossil Crustacea found in Palæozoic rocks.

Belonging to a different category from any of those mentioned are certain Crustacea closely allied to, or identical with, species living in the sea, which inhabit inland lakes where no direct passage from the sea is now possible. Attention was first called to these in the case of some of the large lakes of Sweden, in which Professor Lovén found some Crustacea-Mysis relicta (see Fig. I6, p. 47), Mesidotea entomon, Pontoporeia affinis-almost or quite identical with species inhabiting the Baltic, the Arctic Ocean, and the North Atlantic. There is geological evidence to show that these lakes were once fjords, or arms of the sea, and have become cut. off from communication with the Baltic by gradual elevation of the land. The marine animals which they contained would thus be imprisoned, and as the water became 
less and less salt, by the inflow of rivers, certain species which were able to accommodate themselves to the altered conditions would survive. Some of the species living in the Swedish lakes have since been found to have a wider distribution. Thus, Mysis relicta, which should perhaps be reckoned as only a variety of the Mysis oculata of Arctic seas, has been found in lakes in Russia, North Germany, and North America (Lake Superior and others), and has lately been discovered in Lough Neagh and some other lakes in Ireland.

The brackish waters of the Caspian Sea contain a very remarkable assemblage of animals, including many Crustacea, which, although now quite isolated from the oceans, are certainly of marine, and in part of Arctic, origin. Among these are some species closely allied to or identical with those of the Swedish lakes already mentioned, together with a great variety of species of Mysidacea, Cumacea, and Amphipoda, which appear to have been evolved from marine forms since the Caspian was cut off from communication with the Arctic Ocean.

To such assemblages of animals derived from marine species and isolated in inland lakes the name of "relict" faunas has been given. It is necessary to use caution, however, in extending this explanation of their origin to every case of peculiar lake faunas. For example, there are difficulties in the way of supposing that Lake Baikal was ever in open and 


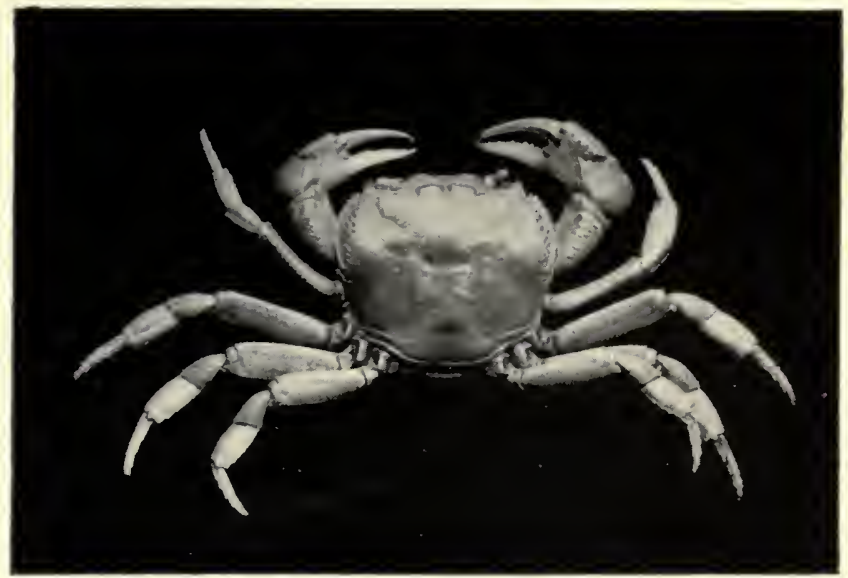

THE RIVER-CKAB OF southers Europe, Potamon edule (or Telphusa fuviatilis) (REDUCED)

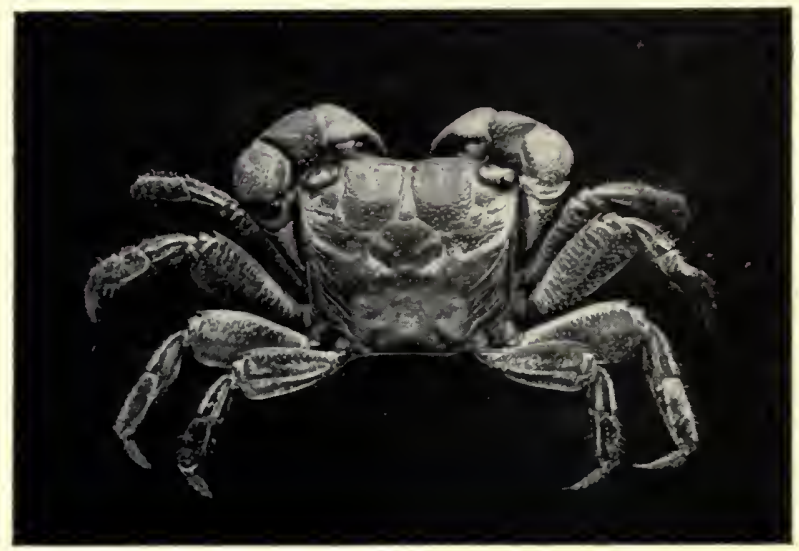

Scsarma chiragra, A FRESHWATER CRAB UF THE FAMILY GRAPSID.E. FRONI BRAZIL. (SLIGHTLY REIULCFD) 

direct communication with the sea, although it contains many animals, such as seals, which are certainly of marine origin. The chief Crustacea of the lake are numerous species of Amphipods belonging to the genus Gammarus, and other genera closely related thereto, and for these, at all events, there is no need to assume a " relict" origin.

One of the most remarkable lakes in the world from a zoological point of view is Lake Tanganyika in Africa. When it was found that this lake contained a fauna very different from that of the other great lakes of Africa, it was rashly assumed that it must be of relict origin, and some remarkable speculations were indulged in as to the former connection between the lake and the sea. Further research, while it has greatly emphasized the peculiar nature of the fauna, has entirely disposed of the view that it originated in this way. The Crabs and Prawns, for example, are not nearly related to marine forms, but belong to groups that are characteristic of fresh waters in the tropics. While Nyassa and the Victoria Nyanza have as yet only yielded a single species of Prawn, and that one of enormously wide distribution (from the Nile to Queensland), Tanganyika contains no fewer than twelve species, all of which are peculiar to the lake, while all except one belong to genera unrepresented elsewhere. Similarly, the Crabs found in the other great lakes of Africa belong to commonplace types of River Crabs of the 
genus Potamon; in Tanganyika, in addition to some of these, there are three species of a remarkable genus, Platytelphusa, not known from any other locality. The Copepoda and Ostracoda of Tanganyika comprise a remarkably large number of species, many of them peculiar to the lake. A most unusual feature is the entire absence of Cladocera. It is not easy to explain the occurrence of this remarkable fauna in Tanganyika, but the evidence from other groups of animals, such as Mollusca and fishes, tends to suggest that the lake must have been, until recently, completely isolated from the other lakes and riversystems of Africa, that it had no outlet, and that the water was consequently more or less brackish. Under these conditions the fauna of the lake, originally similar to that of the other African lakes, has evolved along lines of its own.

A very interesting division of the fresh-water fauna is constituted by those animals which inhabit underground waters. In the South of England there is found not unfrequently in the water of wells a small colourless transparent Amphipod known as the "Well Shrimp " (Niphargus aquilex-Fig. 62), distinguished from the common tresh-water Gammarus by the slenderness of its body, by the elongation of the last pair of tail appendages (uropods), and by the absence of eyes. The proper habitat of Niphargus is not actually in the wells, but in the subterranean reservoirs and streams by which the wells are fed. 


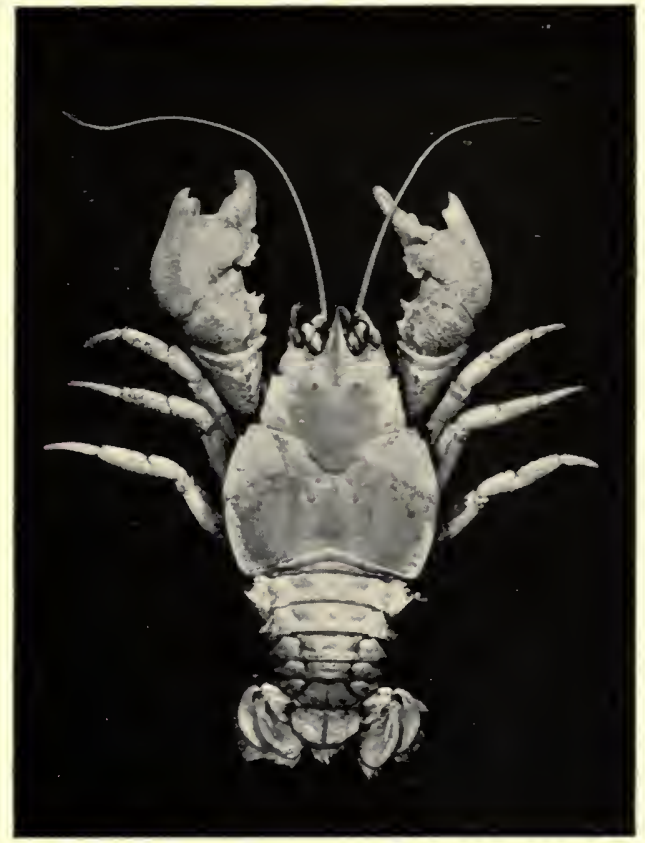

Eglea lavis. South america. (NatUral Size) 



\section{CRUSTACEA OF FRESH WATERS 185}

These subterranean channels intercommunicate over wide areas, and are now known in many parts of the world to contain a peculiar assemblage of animals which become accessible to the naturalist in wells and in the streams and lakes of large caves. Further, the scanty "abyssal" fauna of deep lakes is partly made up of species which enter the lakes by sub-

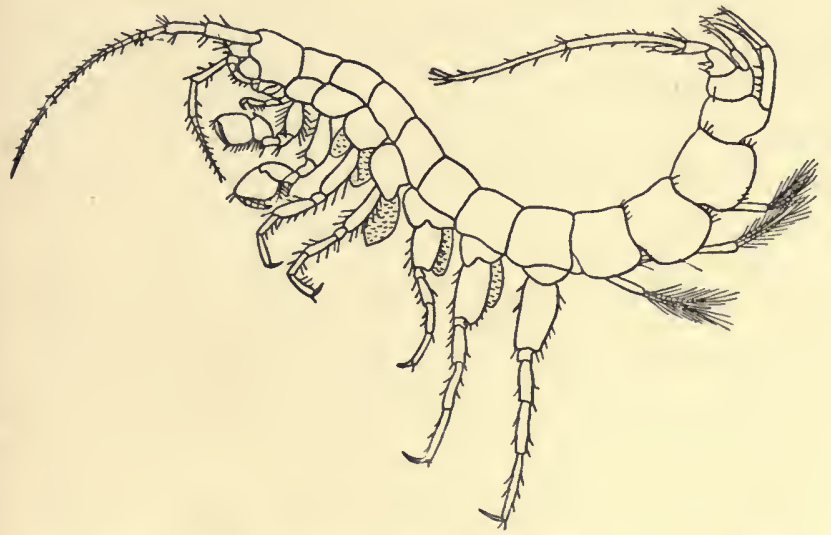

Fig. 62-A Well Shrimp (Niphargus aquilex). $\times$ 7. (After Wrzesniowski.)

terranean channels, and find a suitable habitat in the deep water. Species of Niphargus, for example, have been dredged in Lough Mask in Ireland and in some of the Swiss lakes.

Several species of blind Crayfishes have been found in caves in North America, the best known being one (Cambarus pellucidus-Plate XXV.) found in the Mammoth Cave in Kentucky; and blind Prawns 
belonging to various genera have been discovered in caves in America and Europe.

A very remarkable feature of the subterranean fauna is that a number of the animals appear to be more closely allied to marine species than to any known from fresh waters above-ground. This is especially the case with some of the Isopoda belonging to typically marine families like the Cirolanidæ and Anthuridæ, and it has been suggested that these have been derived from marine species which have entered the underground waters directly from the sea by way of submarine fissures in the crust of the earth.

The environment in which these subterranean animals live resembles that of the deep-sea animals in the absence of light, and the consequent absence of plant-life. They must ultimately depend for food on animal and vegetable débris washed down from the surface, but the food-supply must be scanty, for the water in which they live is usually very clear and free from organic matter. It is not surprising to find that nearly all of them are blind, and the few species provided with visual organs which have been described, from caves, are probably only temporary or accidental immigrants. Whether the degeneration of the eyes is the direct effect of disuse, or is due to natural selection ceasing to keep the eyes up to the standard of usefulness, is a question which has been much debated, and its answer, were we sure of it, would 


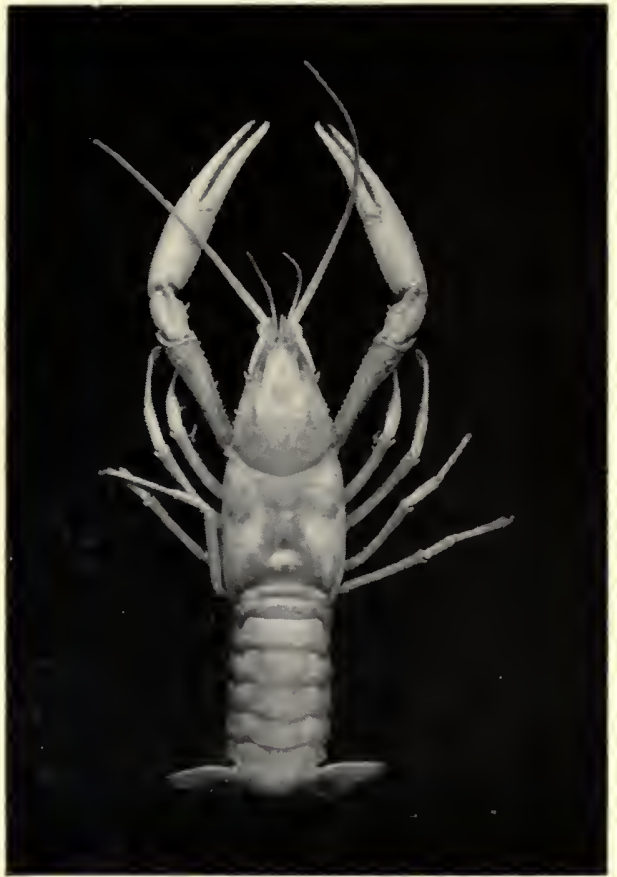

THE BLIND CRAYFISH OF THE MAMMOTH CAVE OF KENTLCKY, Cambarus pellucidus. (NATURAL SIZE) 



\section{CRUSTACEA OF FRESH WATERS I87}

settle some of the most fundamental problems of the evolution theory.

At all events, we do not find in any truly subterranean species large and peculiarly modified eyes like those of many deep-sea animals, and this may be associated with the complete darkness of their habitat, not lighted by phosphorescent organisms as the deep sea is. In another respect these animals differ from those of the deep sea, for they are all colourless or nearly so; while many of the inhabitants of the deep sea, as we have already seen, are brilliantly coloured.

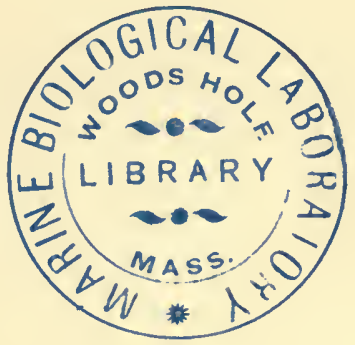




\section{CHAPTER IX}

\section{CRUSTACEA OF THE LAND}

THERE is every reason to believe that the 1 Arthropoda, like the other great groups of the animal kingdom, had their origin in the sea; but they must have invaded the dry land at a very early period, and most of the classes into which the group is divided-the Arachnids, Myriopods, and Insects -are now predominantly terrestrial in their habits. The Crustacea alone have remained for the most part aquatic animals, and only in a comparatively few cases have they succeeded in adapting themselves completely to an air-breathing existence. As already mentioned, a considerable number, both of marine and of fresh-water species, are more or less amphibious in their habits. Thus, the common Shore Crab of our own coasts and the Grapsoid Shore Crabs of warmer seas voluntarily leave the water and scramble about among the rocks between, and even above, tide-marks. Some Crabs, like Ocypode and Gelasimus (see Plate XV.), have gone farther towards becoming land-dwellers, since their 
gill chambers are adapted to serve as lungs for breathing air, and some species may even be drowned by keeping them in water. The marsh-dwelling or fresh-water Crabs of the genus Sesarma (see Plate XXIII.) and allied genera are also apparently to some extent air-breathers, and one species, Aratus pisonii, is stated by Fritz Müller to climb mangrove bushes and to feed on their leaves. Some Crayfishes, like the Engaus of Tasmania (see Plate XX.), already mentioned, are practically land animals. Finally, some Amphipoda, closely allied to the Sand-hoppers of British coasts, live in damp places on land, although they do not show any conspicuous modifications of structure to adapt them to this mode of life. Of one of these Amphipoda, Talitrus sylvaticus, Mr. G. Smith writes: "This species of land-hopper is widely distributed in the highlands of Tasmania, being found under logs and leaves in the forests on Mount Wellington, and in very great abundance in the beech-forests on the mountains of the west coast."

It will thus be seen that it is impossible to draw any sharp distinction between aquatic and terrestrial Crustacea, and it is chiefly from motives of convenience that we have left to be dealt with in this chapter three groups of land-dwelling Crustaceathe Land Crabs of the family Gecarcinidæ, the Land Hermits (Cœnobitidæ), and the Land Isopods, or Woodlice (Oniscoidea). 
The Gecarcinidæ are abundant in the tropics of the Old and New Worlds. Some of the species at least, probably all, visit the sea at intervals for the purpose of hatching off the eggs carried by the females, and the larval stages are passed in the sea. In the case of Gecarcinus ruricola (Plate XXVI.), a species very common in the West Indies, the migration to the sea takes place annually during the rainy season in May. The Crabs are described as coming down from the hills in vast multitudes, clambering over any obstacles in their way, and even invading houses, in their march towards the sea. Stebbing states that "The noise of their march is compared to the rattling of the armour of a regiment of cuirassiers." The females enter the sea to wash off the eggs which they carry attached to their abdominal appendages, or rather, probably, to allow the young to hatch out. The Crabs then return whence they came, and are followed later by the young, which, having passed through their larval stages in the sea, leave the water, and are found in thousands clinging to the rocks on the shore.

On Christmas Island, in the Indian Ocean, Dr. C. W. Andrews studied the habits of another Land Crab, of which the proper name seems to be Gecarcoidea lalandii. He-says: "This is the commonest of the Land Crabs inhabiting the island, and is found in great numbers everywhere, even on the higher hills and the more central portion of the 


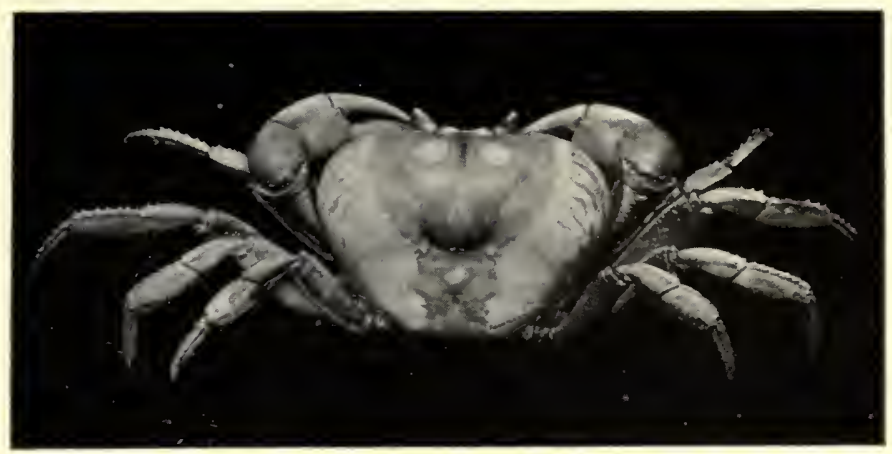

A WeSt indian LAND-CRAB, Gecarcinus ruricola. (REDUCED)

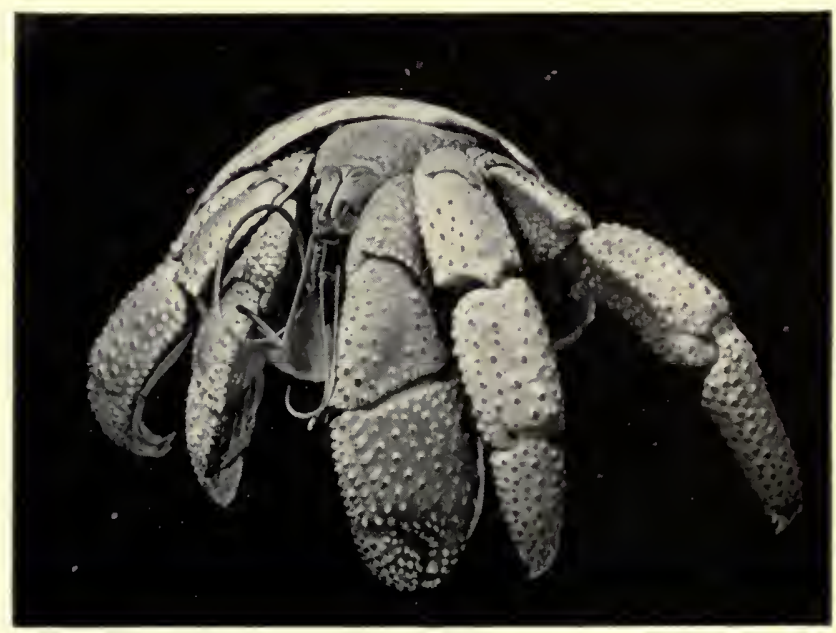

A LAND HERMIT-CRAB, Canobita rugosa. (REDUCED) 

plateau. In many places the soil is honeycombed by its burrows, into which it rapidly retreats when alarmed. These Crabs seem to feed mainly on dead leaves, which they carry in one claw held high over the back and drag down into the burrows. From their enormous numbers, they must play a great part in the destruction of decaying vegetable matter and its incorporation into the soil."

"Once a year, during the rainy season, they descend to the sea to deposit [or, rather, to hatch out] their eggs, and during this migration hundreds may be seen on every path down steep slopes, and many descend the cliff-face itself. They remain on the beach for a week or two, and . . . afterwards gradually make their way back to their accustomed homes."

In the year of Dr. Andrews' first visit to the island ( 1898$)$ this migration occurred in January. On a subsequent visit to the island in 1908 he obtained specimens of a large Megalopa larva (see p. 70) which occurred in enormous quantities in the sea shortly after the migration, and also of a small Crab which appeared in similar numbers at a slightly later date. It seems practically certain that these larvæ and young are those of Gecarcoidea lalandii. A second species of Land Crab, Cardisoma hirtipes, found on Christmas Island, has very different habits from the foregoing. Dr. Andrews says of it: "In this island, at any rate, this species must be regarded as a fresh-water form, and, in fact, when a specimen 
was seen it might be taken as an indication that fresh water was not far off. It lives in deep holes in the mud at the sides and bottom of the brooks." Dr. Andrews tells me that he never saw this species at or near the sea (in marked contrast to Gecar. coidea), and this agrees with the observations of other travellers on species of the genus Cardisoma, so that the breeding habits remain unknown. There is every probability, however, that in this case, also, the young stages are passed in the sea.

The student will find, in many textbooks on zoology, the statement that some Land Crabs of the genus Gecarcinus develop without metamorphosis. Although it is impossible, with our present knowledge, to state definitely that this is not the case, there is absolutely no evidence to support it, and it is an interesting example of the way in which erroneous statements sometimes gain currency in science. ${ }^{1}$ It is based upon the fact that in $I 835$ Professor J. O. Westwood described the early stages of "a West Indian Land Crab," in a paper "On the Supposed Existence of Metamorphosis in the Crustacea," published in the Transactions of the Royal Society. Professor Westwood found that the embryos extracted from the egg possessed all the appendages of the adult except the swimmerets, and that young specimens clinging to the abdomen of

1 I am indebted to Mr. J. T. Cunningham for calling my attention to some of the facts here recorded. 
the parent were perfectly-formed little Crabs. The specimens which he described were sent to him by the Rev. Lansdown Guilding, of St. Vincent, who also deals with the subject in a note published in the Magazine of Natural History in the same year. Neither Westwood nor Guilding refers to the Crab as a Gecarcinus, although Guilding calls it the "Mountain Crab," a name which Patrick Browne in 1756 gives to the Gecarcinus ruricola of Jamaica. So far as I am aware, the first writer to refer to Westwood's Crab as a Gecarcinus, was Professor T. Bell, who in his "British Stalk-eyed Crustacea," published in 1853 , states that some of the original specimens had come into his possession. They consisted of the detached abdomens of female Crabs, with eggs and young adhering to them. It would be by no means easy to identify the species of Crab to which a detached abdomen belonged, and there is nothing in the whole history inconsistent with the supposition that these observations really relate to a River Crab of the family Potamonidæ, of which at least one species, Pseudothelphusa dentata, is known to occur on the island of St. Vincent. As we have already seen, some of these River Crabs are quite as much land animals as the Gecarcinidæ, and they are known to have a direct development.

The Gecarcinidæ possess well-developed gills, but in addition the gill chambers are modified for airbreathing, as in some other amphibious Crabs 
(Ocypode, Gelasimus, etc.). Each chamber is capacious and vaulted, and the lining membrane is thick and richly supplied with bloodvessels, and is folded so as to divide off the upper part of the chamber as a sort of pocket.

The Land Hermit Crabs of the family Cœnobitidæ are found on the coasts of all tropical seas. Like the Gecarcinidæ, they visit the sea periodically for the purpose of hatching off the eggs, and the larval stages are marine. The species of the genus Canobita (Plate XXVI.) resemble the marine Hermit Crabs in general shape, and like them use the shells of Gasteropod Molluscs as portable shelters. Where shells are scarce, other hollow objects are occasionally utilized; for example, large individuals will sometimes carry about the shell of a broken coconut, and a specimen has been seen to walk off in a cracked test-tube discarded by a naturalist who was investigating their habits. In one instance Professor Alcock saw an individual "so big that it seemed to have given up hope of finding a house, and was wandering about recklessly, with its tail behind it all unprotected."

The Cœnobites often climb into bushes in search of food, and Dr. Alcock " once found one of them busy, like a large bee, among the florets of a coconut, which made me wonder whether they may not sometimes play a part in fertilizing flowers." They are, however, by no means exclusively vegetarians. 
The author just quoted describes a visit to Pitti Bank in the Laccadive Archipelago, the breedingground of two species of terns. The ground was everywhere strewn with the dead bodies and cleanpicked skeletons of the young birds. "We soon discovered that one great cause of the wholesale destruction of young birds was the voracity of swarms of large Hermit Crabs (Cenobita), for again and again we found recently killed birds, in all the beauty of their first speckled plumage, being torn to pieces by a writhing pack of these ghastly Crustaceans. There were plenty of large Ocypode Crabs, too (O. ceratophthalmus), aiding in the carnage."

On Christmas Island Dr. Andrews found a species of Canobita not unfrequently in the higher parts of the island far from the sea, and he remarks that the occurrence of large marine shells high up on the hills seemed very puzzling until it was noticed that they were brought by the Hermit Crabs.

The species of Canobita possess a very curious adaptation for aerial respiration. The soft skin of the abdomen is traversed by a network of bloodvessels and acts as a kind of lung, and a pair of contractile vesicles at the base of the abdomen serve as accessory hearts in promoting a specially active circulation in that part of the body. The lining membrane of the gill chambers also appears to aid in respiration as in other terrestrial Decapods.

The "Robber Crab" or "Coconut Crab" (Birgus 
latro-Plate XXVII.) also belongs to the family Cœnobitidæ, and has attracted much notice from its relatively gigantic size and its singular habits. Although resembling Canobita closely in essential structure, Birgus differs from it and from most other Hermit Crabs in not making use of a portable shelter, perhaps owing to the difficulty of obtaining one of suitable size. The necessary protection for the abdomen is obtained by a redevelopment of the shelly plates (terga) on the upper surface of the abdominal somites. The abdomen is carried doubled underneath the body to protect the soft undersurface, and the animal, when threatened, seeks a shelter for its vulnerable hinder part in the nearest hole or cranny. The swimmerets are absent in the male sex, and are present only on one side of the abdomen in the female. This unsymmetrical development of the appendages is interesting as indicating the derivation of the Robber Crab from ancestors adapted to living in the unsymmetrical shells of Gasteropod Molluscs. The last pair of abdominal appendages, which in other Hermit Crabs serve to hold the body in the shell, are here much reduced in size, and quite useless for that purpose. The carapace is very broad posteriorly, owing to the great development of the branchial cavities, which are much too capacious for the very small gills. As in the true Land Crabs, the lining membrane of the gill cavity is thick and spongy, and 


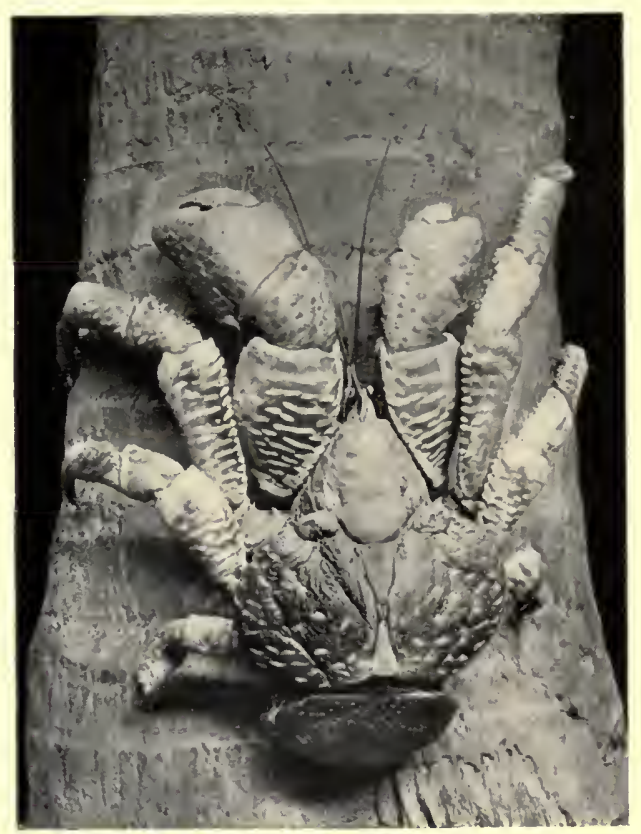

THE COCONUT CRAB, Birgus latro. (MUCH REDUCED) 
traversed by numerous bloodvessels; but in this case its efficiency as a lung is added to by numerous tufted papillæ, which increase the surface exposed to the air.

As in other Hermit Crabs, the last two pairs of legs are shorter than the others, and they end in small chelæ. The last pair are very slender, and are usually carried folded up within the gill chambers, which they possibly serve to keep clear from foreign bodies. The penultimate pair of legs are stouter, and the two pairs in front of these are long walking legs. The chelipeds are very strong and are of unequal size. When attacked, the animal defends itself, not, as might have been expected, with its chelipeds, but with the first pair of walking legs, the sharp points of which form very efficient weapons.

The statement that the Robber Crab climbs lofty trees was first made by the Dutch naturalist Rumphius, in the beginning of the eighteenth century. Its accuracy has been often doubted or denied since then, and only finally put beyond dispute by a photograph taken on Christmas Island by Dr. Andrews, which shows one of these Crabs in the act of descending the trunk of a sago-palm. It seems not impossible that the habits of the animal may vary to some extent in different localities, and that where food is abundant on the ground the treeclimbing habit may be in abeyance. If this were so, it would explain the very definite statements made 
by some observers, that Birgus does not climb trees.

In localities where coconut palms abound, Birgus feeds largely on the nuts, tearing off the fibrous outer husk and breaking open the shell by hammering with its powerful claws at one of the "eye-holes." According to Darwin in his "Naturalist's Voyage," the pincers of the penultimate pair of legs are used for extracting the contents of the nut, but this observation does not seem to have been confirmed. In spite of its name of "Coconut Crab," however, Birgus by no means feeds exclusively on coconuts. On Christmas Island, where until recently there were no coconut palms, the Crabs are exceedingly abundant, and, according to Dr. Andrews, they " eat fruits, the pith of the sago-palm and the screw-pines, dead rats and other carrion, and any of their fellows that may have been injured.... They are excellent scavengers, and have a curious habit of often dragging their food long distances before attempting to eat it. I have seen a Crab laboriously pulling a bird's wing up the first inland cliff, half a mile or more from the camp whence it had stolen it."

Large specimens of the Robber Crab may be at least a foot in length of body when the abdomen is straightened out. Their great strength is illustrated by the fact, related by Darwin, that specimens placed in?a strong biscuit-tin, of which the lid was secured by wire, escaped by turning down the edges 
with their claws, and in doing so actually punched holes quite through the tin.

The breeding habits and mode of development of the Robber Crab have often formed the subject of inquiry by naturalists, but it is only recently that Dr. Willey has been able to prove definitely that the female visits the sea for the purpose of hatching off the eggs, and that the young are hatched in the zoëa stage. The larvæ obtained by Dr. Willey have been described by Mr. Borradaile, who finds that, as was to be expected, they closely resemble those of Canobita. There appears, however, to be no such simultaneous migration of the Crabs towards the sea as has been described in the case of the Gecarcinidæ. The statement, quoted by Darwin, that Birgus visits the sea every night for the purpose of moistening its branchiæ, cannot be universally applicable, since the Crabs are often found, as on Christmas Island, at. distances from the sea which put a nightly journey to it out of the question.

Of all Crustacea, the most completely adapted to terrestrial life are the Land Isopods, or Woodlice, which may be found in every garden. It is true that most species are found in damp places, although some that inhabit the sandy deserts of Asia and Africa must be content with a very slight degree of humidity; and in no case is their dependence on moisture greater than, for instance, that of many Insects and Arachnids which are regarded as typically 
terrestrial animals. Since there is reason to believe that the Woodlice have been derived from marine ancestors-they show no special affinities to the fresh-water Isopoda, like Asellus-it is interesting to find that the most primitive forms, which have departed least from the general Isopod type, are commonly found on or near the seashore. The

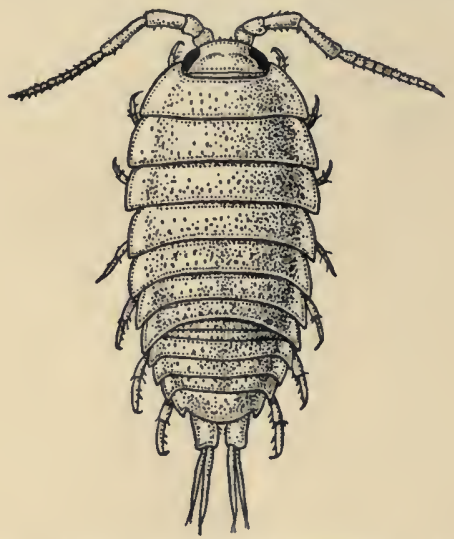

Fig. 63-The Sea-Slater (Ligia oceanica). About Twice Natural Size. (After Sars.)

"Sea-slater," Ligia oceanica (Fig. 63), which is abundant in rocky places on our own coast, is one of the most primitive forms. It has a broad, flattened, greenish-brown body, about an inch long, and it runs quickly, creeping into narrow crevices of the rocks, so that it is not easy to catch. The antennules, as in the other land Isopods, are very minute, but the antennæ are long, and have, besides the five 
segments which form the "peduncle," a "flagellum " of about twelve short segments. The uropods or tail appendages are long, each with two slender, pointed branches. On the under-side of the abdomen can be seen the five pairs of pleopods, each with two plate-like branches attached to a very short peduncle. As in most aquatic Isopods, the plates of the pleopods are soft and thin, and appear adapted to act as gills, although the outer plate of each pair is somewhat stiffer than the inner. The Sea-slater is generally found just above high-water mark, probably always within reach of the salt spray, and it is said sometimes to enter the water of rock-pools.

In almost every garden there may be found, under flower-pots and the like, a Woodlouse, about twothirds of an inch long, of a brown colour, with yellowish blotches arranged in a row on each side of the back. This is Oniscus asellus, a species widely distributed in Europe and North America. It has the antennæ shorter than in Ligia, and the flagellum is composed of only three segments. The uropods are quite short. The endopodites of the pleopods are membranous gill-plates, which serve for respiration in the moist air in which these animals generally live. The exopodites are stiff plates which cover and protect the delicate endopodites; it is probable that they also aid in respiration, for they contain a system of minute channels, filled with air, where the cuticle is separated from the underlying cells. As 
these channels are nowhere open to the outside, the air must find its way in by diffusion through the cuticle.

Even more abundant than Oniscus asellus, and often found together with it, is Porcellio scaber (see Fig. 20, p. 5I). It is usually of a dark bluish-grey, but occasionally it is irregularly mottled with a

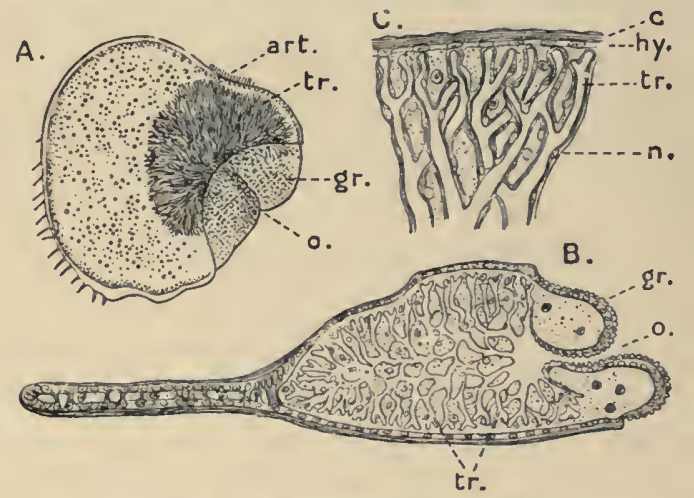

Fig. 64-Structure of the Breathing Organs of Porcellio scaber. (From Lankester's “"Treatise on Zoology," after Stoller.)

A, Exopodite of first pleopod, showing the tuft of air-tubes ("pseudo-tracheæ"), seen through the transparent cuticle; B, vertical section through same; C, part of section more highly magnified. art, Point of attachment of exopodite to peduncle; $c$, cuticle; $g r$, grooved area of cuticle; $h y$, hypodermis, or layer of cells under the cuticle; $n$, nucleus of hypodermis cell of airtube; $o$, external opening; $t r$, air-tubes

lighter colour. The flagellum of the antenna has only two segments. The most interesting difference from Oniscus, however, is found in the pleopods. If the under-side of the living animal be examined with a pocket lens, a white spot will be seen on each 
exopodite of the first two pairs of pleopods. When the structure of the pleopods is investigated by means of microscopic sections (Fig. 64), it is found that the white spots are tufts of fine branching tubes radiating into the interior of the exopodite from a slitlike opening on the outer edge. These tubes arise by an in-pushing of the integument, and they are lined throughout by a delicate continuation of the external cuticle. During life they are filled with air, and they serve to aerate the blood circulating in the interior of the appendage.

Another Woodlouse common in England is Armadillidium vulgare (Fig. 65), a little slatygrey species with a very convex body, which rolls itself

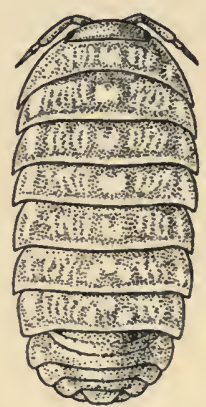

Fig. 65-Armadillidium vulgare. $\times 2 \frac{1}{2}$. (After Sars.) into a ball when touched. Like the last-mentioned species, it has two segments in the flagellum of its short antennæ, and it has tufted air-tubes in the exopodites of the first two pairs of pleopods. It is often mistaken for an animal of widely different structure, which it superficially resembles-the Pill Millipede (Glomeris marginata). The latter, however, may easily be recognized by having either seventeen or nineteen pairs of walking legs (instead of seven pairs), set close together in the middle line of the 
body, and by lacking the plate-like pleopods. The resemblance between the two animals can hardly be regarded as a case of "mimicry," since there is no reason to believe that either benefits by its likeness to the other. As in so many other cases of " convergent resemblance" between animals of different structure, it does not seem possible to get beyond the vague suggestion that a similarity in habits may have led, in some way that we do not understand, to a similarity in appearance.

The presence of air-tubes in the pleopods of many Woodlice raises some questions which are of importance with reference to the classification of the Arthropoda as a whole. The Six-legged Insects, most Spiders and many of their allies, the Centipedes and Millipedes, and the worm-like Peripatus, all breathe air by means of fine tubes which penetrate throughout the body, and bring the air into close contact with the tissues. These tubes, which are known as "tracheæ," arise as ingrowths of the outer layer of the embryo, and are lined by a delicate continuation of the external cuticle. It has been held by some zoologists that so peculiar a system of breathing organs must indicate a common descent of the animals that possess them, and accordingly it has been proposed to separate the Insects, Arachnids, Myriopods, and Peripatus, as a group, Tracheata, from the Crustacea and some other Arthropods which have no tracheæ. The air-tubes of the Woodlice, 
however, are precisely like tracheæ in structure and function, and only differ from the tracheæ of the other groups in the fact that they are confined to the appendages, and do not penetrate into the body. Since the Woodlice are a small and highly specialized branch of the Crustacea, we can hardly suppose that they derive their tracheæ from any ancestral type which they had in common with the widely different Arachnids, for example; and if tracheæ have been evolved independently in these two groups, there seems no reason why those of the Insects may not have arisen independently of either. This is only one example out of many which go to show that, in attempting to reconstruct the genealogy, or phylogeny, as it is called, of the animal kingdom, we must constantly admit the possibility of "convergent evolution."

Although Woodlice are very common animals, comparatively little is known of their habits. They seem to live chiefly on vegetable food, and sometimes damage seedlings and tender plants in gardens and greenhouses, but occasionally they are carnivorous, and even cannibalistic, in their habits. A few spécies live as "guests" in ants' nests, and one of these, the little blind white Platyarthrus hoffmannseggii, is common in many localities in this country. Why the ants tolerate their presence we do not know, for they do not seem to render any service to their hosts, as do the plant-lice and some other insects 
that are kept by the ants for the sake of the secretions which they yield.

The Woodlice, like some other Isopoda, have a peculiar method of moulting. Instead of the whole exoskeleton being cast off at one time, as in other Crustacea, that of the hinder half of the body is moulted first, and it is only after two or three days, when the new cuticle has hardened, that the exoskeleton of the anterior half follows. As a result of this arrangement, it occasionally happens that specimens are found with the fore part of the body differing in colour from the hind part, owing to the one having been moulted more recently than the other.

Woodlice occur in most regions of the globe, and one of the most remarkable features of their geographical distribution is the extremely wide range of certain species. This is probably due, at least in many cases, to their accidental transport by human agency. Thus, Porcellio scaber, so common in this country, is also found in great abundance in New Zealand; but Professor Chilton notes that it is usually found near buildings, and only rarely in the native bush, so that there can be no doubt that it has been introduced by artificial means. 


\section{CHAPTER X}

CRUSTACEA AS PARASITES AND MESSMATES

THE life of every animal is in more or less intimate relation with that of all the living creatures which surround it. Some serve for its food, or supply it with shelter or foothold; others prey upon it, or compete with it for the necessaries of life; and others, again, influence it for good or evil in countless ways more subtle than these, but equally important. There are some associations of a closer and more enduring nature, to which the names of Symbiosis, Commensalism, and Parasitism, are applied, and it is with examples of these that the present chapter is concerned.

The term Symbiosis is strictly applied to an intimate physiological partnership, such as we find in some of the lower animals and plants, and in this sense there are no truly symbiotic Crustacea. The word, however, is sometimes used, in its literal sense of a "living together," to embrace all cases of animals living together for mutual advantage. Commensalism means, literally, "sitting at the same table," 
and ought to be applied only to cases where two or more animals, living together as "messmates," partake of the same food; but it is sometimes used more loosely to include instances where one of the animals does not actually share in the food-supply of the other. Parasitism, again, implies that the parasite lives permanently at the expense of its host, by sucking its juices or otherwise, and in this case also there are innumerable degrees and varieties of dependence, which defy inclusion in a strictly logical scheme of classification. Even such typical parasites as Tape-worms, for example, might strictly be regarded as commensals, sharing in the host's food only after it has entered the alimentary canal. Finally, in all these kinds of interrelation, we find cases where the association is temporary, intermittent, or almost accidental, and where there are no perceptible adaptations of structure directed to its maintenance in either of the partners. From these we may trace a series of gradations leading to cases where the associated organisms are never found apart, and where the structure of both is profoundly modified in adaptation to the particular form of association.

Perhaps the simplest form of association between two animals is found where one utilizes the other as a means of transport. The little Gulf-weed Crab, previously mentioned, is very often found clinging to the carapace or skin of large marine turtles. It is not a parasite, since it can hardly derive any food 


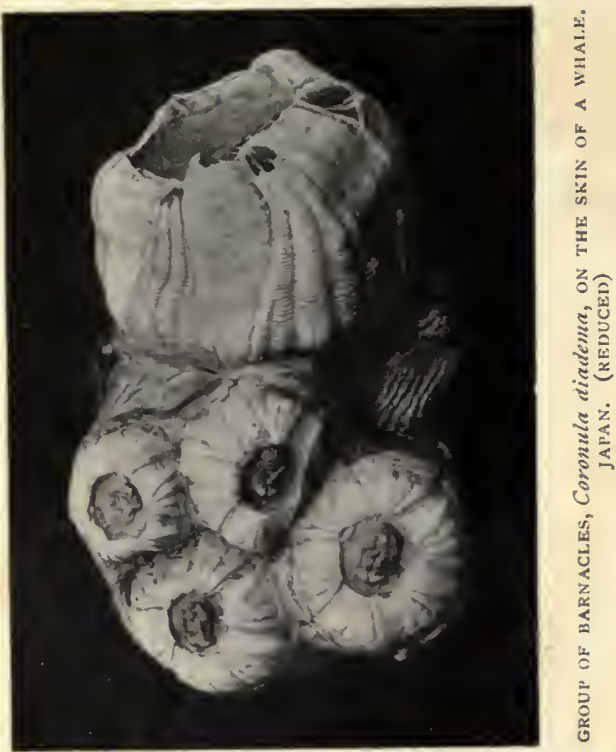
from the Turtle itself; neither is it a commensal, for there is no evidence that it shares in the Turtle's meals. It probably takes to a Turtle, when it can find one, as giving it a wider range of operations than is afforded by its usual drift-log or tuft of sargassoweed. A somewhat similar case is afforded by some of the Barnacles that are found on the skin of Whales. The species of Conchoderma, for instance, are often found on certain Whales, but they may also occur on inanimate floating objects. Other Whale-infesting Cirripedes, however, are specially adapted to their habitat, and never occur elsewhere. For example, Coromula (Plate XXVIII.) is a genus of sessile Barnacles in which the shell is elaborately folded, forming a series of chambers into which prolongations of the Whale's epidermis grow, securely fixing the shell. Tubicinella is even more effectively protected against dislodgment, for its shell is sunk in the thickness of the Whale's skin, with only the opening exposed. Other genera of sessile Barnacles (Chelonobia, etc.) are found adhering to the shell of Turtles. The increased food-supply made available by the host's movements through the water is probably the chief advantage that the Barnacles gain in such cases. This is indicated by the fact that certain small stalked Barnacles (Dichelaspis, etc.), found on large Crabs and Lobsters in tropical seas, generally cluster on the mouth parts of their hosts, near the entrances to, or even within, the gill 
chambers, profiting no doubt by the respiratory currents and the food particles they carry.

A great variety of Crustacea find shelter and defence in association with Sponges, Corals, and other more or less sedentary animals. Sponges are not eaten by many marine animals, the needle-like spicules which often form their skeleton no doubt helping to render them distasteful, and many small Crustacea, Amphipods, Isopods, Prawns, etc., profit by their immunity from attack, and take up their abode in the internal channels and cavities of the Sponge. The beautiful siliceous Sponge known as "Venus's Flower-basket" (Euplectella) very often contains imprisoned within it specimens of a delicate little Prawn (Spongicola vemusta) or of an Isopod (EEga spongiophila). As these Crustacea share with the Sponge the food particles drawn in by the currents of water passing through the pores in its walls, they are in the strict sense commensals.

The Corals and various other animal organisms commonly known as "Zoophytes," forming together with the Jellyfishes the group Cœlentera, are very effectively protected against the attacks of most predatory animals by the possession of "stinging cells," and this protection is shared by many other animals which shelter among them. Thus, the branching Coral stocks which grow in great luxuriance on tropical coasts support a rich and varied assemblage of animals, some of which may actually 
prey upon the Coral polypes, but all of which profit by the fact that few enemies venture to pursue them in their retreats. Innumerable prawn-like animals of the Alpheidæ and other families, and many kinds of Crabs, are found among living Corals. The Crabs of the family Trapeziidæ are especially characteristic of such habitats, and their thin, flat bodies seem to be adapted to slip into slits and crannies of the Coral blocks. The most highly specialized of all Coral
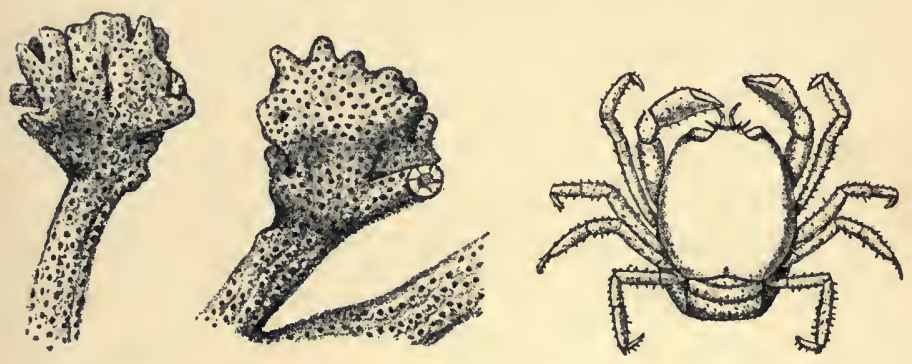

Fig. 66-Two Branches of a Coral (Seriatopora) showing "Galls" inhaBited BY the Crab Hapalocarcinus marsupialis. ON the Right the Female Crab, extracted from the Gall AND FURTHER ENLARGED

Crabs, however, are the species of the family Hapalocarcinidæ, which modify in various ways the growth of the corals on which they live. In some of the more delicately branched kinds of Coral there may sometimes be found hollow bulbous growths, each of which contains imprisoned within it a little CrabHapalocarcinus marsupialis (Fig. 66). It seems that the female Crab (the habits of the male are not definitely known) settles down among the branches 
of the Coral, and that the irritation of its presence causes the branches to grow up and surround it, coalescing with each other to form a kind of cage, and ultimately leaving only one or two small openings. Through these openings water can enter to enable the Crab to breathe, and no doubt food particles find their way in, but it is not possible for the Crab to leave its prison. The production of these abnormal growths of the Coral is closely analogous to the formation of "galls" on plants as a result of the irritation set up by the presence of insect larvæ or other parasites, and it is not inappropriate, therefore, to speak of them as "Coral galls."

The Medusæ, or Jellyfishes, like other Cœlentera, are provided with poisonous stinging cells, which, in the larger species of our own seas, are powerful enough to cause discomfort to bathers who come in contact with them. The protection thus afforded is no doubt of advantage to the little globular Amphi. pods of the genus Hyperia (Fig. 67), which are almost always to be found sheltering under the bells of the larger Medusæ. In what way the Amphipods escape injury from the stinging cells of their host is not known.

In all the cases mentioned, the advantages of the partnership seem to be all on one side, but there are numerous instances in which both partners seem to reap some benefit. A species of Hermit Crab very common in moderately deep water on many parts of 
the British coasts, Eupagurus prideauxi, is always found to have a Sea-anemone (Adamsia palliata) attached to the shell which it carries. The Anemone has a broad base which is wrapped round the shell, the mouth, surrounded by the tentacles, being on the under-side next the opening of the shell. There seems no reason to doubt that the presence of the Anemone does afford some degree of protection to the Hermit, and that, on the other hand, the Anemone benefits by being carried about, and shares in the crumbs from the Hermit's meals. It is stated that,

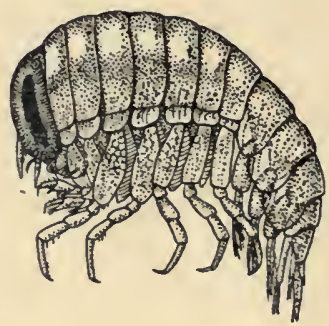

Fig. 67-Hyperia galba, FEMALE. ENLARGED. (After Sars.) when the Hermit removes to

a new shell, it detaches the Anemone from the old shell with its pincers and places it in position on the new one. It appears, however, that it is not always necessary for the Hermit to remove to a larger shell as it grows, for the enveloping Anemone, as it increases in size, extends beyond the mouth of the shell, and so enlarges the shelter. Further, the Anemone in course of time dissolves the shell almost entirely away, and the Hermit is enveloped only by the soft fleshy mantle which it forms.

In a similar way the deep-sea Hermit Crab Parapagurus pilosimanus (see Plate XVI.) is always found 
lodged in a fleshy mass formed by a colony of Seaamenones (Epizoanthus), within which, when it is cut open, may be found the remains of the shell which the Hermit first inhabited. A further development of the same habit is given by Paguropsis typica, found in deep water in Indian seas, which does not inhabit a shell at any time, but carries a fleshy blanket formed by a colony of Anemones.

In dredging off the British coasts, we often find smooth rounded lumps of a Sponge (Suberites ficus), generally yellowish-grey in colour, having a round opening in which the claws of a small Hermit Crab (Eupagurus cuanensis) may be seen. On cutting open the Sponge, the body of the Hermit is seen to be lodged in a spiral cavity, and at the apex may be found the remains of a shell that has been corroded away by the Sponge which settled on and replaced it. Other species of Hermit Crabs constantly have their shells covered with a horny crust formed by Hydroid zoophytes (Hydractinia, etc.), and in this case also the extension of the Hydroid colony beyond the lip of the shell relieves the Hermit from the necessity of so frequently changing to a larger shell as it grows.

A number of other animals are found associated with Hermit Crabs, without, as far as we can see, rendering any service in return for the house-room. The Whelk-shells inhabited by Eupagurus bernhardus (see Plate VII.) often contain one of the bristle- 
footed worms (Nereilepas fucata), which may sometimes be observed to protrude its head from the shell when the Crab is feeding, and to snatch away fragments of the prey from the very jaws of its host. It is thus, in the strict sense of the word, a commensal. Species of Copepods, Amphipods, Porcelain Crabs, and even a Mysid, have been found sharing the lodging of Hermit Crabs in a similar way, and in addition there are various parasites, presently to be mentioned, found on the Crabs themselves, so that each $\mathrm{Crab}$ forms the centre of a whole community of widely diverse organisms all more or less directly dependent on it.

A habit similar to those of some Hermit Crabs is that of the Crab Dromia (see Plate IX.), mentioned in a previous chapter, which carries, as a cloak, a mass of living sponge, holding it in position by means of the last two pairs of legs. Even the "masking" habit of the Spider Crabs, already described (p. 96), may be regarded as a kind of symbiosis, since the sponges, zoophytes, etc., which grow on the Crabs no doubt benefit by being carried about in return $f \phi r$ the protection they give.

One of the strangest habits is that of certain little tropical Crabs, of which Melia tessellata (Fig. 68) is the best known, which carry in each claw a living Sea-anemone and use it as a weapon. The claws or chelipeds are in this case of small size, so that they. woud be of little use by themselves for attack or 
defence; but the fingers are provided with recurved teeth, enabling them to take a firm hold of the slippery body of the Anemone. Particles of food caught by the tentacles of the Anemone are removed and eaten by the Crab, which uses for the purpose the long walking legs of the first pair. The same limbs are also used in the process of detaching the

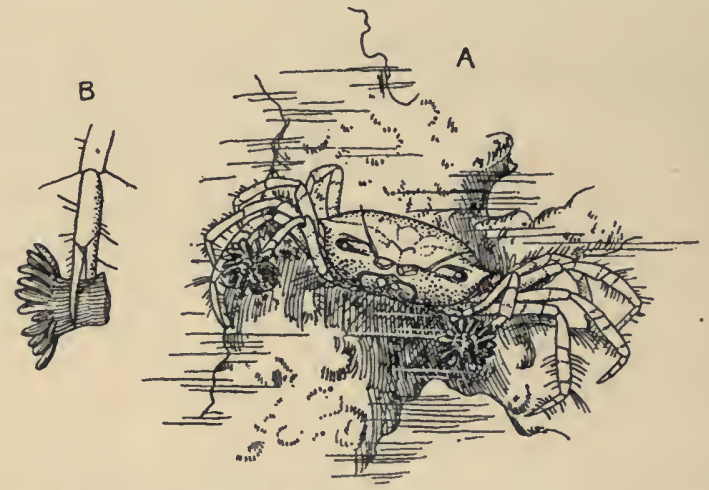

Fig. 68-A, The Crab Melia tessellata clinging to a Branch of Coral, and carrying in Each Claw a living SeaANemone; B, ONe of the Claws Further enlarged to SHOW THE WAY IN WHICH THE ANEMONE is HELD. (After Borradaile.)

Anemones from the stone on which they may be growing. The Anemones do not appear to suffer from the rough treatment to which they are subjected, but whether they can reap any benefit from the partnership is very doubtful.

From remote antiquity it has been known that a little Crab (Fig. 69) is frequently found living within 
the shells of bivalve Molluscs, such as Oysters, Mussels, and especially the large mussel-like Pinna, which is common in the Mediterranean. Ancient writers regarded this as a case of association for mutual advantage, believing that the Pinnotheres warned the Pinna of the approach of enemies or of the entrance of prey between its gaping valves. It is even stated that the Pinna and Crab were depicted in Egyptian hieroglyphics to symbolize the dependence of a man on his friends.

As a matter of fact, however, there is no reason to

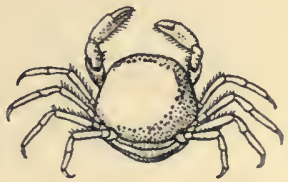

Fig. 69-The Common Pea Crab (Pinnotheres pisum), Female. Natural Size.

believe that the Molluscs which harbour species of Pinnotheres and allied genera benefit in any way by the presence of the Crabs. The latter probably feed, as their hosts do, on particles brought in by the current of water entering the mantle cavity. They are therefore strictly "commensals," though it is usual, and perhaps equally correct, to speak of them as "parasites." The case is, indeed, an example of the difficulty of defining these two terms. At all events, the Pinnotherid Crabs show one of the characteristics of parasites in being to some extent 
degenerate in their structure. The carapace and the rest of the exoskeleton, no longer needed for protection, have become soft and membranous, and the eyes and antennules, the chief organs of sense, are very minute. As in many parasites, also, the eggs produced by the female are very numerous, and the abdomen is very broad and deeply hollowed for their reception.

While most of the Pinnotheridæ live in bivalve Molluscs, some species are associated with other invertebrate animals. Pinnaxodes chilensis is found in a species of Sea-urchin (Strongylocentrotus gibbosus) on the coast of Chili. On opening the shell of the Urchin, the Crab is found enclosed in a thin-walled bag formed by enlargement of the terminal part of the host's intestine.

It did not escape the notice of Aristotle that a little Shrimp sometimes occurred in the Pinna in place of the Crab. This is Pontonia custos, and other species of the same and allied genera have similar habits.

The order Isopoda includes a very large number of parasitic species. The extensive family Cymothoidæ presents a whole series of gradations in habits and structure between actively swimming predatory species and others which in the adult state are permanently fixed to their host, usually a fish, and are incapable of movement. At one end of the series are the species of Cirolana; which have 
powerful biting jaws. Of C. borealis (Fig. 70), Mr. Stebbing remarks that " it is a good swimmer, tenacious of life, a savage devourer of fish, and not to be held in the human hand with impunity." The species is not uncommon in British seas, and numerous individuals will sometimes attack a Cod or other large fish, perhaps after it has been caught on a hook, and gnaw their way into its body, so that when brought to the surface the fish consists of little more than skin and bone.

The little Eurydice achatus, belonging to the same subfamily, FIG. 70-Cirolana borealis. AвоUT

Cirolaninæ, is com- Twice Natural Size. (After monly taken in the

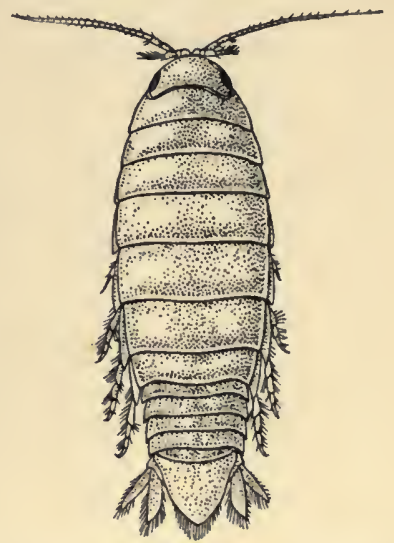
tow-net in sandy bays on our own coasts. It is said sometimes to attack bathers, and to " nip most unpleasantly."

More definitely parasitic are the species of $E g a$ and allied genera, which have piercing and suctorial mouth parts, and suck the blood of fish. They are usually found adhering closely to the skin of their victim by means of the strong hooked claws of the anterior pairs of legs; but they have not lost the 
power of locomotion, and, as females bearing eggs are never taken on fish, it would appear that they drop off after gorging themselves with blood, and probably seek a retreat at the bottom of the sea, where they may hatch their young in safety. The digestive canal of $\mathbb{E} g a$ dilates into a large bag, which becomes distended with a semi-solid mass of blood. This mass, when extracted and dried, is the "Peter's stone" of old Icelandic folklore, to which magical and medicinal virtues were attributed. The species Aga spongiophila, already mentioned, differs in its habits from all the other species of the genus, since it lives, not on fish, but in the interior of a sponge.

The most completely parasitic members of the Cymothoidæ are found in the subfamily Cymothoinæ, including the typical genus Cymothoa (Plate XXIX.) and many others. The adult animals are found clinging to the skin of fishes, the legs being provided with strong hook-like claws that give them a very firm hold. Some species, especially common on Flying-fishes, cling to the tongue of the fish, and almost prevent it from closing its mouth. When young, the Cymothoinæ swim freely, and the shape of the body is not unlike that of the Cirolaninæ; but after they have settled on a host the body often becomes distorted and unsymmetrical. A still more remarkable change occurs in the reproductive organs in some, if not in all members of this 


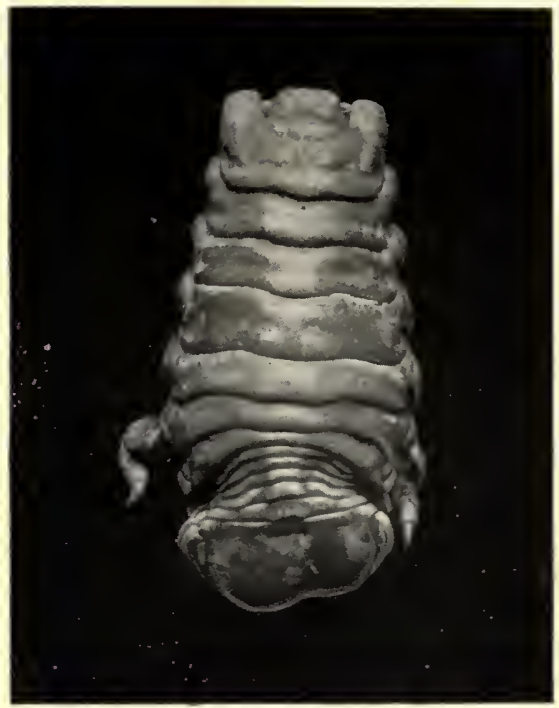

Cymothoa ostrum, AN ISOPOD PARASITE OF FISH (SLIGHTLY ENLARGED)

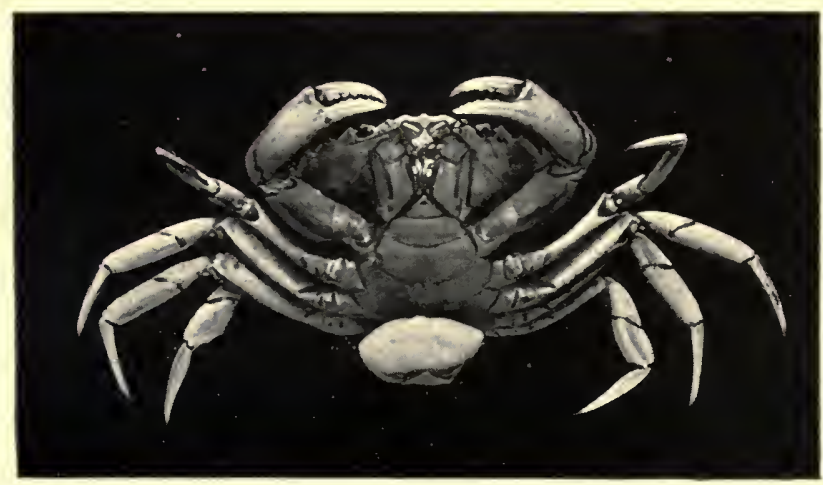

Sacculina carcini ATTACHED UXDER THE ABDOMEX OF A COMMOX SHORE-CRAB (REDUCED) 

subfamily. Each individual, when it first attaches itself to a host, presents the characters of the male sex. Later it becomes a female, develops a broodpouch, and produces eggs. The animals are, in fact, hermaphrodite; but it is to be noted that the hermaphroditism is of a different kind from that presented by the Cirripedia, since the organs of the two sexes are successively, not simultaneously, developed. Where, as in this case, the male phase comes first in the life-history of the individual, the condition is known as "protandrous" hermaphroditism.

Another large group of parasitic Isopods is the suborder Epicaridea, all the species of which are parasitic on other Crustacea. It is not uncommon to find specimens of the common Prawn (Leander serratus) which have a large swelling on one side of the carapace. If the lower edge of the carapace be raised, it will be seen that this swelling is due to the presence in the gill cavity of an Isopod parasite (Bopyrus squillarum). A closely similar form, found on Prawns of the genus Spirontocaris, is Bopyroides hippolytes, represented in Fig. 71. Other allied species are found on Hermit Crabs and other Decapods. When extracted, the parasite is seen to have a flat and curiously distorted body, with extremely short legs ending in hooked claws. The under-side is generally occupied by a relatively enormous mass of eggs, which is only partly covered 
in by the small brood-plates. The mouth parts form a short piercing beak with which the parasite sucks the blood of its host. On the under-side of the abdomen may usually be found the minute male, attached, like a secondary parasite, to the body of the female.

The species of Epicaridea are very numerous, and they infest Crustacea belonging to nearly all the
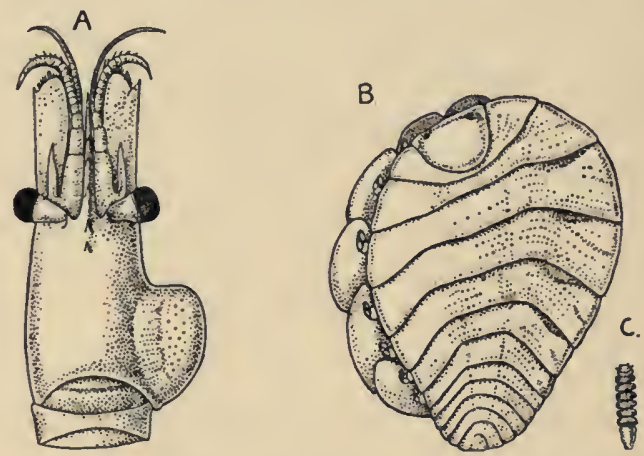

Fig. 7I-A, Front PART of Body of a Prawn (Spirontocaris polaris), FRom Above, showing on the Right Side a Swelling of the Carapace caused by the Presence of the Parasite Bopyroides hippolytes in the Gill Chamber; B, the Female Parasite extracted and further enlarged; C, the Male Parasite on Same Scale as the Female. (After Sars.)

chief groups of the class, a few even being parasitic on other Epicaridea. Many of them differ greatly from the Bopyrus just described, and in some cases it would be impossible to guess from the structure of the adult animals that they were Isopoda, or even Crustacea at all. The life-history is not yet com- 
pletely known. When hatched from the egg, the free-swimming larvæ have a short and broad body, and, as in other Isopod larvæ, have only six instead of seven pairs of legs. A later larval stage, just before attachment to the final host, has a long narrow body and the full number of legs. It has lately been shown, however, that, in all probability, between these two free-swimming stages there intervenes a stage in which the larvæ is temporarily parasitic on certain Copepoda. Further, some of the Epicaridea, like the Cymothoinæ described above, are protandrous hermaphrodites, developing the male organs when in the last larval stage, and passing into the female phase after they have become attached to the host. In Bopyrus and many other genera, however, there is no evidence that the males ever develop into females.

Some of the most remarkable Epicaridea are those belonging to the family Entoniscidæ, which are parasitic on Crabs. In these the parasite penetrates from the gill chamber into the interior of the body of the host, remaining enveloped, however, by a delicate membrane which grows in with it from the wall of the gill chamber. The body is distorted in an extraordinary fashion, so that at first sight it seems impossible to trace any resemblance to the form of a typical Isopod.

Among the Amphipoda there are a few species belonging to various families of the Gammaridea which 
have suctorial mouth parts, and lead a semi-parasitic existence; but the only completely parasitic forms are the Whale-lice, forming the family Cyamidæ (see Fig. 23, p. 55) in the suborder Caprellidea. Although differing greatly in the broad, flattened shape of the body from the slender, thread-like Caprellidæ, they closely resemble them in structure, particularly in having the abdomen reduced to a mere knob. The fourth and fifth pairs of thoracic limbs have disappeared, although the gills corresponding to them are very large; and the last three pairs of legs have long curved claws which enable the Whale-louse to cling firmly to the skin of its host. The mouth parts are adapted for biting, not for sucking blood, and the animals seem to live by gnawing the skin of the Whales. In one respect the Whale-lice are unique among Crustacean parasites: they have not the power of swimming at any period of their life-history. The young settle down near their parents, and masses of many hundred individuals of all sizes are found clinging close together on the skin of the host.

No group of Crustacea exhibits more numerous or more varied examples of parasitism than the Copepoda. Every grade of transition between a free predatory habit of life and the most complete dependence upon a host may be traced in various families of the subclass. Only a few examples can be mentioned here.

The commonest "fish-lice" are the numerous 
species of the family Caligidæ, many of which, belonging to the genera Caligus (Fig. 72), Lepeophthirus, etc., are found on marine fishes on our own coasts. In these the body is broad and flat, but in many of them the resemblance, even in general form, to the freeliving Copepoda is easily traceable. The maxillipeds form powerful hooked claws, by means of which the animals cling to the skin of the fish they infest, and in Caligus the basal segments of the antennules have a pair of suckers which aid in adhesion. The mouth parts are adapted for piercing, and are enclosed in a suctorial proboscis.

When the young Caligid, after passing through the free-swimming larval stages, first becomes attached to a fish, it adheres by means of a

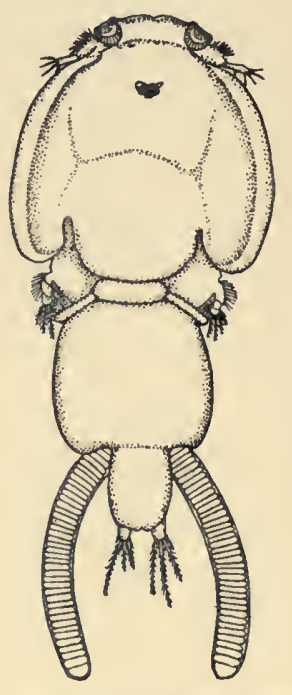

Fig. $72-A$ FisH.LOUSE (Caligus rapax), FEMALE. $\times 5$. (After Wilson.) thread-like process issuing from the front of the head, and formed by the secretion of a gland. At this stage, formerly described as an independent species under the generic name of Chalimus, the parasite is unable to detach itself from its host; but later, in 
many species, it re-acquires the power of swimming, and specimens of Caligus, for instance, are commonly found free in tow-net gatherings.
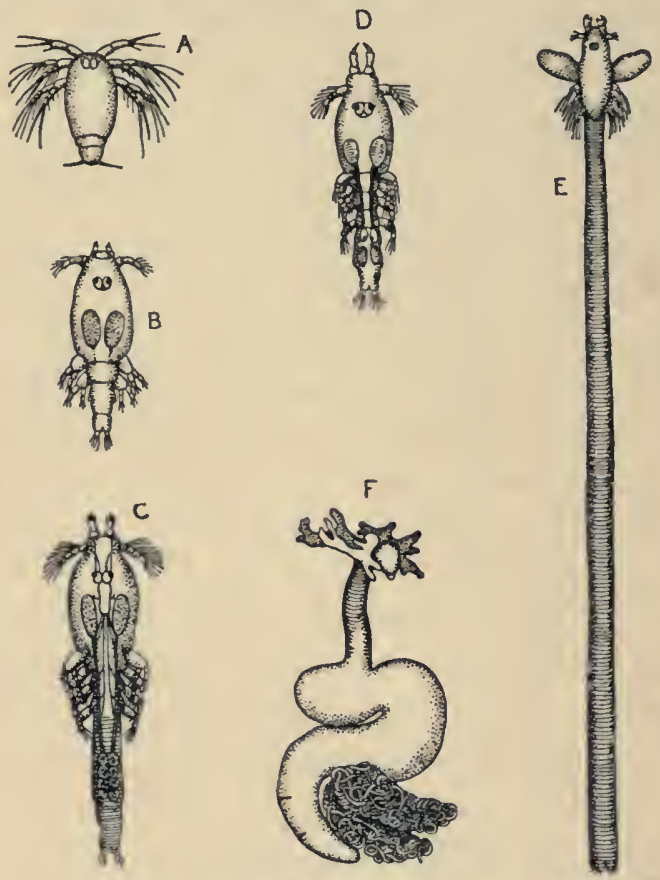

Fig. 73-Stages of Development of Lernaa branchialis. F is SLightly, the Other Figures greatiy, eNlarged. (After A. Scott.)

A, Nauplius, just hatched; B, young female taken from gills of Flounder: C, free-swimming stage of female, after leaving Flounder; D, free-swimming male; E, female just after settling on gills of Whiting; F, fully-developed female.

On the gills of Cod, Haddock, and other common fish, we often find a red worm-like parasite, Lerncea 
branchialis (Fig. 73, F), which at first sight seems to bear no sort of resemblance to a Crustacean. The soft body is curiously doubled up, and is attached to the host by a narrow neck; while dissection will reveal a small head buried in the flesh of the fish's gills, and having three branched outgrowths, which penetrate into the surrounding tissues and make the attachment of the parasite more secure. Near the hinder end of the body are two coiled threads, which are the egg-masses. The reduced mouth parts and the microscopic vestiges of the swimming feet may be detected on and near the head, but apart from these it would be hard to find any characters to show that the animal is a Crustacean.

The life-history of Lerncea is very remarkable. The young are hatched in the nauplius stage (Fig. 73, A), and after passing through some further free-swimming stages they become parasitic on a fish. Curiously enough, however, they choose a very different host from that on which the adults are found, for at this stage (Fig. 73, B) they attach themselves to the gills of one of the Flat-fishes (Pleuronectidæ), such as the Flounder, Plaice, etc., attachment being effected by a frontal cement gland similar to that of the larval Caligidæ, already mentioned. The animal is now without the power of swimming, its appendages becoming reduced to stumps and losing their setæ. After passing some 
time in this condition, the larva again acquires the power of swimming, and leaves its host. Both sexes become mature in this free-swimming stage (Fig. 73, C, D), and impregnation is effected. The males die without developing further, but the females seek a second host, a fish of the family Gadidæ, such as the Cod, Haddock, etc., and, settling on the gills, become metamorphosed (Fig. 73, E) into the adult form described above.

Within the gill cavities of the strange-looking fish known as the Angler or Fishing-frog (Lophius piscatorius) there may often be found specimens of another parasitic Copepod, Chondracanthus gibbosus. It has a soft, unsegmented body about half an inch long, provided with numerous blunt lobes which give it a very irregular shape. On the under-side, near the front, are forked lobes representing two pairs of the swimming feet. At the hinder end are usually attached a pair of long thread-like egg-masses. Just at the point where the egg-masses are attached, close inspection of the under-side of the body will reveal a very minute maggot-like object. This is a male individual, which is attached, like a secondary parasite, to the body of the enormously larger female.

In all the cases mentioned, the animal is parasitic in the final state of its existence-at least in the female sex-but there are a few Copepoda which are free-swimming, both when young and when adult, but parasitic in the intermediate stages. Among the 


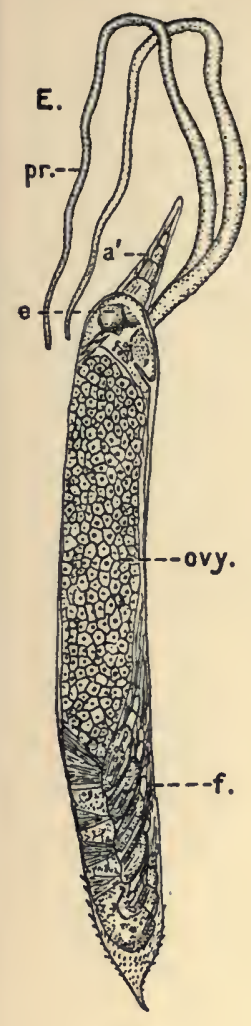

A.

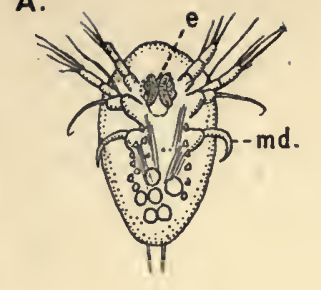

B.

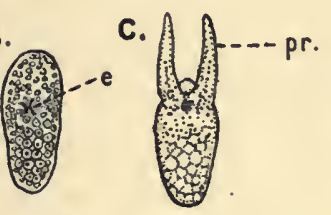

F.
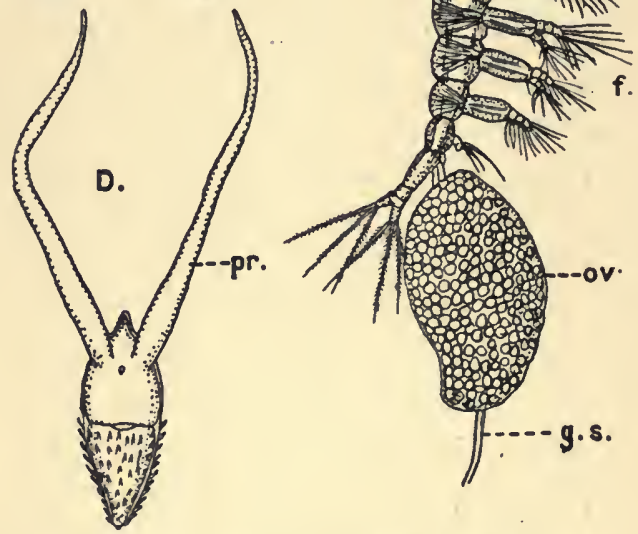

Fig. 74-Stages in the Life.history of Hamocera dana, One OF THE Monstrillid.e. (From Lankester's "Treatise on Zoology," after Malaquin.)

A, Free-swimming nauplius larva; B, embryo after penetrating into the body of the worm Salmacina; C, D, E, successive stages in the body of the host; $F$, free-swimming adult female. (All greatly enlarged, not to same scale.) $a^{\prime}$, Antennule; $b r$, brain ; $c$, nauplius eye ; $f$, swimming feet; $g . s$., hairs on which the eggs are carried; $m$, position of mouth; $m d$, hooked mandible of nauplius ; $n$, nerve cord ; $o v$, mass of eggs carried by female; $o v y$, ovary ; $p r$, absorptive processes. 
Copepoda taken by the tow-net in British seas, there may sometimes be found species of the family Monstrillidæ (Fig. 74, F), which are remarkable for having no appendages between the antennules and the first pair of swimming feet. They have no trace of jaws, and only a minute vestige of a mouth-opening; while internally there is no food-canal, so that the animals are incapable of taking nourishment. Their development was for long a mystery, but it is now known that the greater part of their life is passed as internal parasites in certain bristle-footed worms (Polychæta). The young are hatched as nauplius larvæ (Fig. 74, A) without mouth or foodcanal, but capable of swimming, and having the third pair of appendages (mandibles) furnished with strong hooks, by means of which they fasten on to the worm which is to serve as their host. The nauplius bores through the skin of the worm, casting its cuticle and losing all its appendages in the process, and making its way into one of the bloodvessels in the form of a little oval mass of cells (Fig. 74, B), within which no organs except the degenerating nauplius eye can be detected. It later becomes enclosed in a delicate cuticle, and from one end two long finger-like processes grow out, which are believed to have the function of absorbing nourishment from the blood of the host (Fig. 74, C, D). Within the cuticle the organs of the adult animal are gradually differentiated (Fig. 74, E), and when 
fully formed it bores its way through the tissues of its host by means of rows of hook-like spines surrounding the pointed posterior end of the sac. On reaching the surface the enclosing membrane bursts, and the adult animal is set free.

Of all Crustacean parasites, however, perhaps the most remarkable in their structure and life-history are the Cirripedes of the order Rhizocephala. It is not uncommon on the British coasts to find specimens of the common Shore Crab or other Crabs which carry under the abdomen an oval fleshy body. This is the Rhizocephalan Sacculina carcini (Plate XXIX.), and it would hardly be possible to guess, from its appearance or structure, that it was a Cirripede or a Crustacean at all. It is attached to the under-side of the Crab's abdomen by a short stalk, and in the middle of its opposite surface is a small opening which leads into a cavity separating the outer "mantle" from the body of the animal. Very often this mantle cavity will be found to be full of eggs enclosed in sausage-shaped packets. At the point where the short stalk enters the abdomen of the $\mathrm{Crab}$, it gives off an immense system of fine branching roots, which penetrate throughout the body of the $\mathrm{Crab}$, and even into its legs and other appendages. By means of these roots the Sacculina absorbs nourishment from the body-fluids of its host. Like most Cirripedes, Sacculina is hermaphrodite, and the body within the mantle cavity contains only the 
reproductive organs of the two sexes and a small nerve ganglion representing the whole of the nervous system. There is no mouth, no food-canal, and no trace of appendages. Another Rhizocephalan, Peltogaster, is not uncommonly found attached to the
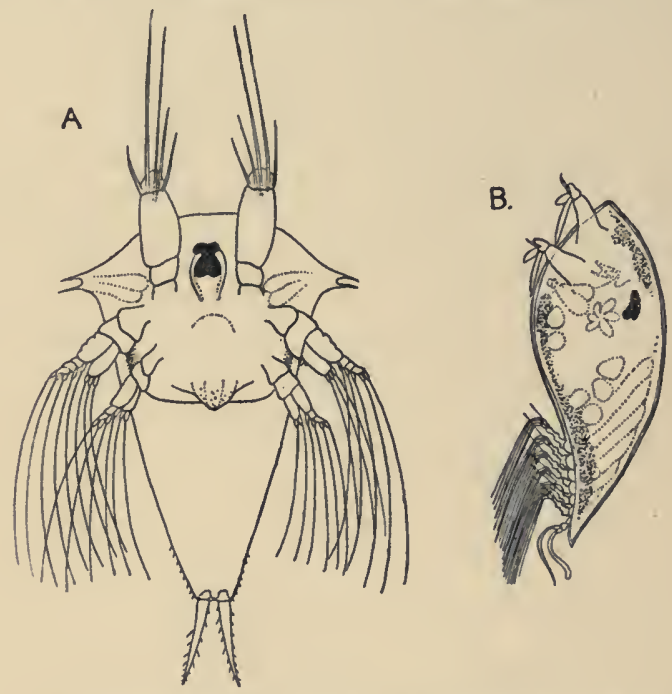

Fig. 75-Free-Swimming Stages of Sacculina carcini. Much ENLARGED. (After Delage)

A, Nauplius; B, cypris stage.

abdomen of Hermit Crabs. Although the nauplius larva of Sacculina was described, and its resemblance to that of the Cirripedia pointed out, as long ago as I836, by that acute observer, J. Vaughan Thompson, it is only recently that the full life-history has been made known by the researches of Professor Delage 
and Mr. Geoffrey Smith. The nauplius larva (Fig. 75, A) resembles that of the normal Cirripedes, especially in the shape of the dorsal shield, which is drawn out on either side in front into a pair of fronto-lateral horns. It has, however, no mouth, and the food-canal is quite absent. As in the normal Cirripedes, the nauplius is followed by a cypris stage (Fig. 75, B), also mouthless, and it is in this form that the Sacculina seeks the Crab on which it is to become parasitic. It would be almost impossible for the cypris larva to settle on that part of the Crab where the adult Sacculina is afterwards to appear, since the Crab usually has its abdomen closely pressed against the under-side of its thorax. The larva therefore attaches itself on some exposed part of the Crab, often on one of the legs, clinging to a hair by means of its antennules. It bores through the cuticle at the base of the hair, and the contents of its body pass into the interior of the Crab as a little mass of cells, the empty cypris shell being cast off. This mass of cells, which constitutes the embryo Sacculina, is carried about by the blood-currents of the Crab till it reaches the under-side of the intestine, where it becomes attached. It now begins to send out roots (Fig. 76), and as it grows the central mass travels backwards along the intestine of the Crab till it reaches the place where the adult parasite is to emerge. As the mass increases in size, and the organs of the Sacculina become differentiated within 
it, its presence causes the living tissues between it and the external cuticle to degenerate, so that when the Crab moults an opening is left through which the body of the parasite protrudes. Owing, no doubt, to the drain on its system due to the presence of the Sacculina, the Crab ceases to grow, and it does not moult again as long as the parasite remains alive.

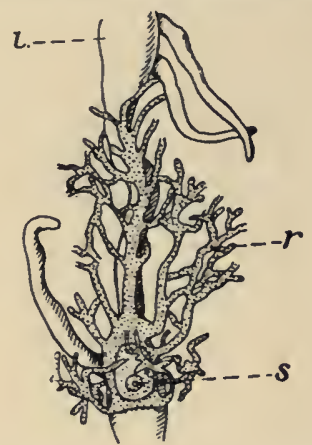

Fig. 76-Early Stage of Sacculina within the Body of a Crab. (After G. Smith.)

$i$, Intestine of the Crab; $s$, body of the Sacculina, which afterwards emerges on the under-surface of the Crab's abdomen; $r$, roots of the Sacculina.

In addition to this arrest of growth, Sacculina produces in its hosts other changes, which affect chiefly the reproductive organs and the structures associated therewith. Crabs of either sex infected with Sacculina are incapable of breeding; the genital gland (ovary or testis) is found on dissection to be shrivelled up, and the external characters indicative of sex become strangely modified. The changes have 
been most fully studied in the case of a kind of Spider Crab common at Naples-Inachus mauritanicus In this species it is found that females infected with Sacculina show no conspicuous external nodification, except that the abdominal appendages, which in the normal females serve for the attachment of the eggs, are greatly reduced in size. Infected males, however, may assume to a greater or less degree the characters proper to the female sex. Some males show little change, except that the chelipeds remain small and flattened, as in the females and nonbreeding males. Other specimens have, in addition, the abdomen much broader than in normal males, and sometimes as broad as in the females. Finally, some males develop on the abdomen, in addition to the rod-like appendages on the first and second somites, characteristic of the male sex, two-branched appendages on the next three somites, as in the females; these individuals are, in fact, so completely intermediate in character between the two sexes that it is only by dissection that it is possible to recognize them as modified males.

An indication of the way in which the degenerate Rhizocephala have been derived from normal Cirripedes is given by a peculiar species of pedunculate Barnacle, Anelasma squalicola, which lives attached to Sharks and Dogfish in the North Sea. In Anelasma the peduncle becomes deeply buried in the flesh of the Shark, and its surface is covered with short 
branching, root-like filaments. As in the case of the Rhizocephala, these roots appear to absorb nutriment from the host, and, although Anelasma possesses a food-canal and mouth, the cirri are reduced in size and devoid of hairs, so that they cannot be used for obtaining food as in ordinary Barnacles. 


\section{CHAPTER XI}

\section{CRUSTACEA IN RELATION TO MAN}

THE Crustacea come into relation with human 1 life in the most obvious and direct way in the case of those species that are used for food. The number of species so used in various parts of the world is very large, almost the only necessary condition being that the species shall be sufficiently large and abundant to make it worth while to fish for it.

As most of the larger Crustacea belong to the Decapoda, it is this order that supplies practically all the edible species, almost the only exceptions being a few Barnacles which are eaten in various parts of the world. Thus the sessile Barnacle Balanus psittacus, found on the coasts of Chili, and growing to a length of 9 inches by 2 or 3 inches diameter, is, according to statements quoted by Darwin, " universally esteemed as a delicious article of food," and the pedunculate Pollicipes cornucopia is used for food on the coasts of Brittany and Spain.

By far the most valuable of all the edible Crustacea are the European and American Lobsters (Homarus 
gammarus and $H$. americamus). The former is found on the coasts of Europe from Norway to the Mediterranean, living mostly a short distance below low-water mark wherever the bottom is rocky. At some places, as for instance at Worthing, Lobsters are common on a sandy bottom, but as a rule they seem to prefer localities where the crevices of a rough hard bottom afford abundance of shelter. They are usually caught in traps known as "Lobster pots" or "creels," which vary in construction in different localities. In some cases they are made of wickerwork, hemispherical in shape, with a funnel-shaped opening on top, so devised as to permit the Lobsters to enter easily, while preventing their escape. Another form is semi-cylindrical, with a framework of wood covered with netting or with wooden spars, and having two funnel-shaped entrances at the sides. These traps are baited with pieces of fish, preferably stale, and are sunk in suitable places, each attached by a line to a buoy or float.

Important Lobster fisheries are carried on in Norway, Scotland, England, Ireland, Heligoland, and other parts of the coasts of Northern Europe. In the South the Lobster fishery is of less importance, other large Crustacea, especially the Spiny Lobster, being more abundant and more highly esteemed.

The American Lobster, as already mentioned, closely resembles the European species, the chief difference being in the form of the rostrum (see 
Fig. 9, p. 32). It is found on the Atlantic coast from Labrador to Cape Hatteras, but it is not abundant south of New Jersey. The canning of Lobsters is a very important industry in Newfoundland, the Maritime Provinces of Canada, and the Northern New England States.

The only other species of the genus Homarus ( $H$. capensis) is found at the Cape of Good Hope, but it is of small size and is of no economic importance.

The European Lobster rarely reaches a weight of ro pounds, although individuals of $\mathrm{I}_{4}$ pounds weight have been caught. In America, there are authentic records of Lobsters weighing 20 and even 23 pounds.

The bad effects of over-fishing have become apparent of late years, especially on the American coast, in the reduced average size of the Lobsters caught rather than in a diminution of the total yield of the fishery. Numerous experiments in legislation have been made with a view to checking the depletion of the fishing-grounds, but in no case with conspicuous success. A "close time" for the spawning Lobsters has often been tried, but the fact that the female carries the eggs attached to her body for nearly a year after spawning makes it quite impossible to give effective protection by this means. In most Lobster-fishing districts a minimum size is fixed by law, below which it is illegal to take or sell Lobsters, and in many cases also the capture of 
females carrying spawn, or, as it is termed, "in berry," is prohibited.

The so-called "Norway Lobster" (Nephrops norvegicus-Plate XXX.), the "Dublin Prawn" of the London fishmongers, is a smaller and much less valuable species than the common Lobster. It may be recognized at once by its long and slender claws, furnished with rows of tubercles or blunt spines, and by the sculptured markings on the somites of the abdomen. When alive it is of an orange colour, beautifully marked with red and white. It differs considerably in its habits from the common Lobster, living at a considerably greater depth (30 to 60 fathoms in Norway), and on a muddy bottom. It is generally taken by trawling, and is captured in large quantities by trawlers fishing in various parts of the North Sea. Since it must be cooked soon after it is caught, and cannot easily be brought to market alive like the common Lobster, only a small number of those actually caught are made use of. Formerly most of those sold in London were caught in the Irish Sea (whence the name of "Dublin Prawn"), but the North Sea is now the chief source of supply. The species is found in suitable localities from Norway to the Mediterranean, and is especially abundant in the Adriatic, where it is caught and sold in Venice and elsewhere under the name of "Scampo."

The Spiny Lobster, Rock Lobster, or Sea-crawfish (Palinurus vulgaris-Plate V.), is common on the 


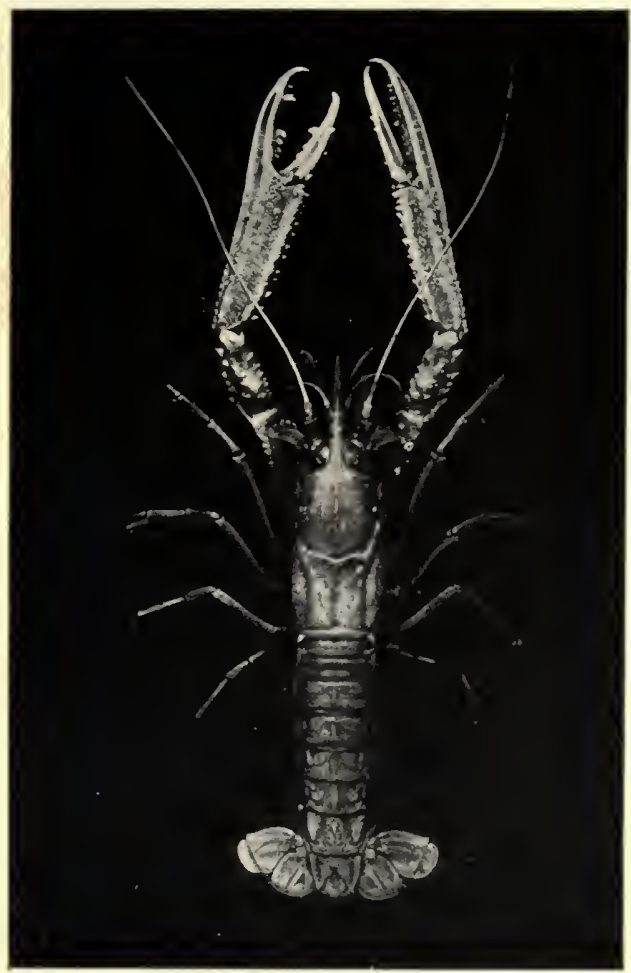

THE "NORIVAY LOBSTER," Nephrops norvegicus, ABOUT ONE-THIRD NATURAL SIZE (From Brit. Mus. Guide) 

south and south-west coasts of the British Islands, becoming rare in the north, although specimens have been found as far north as Orkney, and there is a single record of the species from the West of Norway. It is far less commonly used for the table in this country than in France, where it is known as "Langouste" and is very highly esteemed.

Various species of Spiny Lobsters belonging to the same family (Palinuridæ) as the European species are found in different parts of the world. In tropical countries the species of Panulirus are commonly used for food (for example, $P$. interruptus in California and $P$. fasciatus in India), as are species of Jasus in South Africa, Australia, and New Zealand. Recently a consignment of Spiny Lobsters (Jasus lalandii) was sent to the London market from the Cape, but it appears that the experiment was not altogether successful.

Belonging to the same tribe (Nephropsidea) as the Lobsters are the fresh-water Crayfishes. The English Crayfish (Astacus pallipes) is common in many rivers as far north as Lancashire, and in some parts of Ireland, but is not found in Scotland. It is not much esteemed for the table, and although small numbers are sent to Billingsgate, chiefly from Leicestershire, they are said to be used only for garnishing dishes. The same species occurs on the Continent of Europe, chiefly in the west and south 'France, Germany, Switzerland, Spain, Italy, and 16 
the Balkan Peninsula). It is known in France as "Écrevisse à pattes blanches" (from the whitish colour of the under-side of the large claws), and in Germany as "Steinkrebs," and is distinguished, among other characters, by the shape of the rostrum (Fig. 77, B), which has a tooth on each side close to the point. Far more important as an article of food is the larger Astacus fuviatilis, the "Écrevisse à pattes rouges" or "Edelkrebs," which is found in
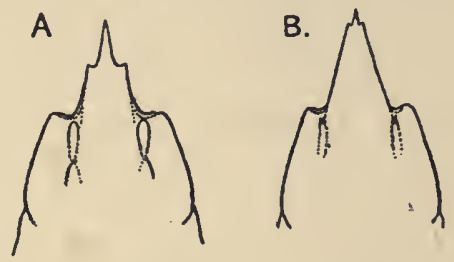

Fig. 77-Rostrom and Fore PART OF CARAPACE, SEEN From A Bove, of (A) RED-CLAWED CRAYFish (Astacus fluviatilis) AND (B) White-clawed or ENGlish Crayfish (Astacus pallipes)

France, Germany, Austria, Southern Sweden, Russia, etc. In this species the under-side of the large claws is generally of a fine red colour, and the rostrum (Fig. 77, A) has a pair of side-teeth about the middle of its length, and a long slender point. The redclawed Crayfish is an important article of commerce on the Continent, and is sent to the London market in considerable numbers, chiefly from Germany and South-West Russia. In France it is cultivated for the market in "Crayfish farms" on a large scale.

A species of Crayfish ( $A$. leptodactylus) occurring in 
the Lower Danube and in other rivers flowing into the Black Sea sometimes finds its way to the London market, although it is less valued than the redclawed species. It is distinguished by its long and slender claws, by the spiny edges of the rostrum, and by other characters. A fourth species (A.torrentium), occurring chiefly in Central Europe, is very closely allied to $A$.pallipes, and, like it, is of little value for the table.

Within the last thirty years the Crayfish fisheries of Western Europe have suffered heavily from outbreaks of an epidemic disease which has all but exterminated these animals in certain districts. In this country it is said to be responsible for the almost complete disappearance of Crayfish from localities where they were formerly plentiful, as, for instance, in the neighbourhood of Oxford. The cause of the disease is believed to be a protozoan parasite belonging to the group Myxosporidia.

In other parts of the world it does not seem that the fresh-water Crayfishes are of much importance as an article of food. Some species of Cambarus are so used to a limited extent in the United States, and the gigantic Astacopsis serratus (Plate XX.) is known as the "Murray River Lobster" in the markets of Sydney and Melbourne.

The Decapods of the suborder Natantia comprise a large number of edible species, generally known as Shrimps and Prawns. The Common Shrimp, 
Crangon vulgaris (Fig. 78), which is plentiful on the British coasts wherever the bottom is sandy, is about two or three inches long, and when alive is of a translucent greyish colour speckled with brown. It differs from most of the Natantia in having the body somewhat flattened from above downwards, and the

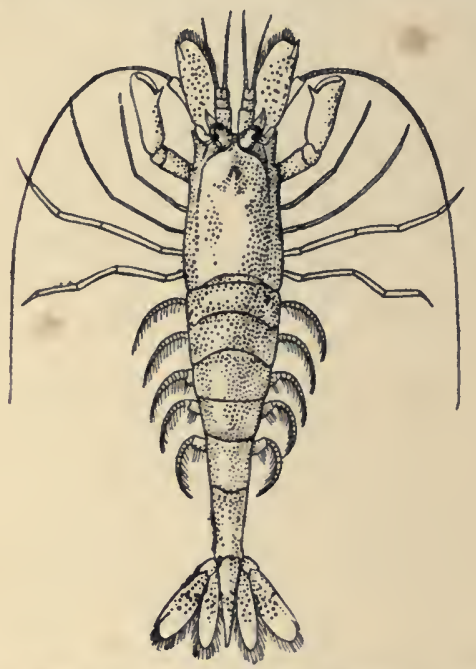

Fig. 78-The Common Shrimp (Crangon vulgaris). Natural Size rostrum very short. When boiled, it is of a reddishbrown colour, and from this it is sometimes known as the "Brown Shrimp." On many parts of the coast the Shrimp fishery is of considerable importance. Most often the Shrimps are caught by means of a large bag-net attached to a semicircular hoop with a long handle, and pushed over the surface 
of the sand by a fisherman wading in the water at ebb-tide.

A variety of species are sold in England under the name of Prawns. The largest of the native species, to which the name of Common Prawn is perhaps most properly restricted, is Leander serratus. It grows to a length of over 4 inches, and has a long serrated rostrum extending beyond the antennal scales and curving upwards at the point. The first and second pairs of legs end in small pincer-claws. When alive the animal is very transparent, and beautifully marked with bands of brown and red on the body and limbs. A smaller species of the same genus (L. squilla), distinguished by the much shorter and straighter rostrum, and another very similar species of which the proper name appears to be L. adspersus (often known as L. fabricii), are said to be sold on some parts of the English coast as "Cup Shrimps."

Much commoner, at least in the London market, than the species of Leander is Pandalus montagui, often sold under the general name of Prawn, but sometimes called the "Pink Shrimp." This resembles Leander serratus in having a long, serrated, up-curved rostrum, but differs from it strikingly in the form of the anterior pairs of feet. The first pair appear to the naked eye to have no pincer-claws, but to end in a sharp point, resembling the third maxillipeds, which are just in front of them. As a matter of 
fact, they do have pincers, but so minute that they can only be detected by microscopic examination. The feet of the second pair are unequal in length on the two sides, that on the left side being the longer, and are very slender. They end in small pincers, and examination with a pocket-lens will show that the carpus, or "wrist," and the segment below it (merus) are broken up into a large number of short

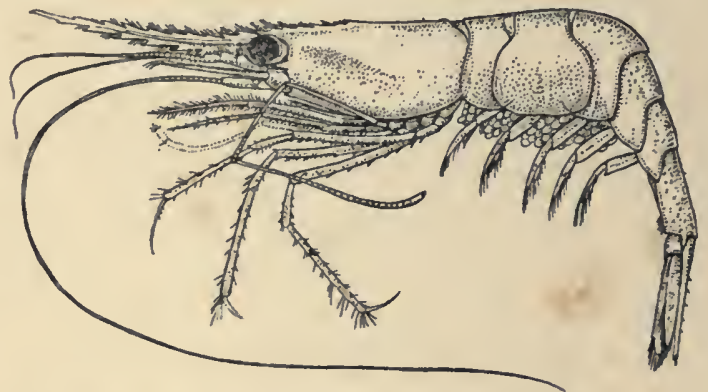

Fig. 79-The Norwegian Deep.water Prawn (Pandalus borealis), Female. (After Sars.)

The second leg of the right side is indicated by dotted lines.

segments, so that the limb is extremely flexible. When alive, the animal is even more handsomely marked than the Common Prawn.

A large species of Prawn is now imported to this country in considerable quantities from Norway. This is Pandalus borealis (Fig. 79), a species closely allied to the last-named, but differing in the longer and more slender rostrum and in many other characters, as well as in its larger size (specimens 
have been recorded of 6 inches in total length). It also differs in its habitat, for while $P$. montagui lives in shallow water, or even between tide-marks, $P$. borealis occurs at depths of 30 to 60 fathoms in the Norwegian fjords. The recent development of the fishery for $P$.borealis in Norway is a striking example of the practical value of zoological research. Until I 898 the species was hardly known except to zoologists, although a small fishery was carried on in the Drammen Fjord, near Christiania. The investigations of the naturalists employed by the Norwegian Department of Fisheries showed that the species existed in vast numbers in the deeper water of many of the fjords, and that it could be captured in abundance by means of a suitably-devised trawl-net. As a result, a very profitable fishery was established, and the "deep-water Prawns" are now not only largely consumed in Norway, but are exported in increasing quantities to the English and other markets.

In the warmer seas the large Prawns of the genus Pencus are of considerable importance. Thus, in the Mediterranean countries, Pencus caramote (Plate IV.) is highly esteemed for food, and $P$. setifer and $P$. brasiliensis are largely consumed in the Southern United States. $P$. monodon and other species are eaten in India. An attempt has been made to send a species of the same genus (apparently $P$. indicus).in a frozen state from Queensland to the London market. 
Numerous other species of Natantia are used for food in various parts of the world, but the only ones that need be further mentioned here are the River Prawns of the genus Palamon, which are abundant in the fresh waters of most tropical countries, and sometimes grow to a very large size. They are generally distinguished by the fact that the legs of the second pair are very long, forming powerful pincer-claws. In the West Indies and Central America, $P$. jamaicensis (Plate XXI.), which reaches a length of Io inches exclusive of the great claws, is sold in the markets, while in India and elsewhere in the East $P$. carcinus, which grows to an even greater size, and other smaller species, are used for food. The fresh-water Prawns of the family Atyidæ, on account of their small size, are not of much importance from this point of view, but Professor Hickson states that the little Caridina nilotica, a very widely-distributed species, is eaten in Celebes.

Among British Crustacea, the next in importance to the Lobster as an article of food is the Edible Crab, Cancer pagurus (Plate XXXI.), known in Scotland as the "Partan." Like the Lobster, it is found on rocky coasts in shallow water, and young specimens are often taken between tide-marks. It grows to a size of more than Io inches across the shell, and may reach a weight of 12 pounds. The means used for its capture are the same as in the case of the Lobster, and the fishery is of considerable 


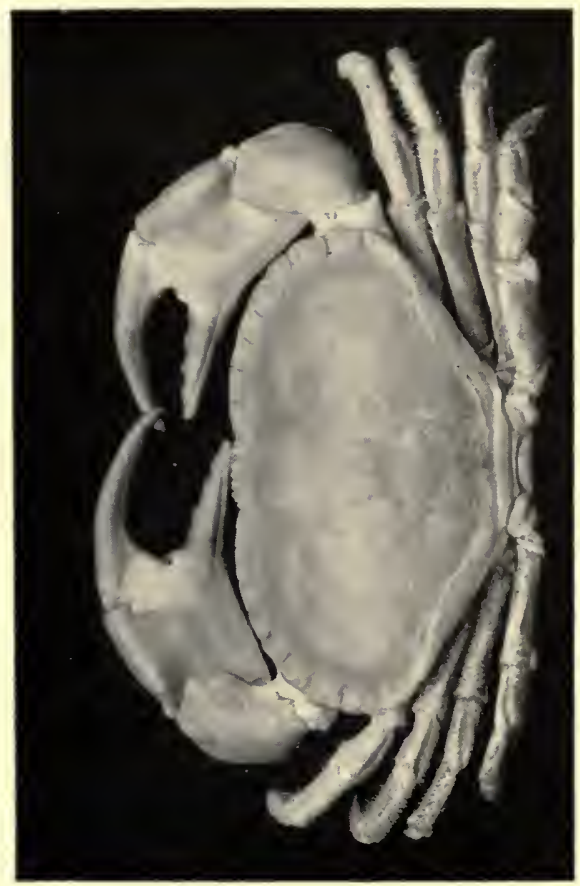

全 

importance on many parts of the British coasts. On the other hand, a Connemara fisherman, who was using these Crabs for bait, received with incredulity the statement that they were good for human food!

The Shore Crab, Carcinus manas (Plate IX.), is not of much importance as food in this country, although it is recorded that fifty years ago great numbers were brought to the London market. On the shores of the Mediterranean and Adriatic, however, and especially in Venice, this species is regarded as a delicacy, particularly in the soft-shelled state after moulting.

On the Atlantic coast of North America, the most important edible Crustacean after the Lobster is the "Blue Crab" (Callinectes sapidus), one of the Swimming Crabs (Portunidæ). This is consumed in large quantities, especially in the soft-shelled state. Several other species of Crabs are eaten in America, including the little "Oyster Crab," a species of Pinnotheres living in the American Oyster. From its small size, and the difficulty of obtaining it in numbers, it is a very costly delicacy.

In the East Indies the most important edible Crabs are various species of Portunidæ, especially the large Scylla serrata and Neptumus pelagicus.

Except as food, the Crustacea are of very little direct use to man. Almost the only instance in which they are otherwise utilized is in the case of 
a species of sessile Barnacle (Balanus) which is cultivated in Japan for use as manure. The method of culture has been described by Professor Mitsukuri. Bunches of bamboo "collectors," like those used for the collection of oyster-spat, are fixed into the ground on tidal flats. After two or three months they are taken up, and the Barnacles with which they have become covered are beaten off and sold for use as manure.

Apart from their direct utility, however, the Crustacea are indirectly of great importance as providing a large part of the food-supply of marketable fishes. From this point of view, a study of the habits and distribution of the commoner species may be of practical value in throwing light on the migrations and other obscure points in the life-history of the fishes that prey upon them. As an example of this, we may refer to some investigations on the Mackerel fishery recently carried out by the naturalists of the Marine Biological Association at Plymouth. In the spring and early summer months the Mackerel migrate into inshore waters for the purpose of spawning. During this period the fish congregate in shoals at the surface of the sea, and are captured in drift-nets. The extent of this "shoaling" varies greatly from year to year, and determines whether the season shall be a profitable one for the fishermen or not. When shoaling, the fish feed exclusively on plankton, consisting largely of Copepoda, and it has 
been shown by Mr. G. E. Bullen that the fluctuations in the yield of the Mackerel fishery from year to year follow very closely the fluctuations in the abundance of the Copepod plankton on the fishing-grounds. The investigation has been carried a step farther by Dr. E. J. Allen, who points out that the abundance of Copepods is determined by the abundance of the Diatoms and other minute vegetable organisms of the plankton. These organisms are very largely influenced by the amount of sunshine during the period of their development in the earlier months of the year. Dr. Allen gives a diagram showing for each of seven years (I902-I 908 ) the average number of hours of bright sunshine during the months of February and March in the South-West of England. With this he compares the number of fish caught in the month of May in each of these years by certain vessels engaged in the western Mackerel fishery. The correspondence between the two is very striking indeed, and justifies his conclusion that the amount of sunshine in the early months of the year determines the abundance of the vegetable life of the plankton, and through it of the Copepods and other animals which form the bulk of the plankton a little later in the year; and although there are doubtless other influences at work determining the success or failure of the fishery, it is largely a matter of the richness or poverty of the plankton harvest. 
None of the Crustacea can be regarded as directly harmful to man. They have not the power of inflicting envenomed wounds which renders some other Arthropods, such as Scorpions, some Spiders, Centipedes, and Insects, formidable in spite of their small size; and although blood-curdling tales of the ferocity of the Land Crabs are to be found in the accounts of old voyages, even the largest of these is hardly an antagonist to be dreaded.

A considerable number of invertebrate animals, not of themselves noxious, are now known to be the indirect cause of much serious injury to human life by harbouring and disseminating organisms which produce disease. The progress of research is adding, almost every day, to the number of species known to be disease-carriers, and it is possible that in the future some Crustacea as yet unsuspected may be added to the list.

At present, however, there is only one case in which a Crustacean has been shown to be concerned in the transmission of a parasite of man. The "Guinea-worm," Filaria (or Dracunculus) medinensis, is a parasite belonging to the group of "Threadworms" (Nematoda) which causes dangerous abscesses under the skin of the legs in many parts of tropical Africa. It has been shown that the embryos of the worm, which are discharged in vast numbers on the bursting of the abscess, do not develop unless they fall into water containing certain 
species of the Copepod Cyclops (see Fig. I4, p. 39). In some way not yet understood, the embryos penetrate into the body cavity of the Cyclops, where they undergo a metamorphosis. For their further development it is necessary that the Cyclops should be swallowed by man, as may easily happen in drinking water from a pond. When the Cyclops is digested the larval worms are set free, and they bore their way through the tissues of their human host till they reach the place (generally under the skin of the leg) where they complete their development and produce the innumerable embryos that are set free in the way just described.

A few Crustacea inflict a certain amount of injury on man in more indirect ways. In tropical countries, Land Crabs are often troublesome in gardens, and may cause serious damage to young plants in sugarcane plantations and rice-fields. In gardens in this country, the Woodlice, as already mentioned, are sometimes destructive to seedlings and delicate plants. The little fresh-water Isopod, Asellus aquaticus, is accused of destroying the nets used in fishing for Pollan in Lough Neagh in Ireland.

Probably the most important of all Crustacea, however, as regards their destructive activity, are the species which bore into wood, and sometimes do extensive damage to the submerged timber of piers, jetties, and similar structures. On our own coast the most destructive is a little Isopod known as the "Gribble" 
(Limnoria lignorum-Fig. 80), which is distributed from Norway to the Black Sea, and occurs also on the Atlantic coast of North America. Several species of the same genus having similar habits are found in other parts of the world. The Gribble was first discovered as a British species by Robert Stevenson, the celebrated lighthouse engineer, who found it in

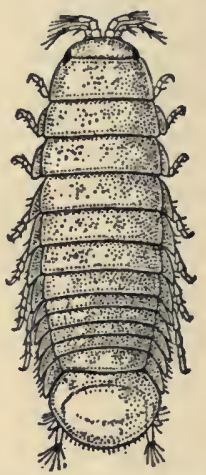

Fig. 80-The Gribble (Limnoria lignorum). Mvch enLaRged (From British Museum Guide, after Sars.)

I8II destroying the woodwork employed in the erection of the Bell Rock Lighthouse, and sent specimens to Dr. Leach of the British Museum. The animal is only about one-eighth of an inch in length, and its cylindrical burrow is about onefifteenth of an inch in diameter, and penetrates for a depth of one or two inches. The excavation of the wood is effected by means of the mandibles, which are unusually strong; and when the animals are 



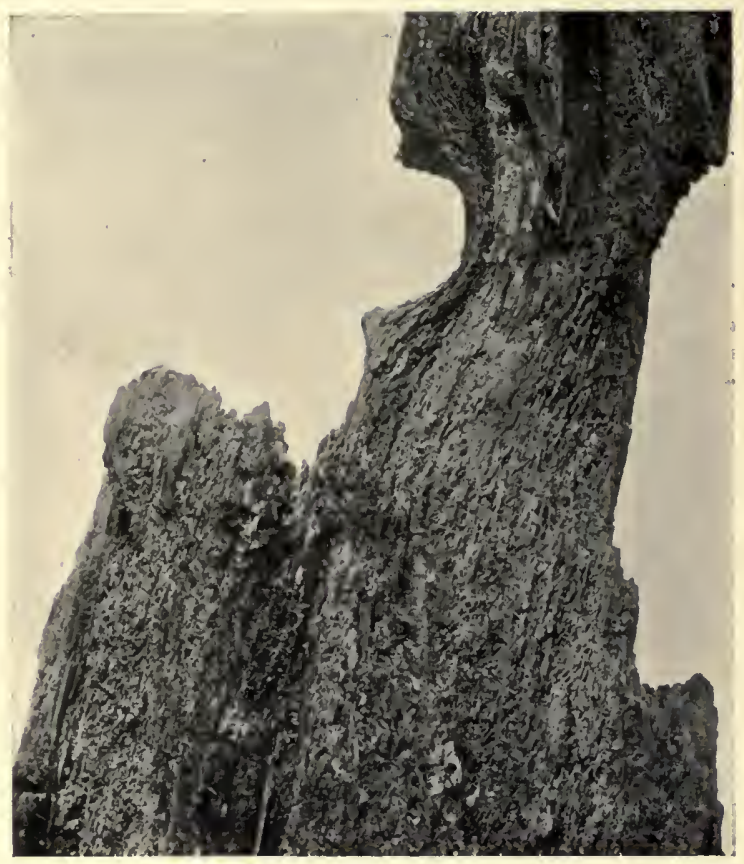

PIECE OF TIMDER FROM RYDE PIER SHOWING DAMAGE CAUSED BY Limnoria AND Chelura

(From Brit. Muss. Guide) 


\section{CRUSTACEA IN RELATION TO MAN 255}

numerous the burrows are driven so close together that the surface of the wood is reduced to a spongy mass which is rapidly washed away by the waves (Plate XXXII.). The Gribble is often accompanied by another Crustacean of similar habits, the Amphipod Chelura terebrans. The latter is about one-fifth of an inch in length, and differs from most Amphipods in having the body somewhat flattened from above downwards instead of from side to side. The burrows made by Chelura are shallower than those of the Gribble, and generally run more or less parallel to the surface of the wood. 


\section{CHAPTER XII}

CRUSTACEA OF THE PAST

SINCE the acceptance by naturalists of the theory $S$ of Evolution as indicating the mode of origin of the various forms of life now existing, one of the chief lines of biological investigation has had for its object the reconstruction of the pedigree (or, as it is called, the "phylogeny") of the larger groups of the animal and vegetable kingdoms. In attempting to do this, there are three main sources from which evidence may be drawn. The results of Comparative Anatomy enable us to decide with more or less confidence as to the degrees of relationship between the groups of organisms, and to distinguish between the more primitive and the more specialized; the study of Embryology is, at least, an indispensable adjunct to Comparative Anatomy, even if it does not, as was once supposed, give us an actual recapitulation of ancestral history; and, finally, the study of Fossil Remains holds out the hope that we may be able to find the ancestral types themselves.

It is clear that evidence from the last-named 256 
source, when it is available, is the most important of all, since the order of succession of the various types is given by that of the rock strata in which they occur, and we can be quite certain that we are dealing, if not with the actual ancestors, at least with the forerunners of existing species. The " imperfection of the geological record," however, is so great that the organisms preserved in the fossil state represent only an insignificant part of the whole number of organisms that have lived on the globe since life began; and it is not surprising, therefore, that in many groups the study of fossils has hitherto afforded little help towards the working out of their genealogical history. Thus, among Crustacea there are many important groups such as the Copepoda, which are entirely unknown as fossils, their small and delicate bodies being ill adapted for preservation, although there is every reason to suppose that they are a very primitive and very ancient group. In many fossil Crustacea only the hard shell or carapace has been preserved, the appendages being lost or represented only by indecipherable fragments, and in some cases it is hardly possible to guess at the affinities of the animals. Further, several important groups are already represented in some of the oldest of the fossil-bearing rocks at present known, and the differentiation of these groups must have taken place in the dark ages before the record of the fossils 
begins. In spite of these disadvantages, however, the study of fossil Crustacea does throw considerable light on the evolution of the group, and it is likely that interesting results in this direction await future investigations.

In the earliest fossiliferous rocks the most abundant and important Arthropods are the Trilobites (Fig. 8I),
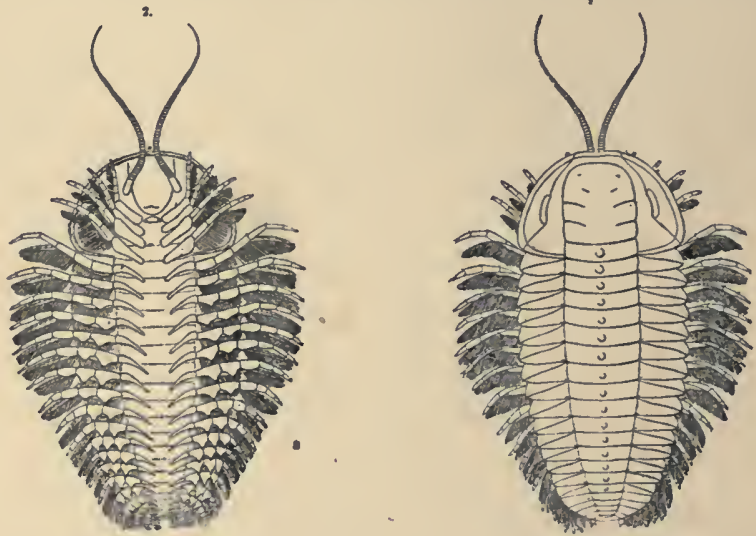

Fig. 8I-Restoration of a Trilobite (Triarthrus becki), showing the ApPendages. UpPer Side on Right, Under-Side on Left. Slightly enlarged. (After Beecher.)

an extinct group which appears to have been related to the primitive Crustacea. The name Trilobite refers to the three-lobed form of the body when seen from the dorsal side, most species having a pair of grooves running lengthwise which divide off a middle lobe containing the principal organs of the body from two lateral "pleural" expansions covering the limbs. 
The head-shield shows indications of being composed of five segments, and bears a pair of sessile compound eyes. It is followed by a number (up to twenty-six) of free somites, and the body ends in a tail-shield, or "pygidium," which is often plainly composed of several somites fused together. Although Trilobites are among the commonest and most familiar of fossils in the older rocks, the nature of their appendages remained quite unknown until within recent years, when specimens of several species showing the structure of the limbs and under-side of the body were discovered in America. From these it appears that the head bore in front a pair of long thread-like antennæ and four pairs of two-branched appendages, each with a jaw process, or "gnathobase," turned towards the mouth, which is covered below by a large anterior lip, or " hypostome." It seems probable that the five pairs of head-appendages correspond respectively to the antennules, antennæ, mandibles, maxillulæ, and maxillæ, of Crustacea; but the second pair appear to have acted as jaws, retaining the gnathobase which, among Crustacea, is only hinted at by the hooked spine on the antenna of the nauplius larva.

Each of the free somites and of those forming the tail-shield bears a pair of two-branched appendages, not differing greatly from the posterior appendages of the head, but becoming smaller and more flattened towards the hinder end of the body. The numerous 
genera and species of Trilobites present great differences in the form and ornamentation of the dorsal surface of the body, and it is probable that considerable differences may also have existed in the structure of the limbs, which are only known in two or three species. Some Trilobites are among the most ancient of known fossils, being found in rocks of the Lower Cambrian epoch. The group reaches its maximum development in the Ordovician, and the number of the species and size of the individuals gradually diminish through the Silurian and Devonian till they become extinct at the close of the Carboniferous epoch, except for a single species found in rocks of Permian age in America.

Although zoologists are not all agreed as to the precise systematic place to be assigned to the Trilobites, there can be little doubt that they were related more or less closely to the most primitive Crustacea, and they are of special interest as preserving for us the stage in which the second pair of appendages were still used as biting jaws, and had not moved forwards in front of the mouth to become antennæ, as in all living Crustacea.

Contemporary with some of the earliest Trilobites, however, are undoubted Crustacea, which, so far as we know their structure, are not very different from types now living. In the Cambrian epoch the Branchiopoda appear to be represented by Protocaris, which in its general form resembles Apus; and 
there are a variety of genera and species of Ostracoda, although, since their shells alone are preserved, it is not possible to determine their exact relations to existing forms. In the succeeding Ordovician and Silurian epochs we first meet with the remains of Barnacles, and it is interesting to note that some of them are referred to the genera Pollicipes and Scalpellum, which are represented by numerous species in the seas of the present day. Along with these, however, are some strange-looking forms (Turrilepas, etc.), having the body covered with rows of overlapping plates. If these are really Cirripedes, they must have differed considerably in structure from the more modern types.

The Malacostraca are more interesting from the point of view of palæontology than the other subclasses of Crustacea, since the evolution of the group appears to have taken place within the period covered by the fossil records, and it is possible to trace the course of that evolution-at least, in its broad outlines. It has already been pointed out that the most primitive of existing Malacostraca are the Phyllocarida (Nebalia and its allies), which are in several respects intermediate between the higher Malacostraca and the Branchiopoda; and it is interesting to find that fossils apparently belonging to the Phyllocarida are found far earlier than any of tine other Malacostraca. In the Cambrian, and more abundantly in the Ordovician and Silurian, there are found 
Crustacea (Fig. 82) that resemble Nebalia in having a large bivalved carapace, with a movable beak-like plate in front, a projecting abdomen without conspicuous limbs, and a pair of large spines at the sides of the telson. Unfortunately, we have almost no knowledge of the structure of the limbs; but it can hardly be doubted that these very ancient Crustacea were allied to the existing Phyllocarida,

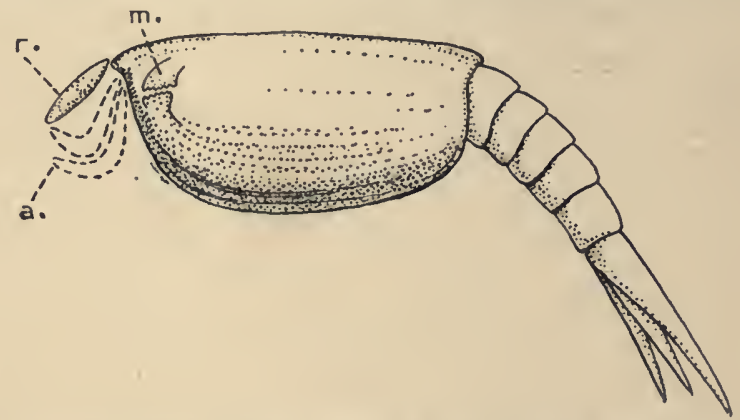

Fig. 82-Ceratiocaris papilio, ONe of the Fossil Phyllocarida. (From Lankester's "Treatise on Zoology," after H. Woodward.) $a$. Traces of antennules ; $m$, possibly mandibles ; $r$, rostral plate

and that they included the forerunners of the higher Malacostraca.

It is in the Carboniferous epoch, in all probability, that we must look for the origin of most of the existing orders of Malacostraca. In the rocks of this age in different parts of the world there have been found a number of undoubted Malacostraca, nearly all of the shrimp-like form which there is good reason to believe to be a primitive character- 
istic. Some of these (Pygocephalus-Fig. 83) have recently been shown to possess a brood-pouch formed of overlapping plates on the under-side of the thorax, and thus resemble the existing Mysidacea, which stand at the base of the Peracaridan series of orders. Others have a pair of strong side-spines near the tip of the telson, and in other ways resemble the recent

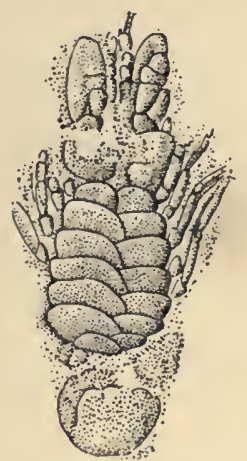

Fig. 83-Pygocephalus cooperi, FRom the COAL-MEasures: UNDERSide of a Female Specimen, showing the Overlapping Plates of the Brood-Podch. (From Lankester's "Treatise on Zoology," after H. Woodward.)

Euphausiacea, so that they may have been primitive members of the Eucaridan series.

Among the Crustacea of the Carboniferous and Permian epochs, there are a number of forms of which the affinities were until recently quite obscure. They have two-branched antennules, a scale-like exopodite on the antenna, and the last pair of appendages (uropods) form, with the telson, 
a tail-fan. In these points they resemble the shrimplike forms, but there is no carapace, and all the somites of the thorax are distinct, so that the form of the body is rather that of an Amphipod or Isopod. On the discovery of the remarkable Crustacean Anaspides (Fig. 84), which lives in fresh-water pools in the mountains of Tasmania, it was pointed out that it agreed with the fossil genera Uronectes, Palco-

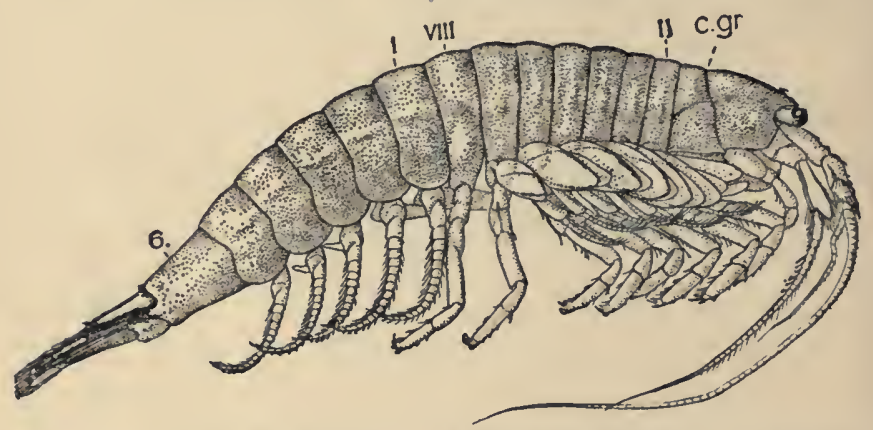

Fig. 84-The Tasmanian "Modntain Shrimp" (Anaspides tasmania), a Living Representative of the Syncarida. SLIGHTLY ENLARGED

c.gy., ". Cervical groove," marking off the first thoracic somite; ii-viii, the remaining thoracic somites; $1-6$, the abdominal somites

caris, and their allies, in those very characters in which they differed from all other Crustacea, and that it must be regarded as a surviving representative of the ancient group to which the name of Syncarida had been given. The more recent discoveries of living forms, Paranaspides from the Great Lake of Tasmania and Koonunga from fresh-water pools near 
Melbourne, and of the fossil Prcanaspides (Fig. 85) from the Coal-measures of Derbyshire, have tended to support this conclusion. There can be little doubt that the Syncarida arose during the Carbon. iferous epoch (or earlier) from primitive shrimp-like forms which lost the carapace; but, after flourishing for a relatively brief period, the group dwindled away,

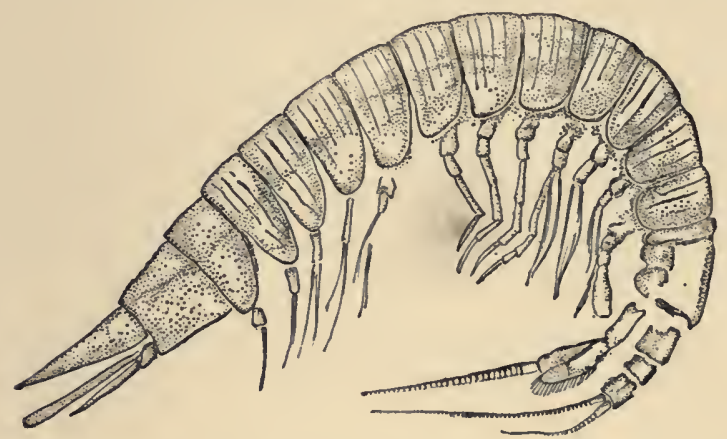

FIG. 85-Praanaspides pracursor, ONE OF THE Fossil Syncarida, from the Coal-measures of Derbyshire. Slightly enLARGED. (After H. Woodward.)

although a few survivors have lingered on, like so many other "living fossils," in the isolated Australian region.

It must be pointed out that, in spite of the resemblance of the body of Anaspides to that of an Amphipod, the Syncarida can have had no close relation to the origin of the Isopoda and Amphipoda. These have also been derived from a shrimp-like type, but their possession of a brood-pouch, among 
other characters, shows that they are linked on to the Mysidacea, and must have arisen from some primitive member of that group, like Pygocephalus. Although palæontology as yet gives little help in tracing the course of their evolution, we can imagine what the intermediate links must have been like by comparison with the living Cumacea and Tanaidacea.

It is possible, indeed, that the divergence of the Isopod line of descent from that of the Mysidacea took place earlier than the Carboniferous epoch, for there has recently been discovered in rocks of Devonian age in Irelarld a single specimen of a fossil, to which the name of Oxyuropoda has been given, which has every appearance of being an Isopod. At all events, undoubted Isopods make their appearance in rocks of the Secondary Period, and some of those from the Jurassic epoch are not very different in general form from types still existing.

Some of the Carboniferous shrimp-like Crustacea present characters which seem to point in the direction of the Stomatopoda, and fossils which clearly belong to that group are found in Jurassic and later deposits. In the Cretaceous epoch there were Stomatopoda resembling modern types so closely that they have been referred to the existing genus Squilla. We are even able to say that they resembled the living Stomatopoda in their mode of development, for larvæ of the type known as Erichthus have been 
recognized in rocks of Cretaceous age from Lebanon. This is a striking example of the way in which, by a fortunate accident as it were, organisms apparently ill-adapted for fossilization may occasionally be preserved.

Of the Decapoda the geological history is tolerably full, and it is possible to trace in its broad outlines the course of evolution of the various suborders. Here again it is likely that the beginnings of the group are to be sought for in the Carboniferous epoch, and some of the obscure shrimp-like forms of that age show hints of an affinity with the Decapods. In the Triassic epoch, however, and more abundantly in the succeeding Jurassic, a number of types are found which seem to include primitive representatives of several of the existing groups of Natantia and Reptantia. It is noteworthy that among them are some forms ( $\mathbb{E g e r}$, etc.) resembling the existing Stenopidea, a tribe which in some respects is intermediate between these two suborders. In the Stenopidea the first three pairs of legs bear pincer-claws, as in the Lobster, but the third pair is much the largest; and $A$ ger agrees with them in this unusual character, though there is little else, in what is known of its structure, to help to determine its affinities.

The tribe Penæidea, which occupies in many respects a primitive place among the Natantia, is abundantly represented in the Jurassic epoch, 
especially in the lithographic stone (Upper Jurassic) of Solenhofen, and by somewhat doubtful specimens from the earlier Trias. All these agree in having the first three pairs of legs with pincer-claws, and not differing greatly in size. Some of the Jurassic and later fossils are of so modern a type that they have been referred to the existing genus Pencus.

The Upper Jurassic rocks also preserve the earliest undoubted specimens of true Prawns of the tribe Caridea, and some of these show swimming branches (exopodites) on the thoracic legs, so that they were probably related to the primitive family Acanthephyridæ, of which the existing members are found in the deep sea. It is possible, however, that Caridea were already in existence far earlier, for some of the obscure Carboniferous forms seem to have the broadened side-plates of the second abdominal somite, which, so far as we know, are exclusively characteristic of that tribe.

The Reptantia, forming the other large division of the Decapoda, also had their origin at least as early as the Triassic epoch, where representatives of the tribes Eryonidea and Scyllaridea are found. The history of the Eryonidea has already been discussed (p. I33) in dealing with the deep-sea Crustacea. The oldest representatives of the Scyllaridea belong to a family (Glyphæidæ) now wholly extinct, and are in many respects more primitive and lobster-like than any of the living Spiny Lobsters and their allies 
(Palinuridæ and Scyllaridæ). Forms with greatly thickened antennæ, indicating a transition to the Palinuridæ, begin to appear in the Jurassic; and in the later Cretaceous a genus, Podocrates, occurs which is hardly to be distinguished from Limuparus, now living in Japanese seas. The Scyllaridæ have the antennæ modified into broad shovel-like plates, and perhaps take their origin from Cancrinus, in the Solenhofen lithographic stone (Jurassic), which has broad and apparently flattened antennæ. True Scyllaridæ are certainly found in Cretaceous deposits, and some, from the Upper Chalk, are even referred to the existing genus Scyllarus.

The Anomura are almost unknown as fossils, but the true Crabs, or Brachyura, are abundantly represented. They first appear about the middle of the Jurassic epoch, and, as already pointed out, the earliest forms (Prosoponidæ) are referred to the Dromiacea, and appear to be closely related to the primitive Homolodromiidæ now living in the deep sea (p. 134). One of the oldest, and at the same time one of the most completely known, is Protocarcinus, from the Great Oolite of Wiltshire, which is preserved (in the only known specimen) with the abdomen partly extended, possibly indicating that the abdomen was less closely doubled under the body than in modern Crabs.

The next group of Crabs to appear are the Oxystomata, which are found from the middle of the 
Cretaceous epoch onwards. The Brachyrhyncha perhaps begin to appear about the same time, but the affinities of the earlier types are doubtful, and it is only in the Tertiary that they become abundant and unmistakable. Several living genera, such as Cancer, date back to the Eocene. The Spider Crabs (Oxyrhyncha) are rare as fossils, and the earliest specimens are found near the beginning of the Tertiary. 


\section{A P PEN DIX}

I. METHODS OF COLLECTING AND PRESERVING CRUSTACEA

$\mathrm{T}$ may be useful to give here a few hints as to the 1 methods of collecting Crustacea. Of the species that live in the sea, many may be found between tidemarks by turning over stones and searching among sea-weeds and in rock crevices. A small hand-net, made by fastening a bag of coarse muslin to a stout wire ring of a few inches diameter, is useful for fishing in rock pools. Shore-collecting in this manner is most productive at spring-tides, when the deeper levels of the shore are open to exploration.

Many burrowing species are to be found by digging in the sand near low-water mark. In addition to Crabs and other large species, many minute forms, Amphipods, Cumacea, and the like, inhabit such localities. The best way of collecting these is to stir up a spadeful of the sand in a bucket of water, and, after allowing the sand to settle for a few seconds, to pour off the water through a muslin bag. After repeating the operation two or three times, the contents of the bag are washed out into a jar or dish 
of sea-water for examination with a lens or under the microscope.

Dredging is the most effective method of obtaining Crustacea that live in deeper water. The dredge usually employed by naturalists consists of a heavy rectangular iron frame to which is attached a strong bag-shaped net. The two longer sides of the frame are sharp-edged and bevelled outwards, so as to "bite" when the dredge is dragged along the seabottom. To the shorter sides are hinged a pair of arms ending in rings. The dredge-rope is made fast to one of these rings, while the other is held only by a "stopping" of yarn, which gives way if the dredge should catch on a rock, and permits it to be dragged sideways off the obstruction. The size and weight of the dredge may vary according to the depth at which it is to be used and the power available for working it. A convenient size for use with a small sailing boat at moderate depths has a frame 20 by 5 inches.

Apart from-dredging, many specimens from moderately deep water may be picked out from among the "rubbish" brought up on fishermen's lines or by the trawl, and various Crustacea besides the edible species find their way into Lobster and Crab pots. The true deep-sea fauna is, for the most part, only to be reached by specially-equipped expeditions, although specimens from great depths are occasionally obtained during the operations for the repair of submarine telegraph cables.

The floating animals of the surface of the sea are 
to be captured by means of the tow-net. This consists of a conical bag of muslin, cheese-cloth, or, best of all, silk " bolting-cloth," attached to a galvanized iron ring of one or two feet in diameter, and having a zinc can or a strong glass jar fixed to the narrow end. The ring is attached by three equidistant cords to the towing line, and the net is towed slowly at or near the surface of the sea. When taken on board, the contents of the can are emptied into a jar of sea-water for examination. The tow-net is best used when there is only enough way on the boat to keep the net from sinking; if towed more rapidly, delicate organisms are apt to be crushed by the pressure of the water, or the net itself may be burst. The use of unnecessarily, fine nets should be avoided. A fine-meshed net may not capture a single specimen of the larger Crustacea, even though these may be swarming in the water through which it is drawn.

By weighting the tow-net it may be used at various depths to capture the floating animals of mid-water. When it is so used, however, it is impossible to tell from what depth any particular specimen may have come, since it may have been captured during the hauling in of the net. For more precise investigations in deep water, "closing tow-nets" of various types have been devised, which can be opened by a "messenger" sent down the line when the net has reached the desired depth, and closed again by another "messenger" before it is hauled in.

A simple method that has proved very successful I 8 
for collecting small Crustacea living on a sandy bottom in shallow water is to employ a light tow-net with a cane ring, and with a heavy sinker attached to the towing line at a distance of a few feet in front of the net. As the sinker is dragged along the bottom, the net floats up behind it, and catches small animals stirred up by its passage.

For collecting the smaller fresh-water CrustaceaWater-fleas and the like-a small muslin ring-net may be used in ponds and ditches. The plankton of the open water of lakes is best obtained by means of a tow-net like that described above for use in the sea.

The interesting blind species known as "Well Shrimps" are to be looked for in the water of springs and wells. In wells fitted with a pump, Professor Chilton found that "the Crustacea are often brought up most abundantly when pumping is first commenced, and that jerking the handle of the pump somewhat violently is often more successful than pumping at the ordinary rate." In disused open wells, they may be trapped by baiting a muslin ring-net with a piece of stale meat or fish, and pulling it up rapidly after it has remained in the well for a few hours. The subterranean waters of caves have yielded many curious species in various parts of the world. For the capture of species living in the deep water - of large lakes, a special form of dredge has been devised with runners to prevent it from sinking into the soft mud, while the mouth of the net is raised a few inches above the bottom. 
For preserving Crustacea the best medium to use is 70 per cent. alcohol. Strong spirit diluted with a little less than one-third its bulk of water gives about the required strength. If too strong spirit is used, the specimens tend to be hard and brittle, and delicate organisms become shrivelled. Methylated spirit as sold in the shops in this country contains mineral naphtha, and turns milky when water is added, so that it is unsuitable for preserving specimens. Methylated alcohol without naphtha can be bought, by permission of the Inland Revenue authorities, but only in considerable quantities at a time.

Formalin is very cheap and readily obtained, but it is much less suitable than spirit for most Crustacea, as it tends to make them stiff and fragile, and small forms containing much lime, such as Cumacea, may become decalcified. For Crustacea collected by the tow-net, however, formalin gives good results. A few drops of strong formalin, added to the water into which the tow-net has been washed, kills the animals in a few minutes. After they have sunk to the bottom, the liquid may be poured off and replaced by formalin diluted with sea-water (for marine plankton), or by a mixture of formalin and spirit. The most suitable strength of formalin varies with different organisms, but 5 per cent. (i.e., I part of commercial formalin to I9 parts of water) is perhaps most generally useful.

Crabs, Prawns, and the like, if put alive into strong spirit, may throw off some of their limbs, 
or else become so rigid that these break on the slightest manipulation. This may often be avoided by killing the animals in weak spirit (3o per cent. or less) before preserving in strong spirit. Marine species may also be killed by placing them in fresh water, care being taken not to allow them to remain in it longer than is necessary, as it causes distortion of the membranous appendages.

The larger Crabs, Lobsters, and the like, may be preserved dry, although in this state they are unsuitable for examination of the more delicate appendages. The carapace should be detached, and the soft parts cleaned away as far as possible, a bent wire being used, if necessary, to remove the flesh from the legs. The specimens should be dried in the shade, to preserve as much as possible of the natural colour.

With specimens intended for permanent preservation in spirit, the use of corks should be avoided, as they discolour the spirit, and ultimately the specimens. Small specimens are most conveniently kept in glass tubes closed with a piece of clean elder-pith (not cotton-wool), and placed, upside down, in a bottle of spirit. Labels to be placed inside the tubes are best written with Indian ink, and allowed to dry before immersion in the spirit. 


\section{NOTES ON BOOKS}

The literature of Carcinology is bewildering in its extent, and is for the most part scattered through the volumes of scientific periodicals and the publications of learned societies in most of the languages of Europe. A guide to the current literature is provided by the Zoological Record, the latest volume of which, relating to the year I909, enumerates no fewer than 337 papers dealing wholly or in part with this group of animals.

The following short list of books in the English language may be of some help to the beginner. Most of them give references to the literature which will provide the necessary guidance towards a further study of the subject.

\section{General Work}

Huxley, T. H. The Crayfish : an Introduction to the Study of Zoology. International Science Series, vol. xxviii. London, 1880.

Stebbing, $T . R . R$. A History of Crustacea : Recent Malacostraca. International Science Series, vol. lxxiv. London, 1893 .

Calman, W. T. Crustacea. A Treatise on Zoology, edited by Sir Ray Lankester. Part vii., fascicle iii., London, 1909. Smith, G., and Weldon, W. F. R. Crustacea. The Cambridge Natural History, vol. iv. London, 1909.

Lister, J. J. Crustacea, in "A Student's Textbook of Zoology," by Adam Sedgwick. Vol. iii. London, 1909. 


\section{British CRUSTACEA}

Baird, W. The Natural History of the British Entomostraca. (Ray Society.) London, I850.

Bell, T. A History of the British Stalk-eyed Crustacea. London, 1853 .

Spence Bate, C., and Westword, J. O. A History of the British Sessile-eyed Crustacea. 2 vols. London, 1863 and 1868. Brady, G. S. A Monograph of the Free and Semiparasitic Copepoda of the British Islands. (Ray Society.) 3 vols. London, 1878-1880.

These works, although still valuable, and indeed indispensable, are now more or less out of date. A list of British Malacostraca (except Amphipoda) will be found in Mr. Stebbing's volume mentioned above.

Sars, G. O. An Account of the Crustacea of Norway. Vol. i., Amphipoda, 1890-1895. Vol. ii., Isopoda, I896-1899. Vol. iii., Cumacea, 1899-1900. Vols. iv. and v., Copepoda, 1903 (in progress). Christiania and Bergen.

A very large proportion of the British species in the groups mentioned are described and figured in this splendid series of volumes. The text is in English.

Norman, A. M., and Scott, T. The Crustacea of Devon and Cornwall. London, 1906.

$W e b b, W . M$., and Sillem, C. The British Woodlice. London, 1906.

Memoirs of the Liverpool Marine Biology Committee, edited by Professor W. A. Herdman. A useful series of mono. 


\section{NOTES ON BOOKS}

graphs on the structure and life-history of common British marine animals and plants. The following relate to Crustacea :

Memoir VI. Lepeophtheirus and Lernæa (Parasitic Copepoda). By A. Scott. 1901 .

Memoir XII. Gammarus (Amphipod). By $M$. Cussans. 1904.

Memoir XIV. Ligia (Isopod). By C. G. Hewitt. 1907.

Memoir XVI. Cancer (Edible Crab). By J. Pearson. 1908.

Descriptions of all the British species of Barnacles will be found in Darwin's "Monograph of the Sub-class Cirripedia." (Ray Society.) 2 vols. London, 1851-1854. 


\section{INDEX}

AвDOMEN of Lobster, 6 Abyssal fauna of lakes, 185 Acanthephyridæ, 268

Acoril-shells, 4I

Aga: in Sponges, 210 ; parasitic on fish, 2 Ig

Ager, 267

E glea, I8I

Air-breathing Crabs, 188

Albunea, 102

Alcock, A.: on habits of Ocy. pode, 105; on temperature of sea, 120 ; on eyes of deep. sea Crustacea, 124; on colour in deep-sea Crustacea, I27 ; on luminosity of deep-sea Crustacea, I25, I26; o11 eggs of deep-sea Prawn, I30; on Nephrops, I32 ; on habits of Conobita, 194, I95

Allen, E. J., on Mackerel fishery, 25I

Alpheidæ, 2 II

American Lobster, 32

Amphibious Crustacea, I04, I 88

Amphipoda, 52 ; seashore, 95 , ro7; plankton, 145; terrestrial, 189; fresh-water, I 72 ; in Sponges, 210; on Jellyfishes, 2I2; and Hermit Crabs, 215; parasitic, 223 ; wood-boring, 255

Amphithoë, 95

Anaspides, structure and fossil allies, 264

Andrews, C. W.: on Land Crabs, I90; on habits of
Conobita, I95; on labits of Birgus, I97, 198

Anomalocera, 150

Anomura, 60; fresh-water, 18I Anostraca, 36 ; habits, I62, I64 Antennæ of Lobster, 8, I4 ; use in respiration in Corystes, IOO; in Albunea, 102

Antennule of Lobster, 8, I4

Ants, Woodlice living with, 205

Apseudes, 50

Apus, 36 ; habitats, I6I ; occurrence in Britain, I62; habits, $16_{3}$; hæmoglobin in, I65; fossil allies of, 260

Appendages of Lobster, 8; of Trilobites, 259

Aratus, 189

Argulus, 4I

Aristotle on Shrimp living with Mollusc, 218

Armadillidium, 203

Artemia : larvæ of, 81 ; habitat, I64

Arthropoda, 2 ; classification, 204

Asellus, 172 ; destroying fishing nets, 253

Astacidæ, 176

Astacoides, 178

Astacopsis, 177; used for food, 243

Astacura, 60

Astacus : habits, I74 ; young, 76 ; distribution, I77; used for food, 24I

Asymmetry of Lobster, 29 
Atyidæ, 179 ; used for food, 248

Autotomy, II 3 ; in Lobster, 30

Baikal, Lake, 182

Balanus, 42 ; larvæ, 83 ; habits, II4 ; used for food, 237 ; cultivated for manure, 250

Barnacles, 4I ; development, 83 ; seashore, I14; of high seas, 155; on Whales, Turtles, and Crabs, 209; parasitic, on fish, 235; used for food, 237 ; cultivated for manure, 250 ; fossil, $26 \mathrm{I}$

Bathynomus, I3I

Beach.fleas, 107

Bell, T., on development of Land Crabs, I93

"Berry," Lobster in, 28

Bipolarity, I32

Birgus, 94; habits and structure, 195; breeding habits, 199. See also Robber Crab

Bloodvessels of Lobster, I7

Blue Crab, 249

Bopyroides, 22I

Bopyrus, $22 \mathrm{I}$

Borradaile, L. A. : on habits of Remipes, ro2; on Huenia, II0; on larvæ of Robber Crab, I99

Bouvier, E. L., on Dromiacea, I34

Brachygnatha, $6_{3}$

Brach yrhyncha, 64 ; fossil, 270

Brachyura, 62 ; fossil, 269

Brain of Lobster, 20

Branchiopoda, 35; larvæ, 80 ; habitats, I6I ; fossil, 260

Branchiostegite, I8

Branchipus, 165

Branchiura, 4I

Brine Shrimp, 164; larvæ, 8I

Brood-pouch of Peracarida, 46

Brown Shrimp, 244

Browne, F. Balfour, on Apus in Scotland, I62

Browne, Patrick, on Mountain Crab, I93
Bullen, G. E., on food of Mackerel, 25I

Bythotrephes, 168

Caligidæ, 225

Caligus, 225

Callianassa, 103

Callinectes, 249

Calocalanus, I49

Cambaroides, 177

Cambarus : distribution, $\mathrm{I} 77$; habits, I78; blind species, I85; used for food, 243

Cancer: used for food, 248 ; fossil, 270. See also Edible $\mathrm{Crab}$

Cancrinus, 269

Canthocamptus, I70 ; resting stage, I 7 I

Caprella, 54

Caprellidæ, 55 ; habits, 109

Carapace of Lobster, 6, 9

Carcinus: larval stages, 68 ; habits, 107. See also Shore Crab

Cardisoma, I9I

Caridea, 59; zoëa of, 73; fossil, 268

Caridina, 248

Carp-lice, 4 I

Caspian Sea, 182

Caudal fork, 40

Cephalothorax of Lobster, 8

Ceratiocaris, 262

Chalimus, 225

Chela of Lobster, I2

Cheliped of Lobster, 8

Chelonobia, 155, 209

Chelura, 255

Cheraps, I77

Chilton, C., on Woodlice in New Zealand, 206

Chirocephalus, 35, I6 I

Chitin, 15

Chondracanthus, 228

Chromatophores, 3 I, IIo

Chun, C., on eyes of plankton Crustacea, I54

Chydorus, 165

Cirolana, 218 
Cirripedia, 4I ; development, 82 ; on Whales, 209 ; parasitic, 23I ; fossil, 26I. See also Barnacles

Cladocera, 37; development, 80 ; habits, 165 ; in plankto11 of lakes, 168; absence from Tanganyika, 184

Claspers of Chirocephalus, 35

Classification of Crustacea, table, 34; of Decapora, table, $5^{8}$

Close time for Lobsters, 239

Coconut Crab. See Robber Crab

Cocoons of Copepoda, I7 I

Coenobita : habits, 194 ; respiration, 195

Cœnobitidæ, 6I ; habits, 194

Colour of Lobster, 31 ; deepsea Crustacea, 127; plankton Crustacea, I50; Branchiopoda, 165 ; subterranean Crustacea, 187

Colour-change, I Io

Columbus and Gulf - weed Crab, I55

Commensalism, 207

Conchoderma, 209

Conchoecia, I44

Conchostraca, 37 ; habits, 163

Convergent evolution, 205

Copepoda, 40; development, 82 ; of open sea, I40; plankton, I49; luminosity, I50 ; eyes, I52; of fresh water, I70; of Tanganyika, I84; and Hermit Crabs, 215 ; parasitic, 224; as food of Mackerel, 250

Copilia, I52

Coral of Lobster, 27

Corals, Crustacea on, 210

Coronula, I 55, 209

Corycæidæ, 152

Corystes, 99

Crabs: true, 62 ; sand-burrowing, 99; of fresh water, I79; of Tanganyika, 183; on Corals, 2II; carrying Sea- anemones, 215 ; living with Molluses, 2I7; living in Sea-urchin, 2I8; Isopods parasitic on, 223; Rhizocephala parasitic on, $23 \mathrm{I}$; used for food, 248; fossil, 269. See also Shore Crab, Edible Crab, etc.

Crangon, 59; habits, 97; fishery, 244

Crawfish, Sea-, 59

Crayfish: young of, 76 ; habits, I74; distribution, I76; terrestrial, 178, I89; blind, in caves, I85; in British Isles, 24I; used for food, 24I ; disease of, 243

Cumacea, 48; habits, 98 ; of deep sea, I29; of plankton, I4I

Cunninghan1, J. T., on developnient of Land Crabs, 192

Cup Shrimps, 245

Cyamidæ, 56; habits, 224

Cyclops, 40; nauplius, 82 ; habits, I7o; resting stage, I7I ; as host of Guineaworm, 252

Cymothoa, 220

Cymothoidæ, habits, 218

Cymothoinæ, habits, 220

Cypris, 38 ; reproduction, 172

Cypris stage of Barnacles, 84 ; of Sacculina, 233

Cystisoma, I45

Cythereis, 38

Daphnia, 38; development, 8I ; habits, 165; in plankton of lakes, 168

Darwin, C.: on fresh - water fauna, I 57, I59; on habits of Birgus, 198, 199; on Barnacles used for food, 237

Decapoda, 57 ; fossil, 267

Deep-water Prawn, 246

Delage, Y., on development of Sacculina, 232

Development of Lobster, 28 ; 
of Crayfish, 77; of River Crab, 78 ; of Peracarida, 78 ; of Woodlice, 79; of Opossum Shrimp. 79; of Cladocera, 8o; of Ostracoda, 81 ; of Copepoda, 82 ; of fresh - water Crustacea, 160; of Exicaridea, 223; of parasitic Copepoda, 225, 227, 230; of Rhizocephala, 232

Diaptomus, I70

Diastylis, 49

Diatoms, 139 ; relation to Mackerel fishery, 25I

Dichelaspis, 209

Digestive gland, I7

Dispersal of fresh-water Crustacea, I59; of Crayfishes, I74

Distribution of Woodlice, 206

Doflein, F., on luminosity in marine animals, 126

Dogfish, Barnacle parasitic on, 235

Dorippe, 95

Dracunculus, 252

Dromia, 63; habits, 96; and Sponge, 2 I5

Dromiacea, 63; of deep sea, I28, 134

Dublin Prawn, 33; fishery, 240

Ebalia, 63; protective resemblance, 109

Écrevisse, 242

Edelkrebs, 242

Edible Crab, 64, 248

Eggs of Lobster, 27 ; of deepsea Crustacea, I30; of freshwater Branchiopoda, I6I

Endopodite, I I

Engaus: distribution, I77 ; habits, I79, I89

Entoniscidæ, 223

Ephippium of Cladocera, 167

Epicaridea, habits, 22 I

Epiplankton, I43

Epipodite, I I

Epistome, 62

Erichthus larva, fossil, 266

Eryon, I35
Eryonidea, 6o; eye-stalks of, I22; luminosity, 126; eggs of, I3I; fossil and living species, 133, 268

Estheria, 36; habitats, I6I

Eucarida, 56

Eucopepoda, 4 I

Eumalacostraca, 45

Eupagurus, 91; commensals, 213

Euphausiacea, 56; larvæe, 76; of deep sea, I24, 125; luminous organs, I25, I5I; eyes, 153; fossil, 263

European Lobster, 32

Eurydice, 2 I9

Evolution, 256

Excretory organs, I9

Exopodite, Io

Exoskeleton, I5

Eyes of Lobster, 20; of Cyclops, 40; of deep-sea Crustacea, I2I ; of plankton Crustacea, I5I; of Bythotrephes, 169; degeneration in subterranean Crustacea, I86

Eye-stalk of Lobster, 14

Fairy Shrimp, 35 ; habitats, I6I

Filaria, 252

Fiddler Crab: habits, I06 ; colour-change, I I I

Fish : attacked by Isopods, 2 I9; Crustacea as food of, 250

Fish-lice, 224

Flagellum, I4

Foraminifera, I 8

Fossil Crustacea, 256

Galathea, I30

Galatheidea, 60

Galls on Corals, 2 I I

Gamble, F. W., on colourchanges, II I

Gammaridea, eyes of, I54

Gammans, 53; distribution, I72; in Lake Baikal, I83

Ganglia of Lobster, 20 
Garstang, W., on habits of Masked Crab, Ioo

Gastric Mill of Lobster, I7

Geographical distribution of Lobsters, 32 ; of Crayfishes, I74

Gecarcinidæ, I90

Gecarcinus, I90; supposed metamorphosis, I92

Gecarcoidea, I90

Gelasimus, I88; habits, I06; colour-changes, I II

Generative organs of Lobster, 27

Giant Crab, 64

Giesbrecht on luminosity of Copepoda, I5O

Gill chamber of Lobster, I8

Gills of Lobster, I2, I8; of Mysidacea, 48

Globigerina ooze, I I9

Glomeris, a Millipede, 3, 203

G1yphæidæ, 268

Grathobases of Trilobites, 259

Gnathophausia, 48

Goose Barnacle, 42

Gosse, P. H., on Porcelain Crabs, II5

Grapsidæ, 180

Grapsus, 107

Green gland, I9

Gribble, 253

Guilding, L., on development of Land Crabs, I93

Guinea-worm, 252

Gulf-weed Crab, I55 ; on Turtles, 208

Habitations of shore Crustacea, 95

Hamocera, 229

Hæmoglobin in Branchiopoda, I65

Hairs of Lobster, 22

Hall. See Spencer and Hall

Halocy pridæ, I4I, I44; luminosity, I5I

Hapalocarcinus, 2 II

Head of Lobster, 7
Hearing, sense of, in Lobster, 22

Heart of Lobster, I7

Hermaphroditism of Cirripedia, 43; in Isopoda, 52 ; of Cymothoinæ, 22I ; of Epicaridea, 223; of Rhizo. cephala, 23 I

Hermit Crabs, 6I ; of seashore, 9I; of deep sea, I24, I36; terrestrial, I94; commensals, 2I3; Isopods parasitic on, 221

Heterocarpus, I25

Hickson, S. J., on Caridina, 248

Hippa, 102

Hippidea, 62; habits, I02

Hippolyte, colour-changes, II I Holopedium, I 70

Homaridæ, 33

Homarus, 32 ; fishery, 238

Homolodromiidæ, I34; fossil allies, 269

Homologous organs, 10

Hoplocarida, 64

Huenia, I09

Huxley, T. H.: on Barnacles, II5; on distribution of Cray. fishes, 176

Hyas, masking habits, 96

Hyperia, I42; on Jellyfishes, 212

Hyperiidea, I4I ; eyes, 154

Hypoplankton, I 43

Hypostome, 259

Inachus infected with Sacculina, 235

Intestine of Lobster, I6

Isopoda, 5I ; deep-sea, I3I ; fresh - water, I72 ; subterranean, I86; land, I99; in Sponges, 210 ; parasitic, 218 ; wood-boring, 253 ; fossil, 266

Jasus, 24I

Jellyfishes, Amphipods on, 212

Keeble, F., on colour-changes, II I 
Kidney, 19

Koonunga, 264

Land Crabs, I89; injuring crops, 253

Land Hermit Crabs, 194

Land-hoppers, I89

Langouste, $24 \mathrm{I}$

Lankester, E. Ray, on hæmoglobin in Branchiopoda, 165

Larvæ of Lobster, 28 ; of Norway Lobster, 7 I ; of Stomato. poda, 80 ; of Brine Shrimp, 8I; of Land Crabs, I9I; of Robber Crab, I99; fossil, of Stomatopoda, 266

Larval stages, 66; significance of, 85

Latreillia, $\mathrm{I} 28$

Leach, IV. E., on the Gribble, 254

Leander, 59, I79; Isopod parasitic on, 22 I; used for food, 245

Legs of Lobster, 8, I2

Lepas, 42 ; habitat, I55 ; nauplius, I 48

Lepeophthimus, 225

Leptodora, 169

Leptostraca, 45

Lerncea, 226

Leucosiidæ, 109

Ligia, structure and habits, 200

Limnoria, 254

Limuparus, 269

Lithodes, 62, 94

Lithodidæ, 6I

Liver of Lobster, I7

Lobsters: deep-sea, I2I ; fishery, 238

Lovén, S., on relict Crustacea, I8I

Luminosity of deep-sea Crustacea, I25; of plankton Crustacea, 150

Lynceidæ, I65

Mackerel feeding on plankton, 250
Macropodia, masking habits, Maia, masking habits, 96

Malacostraca, 43; fossil, 26 I

Mammoth Cave, Crayfish of, 185

Mandible of Lobster, 8, I4

Masked Crab, 99

Masking of Crabs, 96, 215

Maxilla of Lobster, 8; of $A r$ gulus, 4I

Maxillipeds of Lobster, 8, II

Maxillula of Lobster, 8

Medusæ, Amphipods on, 212

Megalopa of Shore Crab, 70

Meganyctiphanes, 56, I5I

Melia, 215

Mesidotea, I8I

Mesoplankton, I43

Messmates, 208

Metamorphosis of Lobster, 28; of Land Crabs, I9I

Metanauplius of Penceus, 75

Mimicry, 204

Mimonectes, I45

Mitsukuri, K., on cultivation of Barnacles, 250

Mole Crabs, 102

Monstrillidæ, 230

Moulting of Lobster, I5; of Woodlice, 206

Mountain Shrimps, I8I ; structure and fossil allies, 264

Mouth-frame of Crabs, 62

Müller, Fritz: on larval stages of Penceus, 73 ; on habits of Aratus, I89

Müller, O. F., on Nauplius, 82

Mrunida, larva of, $7 \mathrm{I}$

Munidopsis: eyes, I23; eggs, I30

Murray River Lobster, 243

Mussels and Pea Crab, 217

Myodocopa, 39

Mysidacea, 46; development, 79 ; luminosity, I27; eyes, I53 ; and Hermit Crabs, 2 I $_{5}$; fossil, 263

Mysis, 47; in lakes, I81, I82 
Natantia, 58; used for food, 243

Nauplius of Penceus, 73; of Crayfish, 79; of Opossum Shrimp, 79; of Branchiopoda, 80; of Cyclops, 82 ; of Ostracoda, 82 ; of Barnacles, 83 ; of Lepas, 148; of Leptodora, 170; of Sacculina, 233; eye, 40

Nebalia, 44 ; fossil allies, 26 I

Nebaliacea, 44

Necton, I38

Nematocarcinidæ, 128

Nephrops, 33 ; larva, 71 ; distribution, I32; fishery, 240

Nephropsidea, 33, 6 \%

Nephropsis, I2I

Neptunus, 156; used for food, 249

Neritic plankton, $14 \mathrm{I}$

Nervous system of Lobster, 20

Niphargus, 184

Northern Crayfishes, I 76

Norway Lobster, 33; larva, $7 \mathrm{I}$; fishery, 240

Norwegian Prawn, 246

Notostraca, 36 ; habits, I62

Oceanic plankton, I4 I

Octopus preying on Crustacea, 89

Ocypode, r88; habits, I04; carnivorous, I95

Olfactory filaments of Lobster, 25

Oniscus, 5I ; structure and habits, 20I

Operculata, 43

Opossum Shrimps, 46; development of, 79

Orchestia, 107

Orientation, organs of, 24

Ostracoda, 38; developnient, 8I ; luminosity, I27, I5I ; plankton, I44 ; fresh-water, I72; of Tanganyika, I84; fossil, $26 \mathrm{r}$

Ovary of Lobster, 27
Oxyrhyncha, 64; masking habits, 96; fossil, 270

Oxystomata, 63; habits, 10I ; protective resemblance, I09; deep-sea, I 28 ; fossil, 269

Oxyuropoda, 266

Oyster Crab, 249

Oysters and Pea Crab, 217

Paguridea, 6I

Paguropsis and Sea-anemones, 2 I4

Palcmon, 179; used for food, 248

Palcemonetes, 174

Palinura, 59

Palinuridæ, 24I ; fossil, 269

Palinurus, larva of, 72 ; fishery, 240

Palp, I4

Pandalus, 59, I37; used for food, 245

Panulirus, 24 I

Paracyamus, 55

Paranaspides, 264

Paranephrops, I77

Parapagurus, 124 ; and Seaaneniones, 213

Parasitism, 208

Parastacidæ, 176

Parastacus, 178

Partan, 248

Parthenogenesis, $\mathrm{I}_{3}$; of $\mathrm{Cla}$ docera, I66; of Ostrasoda, $17^{2}$

Pea Crab, 217

Pedunculata, 43

Peltogaster, $23^{2}$

Penæidea, 59; fossil, 267

Penauls, 59; larvæ, 73 ; used for food, 247 ; fossil, 268

Peracarida, 46; development, 78

Pericardium, I7

Peripatus, tracheæ of, 204

Peter's stone, 220

Philomedes, 38

Phosphorescence. See Luminosity

Photophores of Euphausiacea, I25 
Phreatoicidea, 173

Phronima, I54

Phronimidæ, eyes of, 154

Phtisica, 54

Phyllocarida, 26I

Phyllosoma, I49; of Spiny Lobster, 72

Phylogeny, 205, 256

Pill Millipede, 203

Pink Shrimp, 137, 245

Pinnaxodes, 218

Pinnotheres, 217; used for food, 249

Planes, 155

Plankton, I39; of fresh water, 160 ; of lakes, 168 , I70 ; relation to fisheries, 250

Platyarthrus, 205

Platycuma, 129

Platymaia, 130

Platytelphusa, 184

Pleuron, 9

Podocopa, 39

Podocrates, 269

Pollicipes used for food, 237 ; fossil, 26I

Polycheles, 133

Pontonia, 218

Pontoporeia, I8I

Porcelain Crab : zoëa of, 7o; autotomy, II4 ; feeding, II5 ; and Hermit Crabs, 215

Porcellana: zoëa of, 7o; autotomy, II4; feeding, II 6

Porcellanidæ, 60

Porcellio, 5I; structure and habits, 202 ; distribution, 206

Portunidæ: swimming, 90 ; sand-burrowing, 99; used for food, 249

Potamobiidæ, I 76

Potaniobius, I74

Potamon, I80; young of, 78

Prcanaspides, 265

Prawns, 58; luminosity of, 127; of deep sea, 136 ; of fresh water, I74, I79; of Tanganyika, 183 ; blind, in caves, 185 ; in Sponges, 210 ;
Isopods parasitic on, 22I ; Common, 245 ; used for food, 245; deep-water, 247 ; fossil, 268

Prosoponidæ, 135, 269

Protandrous hermaphroditism, $22 \mathrm{I}$

Protective resemblance, 108

Protocarcinus, 269

Protocaris, 260

Protopodite, Io

Protozoëa of Penceus, 75

Psathyrocaris, 130

Pseudothelphusa, 193

Pseudo-tracheæ, 202

Pygidium, 259

Pygocephalus, $26_{3}$

Pylocheles, 94

Pylochelidæ of deep sea, 136

Recapitulation, theory of, 86

Red-clawed Crayfish, 242

Regeneration in Lobster, $3^{\circ}$

Relict faunas, I82

Remipes, 102

Reproduction of Cladocera, I66; of Leptodora, 169; of Cymothoinæ, 220

Reptantia, 59

Respiration in sand-burrowing Crabs, 99; in amphibious Crabs, 106 ; in Land Crabs, 193; in Conobita, 195; in Birgus, 196; in Land Isopods, 20I, 202, 203

Resting eggs of Cladocera, I66; of Copepoda, I70

Resting stage of Copepoda, I7 I

Reversal of asymmetry in Lobster, 30

Rhizocephala, 43； larvæ, 84; structure and development, 231

River Crabs: young of, 78 ; habits and distribution, I80; development of, I93

River Prawns, I79; used for food, 248

Robber Crab, 6I, 94; habits 
and structure, I95; breeding, 199

Robertson, David, on habits of Crabs, 97

Rock Lobster. See Spiny Lobster

Rostrum of Lobster, 6

Sacculina, 23 I

Salt lakes, Branchiopoda of, I65

Sand-burrowing Crustacea, 97

Sand-hoppers, 52; habits, Io7, I 89

Sapphirina, 150

Sargasso Sea, 155

Scampo, 240

Scapellum, fossil, 26I

Scaphognathite, I9

Schizopod stage of Lobster, 7 I ; of Pencus, 75

Scylla, 249

Scyllaridæ, fossil, 269

Scyllaridea, 59; Phyllosoma larvæ, I49; fossil, 268

Scyllarus, fossil, 269

Sea-slater, 200

Sea-anemones: and Hermit Crabs, 2 I3 ; carried by Crab, 2 I 5

Sea-crawfish. See Spiny Lobster

Sea-urchin, Crab living in, 218

Sedentary Crustacea, II4

Self-mutilation in Lobster, 30

Senses of Lobster, 25

Sergestes, zoëa of, 75,148

Serial homology, Io

Sesarma, habits, I 80 , I 89

Sessile Barnacles, 43

Sexes of Lobster, 26

Sexual characters of Crabs infected with Sacculina, 235

Sharks, Barnacle parasitic on, 235

Shore Crab, 64 ; larval stages, 68; habits, IO7, I88; in. fested by Sacculina, 23I ; used for food, 249
Shrimps, 58 ; fresh-water, 53 , I 72 ; Common, habits of, 97 ; protective resemblance, I08; living with Mollusc, 2I8: fishery, 244. See also Brown Shrimp, Pink Shrimp, etc.

Sight, sense of, in Lobster, 2I

Skeleton Shrimps, Iog

Slaters, 5 I ; Sea-, 200

Sloane, H., on Gulf-weed Crab, 155

Smell, sense of, in Lobster; 24

Smith, G. : on terrestrial Amphipoda, 189; on developnent of Sacculina, 233

Smith, S. I., on habits of Ocypode, 105

Sonites of Lobster, 6, 8

Southern Crayfishes, I 76

Spencer and Hall on Australian Branchiopoda, I6I, I63

Sperm-receptacle of Lobster, 27

Spider Crabs, 64; masking habits, 96,215 ; deep-sea, 128 Spiny Lobster, 59; larva of, 72 ; fishery, 240

Spirontocaris, Isopod parasitic on, 221

Sponge Crab, 95

Sponges, Crustacea in, 210

Spongicola, 210

Squilla, 64; larva of, 80 ; fossil, 266

Stalked Barnacles, 43

Statocyst of Lobster, 24 ; of Mysidacea, 47

Statolith, 47

Stebbing, T. R. R.: on Land Crabs, Igo; on habits of Cirolana, 219

Steinkrebs, 242

Stenopidea. 59; fossil, 267

Stenorhynchus, 97

Sternum, 9

Stevenson, R., on the Gribble, 254

Stomach of Lobster, I6

Stone Crab, 6I, 94 
Stomatopoda, 64; larvæ, 80; liabits, I04; fossil, 266

Stridulating organ of Ocypode, I05

Subterranean Crustacea, I 84

Swimmerets of Lobster, 6, Io

Swimming Crabs, 90 ; sandburrowing, 99; used for food, 249

Symbiosis, 207

Syncarida, 45, I8I ; fossil, 264

Tail-fan of Lobster, 6

Talitridæ, 107

Talitrus: habits, 107; terrestrial species, I 89

Tanaidacea, 50

Tanganyika, Lake, Crustacea of, I 83

Taste, sense of, in Lobster, 25

Telphusa, 180

Telson of Lobster, 6

Tergum, 8

Testis of Lobster, 27

Thalassinidea, 6I ; habits, I03

Thaumastocheles, I30, I32

Thompson, J. Vaughan: discovery of metamorphoses of Crustacea, 67; on larvæ of Cirripedia, 83 ; on development of Sacculina, 232

Thoracica, 43

Thorax of Lobster 7

Thread-worms, 252

Touch, sense of, in Lobster, 22

Tracheæ, 204

Tracher, pseudo-, 202

Trapeziidæ, 2 I I

Triarthrus, 258

Trilobites, structure and history, 258
Tubicinella, 209

Turrilepas, 26I

Turtles: Barnacles on, 209; Gulf-weed Crab on, 209

Underground Crustacea, I 84 Uropods of Lobster, 6

Venus's Flower-basket, Crustacea in, 210

Water-fleas, 37, 165

Weismann on parthenogenesis of Cypris, 172

Well Shrimp, I84

Westwood, J. O., on development of Land Crabs, I92

Whales, Barnacles on, 209

Whale-food, 138

Whale-lice, 56 ; habits, 224

White-clawed Crayfish, 242

Willey, A., on breeding of Robber Crab, 199

Williamson, H. C., on habits of Lobster, 25

Wood-boring Crustacea, 253

Woodlice, $5 \mathrm{I}$; development of, 79; habits and structure, 199; distribution of, 206; destructive in gardens, 253

Worms: and Hermit Crabs, 215; Copepoda parasitic in, 230

Zoëa of Shore Crab, 69; of Caridea, 73; of Porcelain Crab, 70; of Munida, 7I ; of Pencus, 75; of Sergestes, 75. I48; of Robber Crab, 199 
Printed by

Billing and Sons, Ltd.

GuILDFORD 

th

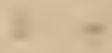

$-$

$+2$

a

$-1$

政

$\eta$
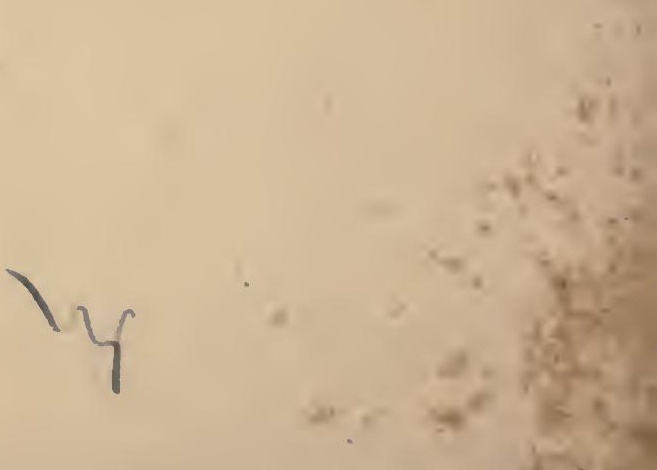


$\therefore$

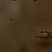

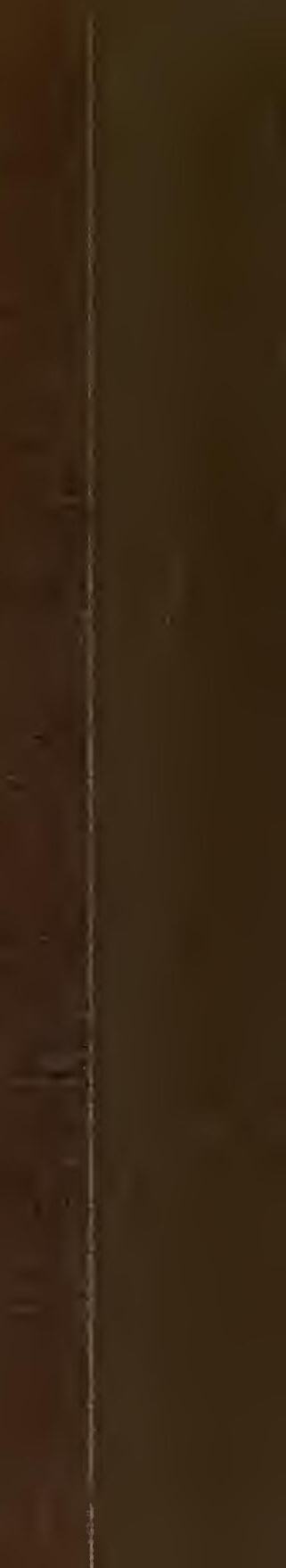

